$$
\text { Sociology. }
$$



ID 308101 
Digitized by the Internet Archive in 2007 with funding from Microsoft Corporation

http://www.archive.org/details/sociologypopular00brooiala 
- 


\section{JAMES H. WEST, Publisher, Boston.}

COMMENTS FROM PRIVATE SCIENTIFIC SOURCES.

"It is a book not to be lightly passed over,-indicating almost a new epoch in the evolution propaganda."

"The book is $A$ BOOK. It is unique. I do not believe there is any other such book, nor that there will be. It will universally take. Only a few glances at it are required, and then the expressions of astonishment and interest follow."

[From Herbent Spexcer.]

"The mode of presentation seems to me admirably adapted for popularizing Evolution views."

[From Jous Fiske.]

"I think your schedule attractive and valuable."

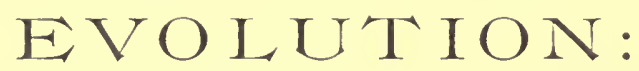

Popular Lectures and Discussions Befole Tile Brooklyn Etrical Association.

"A colleetion of essays, exhibiting the cloetrine of Evolution as applied to religious, seientitic and social matters. by well-read and eultivated gentlemen. Fieholarly and instruetive; we eommend the book." - New Fork sith.

"Among all these papers there is not one that is weak, eommonplace or uninteresting. They are all full of thought, presented in clear language, and in an adinirable spirit." - Lieligio-Philosophical Journal.

"Extremely entertaining and instructive. . . the book is especially intended to spireal a knowledge of the views of the masters of the Evolution theory, making a smooth, even path for the ordinary mind to move forward on, so that the general eomprehension of the subjeet may he made easy."Brooklyn Citizen.

\section{OTTLINE OH CONTENTS:}

Herbert Spencer : His life, writings, and philosophy.

Diniel Greenleaf Thompson.

Charles Robert Darwin: His life, works, and intluenee.

liev. John W. Chadwick.

Solar and Ilanetary Evolution $110 w$ suns and worlds come into being.

Evolution of the Earth: The story of geology.

fiarrett 1". Serviss.

Evolution of Vegetal Life: Ifow life hegins.

Dr. Lewis G. Janes.

William l'ott:.

Evolution of Inimal l,ife :

Rositer W. Raymoud, l'h.I).

The bescent of Man: His origin, antiquity, growth.

Evolution of Mind: Its nature, amd development.

F. 1). ('ope, I'l.1).

Evolution of Society : Families, trilies, states, elasses. Fvolution of Theology : Inevelopment of religions heliefs. Z. Nidnoy. sumpon. Evolution of Morals: Fugoism, altrujsm, utilitarianism, ete.

l)r. Lewis (i. Janes.

l'roofs of Evolution: The eight main seientific arouments. Selson f'. I'arsluall. Evolution as lielatel to Religions Thouglit. Rev. Jolun IV. Chalwick. The l'bilosuley of Evolution: 1t: redation to prevalling systems.

Stary 11. Nieluchs.

The Effrots of Evolution on the coming ('ivilization. Rev. Minot I. Savage.

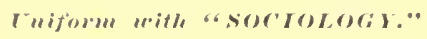

ONE VOLUME, Fine Cloth, 408 Pages.

ILLUSTRATED. Complete Index. \$2.00, postpaid. 


\section{JAMES H. WEST, Publisher, Boston.}

\section{EVOLUTION ESSAYS, -.- SECOND SERIES.}

"Deserve the attention of readers of popular science. They include, so far, excellent lectures."-Literary World.

"One of the most systematic, concise, and comprehensive presentations in popular form of the foundation and theory of evolution. Excellent, .. succint, . . interesting."-l'ublic Opinion.

\section{Uniform with "EVOLUTION." \\ SOCIOLOG Y :}

Popular Lectures and Discussions before the Brooklyn Ethical Association.

\section{OUTLINE OF CONTENTS :}

The Scope and Principles of the Evolution P'lilosophy, Dr. Lewis G. Janes. The Relativity of Knowledge,

Dr. Robert G. Eccles.

Primitive Man,

Z. Sidney Sampson.

Growth of the Marriage Rclation,

C. Staniland Wake.

Evolution of the State,

Evolution of Law,

Joln A. Taylor.

Evolution of Medical Science,

Prof. Rufus Sheldon.

Evolution of Arms and Armor,

Dr. Robert G. Eceles.

Evolution of the Mechanic Arts,

Rev. Joln C. Kimball.

Frolution of the Wages System,

James A. Skilton.

Education as a Factor in Civilization,

Prof. George Gunton.

Evolution and Social Reform: 1. The Theological Method,

Rev. Joln W. Cliadwick.

Evolution and Social Reform: 2. The Socialistic Method, William Potts. Evolution and Social Reform: 3. The Anarelistic Method,

Evolution and Social Reform: 4. The Scientific Method,

Hugh O. J'entccost. Daniel Grcenleaf Thompson.

Asa Gray,

Edward Livingston Youmans,
Mrs. Mary Treat.

Prof. John Fiske.

ONE VOLUME, Fine Cloth, 4 I2 Pages.

With Diagram. Complete Index. \$2.00, postpaid.

** The above sent postpaid on receipt of price. Address,

\section{JAMES H. WEST, publisher,}

196 Summer Street, BOSTON. 


\section{Speeimen Press Notices of "Evolution."}

"A book which serves a double purpose: to present, suceintly yet eompletely, the evolution plilosophy; and to show its applieation to and influenee mpon all the interests of life. It is not possible to speak of this look with any legree of reserve. It is entirely almirable. It should be a matter of pride to every Ameriean that sueh an adequate presentation of a vital prineiple has been made on this side of the Atlantic."-Boston Times.

"Devoted to eoneise and remarkably elear expositions of evolution as a plilosophy, as relating to the plisieal world, to man, to soeiety, to theology, to morals, and religious thonght. The look is prefaeel by two extremely interesting biographieal ehapters."-('umbridye (Mass.) Tribune.

"The subjects are very fully diseussed, and the seeker for information ean seareely find the ease of the evolntionists better stated in a popular form. 'This eombination of thought and study in one inexpensive volume is timely and valuable." $-N e w$ lisedforil bereury.

"The whole field of Wvolution is presented in a poptular manner, in a hanclsomely printed book, . . . one of the elearest and most eomprehensive on the subjeet that has yet appeared. It will prove most aeeeptable to the general reacler."-Cincinuti Comimercial Guzette.

"The writers seem to have taken pains to make their subjeets plain, and to have had good sueeess in loing so. We reeommend this eolleetion of essays to those wlo wish for a simple lut aceurate exposition of the evolutionary plilosophy." - Sciture (ieu jork).

"One of the hest thoroughly popular works on the general subjeet that have yet appeared." - Public Opinion.

"An aclmirable contribution of thought npon this problem,-one of the most eomplete yet made,- and will be found of interest to everybody."-Laurence Aneriorits.

"The subjects are all broadly treated, and, taken together, these essays eomprise a elear and eoncise presentation of the theory of evolution." - Boslon Budyet.

"Seholarly and instruetive."-New" lork Sun.

"These esirs present the doetrine of Evolution in almost every aspect, and a glance at the list of anthors will suffieiently indieate the admirable skill and thomglit that have been brought to bear upon the suljeet in this edifying volume. The book merits hearty eommendation." - Boston Sut widay Evening fiazetie.

"They are, withont exception, extellent in thourht, spirit and nethod of treatment."-Truth (Pitlshloryh).

"It is most comprehensive, yet pojular, in its morle of treating its snljects, and furnishes in eompaet form the last worls which have vet appeared on the suljects of which it troats." - New Ilaten I"allarlimm.

"The value of the book cannot lie overestimated, for it is representative of the foremost thouglit on the forenust theory of the age."-Buffolo courier.

"livery essay in the work recognizes evolution as a miversal law. It is made to accomnt for all the phenomena of the miverse, and to us it alppears to aceonnt for them remarkibly well. W' tomfess, with something of ehagrin, that we can fliseover nothing atheistio, inmoral or heterodox in their peeuliar opinions. We had luekled on onr armor, and set om (oontroversial lance in rest, in preparation for a tilt with

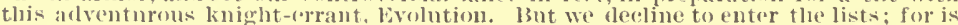
not the mailol warror whom we mistook for an enemy the miglitiest eluampion of trutlı?. . The book is handsomely printed, sulstantially bound, and fully indexecl." - lowell Times.

"The bonk is one that will finc a weleome among atvaneed thinkers."-I"hilutelphin 'Times.

"A work of munsual interest - a bouk to set thinkers to thinking." - T'ro!l 'Jmes.

"The volmme is one which every man who wishes to lieele ale rombul witl the latest plases of thomerlit, but las not the leisure to master elaborate treatises. should

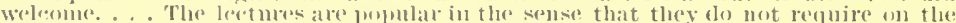

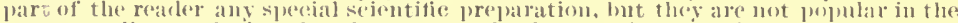

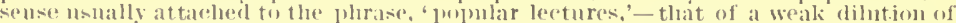
thought and knowledge to meet tho capacity of weale intelligences. . . Each lecture is followed hy an alstact of the disoussion which the lecture evolved, and the dissentient reader may often lave the safisfaction of finding his own eritieisms

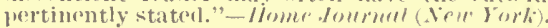

"The arift of the wolmue altogetler is in the flirection of intellectual expansion." - Iral Vorli Tilulme.

"It js a systematie, eomeise, and romprehensive presentation, and slonlel be read lyy all interested in the subject whether from a biologieal, sociologieal, or philosophl-

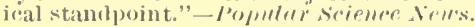


SOCIOLOGY 
The eye reads omens where it goes, And speaks all languages the rose; And, striving to be man, the worm Mounts through all the spires of form.

-Nature, $i ., 7$.

THE fossil strata show us that Nature began with rudimental forms, and rose to the inore complex as fast as the earth was fit for their dwelling-place; and that the lower perish as the higher appear. Very few of our race can be said to be yet funished inen. We still carry sticking to us some remains of the preceding inferior quadruped organization. . The age of the quadruped is to go out, - the age of the brain and of the heart is to come in. And if one shall read the future of the race hinted in tle organic effort of Nature to mount and meliorate, and the eorresponding impulse to the Better in the human being, we shall dare affirm that there is notling he will not overcome and convert, until at last culture shall absorb the chaos and gehenna. He will convert the Furies into Muses and the hells into benefit. - Culture. 


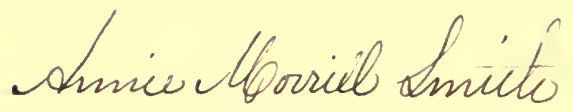

78 Vrangevel

SOCIOLOGY Rurklyu

unmonkew $189 \%$

Popular Lectures axd Discussions

BEFORE THE

Brookly Ethical Association.

III

BOSTON :

JAMES H. WEST, Publisher.

196 SUMMER STREET

1890 


$$
\begin{aligned}
& H M I 5 \\
& +16
\end{aligned}
$$

COPYRIAIT BY

JAMES H. WEST,

1890. 


\section{PREFACE.}

Sociology : a new word for a new generation: the name of a new science - the science of social evolution. To Auguste Comte we owe the name, and some pregnant suggestions as to the character of the new science. To Herbert Spencer, more than to any other thinker, we owe the formulation of its laws, and the collection and classification of the facts on which they are bascd. $A$ growing multitude of other writers, however, have ably contribnted to the numerous departments of sociological research, bringing to this new field of study a wealth of patience in scicntific investigation, and thoughtful consideration for social phenomena.

Sociology is a science yet in the making. It is not an exact science, like mathematics. It formulates no dogmas. It recognizes the relativity of societary forms, customs and institutions. It has 110 authoritative priesthood. It presents no panaceas for the reformation of social ills. It clearly indicates, lowever, the natural trend of societary evolution, and thus affords wise suggestions for our guidance in practical affairs. Its word is one of salutary caution rather than of definite and formal instruction concerning the duties of the hour.

Sociology is based on Evolution. The present interest in its problems, and their supreme importance to liuman well-being, rendered it the natural topic for the consideration of the Brooklyn Ethical Association, following the general discussion of the loctrine of Evolution in the previous volume of these lectures. sociology recognizes that the method of Nature in society is identical with its method in the development of suns and planetary systems, of vegetal and animal life, and of the bocly and mind of individual man. This method is the method of natural growth as contra-distinguished from supcruatural creation or artificial manufacture. It involves that element of spontaneity which is inherent in all processes of organic growth, and which in the mind of man appears under the form of self-conscious freedom. Societary growth is regular, orlerly, in accordance with its own inherent laws: but these laws are not mechanically imposed conditions. They are the spontaneous expressions of progressive tendencies resident in society itself, or in the individuals of which it is composed, the operation of 
which, though ordcrly, is infinitely varied, and adaptable to an infinite variety of social conditions.

It follows, thereforc, that the a priori scheme of the social reformer can never be made to cxactly fit the actual conditions of any given society. It may scrve to stimulate thought, to promote altruistic endeavor, to educate the individual: it cannot become a practicable panacea for social ills. Abundant are the schemes of this sort which are presented to-day for our consideration: Nationalism, the Single-tax, Socialism, Anarchism, Free-trade, Protection, Prohibition, and what-not? Evil will be the day when we legislate any one of them into being, expecting thereby the abolition of poverty and crime, or the speedy renovation of society.

Evolution - Sociology - points to the safer and wiser way of individual enlightenment and moral education. It studies carefully the past history of man, that it may act wisely for the amelioration of his present condition. It aims directly at the improvement of individual character. It seeks not so much to antagonize the schemes of social reformers as to subject them all to the operation of the principle of Natural Selection:- wisely to choose what is instructive and good in each; wiscly to take such forward steps as are practicable and may be securely held; to substitute the method of evolution for that of violent and spasmodic cliange, and thus to promote, surely if slowly, the permanent wellare of societies and individuals.

If this book - the thoughtful contribution of frec individuals working with no selfish aims or conscious dogmatic or partisan bias-shall be of some slight service in forwarding this most worthy and desirable end, in promoting scientific thought and wise action on the pressing problems of social life, the labors which have brought it into being will be abundantly repaid. 


\section{CONTENTS.}

Preface,

The Scope and Prixciples of the Evolution Phi-

LOSOPHY,

Wallace on Darwinism; evolution a universal method; agnosticism - what is it? the nature and limitations of knowledge; the relations of the evolution philosophy to materialism and idealism; to the doctrines and methods of the Christian cluuch; its relations to sociology; its attitude toward the practical problems of social life.

By Dr. Lewis G. Janes.

\section{The Relativity of Kxowledge,}

The nature of sense-perception; siglit, sound, taste, smell, feeling; the doctrine of the Unknowable; the relative nature of matter, motion, form, weight, extension; the relativity of ethical and social theories; the truth of definite relations; the doctrine of relativity assures charity and mental freedom.

By Robert G. Ecches, M.D.

\section{Primitive Max,}

Man as revealed by archæological studies; evidences of man's antiquity; geological periods; man's appearance in the pliocene; palioolithic and neolithic races; the ages of bronze and iron; cave-men and lake-dwellers; dolmenand mound-builders; primitive implements and tools; proofs of man's natural evolution.

By Z. SiDNey SAMpsox.

Growth of the Marriage Relation, . . .

Marriage a primitive institution; its earlier forms; no evidence of original promiscuity; exogamy and endogamy; group-marriage; polygyny, polyandry and monogamy; marriage by capture; monogamy the highest form of the relation; divorce and divorce-laws; marriage a contract; its regulation by the State.

By C. Staxiland Wake.

Evolutiox of the State,

The growth of political institutions; the patriarchal family; the tribe and clan; the ancient city; monarchical and 
representative governments; constitutions - written and unwritten; the American Republic - its success and its langers; evils of municipal government; what final form will the State assume?

By JoIr A. TAxLor.

\section{Evolution of Law,}

How law begins; statute law and judge-made law; the conversion of customs into law; religious sanctions; legal fictions; the development of cquity jurisprudence; the common law; legislation; the codification of laws; laws for the collcction of debts; personal rights under the law.

By Prof. Rufus Sueldon.

Evolution of Medical Sciexce, . . . . . . 133

Supernatural ideas of disease; fetishism in medicine; the beginnings of medical science; Pythagoras and Hippocrates, Celsus and Galen; Clristianity and medical science; the Mohammedan influence; homeopathy and allopathy; foods and poisons; the development of surgery, anatomy, pliysiology, clıcmistry and pharmacy; bacteriology; the growth of sanitary science.

By Robert G. Eccles, M.D.

Evolution of Arms and Armor, . . . . . 159

The necessity for arms and armor under the struggle for existenee; Nature's two methods - among animals, plants, men, nations; how arms and armor have led to the industrial arts; to a higher manlood; to co-operative effort; to individualism; the weapons of thought; our National policy as regards defenses; the two methods in religion, morals, law, social safety; on this rude stalk the flower at last of universal peace.

By Rev. Joun C. KingBai.t.

\section{Evolution of the Mechaxic Arts, . . . . .}

Development of the human hand; the earlicst use of implements and tools; man's mechanical structure and adaptation for work; the psycliology of the meelıanic arts; the relation of mechamics to mental evolution; the genesis of invention; patents and patent-laws; inventions in agrieulture and inanufactures; have they benefited the laboring classes?

By JAMES A. SKILTox.

Evolution of the Wages System, . . . . . 217

The definition of wages; economie eharacteristics of the wages system; wages the outgrowth of slavery; origin and development of the wages system; its relation to 
material improvement, social freedom, and a progressive civilization; to the welfare and progress of the laboring classes; the factory-system; importance of stipulated incomes; the wages system compared with Nationalism and Socialism; its relation to social reform.

By Prof. George Gunton.

Education as a Factor is Civilization, . . .
The beginuings of education; early metlods in Egypt, Persia, China, Greece and Rome; early Christian ideas of education; Catholic and Protestant views; the commonschool system; influence of Comenius, Pestalozzi and Froebel; the kindergarten; manual training; education and crime; the university; classical and scientific studies; the ligher education of women; co-education; the future of our educational system.

By Miss Carolive B. Le Row.

\section{Evolution and Social Reform: I. The Theological} Method, . . . . . . . . . . . . . .

Religion the formative principle of social growtl; its relation to Socialism; theological morality; influence of Christianity on social development; New 'Testament ideas of marriage and wealth; early Cliristian Socialism; monasticism; influence of the Jews and Mohammedans; the church and industrialism; usury or interest; the church and slavery; alms-giving and pauperism; the effect of preaching on character; repentance, conversion and atonement; the religious method the method of personal cliaracter.

By Rev. John W. Chadwick.

Evolution and Soctal Reform: II. The Socialistic Method, . . . . . . . . . . . . 277

Communism, Socialism and Nationalism; the methods defined; origin of their modern phases; tendencies of Socialism to militantism; State-socialism; the doctrine of equality of earnings; equality $v s$. liberty; Mr. Bellamy's theory criticized; Henry George and the "single tax"; the injustice of land-confiscation; relation of land-values to the value of improvements; socialistic schemes artificial, not organic; profit-sharing and voluntary co-operation; opportunism.

By William Potts.

\section{Evolution and Social Rfform: III. The Anarch-} istic Method,

Anarchy regarded as a science; its opposition to government by pliysical force; its methods not revolutionary but 
evolutionary; anarchism in social customs; its economic principles; involuntary poverty, its causes and cure; injustice of rent, interest and profits; social parasites; anarchism and the ballot; its method that of education and peaccful propagandism; its ideal that of mutualism between free individuals.

By IIvgir O. Pentecost.

Evolution and Social Reform: IV. The Scientific Method, . . . . . . . . . . . . . .

The scientific method based on the uniformity of Nature; the polarity of Individualism and Socialism; the psychological argument; necessity for governmental limitation; the scientific method as distinguished from the theological, the socialistic and the anarchistic; it advocates the golden mean; it cultivates individual independence; its relation to education and ethical culture.

By Daniel Greenleaf Thompsox.

\section{Asa Grat: His Life and Work,}

His birth and youth; his indebtedness to Amos Eaton; his relations with Dr. John Torrcy; his works on botany; the "North Amcrican Flora"; his contributions to the doctrine of Evolution; his correspondence with Darwin; his personal characteristics; his genius recognized by other botanists; his great industry; lis umobtrusive modesty; causes of his unfinished work.

By Mrs. Maliy Tireat.

Edward Livingston Youmans: The Max and His

Work,

Ilis birth and ancestry; his education; his carly interest in natural science; his blindness; his interest in reforms; his contributions to chemistry; his carecr as a scientific lecturer; his acceptance of the cloctrine of Evolution; his introduction of Herbert Spencer to America; his establishment of the "International Scientific Series" and the I'opular Science Monthly; his visits to England; his broad, democratic spirit and unselfish personal character.

By Prof. Jour Fiske.

Index, 


\section{THE SCOPE AND PRINCIPLES OF THE EVOLUTION PHILOSOPHY}

BY

LEWIS G. JANES

Author of "A Study of Prinitive Christianity," "The Evolution of the Earth," "Evolution of Morals," etC., ETC. 
COLLATERAL READINGS SUGGESTED.

Spencer's "First Principles," "Principles of Psychology," and "Principles of Sociology ;" Fiske's "Cosmic Philosophy"; Wallace's "Darwinism" ; Thompson's "A System of Psychology" ; Huxley and Wace's "Christianity and Agnosticism"; Abbot's "Scientific Theism," and "The Philosophy of Free Religion," in The New Ideal ; Case's "Physical Realism" ; Carus's "Fundamental Problems" ; W. B. Carpenter's "Nature and Man."

(2) 


\section{THE SCOPE AND PRINCIPLES OF THE EVOLUTION PHILOSOPHY.*}

Since the interesting biological lectures of our last year's course were delivered, a noteworthy contribution has been made to that department of evolutionary thought, by the publication of Alfred Russel Wallace's "Darwinism: An Exposition of the Theory of Natural Selection, with some of its Applications." A co-discoverer with Charles Darwin of the law of Natural Selection, Mr. Wallace resembles him as a writer in the simplicity and lucidity of his style; and the wealth of facts with which he has illustrated his discussion of the subject, indicating the utmost patience and thoroughness of research, is nowhere equaled save in those epoch-making books which indicated Darwin as the foremost naturalist of his own, or, perhaps it would not be too much to say, of any time.

Writing thirty years after the publication of "The Origin of Species," and in the light of all the objections which have been brought against the theory of Natural Selection, Mr. Wallace declares that Darwin "did his work so well that 'descent with modification' is now universally accepted in the organic world; and the rising generation of naturalists can hardly realize the novelty of this idea, or that their fathers considered it a scientific heresy to be condemned rather than seriously discussed." In the defense of "Natural Selection" as the fundamental law of biological evolution, Mr. Wallace is even more of a Darwinian than Darwin himself - showing, it would seem eonclusively, that many of those variations which Darwin attributed to sexual selection, can be explained by natural selection, including nearly all those brilliant colors in the ornamentation of male birds and animals which Darwin assigned to the choice or preference of the female.

Mr. Wallace also trenchantly criticises the supposed law of use and disuse as affecting biological evolution,- the socalled "Lamarckian factor," - the importance of which

* Copyrignt, 1889, by James H. West. 
was explicitly admitted by Darwin, though that fact is often ignored by his critics, and has been emphasized by Mr. Spencer in his "Factors of Organic Evolution," as well as by Prof. Cope, Dr. Raymond, and the American School of Evolutionists generally. "There is now much reason," Mr. Wallace declares, "to believe that the supposed inheritance of acquired modifications - that is, of the effects of use and disuse, or of the direct influence of the environment - is not a fact, and if so, the very foundation is taken away from the whole class of objections on which such stress is now laid." Such effects, for example, as the diminished jaw in civilized man, and the diminution of the muscles used in closing the jaw in case of pet dogs which are fed on soft food, are wholly accounted for by the simple fact of the withdrawal of natural selection in keeping up the parts in question to their full dimensions, in connection with Mr. Galton's law of "Regression toward Mediocrity," whereby, it has been been proved experimentally, there is a tendency of organs which have been increased by natural selection, to revert to a mean or average size, whenever the stress of circumstances which compelled the operation of this law is removed. Investigating the supposed effects of use and disuse in wild animals, Mr. Wallace notes the circumstance that " the very fact of use, in a wild state, implies utility, and utility is the constant subject for the action of natural selection; while among domestic arimals those parts which are exceptionally used are so used in the service of man, and thus become the subjects of artificial selection." "There are no cases among wild animals," he says, "which may not be better explained by variation and natural selection," than by the law of use or disuse. He quotes Galton, and Prof. Weismann in his recently published "Essays on Heredity," - two of the most careful students of this subject, - in support of the non-heredity of acquired variations; and on the whole makes an exceedingly strong argument in favor of natural selection as the great and controlling factor in organic evolution. Prof. Cope and the American evolutionists, he says, "liave introduced theoretical conceptions which have not yet been tested by experiments or facts, as well as metaphysical conceptions which are incapable of proof. And when they come to illustrate these views by an appeal to pałæontology or morphology, 
we find that a far simpler and more complete explanation of the facts is afforded by the established principles of variation and natural selection." Mr. Wallace's general conclusion is that all other laws and factors in organic evolution " must have operated in entire subordination to the law of natural selection," - a conclusion which he supports by logical argument from such a wealth of accumulated facts, that it will be extremely difficult for his opponents successfully to combat his views.

While asserting the continuity of man's progress from the brute, and of the higher animals from the protoplasmic cell, Mr. Wallace believes that at three definite stages in the progress of organic evolution there has been an introduction of new causes, not involved in nor evolved from the forces previously operating. 'These are, 1st., the change from inorganic to organic life, otherwise involved in the conception of spontaneous generation; 2nd, the introduction of sensation or consciousness, which "is still more marvelous, still more completely beyond all possibility of explanation by matter, its laws and forces"; and, $3 \mathrm{rd}$, the development of certain noble characteristics and faculties in man, as, for example, his moral and intellectual nature, and the mathematical, artistic and musical faculties, which differentiate him from the brute animals, indicate the reality of a spiritual universe, and prophetically assure an immortal life for the spiritual nature of man.

His peculiar views on these topics will probably appear more or less reasonable to different persons according to their temperamental tendencies and educational bias; but no one, I think, can lay down this book without a conviction of the great ability and transparent sincerity of its author, of its pre-eminent value as a contribution to the general literature of evolution, and of the weight of its arguments in defense of Natural Selection as a controlling factor in organic developinent.*

Evolution may be true, in the field of biology, it may yet be said, but what of it? Man may be the descendant of an anthropoid ape, "probably arboreal in its habits,"

* Note should also be made of Prof. Angelo Heilprin's recently pullished book on "The Bermuda Islands," which contains a careful study of the formation of coral reefs, entirming Darwin's theories on this subject, which some recent writers have brought in question. The tendency of the most recent studies has unquestionably been to strengthen the high regard in which Iarwin has heen justly held as a careful, conscientious investigator and safe theorizer in the field of evolutionary research. 
though of this we are not convinced; but why is it necessary to announce the fact? Any one who traces his ancestry back far enough, will probably discover relationships of which he will not be particularly proud - but he does not therefore find it necessary to bruit the matter abroad, so to speak, - to publish it upon the housetops. Truth is a good thing, indeed, but there are times when silence is golden and speech is leaden - when discretion in speech is the better part of intellectual valor. What moral or religious end can possibly be attained by the public proclamation of a belief in Evolution? Such are the comments, no doubt, of some of the self-constituted critics of the work of this Association. Another sort of criticism of certain phases of evolutionary thought is often heard from those who are quite ready to declare themselves converts to the doctrine in its purely physical and biological aspects: Erolution is only a method, these critics declare; it is not a philosophy, it is not a religion; - the great problems of ethics, of metaphysies, of life, what lave these to do with the nebular hypothesis, the origin of species by natural selection, or the descent of man from lower forms of life?

It should be sufficient, perhaps, to remind intelligent people that if evolution is "only a method," it is, so far as we are able to discover, a universal method, penctrating into all the phenomenal activities of nature; explaining not only the processes whereby suns and worlds have come into being, and the varied and bountiful forms of life have successively appeared upon the earth, but also how the sereral faculties of the mind have grown out of the simplest form of conscious apprehension, how the special senses have been developed, how individuals have been impellerl to combine, forming the complex organizations into which our civilized societies are divided, how govermmental forms have evolved and the institutions of religion have come into being - how religion itself, incleed, and that sense of obligation which constitutes the foundation of man's moral nature, have arisen by processes entirely orderly and natural, ont of the interation between certain primitive instincts and tendencies of the hmman mind, and the environing conditions under which they have found expression.

If we are right in assuming, with Spencer and Fiske and other great leaders in this new movement of thought, that evolution is thus practically illimitable in its range 
throughout the universe of physical and mental phenomena, then indeed must we confess that it is not merely a method whereby the myriad forms of organic life have come into being - it is a method which searches into the deeper problems of religion and philosophy, compelling a reconsideration of old conclusions - a reconstruction of many of their fundamental conceptions. To speak of "the philosophy of Evolution," therefore, is not without warrant. We may well term it, with John Fiske, a "cosmic philosophy," since it is thus universal in its scope and application; or with Mr. Spencer, a "synthetic philosophy," since, like the founder of Christianity, it comes not to destroy but to fulfill, discovering the measure of truth which resides in each antagonistic system, and by a new and deeper synthesis combining them into a harmonious and perfect whole.

If it should appear to some superficial thinkers that the advocates of this philosophy unnecessarily antagonize the creeds and methods of the prevalent religious faith,ideas and conceptions that by many are deemed sacred,the reply must be that the truth is more sacred than any existing institution, or theological or cosmological conception, however venerable. In the language of Emerson, "Nothing at last is sacred but the integrity of your own mind." There is an ethics of the intellect which imposes upon every leverent thinker the obligation to follow absolutely the dictates of his enlightened reason, and frankly to confess his innermost convictions. In the noble passage with which Mr. Spencer concludes the first part of his "First Principles of Philpsophy," he says :

"Whoever hesitates to utter that which he thinks the highest truth, lest it should be too much in advance of the time, may reassure himself by looking at his acts from an impersonal point of view. Let him duly recognize the fact that opinion is the agency through which character adapts external arrangements to itself - that his opinion rightly forms a part of this agency - is a unit of force, constituting, with other such units, the general power which works out social changes; and he will perceive that he may properly give utterance to his innermost conviction: leaving it to produce what effect it may. . . . He must remember that, while he is a descendant of the past, he is a parent of the future; and that his thoughts are as 
children born to him, which he may not carelessly let die. He, like every other man, may properly consider himself as one of the myriad agencies through whom works the Unknown Causc ; and when the Unknown Cause produces in him a certain belief, he is thereby authorized to profess and act out that belief. For, to render in their highest sense the words of the poet, -

\section{‘. Nature is made better by no mean, But Nature makes that mean; over that art Which you say adds to Nature, is an art That Nature makes.'}

"Not as adventitious, therefore, will the wise man regard the faith that is in him. The lighest truth he sees he will fearlessly utter; knowing that, let what may come of it, he is thus playing his right part in the world; - knowing that if he can effect the change he aims at - well: if not,- - well also, though not so well." *

This passage is noteworthy not only for the nobility of its thought and the transparent clearness of its diction, but also because it suggests some of the foremost questions involved in the discussion of the evolution plilosophy. In naming the Power which works in the thoughts of men as well as in the processes of external Nature, "the Unknown Cause," Mr. Spencer brings us face to face with the fundamental problem of the nature of our knowledge - and with that mental attitude which is popularly termed Agnosticism, the bette-noire of this philosophy in the minds of its orthodox critics, as well as those of the extreme radical or materialistic school of thought. In the misconception and denunciation of the doctrine of the relativity of knowledge which constitutes the philosophical breastwork of the agnostic's position, extremes meet, and the Catholic Mallock, the anti-Christian realist Francis Ellingwood Abbot, and the materialist, ably represented last season on this platform by Mr. Starr H. Nichols, $†$ clasp hands, and mingle their otherwise inharmonious roices. Leaving the fuller explanation and illustration of the doctrine of the relativity of linowledge to my able successor in this course. I shall endeavor hereafter briefly to define philosophical agnosticism; to show that its attitude is neither idealistic, strictly speaking, nor irreligious; that it is not inconsistent

* First Principles, p. 123.

†The l'hilosophy of Evolution, Evolntion Essays, 1'p. 343-361. 
with a realistic conception of the external world, nor with the obligation to use and trust those high faculties of intellect and reason which constitute the distinguishing features of the mind of man - that in every department of scientific, historical and true philosophic investigation, indeed, it is consistent and coincident with the meta-gnosticism of my friend, Mr. Skilton.* In speaking of individual opinion as a unit of that "general power which works out social changes," Mr. Spencer places uppermost as the goal of intelligent thought and action, a practical rather than a merely speculative purpose - thereby turning our attention to the field of practical ethics which is involved in the discussion of sociological evolution. To a further consideration of the relations of the evolution philosophy to this topic, foremost at the present day in the arena of discussion and of practical statesmanship, I shall ask your thoughtful attention during the concluding portion of my paper.

What, then, let us ask at the outset, is an Agnostic? What is philosophical agnosticism? The word, as is wellknown, was first introduced into English usage by Prof. Huxley, and was derived by him from Panl's designation of the "Agnostic" or unknown God, whose altar was established by the pious Athenians. As Prof. Huxley himself describes its meaning and origin, it arose from a conviction produced by his early reading of Sir William Hamilton's essay "On the Philosophy of the Unconditioned," strengthened by subsequent reflection and the study of Hume and Kant. Of the essay of Sir William Hamilton, Prof. Huxley declares: "It stamped upon my mind the strong conviction that, on even the most solemn and important of questions, men are apt to take cunning phrases for answers; and that the limitation of our faculties, in a great number of cases, renders real answers to those questions not merely actually impossible, but theoretically inconceivable." $†$ As regards the validity of speculative conclusions, lie was therefore forced to adopt the conviction thus stated by Kant in his "Critique of Pure Reason": "The greatest and perhaps the sole use of all philosophy of pure reason is, after all, merely negative, since it serves not as an organon for the enlargement [of

* The Evolution of Society, Evolution Essays, pp. 225-227.

tCh-istianity and Agnosticism, Huxley-Wace Controversy. 
knowledge,] but as a discipline for its delimitation, and instead of discovering truth, has only the modest merit of preventing error." In other words, the only practical result of metaphysical studies is to convince the unbiased student that the human mind is incapable of grasping ontological facts. In the clearer language of Mr. Spencer, "all our knowledge is relative." We can know nothing of the external universe - nothing even of the nature of our own bodies and of our own minds-save as they are directly related to our knowing faculties. Involved in this phenomenal knowledge, however, and accompanying it at every step, we have the inexpugnable testimony of our reason and consciousness that behind the world of phenomena there exists an Infinite and Eternal Energy which is the source and efficient cause of all phenomena, both physical and mental. As thus stated, the doctrine seems almost a truism. How, indeed, can it be possible that man should know anything which is wholly out of relation to his intellectual faculties? Nay, of what use or interest to him would such knowledge be if it were possible to attain it? And on the other hand, how is it possible for him to view the orderly procession of phenomena - any single phenomenon, indeed - without conceiving it as a manifestation of immanent causal energy? A sense of dependence upon a Power which is greater than our human capacity of comprehension - an alprehension of our own finitude and of that of the phenomenal universe, in the presence of this Power-is indeed as necessary to supply the demands of our intellectual as of our enotional and religious nature. If we think at all, we cannot escape from the implication involved in this belief. It rebukes our intellectual conceits, and touches with an infinite awe and reverence every discovered beauty, every hidien mystery, the existence of which is forced 11pon us by the contemplation of the world of phenomena. In the very fact that the depths of this mystery can never be somded ly the finite plummets of our thought, lies its capacity to forever satisfy the artistic, the poetic, the religious demands of our nature. "Who by searching can find out (iod? Who can know the Almighty to perfection?" Greater than any object of our definite knowledge is the human mind itself. The noblest product of evolution, it bows before no mere conception of the phcnomenal universe, even 
though infinitely extended in time and space. It yields supreme allegiance, reverence and worship only to that efficient Cause which underlies the world of phenomena, both mental and material, which dwells alike in star and flower, in the wonders of the physical organism, in the heights of thought and in the infinite depth of love, touching all that we see and all that we know with a tender halo of musearchable mystery. Like the purple haze in which twilight robes the aistant mountain-summits, fading away into the infinite depths of the stellar spaces, and softening the harsh outlines of rock and forest into lines of perfect beauty, - so the apprehension of the Unknowable Cause of phenomena mellows the sharp boundaries and limitations of the known, softens the crude details of our human picture, and gives it a symmetry and unity which satisfy the resthetic longing, while it also meets the exigent demands of intellect and reason.

"The conviction that liuman intelligence is incapable of absolute knowledge," says Mr. Spencer, "is one that has slowly been gaining ground as civilization has advanced. Each new ontological theory, from time to time propounded in lieu of other ones shown to be untenable, has been followed by a new criticism leading to a new scepticism." * Whether we investigate the product of thought or the process of thought, this conviction is forced anew upon our minds. Analyzing the nature of the simplest prodnct of our knowledge, we find that we know it only by a process of classification with something already known. The botanist who discovers a new flower studies its structure, investigates its method of growth, and finally assigns it to its proper order and class with others which he knows, and thus determines its true character. But the Infinite and Absolute, it is evident, cannot be thus classified. There can be but one Infinite; our knowledge of its essential nature and attributes must be forever negative. 'The nature of life and of knowledge alike testify to the fact that we can know only relations. "Life in all its manifestations, inclusive of intelligence in its highest forms, consists in the continuous adjustment of imner relations to outer relations." $\dagger$ "Every act of knowing is the formation of a relation in consciousness parallel to a relation in the enviromment." Beneath this vital tissue of sequences

\footnotetext{
* First Principles. +1 bid.
} 
and coexistences we cannot penetrate. The very conception of relativity, however, carries with it the knowledge of the Absolute as existing, and as involved in all phenomenal processes. As we cannot liave a shadow without light, so we cannot have the relative without the Absolute: the existence of the one is proof positive of the existence of the other. And since the relations which we know are constant, since the law of cause and effect is universally operative throughout the world of phenomena, our knowledge, though relational, is real — as real to us as would be our knowledge of the thing in itself, were such knowledge attainable. In knowing plienomena we do know the noumenon as it is related to us.

The materialistic critic of the evolution-philosophy comes to us, indeed, with the assumption that the universe is just what we see it to be, and nothing else. As it is in sense-perception, so it is in its essential nature. Hind itself is material. "The brain secretes thought as the liver secretes bile" - thought itself is a material product. We must assume something, he says: why not assume that the testimony of our senses is final and conclisive? It is evident, however, that this position of the materialist is reached not by a process of thought, but by the negation of thought. He is either ineapable of duly considering the problems involved in this discussion, or else he deliherately refuses to consider them, denouncing them as futile and unprofitable speculations. 'The evolutionist, howerer, assumes nothing, except the actual facts of experience; his ultimate criterion of truth is the inability to conceive the opposite of the proposition under discussion. The "fundamental assumption" of the materialist is neither logical nor scientific - it is essentially a metaphysical assumption, and illustrates a very crude and primitive sort of metrphysies at that. 'The evolutionist indulges in no assumptions, falls back on no "first principles," or "axiomatic truths," the origin and history of which he cannot trace in the experience of the race. Every conscions experience constitutes a unit of knowledge, and science is simply the orderly classification and interpretation of such experiences. To science, therefore, the evolutionist appeals not to metaphysics - and by science is the position of the materialist undermined and overthrown.

Consider, for example, what science teaches us of the 
nature of sense-perception. That phenomenon which our minds recognize as sound, science declares to be objectively certain vibrations or waves produced in the atmospheric medium. Between the two orders of phenomena, the external fact and the subjective perception of it, there is no relation of identity - only one of concomitance. One is subjective, wholly, - the other objective; one is mental, the other material. Without an ear, a recipient brain and a conscious mind, the atmospheric vibration might go on forever, and there would be no phenomena of sound. 'The same principle holds good also in sight. That which to our minds appears as color, externally is the inconceivably rapid vibration of the intangible ether which surrounds and penetrates the atmospheric envelope of the globe. Without the eye, the recipient brain, and the subtle synthesis of thought, the phenomenon of vision were impossible.* And so of the other special senses. But what we call matter is inseparable from these sense-perceptions, - it is made up of them. 'Take away what we know as form and weight and color and extension, and nothing material remains. It does not follow, however, that the Unknown Reality which caused in us these sensations lias ceased to exist. As firmly as we believe in our own existence, do we believe in that of a Reality external to ourselves, and by precisely the same warrant_- the unthinkableness of the contrary proposition. To beings constituted differently from ourselves, however, this reality might present an appearance totally distinct from that which we know as matter. 'To the simplest form of organism, for' example, whose consciousness is limited to a single undifferentiated mode of sense perception, those affections of matter which we know as color, taste, odor, sound, extension, would be wholly incomprehensible. The limitation of our own senses, both in number and in range, is entirely arbitrary. $\dot{\dagger}$ It is quite conceivable that there may be beings

\footnotetext{
* Maxwell's new magnetic theory of light emplasizes still more strongly the principle here laid clown.

† The president of the British Association, Professor Flower, indorses Sir Jolin Lublock's iclea that there may be "fifty other senses as different from ours as sound is from sight; and even within the boundaries of our own senses there may be endless sounds which we cannot hear, and colors as different as red from green of which we have no conception. These and a thousand other questions remain for solution. The familiar world which surrounsls us may be a totally different place to other animals. To them it may loc full of music which we cannot hear, of color which we cannot see, of sensations which we cannot conceive."
} 
on some other planet, like the resident of Saturn imagined in the satire of Voltaire, with seventy senses instead of five - to whom the universe would present an appearance quite unfamiliar and incomprehensible to our understanding. 'To the old and ingenious play upon words involved in the familiar and brief philosophical catechism: "What is Matter? Never mind. What is Mind? No matter. What is the nature of the soul? It is perfectly immaterial," - science and evolution, therefore, enter an enphatic protest. Matter, it declares, is the Unknowable Reality as reflected in mind through the mediation of the senses. Mind is that Reality as it appears directly in the operations of consciousness. It is, so tar as we know, inseparable from inaterial conditions; but it is a false logic which therefore infers that it is itself material. You can neither see, feel, smell, taste, weigh, measure, nor chemically decompose a thought. It responds to no material tests. Yet in it lies a power greater than that of the Archimedean lever - a power sufficient to move the world. Of a soul distinct from mind and form, science knows absolutely nothing; but since it also knows nothing of the nature of the $A$ bsolute Reality of which mind and form are manifestations, no divine possibility is slain by this admission. Materialism and Idealism both err in assuming that knowledge is absolute instead of relative. Botl declare that the universe is just what it appears to be to our senses - refusing, like the Electoral Commission, to "go behind the returus" and investigate the actual character of the suffrage. Materialism assumes that matter is the mould of consciousness; Idealism, that conscionsness is the mould of matter. The truth lies between the two extremes, inchuding what is true in both.

The error of Materialism is cruder and more easily refnted than that of Idealism; in view of the testimony of science as to the nature of our sense-perception, it has not a foot to stand upon. In declaring that the Reality which is external to our consciousness is identical and coterminous with that which we know as matter, it bases its whole philosophy on an unverified and unverifiable assumption which is contradicted by the entire testimony of science. Bnt in assuming that there is no Absolute Reality external to ronsciousness, Idealism is equally metaphysical and unscientific. The question in reality is simply one of pliysi- 
ology - of a scientific understanding of the nature of senseperception; there is nothing speculative or metaphysical about it, whatsoever.

'The Materialist's position in philosophy reminds one of certain crude attempts at art, which, ignoring all sense of perspective, and disregarding the beautiful blending of lights and shadows as we see them in the natural landscape, illustrates a sort of sharply-defined wooden realism, which is as distressing to the cultivated eye as it is thoroughly materialistic in its conception and execution.

'The Idealist's position, on the contrary, reminds one of an artist who should eschew the use of vulgar material paint, and attempt to dip his pencil in the prismatic hues of the rainbow. Of the two, it must be admitted that the materialistic painter would produce something, though it would not resemble anything that we ever see in Nature; while the idealist would produce nothing, external to his own imagination.*

In the language of Professor Fiske:

"Our conclusion is simply this, that no theory of phenomena, external or internal, can be framed without postulating an Absolute Existence of which phenomena are the manifestations. And now let us note carefully what follows. We cannot identify this Absolute Existence with Mind, since what we know as Mind is a series of phenomenal manifestations : it was the irrefragable part of Hume's argument that, in the eye of science as in the eye of common sense, Mind means not the occult reality but the group of phenomena which we know as thoughts and feelings. Nor can we identify this Absolute Existence with Matter, since what we know as Matter is a series of phenomenal manifestations; it was the irrefragable part of Berkeley's argument that, in the eye of science as in the eye of common sense, Matter means not the occult reality but the group of sensations which we know as extension, resistance, color, etc. Absolute Existence, therefore, - the Reality which persists independently of us, and of which Mind and Matter are phenomenal manifestations,- cannot be identified either with Mind or with Matter. 'Thus is Materialism included in the same condemmation with Idealism." $†$

* That which the Ieleahst would produce in his imagination, however, might be infinitely finer than the crude objective production of the Materialist.

† Cosmic l'hilosophy, Fol. 1. The Evolutionist is justified in affirming "the eternity and uncreatability of matter," which is the datum on which the 
This, then, is the conclusion of the evolution philosophy, differing as widely from Materialism on the one hand as it does from Idealism on the other: a conclusion, moreover, to which we are compelled by an irresistible logic from no basis of metaphysical assumption, but from data furnished by science itself, reinforced by that ultimate criterion of truth which bases the postulates of our reasoning upon the inconceivability of their opposites. The ultimate data both for the scientific conclusions upon which the doctrine of the Unknowable is based, and for the laws of thought under the operation of which it is logically established, are given in experience, which is the final court to which the evolutionist appeals.

Philosophical agnosticism, it would appear, therefore, is not identical with materialism; it is not a cowardly philosophy which refuses to think; it is by no means to be confounded with that crude liberalism which dogmatically denies God and immortality. It is antagonistic neither to religion nor to reason; it is antagonistic only to those unverifiable assumptions dogmatically asserted as assured truths, which transform religion into superstition, and philosophic reasoning into idle dreaming and unfruitful speculation. The evolution philosophy affirms the duty of thinking out all intellectual problems to their ultimate conclusions, and asserts the competence of reason to deal with the data given in experience, throughout the entire phenomenal universe of matter and of mind. The universe of matter is infinitely knowable; the realm of mind is infinitely knowable. And in knowing mind and natter we know the Infinite and Eternal Energy on which they depend, in all its possible relations to our own consciousness. It is the duty of man to use and trust his intellectual faculties in the investigation of all matters which eome within the scope of his intellect and understanding. All knowledge which can possibly rome within the range of our faculties is open to us ; henee there is no real loss or privation in the conception that the mind camot penetrate behind the veil of phenomena. The superficial appearances of things,

plysical sciences rest,-meaning thereby that "the Reality which persists independently of ns" is constant in its relations, and would always manifest. itself as matter to a being or heings possessed of a consciousmess like ours. The idealistic conception that material objects are creations of the individnal conseionsness, and liave no sulstratum of real existence which endures when that conseiousness is no longer active, is of course inconsistent with all forms of scientitic realisin, and is therefore rejected by the evolutionist. 
when tested by scientific methods, are found to be almost always illusory and misleading. The perception of this fact imposes upon us the sacred obligation to penetrate beneath the surface - to discover the causes and the real relations of phenomena, and to apply the knowledge thus gained to the advancement and betterment of human life.

No realm of thought is thus too sacred for the human mind to penetrate. Into the nature, origin and historical evolution of religion, into the character and history of man's moral sense, into the realms of psychology and of the physical sciences, the reason must search for material wherewith to broaden and deepen the life of man, and enlarge the area of human happiness. Nor is man even forbidden to enter into the lofty regions of speculative thought: only he is bidden to remember that, in exercising his reason upon ontological problems, he can do no more than to create symbols and imaginative pictures of that which is, from the nature of things, in its absolnte essence beyond our human ken. Something of gain in the way of mental discipline there is, doubtless, in climbing occasionally into the thin air of these upper regions of speculative research, if by breathing it we do not become intoxicated with the conceit that we are thereby acquainting ourselves with the actual verities of Absolute and Unconditioned Being. Compared with the results of research into the relations of phenomena, conducted according to the scientific method, metaphysical speculation has proved unproductive, unprogressive, and sterile of practical benefits to man. There is no agreement as to results among speculative thinkers. The schools of metaphysics are as numerous as theological sects, and for a similar reason: there is no criterion of truth which all agree to accept.

It is evident that the content and methods of religion as reconstructed in accordance with the principles of science and the philosophy of evolution, will differ essentially from those which have governed and still largely govern the work of the Christian church. Yet in so differing they will, if we mistake not, come nearer to the essential thought of the founder of Christianity. Instead of urging man to an egoistic strife after personal salvation, religion thus reconstructed will bid him so enlarge and cultivate his own nature that he can render the worthiest and most profitable service to his fellow-men. Instead of basing 
salvation on dogmatic belief, it will make it a process of moral and intellectual growth - a process of characterbuilding. Instead of repressing the intellect, disparaging human reason, and discouraging free thought, it will bid man remove all shackles and fetters from the mind, to think deeply, to think beyond the superficial appearances of things - to breathe the keen air of the intellectual life with perfect freedom, finding therein an inspiration to the noblest living and most devoted service. Instead of urging man to an emotional spasm of repentance for wrongdoing, it will bid him carefully ponder upon the results of his actions, note the instant effect of an evil deed in repressing fulness of life - in atrophying the character of the doer. It will show him that the penalty of wrongdoing is intrinsic instead of extrinsic - that heaven and hell are conditions of the inind rather than definite localities in space.

It will regard religion as a life rather than a ceremonial or a creed. It will inculcate justice in place of charity. Instead of accepting poverty, ignorance and wretchedness as ordained of God,- as conditions of life to be accepted with resignation and mitigated in some small degree by alms, - it will endearor as far as may be to abolish these conditions, by rendering the poor self-helpful, by educating the ignorant, and by removing the causes of disease and vice. thus laying the foundations of a nobler individual manhood, which is the only sure basis for a regenerated society.

If we accept Cicero's derivation of the word "religion," its essential meaning is fuithfulness, thormghness. This principle of faithfulness evolution will teach man to carry into every department of his thonght and labor. 'The reply of the servant-girl, who had recently united with the church, to the question of her mistress as to what evidence she had of her conversion: "I know I have got religion. hecause, now, I sweep under the mats," is suggestive of that conscientious element that a rational religion based "pon evolution shonld introluce into human life. Matthew Arnold's definition of religion is, "Morality tonched with "motion": a morality lifted out of mere conventionalisms, a morality which will make the employer recognize the humanity of his employee, striving to render him a just compensation for his labor, instead of treating him as a mere money-making machine; which will make the work- 
ingman anxious that his work shall be well done, rather than make him strive to do as little as possible for his wages; which shall abolish shoddy clothes and Buddensiek buildings; which shall do away with the adulteration of foods and drugs; which shall create a divine discontent with the "old clothes" of superstition and unreason with which the average man has been satisfied to array his intellectual and religious nature, - this, if not answering to all that we mean by religion, is the natural and consistent product of a Religion of Life. Go into yonder church select it almost at random, if you please, from any quarter of these two great cities - these siamese twins whose common artery is our beautiful Brooklyn bridge - and question its members as to the character and meaning of its creed. How many will you find who really know anything about the dogmas which they are supposed to profess and believe - a belief in which, in many instances, is deemed essential to salvation? How many of our city congregations, of whatever sect, would sit patiently and hear the cold logic of Calvinism brought home to their understandings? Against all these duplicities of thought and life, so prevalent in this transition period, the philosophy of evolution enters an emphatic protest, seeing that that only can promote growth of manly and womanly character which is vitally and really appropriated by the understanding, and allowed its legitimate bearing upon the healthful activities of life.

Evolution recognizes the continuity of thought - the solidarity of the race - the indebtedness of the present to the past. It does not therefore endeavor to establish the new truth or the higher social ideal by violent or revolutionary methods. It seeks for the soul of truth in things false - for the soul of good in things evil--seeing that evils and falsehoods are usually goods and truths out of their proper relations. Evil is mal-arljustment. Its correction should therefore be sought by readjustment, rather than by destruction. Erolution would build on the existing good, rather than seek to lay an entirely new foundation. In the church, Evolution beholds an institution capable of bestowing infinite benefits upon mankind; yet as organized and directed in the past, and to a great degree in the present, it has been and is an institution of doubtful utility. It has repressed the individual reason, teaching 
its devotees to accept as authority the commandments of pope, or priest, or ecelesiastical synod, or sacred book. It lias made the past a shackle upon the present, instearl of a lelp and an inspiration to a larger and more progressive life. It lias fostercd a morbid and mhealthy other-worldliness, instead of seeking to better the condition of men here and now. It has cultivated a low pretense of familiarity with the person and attributes of the 1)eity, as it has assumed to define them, instead of bidding the soml stand in reverent awe in the presence of "the Infinite and Eternal Energy whence all things proceed." All these things must be changed if the church would remain a living and progressive force in the individual life and in the ordering of society.

Instead of ceremonies and worship based upon the current anthropomorphic conceptions of the deity, there will arise "observances tencling to kcep alive a consciousness of the true relation in which we stand to the Unknown Canse, and tending to give expression to the sentiment underlying that consciousness." As to the character and attributes of this cause, the religious teacher, accepting the teachings of Evolution, will not arbitrarily dogmatize. In the language of Mr. Spencer, "duty requires us neither to assert nor to deny that it has personality, but to submit ourselves with all humility to the established limits of our intelligence, in the conviction that the choice is not between personality and something lower, but personality and something higher, and that the ultimate reality is no more representative in terms of luman consciousness than human consciousness is representative in terms of a plant's functions." "The fact that we stand continually in the presence of this Ultimate Reality, that it is involved in every phenomenal activity, whether of mind or of matter, will however, be kept continually before us. The use of the term "Unknowable," as applied to this Reality, is unfortunate if thereby it conveys the idea of that which is practically or actually non-existent,-a superficial interpretation of Mr. Spencer's doctrine with which we are frequently assailed by his self-constituted critics, but against which he cverywhere carefuly guards limself, to the understanding mind. As he himself derlares: "the Ultimate Reality is the sole existence; all things present to consciousness being but shows of it."

In the words of an able popular interpreter of the ero. 
lution philosophy: "The agnostic minister will be chiefly a moral educator; but while discussing ethical questions, which must of themselves exert a highly elevating influence on his hearers, he will, at the same time, have ample opportunity of ministering to their spiritual needs by appropriate references to the mysteries of cosmology, either for the purpose of quickening the religious emotions and reinforcing the religions consciousness, or with a view to emphasizing some moral lesson which he may wish to bring home to the hearts of his hearers. Thus will man's conduct be influenced in the right direction. On the one hand, the necessity of leading a moral life will be impressed upon him; on the other haud, he will be led to reflect upon that inscrutable power whose marvelous energy reveals itself in a universe of wonders - a power which, though indefinable, nay inconceivable, is yet as real in its existence as it is unknowable in its attributes." * Though incomprehensible, this power is apprehensible; though unknowable in its essential nature and attributes, it is known as existing, known as infinite and eternal, known as the Energy from whence all things proceed, and known symbolically in its relations to man and to the phenomenal universe. This knowledge satisfies every legitimate hunger of the heart and mind. The attitude of the mind, therefore, in contemplating the Infinite Source of phenomena should be profoundly reverential and worshipful; yet its truest service will be found in no ritual or stated ceremonial of religious worship, but in the active and intelligent service of man. And in and through this service, making life itself seem ever grander, more precious, more beautiful, there may grow up in the mind a rational hope for personal continuance hereafter, to supplant the dogmatic assurance of the old theology, in which, as inculcated by the Christian church, thoughtful minds are everywhere coming to have a less and less confident belief. Evolution teaches the essential goodness and desirability of life; and on this foundation, if on any, a rational hope of immortality must finally be based. In this direction the healthy emotions of a rational mind are entitled to have free play, "so long as they do not trespass upon the domains of the intellect."

* The Moral and Religious Aspects of Herbert Spencer's Philosophy. By Sylvan Drey. (London: Williams \& Norgate. Boston: James H. West, I'ublisher.) 
Whether this hope in individuals be vivid or dim will probably be largely a matter of temperament and predisposition; but it will doubtless be even more dependent upon the lively comprehension of this fundamental doctrine of biological evolution - the doctrine of the essential goodness and desirability of life itself.

From what has lieretofore been said, it is evident that Evolution, whether regarded in its philosophical or in its religious aspects, will largely interest itself in the praetical problems of sociology - in the promotion of more aetive and more widely extended human sympathies, in the elevation of the poor, the vicious and the down-trodden - thus extending the boundaries and the satisfactions of life not only among the remote and barbarous populations of the earth, but also, primarily and correlatively, in eaeh individual nember of society. "The word "soeiology," as applied to the science of soeiety, - or its Freneh equivalent, - is, I believe, the invention of Auguste Comte; bnt the credit of working out this seience of society, from strietly seientific data, into a natural and comprehensive system, is due, more than to any one else, to Mr. Herbert Spencer. It is to this study, most vital in interest and importanee to every lnman being, that this series of lectures will direet onr attention.

Whether or not society may be properly termed "an organism," in the strict sense in which the individual products of biological evolution are thus designated, it eertainly bears a elose relation to them in many important respects, and especially as to the eharaeter of its process of growth. As compared with the development of inorganic materials, which grow by simple accretion or addition to their bulk, organie snbstances grow by intussusception - a process of waste and repair which reaches every particle thronghont their internal struetmre. In this respect the growth of societies resembles that of organie substances; it is a sort of vital chemistry. All actual and permanent enlargement of society proceeds from the voluntary co-operative artion of individuals. Affection and self-interest are the attractive forces which weld society together, and these forces operate directly in and upon individual minds, througlout the social structme. The death of individuals, and the birth and growth of others to fill their places in society, proceeds in like mimmer with the proeesses of waste and 
repair in organic structures. There is such an intimate relationship between biological and social studies, that some knowledge of the laws governing biological growth is necessary to fit one for forming correct judgments on sociological problems. Biology and sociology both treat of the phenomena of life - both involve psychological as well as merely physical conditions - the one leading up to the other by an entirely orderly and natural process of development. Evolution shows that the phenomenal universe is "all of one piece," - and in its unity of method symbolizes an essential unity of Being, which, if we may not directly affirm it as a demonstrated fact, at least constitutes the most satisfactory and rational theory of the nature of things.

In this higher field of sociological study, how many and varied are the problems that are presented for our investigation - the profoundest, most deeply interesting of any which the human mind can attempt to solve; for they are problems which concern the origin, the essential character, the temporal and final destiny of man as an individual, and of Man as a race. Without attempting to forestall the solution of any of these problems, I may, in conclusion, state negatively the attitude of the evolution philosophy toward sociological studies.

I. Evolutionists have no special schemes for social reform to urge upon society. They regard all earnest efforts for the amelioration of existing social evils and inequalities, witl sympathy and appreciation, but insist that the various "rapid transit" plans for achieving these much desired ends shall be rigidly examined in the light of social science, and not be too hastily accepted for all that their originators claim them to be. Evolutionists realize that "Nature does not advance by leaps," and they would carefully note the trend of past events, and study the nature of individual man in history and in connection with his present institutional environment, before urging him to a definite, forward step, in a direction contrary to that which he has been pursuing. To the Evolutionist, the a priori scheme of the social reformer bears a certain resemblance to the philosophical system of the metaphysician, and, like the latter, he thinks the former should be submitted to the test of the experiential method. 
II. In urging the study of Man in his historical relations, however, evolutionists do not claim that society should take no forward step, or that man should simply imitate or repeat the past. An able student of social and economic problems, P'rof. Wm. G. Sumner, a gentleman whose abilities I admire and with many of whose conclusions I agree, in an article entitled "What is Civil Liberty ?" in a recent number of the Populur Science Monthly, makes the remarkable statement that the doctrine of man's natural liberty is a "dogma," of purely metaphysical oricrin, and asserts, in italicised phrase, that "that dogmu has nerer had an historical foundation, but is the purest example that could be brought forward of an out and out a priori dogma." "The doctrine of evolution," he adds, "instead of supporting the natural equality of all men, would give a demonstration of their inequality; and the doctrine of the struggle for existence would divorce liberty and equality as incompatible with each other." "Civil liberty," he says elsewhere, "is not a scientific fact. It is not in the order" of nature"; and all these startling assertions he makes in defense of the doctrine, the natural foundations of which he arbitrarily endeavor's to undermine.

To the evolutionist it is quite evident that if the learned Professor was as well instructed in biology as he is in theology, metaphysics and the a priori discussions of political economy, he would quite otherwise interpret the sociological teachings of Evolution. He is but a poor student of natural science, indeed, who would simply content himself with learning facts, without endeavoring to trace their relations, to study their causal connections, and therefrom to draw prophetic inferences to guide his future investigations, to interpret underlying laws, and thns enable him to push forward to new discoveries. * To say that Evolution " does not point toward civil liberty" because eommunities of men have never existed completely under its beneficent sway, is to cut away from seientific research that very synthetizing and prophetic quality which is its noblest ancl

\footnotetext{
*If the doctrine of man's natural liberty is only a "dogma," as the Professor cleclares, - a nere speeculative icleal, and nothing more, - the'll it is itle to pursue such a chimara, or to lose upen it a social philosoploy. list if it is a condition of social equilibrimm, toward the realization of which man has beon working throughout all the stages of social clevelopment. then, like the moral law, it is liscoverable through experience and historioal investigation. and is strictly "in the order of nature," though not as a completely realized ideal in society.
} 
most fruitful characteristic, and has been the foundation of all advancement, invention, and discovery, from the birth of modern science throughout the entire history of its magnificent achievements. The history of the past gives us pointers for the future - and they point always away from the crudities, errors and failures of the past, in the direction of an ideal perfection. In all evolutionary progress, Nature moves along the lines of the least resistance, and these lines are not usually discovered by the use of metaphysical divining-rods, but by patient, unbiased, persistent investigation. Myself a firm believer in the advantage and necessity of a larger commercial liberty between nations, I do not believe that the beneficence of this principle will ever be brought home to the convictions of the people by a priori theorizing. The sooner our Economic professors and social reformers appeal to the facts and lessons of experience, instead of to metaphysical dogmas, and adopt the method of Evolution in place of that of speculative theory, the better it will be for the reforms which they advocate.

The method of Evolution, as the name indicates, is in its very nature progressive. Evolutionists know that there is no such thing in nature as absolute quiescence: we must have either the activity of progress, or the activity of retrogression. The one leads to a higher and more perfect life - the other to dissolution and death. Let us see to it that we choose the way of progress, and of Life!

"The outworn right, the old abuse, The pious fraud transparent grown,

The good held captive in the use

of wrong alone -

"These wait their doom, from that great law Which makes the past time serve to-day ;

And fresher life the world shall draw

From their decay.

"O backward-looking son of time ! The new is old, the old is new The cycle of a change sublime Still sweeping through.

"So wisely taught the Indian seer:Destroying siva, forming Brahm, 
Who wake by turns earth's love and fear, Are one - the same.

"As idly as in that old day

Thou mournest, did thy sires repine. So, in his time, thy son, grown gray, shall sigh for thine.

"Yet not the less for them or thou The eternal step of Progress beats To that great anthem, calm and slow, Which God repeats !

"Take heart! - the waster builds again A charmed life old Goodness hath ; The tares may perisls - but the grain Is not for death.

"God works in all things; all obey His first propulsion from the night; Ho, wake and watch ! - the world is gray With morning light!" *

"Whittier, "The Reformer." 


\section{THE RELATIVITY OF KNOWLEDGE}

BY

ROBERT G. ECCLES, M. D.

Acthor of "Evolution of Misd: its NAture AND Developdento" 


\section{COLLATERAL READINGS SUGGESTED.}

Spencer"s "First Principles," and "Principles of Psychology", Fiske's "Cosmic Plilosophy" ; Kant's "Critique of P'ure Reason." The works of Brumo, Locke, Bacon, Spinoza, Hume, Mill, Reid, Mansel and Hamilton. 


\section{THE RELATIVITY OF KNOWLEDGE.*}

As this is a Sunday evening lecture, I suppose it is proper to begin with a text. I select the following, therefore:

"And they said, Go to, let us build us a city and a tower, whose top may reach unto heaven."-Gen. xi., 4.

The childish notion expressed in these words is to-day so palpably absurd that a boy of ten years of age would laugh at it, if it were seriously proposed. As transparently ridiculous as it is in physics, the same notion is quite common in philosophy. Men expect to build towers of speculation whose tops can reach the Absolute. The projectors of Babel's tower no more seriously hoped to touch the region known as heaven than do our philosophers, who strive to know things as they are in themselves, to reach the indeterminate. Copernicus, Kepler and Galileo cut away the foundations from the earth and left it floating in the ocean of immensity. Hume and Kant, Berkeley and Spencer, cut away the foundations of the supposed stability of truth, and left it a tiny speck amid the endless deep. A tower from either foundation reaching to the infinite is simply ludicrous in its absurdity. All we know or ever hope to know is practically wiped out when contrasted with the infinite. 'Two points along any straight line that are at an equal distance from any third point, and in the same direction, must be exactly together, and are not two points at all. From our first item of knowledge to the end of endless knowledge is no farther than from our last item to the same. All we can grasp in thought pales into nothingness before the infinite ocean of facts. If a worm cannot compass our conception of the universe with its limited fund of experience, neither can we compass that of a being millions on millions of times farther beyond us in progress than we are beyond a worm.

Natural Philosophy is steadily proving the kinship of our senses of seeing, hearing, feeling, tasting ald smelling.

* Copyright, 1889, by James H. West. 
We have been taught at school and college to look upon sound and colos, ollor and taste, as resultants of motion and sensation. The phonograph and teleplone are daily demonstrating that sounds of all kinds are merely vibrations borne to our senses by means of the ear. The speed and method of vibrating of the disk form all the vocal sounds in complete fidelity. A slow vibration gives a low pitch, and a rapid one a high pitch. All the colors of Howers, ribbons and rainbow are borrowed reflections from the white light of the sun. Monochromatic light woukd give a ghastly world. (Here the lecturer illustrated by illuminating with monochromatic light.) Light vibrations give us the sensation of color. The slowest moving waves give us red and the most rapid violet. Taste and odor are due to contact-vibration rather than to that of waves, but are subject to somewhat similar laws. Every sense has an exceedingly narrow range. Less than a certain number of atmospheric beats per second will give us no sound. More than a certain number will likewise leave us in silence. Ears are not all alike in this, some being able to hear a higher pitch and others a lower one than their neighbors. The sounds our ears can hear are within a finite range; those possible to Nature spread off into the infinite both above and below our powers. Colors are subject to the same law. What the eye can see downward is limited by the speed producing red, while vibrations of ether slower and slower down to infinity probally exist. What it sees upwarl is a somewliat greater but still limited speed giving violet, while waves of greater and greater speed rumning upward infinitely are embraced in Nature's compass. Nake proper telephonic commection from the somnding-board of a piano to a remote room; connect an octave of tuning-forks, properly arranged for damping; play any tune on the piano within the range of the forks, and they will reproduce it. (The lecturer illustrated by striking a tuning-fork, which conveyed its note to a second fork on a sounding-board, which continued to vibrate after the one originally struck was damped.) Strike notes higher or lower than your forks and they will remain practically silent. A harp with the range of a single octare will do the same. Duplicate every note of the piano with a corresponding one in a tuningfork, and a reprodnction of erery liece played on the piano, whether high or low, becomes possible. We are 
like the single octave of forks, and Nature is like the piano that goes both above and below our powers.

But while the piano itself is a finite series, and only a little beyond the octave of forks, Nature is endless in her range, defying our powers of imitation both upward and downward. A worm, claiming to know the universe as it is, becomes an edifying spectacle. A blind fish in the Mammoth Cave would know the folly of the worm, although repeating the same silliness for itself. Man can see that neither the worm nor the fish can compass anything like a correct conception of things as they are. The creature last produced, no doubt always in the pride of its heart thinks its own knowledge final, and is willing to stake everything on it. A being as far beyond us as we are beyond a worm would wonder at our presumption, if made aware of it. Then beings millions on millions of times beyond him, along the infinite scale of impossible conception, would see that even his knowledge was as nothing to the whole.

From the single sense of the lowest animal, to the most accurately adjusted five senses of the highest Caucasian, is but a narrow step. We are not one whit nearer that endlessness of sense-potentiality here depicted for the knowable than is the lowest creature that lives and breathes. Its knowledge of the actual state of the heart of things is as great as ours. It is as near the final synthesis of the awful abyss of endless fact as we are or ever shall be, though we may go on trying to approach it forever and forever. Science may explain and explain, yet, after all, what do her explanations amount to, before this awful problem that our conceit thinks it has solved? Physics and chemistry, biology and astronomy, are all vying with each other in trying to explain all things as modes of motion.

Our friend Mr. Perrin has taken this cue, and worked out a philosophy where everything is knowable.* He asks us if motion is not the final fact of experience; if all facts are not at last resolvable into facts of motion. Well, what if this be so? Suppose we can show that we have no evidence of the existence of motion? Even if we acknowledge that things do actually move, instead of merely appearing to do so, we can still ask him to tell us

* The Religion of Philosophy. By Raymend S. Perrin. 
how he can have motion unless there is something, not itself motion, that can be moved. If all human experiences are due to motions, what is the unknown something that makes motion possible? On a ship coming from Liverpool to New York, if you walk from stem to stern at the rate of three miles an hour, you may be very certain that you are moving, and those of your fellow-passengers who see you are equally positive. If the boat is going with just the same speed in the opposite direction, it becomes evident that you were all mistaken. As you walked east. ward you no doubt were confident of the direction of your motion; yet if the boat was going thirty miles per hour in the opposite direction, it is clear that instead of going three miles eastward, as you at first believed, you were really going twenty-seven miles an hour westward. But oven this correction can be challenged. The earth carries bont, ocean and passengers at a rate of about 1,000 miles per hour eastward, so that it seems you are going East after all at the rate of about 973 miles per hour. Again, this can be challenged; for the orbital motion changes all our previous computations. Once more, this last can be challenged, for the novement of the solar system among the fixed stars must be considered. Motion cancels motion as we go along in our discoveries, until we finally see that, for aught we know to the contrary, every motion ever male, considered absolutely, may be a mere illusion of sense, due to position, as in the cases we have noted.

Could we tracc our way through the depths of infinity, we have no reason for assuming that the cancellations, both in direction and time, are not endless. Analogy would say they are. Who then can ever know whether or not therc ever was any such thing as an absolute change of place at all? Of relutive change we have an abundance of evidence; of absolute change, none. As science on the one hand resolves everything into motion, and on the other hand proves that we have no evidence of the actual existence of motion, it very plainly cancels its own testimony and leaves us without a guide.

In considering the physiology of sensation, this cancellation becomes still more complete. 'The thought of a moving body is but a mode of consciousness. 'The whirl of a wheel gives us no evidence that it, too, is a mode of consciousness. We can truly picture with some approach 
to accuracy the ideas of other minds. Why? Because their ideas and ours are both of a kind - they are both ideas. We cannot so picture the actual state of that external reality which produces in us the sensation of a revolving wheel. A sharp knife will produce the sensation of pain. Have we any reason for believing that the pain thus produced was part of the knife-blade, that got into us from it? A flea moving over our backs will give an itching sensation. Does the sensation, "itch," escape from the feet of the flea and enter the back? A gentle touch of the ribs by mischievous finger-tips will produce the sensation of tickle. Is the "tickle" first in the finger-tips and then in the ribs? An electric induction-coil produces a sensation of shock. Is the shock first in the coil and then in the person shocked? Our judgments demand that these questions be answered in the negative. Whatever stimulates the nerve-centres susceptible of itching, pain, or tickle, will give us these sensations; and the stimulating thing need in no sense resemble the sensation produced.

Now, it is precisely so with the nerve-centre which apprehends motion. Whatever stimulates it, makes motion visible to our senses. The poisonous ptomaines of the blood in the delirium of fever produce just such stimulation. Drugs can do the same. An undigested supper will make us see bodies in motion, or believe we move ourselves, in dreams. As the fingers tickle the ribs, so drugs and poisons tickle the brain into seeing moving bodies. They evoke the sensations of space and motion. The space and motion I am conscious of in a dream is, so far as my sensations are concerned, the same space and motion of iny normal, waking moments. Surely you will not assert that the dream-space and dream-motion, and a badly digested supper that tickled it into being, are identical? If a dose of rich pie-crust can make the sensations of space and motion appear in consciousness, what evidence have we that the actual things in themselves, that encompass us within Nature, are any more like these sensations than the pie-crust is? If alcohol in excess can tickle our nerve-centres into seeing moving snakes, how do we know that the real snakes are not as unlike these sensations which they produce as the alcohol is? We can believe that our sensations of space and motion, and the things normally causing them to appear, are just alike. We can also, if we wish, believe that mis- 
chievous fingers contain the tickle that enters the ribs. Our belief one way or the other cannot alter the facts. This much we call know - that the proof in the case of the tickle is just as strong as in the case of space and motion. He who perversely asserts that the finger-tips first contain the tickle that is given up to the ribs, that the flea's feet hold the itchiness that is given up to the back, and that the knife-edge has the pain that enters the cut, is just as rational as those who declare that the outer realities of being resemble the space and motion sensations produced in us by their stimulations. He who asserts that the substances which stimulate the nerve-centres of space and motion, producing a delirium of these sensations, is like the sensations themselves, has as much proof as he who holds that anything we see is in any known way like the realitics of absolute being. Io whiskey-molecules shape themselves into wriggling snakes when they enter the brain? Do Indian hemp and morphine, on entering the brain, assume the forms of space, time, and actual world-objects? Surely no one will hold to a notion so crude. Yet it is not one whit cruder than the current notions of men who believe that the Absolute Reality, external to consciousness, can in its real natmre in any sense ever be known.

The logic in both instances is positively identical. Space and time, matter and motion, as known to us, are only states of our own consciousness, which the actual conditions of being tickle into perception. Whatever outer reality answers to space, stirs up that feeling in us. Whatever outer reality answers to motion creates in us that feeling. Whatever outer reality answers to matter induces that feeling. The outer reality bears the same relation to our conception of space, motion, and matter, as the fingers, fleas' fcet and knife-blade do to the tickle, itchiness and pain. A picture in perspective (illustrated by stereopticon views) will stir up in the proper nerve-centres a sensation of depth or distance in space, although we know it is not the same as the onter reality that usnally stirs up the same feeling. We know it is on a flat surface. A stereoscope will make the sensation morc intense. A rotating Geissler-tnbe, when illmminated, may be made to induce the sensation of right-hand motion when really rotating toward the left, or of left-hand motion when whirling towarl the right, or of 110 motion at all, when, 
relative to other senses, it is in rapid motion. On a railroad-train we have all observed how our motion-centres have been agitated into a belief that we are moving, when it is another train that moves, and not ours. As space and motion are but forms of our own consciousness, having some answering correspondence out of the consciousness that produces them, so the tastes and odors, as well as the colors and forms, of objects, are in the same condition of relativity. If $I$ look at a grain of sand through a magnifying glass, I observe that what I see is magnified; but the grain itself does not change its size. If what I see is made larger, but the thing itself is not made larger, the conclusion is inevitable that I do not see the thing itself. This is no trickery of logic, but unchallengeable reason. With crossed fingers I feel one marble as two. I do not actually feel two marbles, but two sensations proceeding from one. If what I feel is doubled, and the thing itself not doubled, I do not feel the thing itself.

'Take oxygen, hydrogen and carbon atoms. Arrange them one way and you have oxalic, acetic, tartaric or citric acids. Arrange them another way and you have sugar, glucose or levulose. Arrange them other ways, and you have tannin, or the various non-nitrogenous bitter principles of plants. Surely, the same thing cannot in itself be sweet, sour and bitter. The various new arrangements only enable it to tickle our nerve-centres in a somewhat different manner. 'Turpentine, oil of lemon, oil of berganot, oil of orange, and oil of pepper, are not only composed of the same kinds of atoms but in precisely the same proportions. 'The shapes into which they are built enable them to affect our nerve-centres differently. The scarlet and yellow iodide of mercury vary only in the way each crystallizes, and the color can be changed at will. (The lecturer illustrated by exhibiting scarlet iodide of mercury on a paper. Heating it over a lamp, it became yellow. Crushing the yellow crystals with the hand, it again became scarlet.) Salts of mercury, and iodine, may exist together as perfectly transparent solutions, or as densely opaque ones, according as they are able to affect our nerves. (Illustrated by experiment.) Cold substances brought together may produce heat.

'The relativity of all these properties appears plain after a few such considerations as the following: Dissolve a 
small quantity of tartaric acid in a large amount of water, until it is just slightly sour. Let one gentleman swallow some very sour solution slowly, and another one a very sweet one. Now let both taste the dilute acid. No. 1 will declare it positively sweet, and No. 2, amnoyingly sour. 'The thing itself is surely not both sweet and sour at the same time. Put your right hand into hot water for a while, and your left into cold. Now withdraw both and insert them into a single pail containing tepicl water. 'T'o the right hand it will be cold, and to the left hot. Surely that water is not both hot and cold at the same instant. Let two persons stare, the one at a very red object and the other at a bright green one; then let them simultaneously look at a light pink object. The man who stared at the green will be sure it is bright red, and the man who stared at the red will be equally sure it is bright green. (Illustrated on the screen, by the stereopticon.) Is it both red and green at the same time?

The fact revealed by all these experiments is that sensations are states of the conscious-being, and that we have no reason for assuming that things in themselves are like the sensations they prodnce. Changes in the individual produce changes in the sensations, though we are morally certain that no corresponding change occurs in the external things themselves. Every one has observed how differently his taste has been affected by the same articles of food when sick and when well. So decided, indeed, does this difference become, that things at one time desired, at another become positively ohnoxious. There is no change in the food. The change is in the patient. Then, on the other hand, tobaceo, at first decidedly disgusting, comes at last to be craved as a sweet morsel. If taste was an actual gnality existing in the things, no change of the individual could alter it. We do know with rertainty how things affect us, but when we assert that this efferet is like that which raused it we go farther than sound reasoning can tolerate.

While thus snbject to fluctuations, there is a sort of parallelism between sensations and the things which induce them. Sugar when out of the mouth, though free from sweetness, does possess some property that in the mouth produces sweetness. A cimmon, fired where there are no ears, may evoke no sound; but there is something produced 
that is capable of stimulating ears, when present, into hearing a loud sound. The object I call red may be innocent of redness in the absence of eyes, yet it always has something that stirs up the red sensation when eyes are turned toward it in the light. The universe emptied of conscious beings would probably have no length, breadth or thickness. It, however, would still possess some constant properties as essential to its being as dimensions are to our conception of it. If we compare things in themselves to the German language and our knowledge of them to the English language, it will be seen that, so far as practical, every-day affairs are concerned, our ignorance is not pressingly important. All our ideas can freely be conveyed by the English language, and, while a knowledge of German might also have its advantages, we can really get along very nicely without it. Even so, our knowledge of phenomena can answer our requirements very well without our knowing the answering facts of the noumena. Should an English-speaking person be called upon to give up his language, he, if he knew no other, would feel that such an edict demolished all language. When the doctrine of the relativity of knowledge proves to us that in the actual universe of being there are neither time nor space, matter nor motion, form nor force, as we know them, to those who cannot look beyond this fact it seems positively a denial of being itself. The Englishman forbidden to speak English and unacquainted with any other language is struck perfectly dumb. Conscious beings forbidden to think in terms of thought and experience are launched into helpless unthinkability. To conceive of matter without length, breadth and thickness is utterly impossible; and to attempt to picture the universe in thought as spaceless wonld be absurd. If we are practical realists we have our theory of the universe. We believe it to be just as it affects us. If we are savants, we know this is absurd, and so we alter it into terms of extension and motion. If we are idealists, we assert it as consciousness impressing consciousness. If we are solipsists, we declare it to be non-existent save in ourselves. Realist, scientist, idealist and solipsist are simply theorizers producing languages of their own, while the true language lies behind and out of reach of all. We must have a theory of the universe of some kind. Without it life would be, so far as we know, impossible. The 
Agnostic perceives that all these theories are wrong, yet knows that he is himself powerless to provide the right one. He therefore adopts the one that practically is least objectionable, and that, of course, is usually the transfigured realism of Science. To his mind there naturally comes a condition of perfect freedom from bias of a fixed type. He sees that pretensions to supernatural knowledge are unfounded, but he also sees that the claims of impossibility hurled at such knowledge by the sceptic are just as little susceptible of proof. Fairy tales and Arabian Night tales he may look upon with incredulity, but of the facts they record he will not be eaught asserting the absolute impossibility. Modern Science itself has forced upon us conchusions that seem as devoid of reason, to non-scientific people, as the tales of Baron Munchausen. 'Take for instance, the idea of the physicist concerning the universal ether. Space, he tells us, must be filled everywhere, even in a so-called vacumm, with a substance immensely more elastic and dense than the densest steel.* The dense walls we camnot penetrate are vastly less dense than the space we think is vacant, and in which we move around without perceptible resistance. The undulatory theory of light and heat force him to this conclusion in spite of himself. $\dagger$ School text-books usually endeavor to avoid this rock of stumbling by avoiding its mention. Maxwell's new magnetic theory of the cause of the undulations strengthens the implication by giving more evidence of it. 'The doctrine of the correlation and conservation of physical forces, mpon which we may safely say our whole civilization has been reared, becomes an unthinkable jumble of mintelligibility without it. Om railways, steamboats, steam looms, and myriad forms of steam engines, onl telegraphs, telephones, electric lights and electric engines, our modern chemistry, with its means of smpplying beauty in clothing, jurity in food, and medicines, have all heen added by following the very line of thought that makes theoretically necessary this dense, elastic ether. The doctrine of Evolution is itself the ontcome of a chain of facts that point to this seeming absurdity as a solemn truth.

Only totally denying the existence of matter, or accepting the more rational hypothesis of rhythm among attenu-

* Jevon's P'rinciples of Scienoe, Vol. 2. p. 145.

$\dagger$ Familiar Lectures on scientific suljects, 1). 282. 
ated atoms, will help us transcend the difficulty. No matter how continuous a body may seem to be to our senses, chemistry and physics join hands in telling us that this is a mere illusion. The most solid steel is built of molecules that are not and cannot be in actual contact with each other.* They exist in it like a cloud of gnats or flies, and only appear one instead of many because they move together as a mass. If two pieces of steel resist each other, and refuse passage-way the one to the other, it is not because there is not room enough for both pieces within the same superficial limits, but because they are acting like two belligerent flocks of birds, and meeting with their molecules, breast to breast. How easy it would be for two flocks of pigeons to pass each other in opposite directions, without the least resistance, if they would only fly in intermediate spaces. A distant onlooker could then see them apparently occupying the same space at the same time. The mass of a cubic inch of mercury is far greater than that of a cubic inch of aluminum, and yet the resistance of the latter is far greater than that of the former. If a trip-hammer is adjusted in its rhythm to seconds, and your finger can be waved to and fro beneath it in intermediate time, no harm can befall you. A single maladjustment will cause resistance, or the destruction of your finger. Let the rhythm of the molecules of this disk be adjusted to the rhythm of those of my hand so that they can freely pass each other, and practically the desk will have become non-existent. Adjust those of our bodies to those of the wall, and we will no longer need doors. The wall resists light just as it does our bodies; but glass that may be much denser allows that same light to go throngh, practically unobstructed. As the light goes through the glass, or electricity through a copper wire, although neither can force a passageway through a brick, so we go through the solid ether, but cannot pierce the less dense wall. Solidity is only a term belonging to relations, and not an actual condition of being in itself. For anything that we can know to the contrary there may be, right here and now, passing through us and this world, some planet invisible to us, with mountains, oceans, lakes, rivers, cities and inhabitants.' 'To either' affirm or deny betrays our mental weakness. We are

* Maxwell's Theory of lleat, pl. 281-287.

† Jevon's Principles of Science, Vol. 2, p.145. Young's "Works," Vol.1, p.417. 
bound either to limit infinitc nature to our finite conceptions, or to fly off at an insane tangent to the region of fairies. We simply do not and cannot know, one way or the other. For anglit that we know to the contrary, the lieavenly bodies above may play the part of molecules in forming worlds as much vaster than ours as it is larger than a hyclrogen molecnle. In such colossal globes there may be intelligent creatures of corresponding magnitnde, to whom our little world may be merely a tiny molecule.

Again, downward anid onr smallest specks of hydrogen, may be complexities as great as those to which we are accustomed. There may be beings and a civilization there. No one can tell. If our world and all it contains, with all visible things, should instantly expand from its present size to that of a giant planet having globes of the present conceived size as its molecules, we could not know it. If at the next instant it should shrink back again, and past our present conceived point, to that of a liydrogen molecule, we and all other things changing in perfect accord, the alteration would be equally unknown to us. All our relations remaining fixed, no method of experiment or investigation could tell of the change. Perhaps now, while we speak, such a swing may be incessantly going on. We know that, relative to one another, the sizes we bear are the same as they were ten minutes ago; but we do not know whether in an absolute or infinite scalc we have not expanded or shrunk billions of miles in onr dimensions. We are in utter darkness upon the subject, and it is well for us to know it. Ignorant conceit, only, shrinks from such considerations.

As we do not know whether we move at all or not, or, if we do, in what direction we move, so we do not know what size we alsolutely bear, or whether we bear any constant size at all. Motion and size are meaningless terms ontside of mere relations. T'mrning to the weights of bodies, we find ourselves forced to the similar conclusions, although weight is our test of mass. 'The amount of substance in a thing is supposed to be known by its weight. A grocer, with what we call aceurate scales, gives us a pound of butter. Carried to the equator it is found to be less than a pound. Carried to the pole it is found to he more than a pound. 'Taken to the moon, it would require nine times as much to make a pound. 'Taken to the sun, it wonld weigh 
a ton. Taken to a star a thousand times larger than Sol, it would weigh 1,000 tons. 'Taken off into the depths of space far from any matter, it would gradually get less and less in weight, down to tlie minutest fraction of a grain. What is its absolute weight? Has it any? Its mass, its form, and all its properties which we know, belong only to its relations in the same manner. In itself it has none of them.

Absolute truth is hidden from us at every turn and in every place. To us things are true or false, right or wrong, good or evil according as they relate themselves to our understanding. To say whether a thing is true or not we must know its relations. Principles and ideas are true or false according to the standpoint we take in viewing them. Men may positively contradict each other, and both be true and right. In the illustration already given, the man walking toward the stern in the steamboat bound for New York, can honestly maintain that he is going eastward at the rate of three miles an hour, while a more far-seeing traveling companion contradiets him, and says he is not going eastward but westward, and not going three miles an hour but twenty-seven miles an hour. A still more far-seeing gentleman can lonestly and truly contradict both, and assert that the walker is right in saying he is going eastward, but wrong in saying his speed is only three miles an hour; for it is over 900 miles an hour. Unless all of them can keep their tempers, and honestly try to find out what the others mean, each will conclude that the others are either fools or stubborn knaves. The zeal that kills, punishes, and hates one's fellows, because they disagree with us, is born of the belief that man can possess absolute and unchangeable knowledge. To the zealot, a thing is either true or false, always and under all circumstances. He cannot see that the lighest truth is only the last point to which our minds have shifted along a contradictory line. Everything we call truth is only tentative. It is the synthesis of all the facts we have mastered. Additional facts will carry us beyond, to a point that will make our last belief appear a falsehood. Certain things are good and true to our present form of civilization. Change this form, and good becomes bad, right wrong, and truth error. Within this civilization, and harmonic with its structure, there are truths that are now and to us positively true. Change the civilization, and 
that which was before harmonic, and therefore good, may become discordant and therefore bad.

'The believer in the Relativity of Knowledge must necessarily be a free man mentally. He can listen dispassionately to the wildest dreams of Utopia, and say "Yes, when men change in such and such ways your ideal may be realized." Mohammedan, Brahmin, Anarchist, Mormon, Spiritualist, Materialist, Catholic, P'rotestant, Atheist and 'Theist, all alike can tell their story to him, and he will perceive that every one of them has ideas that occupy proper rlaces somewhere along the path of the shifting pendulum of relativity. 'They all occupy, in relation to each other', lower and higher planes of thought, containing some relative truth and a good deal of even relative error. The latter is born of lack of knowledge of facts. The Agnostic is a man who is completely disenthralled from the narrow prejudices so characteristic of his race. He is as earnest in defending the truth of definite relations as anybody, but he does not fight over the question as to the absoluteness of such relations. He knows that everything is shifting incessantly, and that the truth of to-day may be the error of to-morrow. He has discovered this truth of truths, and realized, in the fullest sense of the words, the exact meaning of that saying of Jesus, "And ye shall know the truth, and the truth shall make you freer" (John viii., 32.) 


\section{PRIMITIVE MAN}

BY

Z. SIDNEY SAMPSON

AUtHor OF "THE Evolution OF THEOLOGY." 


\section{COLLATERAL READINGS SUGGESTED.}

Spencer's "Prineiples of Soeiology"; Lyell's "Antiquity of Man"; Winehell's "Pre-Adamites"; Joly's "Man bcforc Mctals"; Force's "Prehistoric Man"; Lubbock's "Prehistoric Times," and "Origin of Civilization"; Keary's "Dawn of IHistory"; Lind"s "Man"; Nadaillae's "Prehistorie Man in America"; Nillson's "Prehistorie Man in Skandinavia"; Evans' "A neient Stone Implcments in Great Britain," and "Bronze Implements in Great Britain"; Quatrcfagc's "The IIuman Racc"; Tylor's "Anthropology," "Primitive Culturc," and "Early History of Mankind"; Wilson's "Anthropology"; Wright's "The Icc Age in North America"; Wool's "Natural IIistory of Man"; Lewis's "The Antiquity of Man in Eastern Ameriea" (in Am. Geologist, 1880). 


\section{PRIMITIVE MAN.*}

Max, whence and whither? These problems have puzzled all the ages and perplexed all the philosophies. If the most advanced doctrine of Evolution be true, and if not only the complex physical organization of Man, but his royal intellect as well, have been compacted of the nebulous mists of the ancient heavens, the inystery and wonder are intensified in manifold degrees, and man becomes a greater enigma to himself than ever.

"We walk between two eternities," said Diderot. "Our birth is but a sleep and a forgetting," writes Wordsworth. Says the Sphinx, in Emerson's Poem:

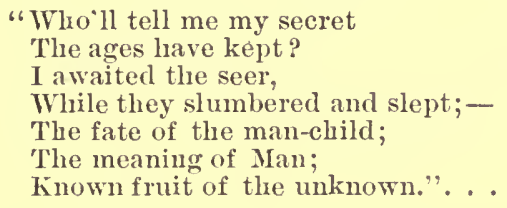

Something, however, - thanks to the science of late years, which has supplanted the former guess-work that went by the name of science,- - is known of the character of man's life upon the earth prior to historic records; and the same science is pressing hopefully onward to open new avenues of exploration, and to perfect such knowledge as we possess.

In our course of lectures last year we were amply instructed as to the present accomplishments of science on the question of the "Descent of Man." We are now, in a supplementary way, to inquire what has been the life record of man since the period when first he stood forth as truly man, asserting through some superior, though at first, slight prescience, his mastery over the mere brutes that perish. If the conclusions are subversive of some cherished legends of the historic past, yet here, as on so many other lines of Evolution, we obtain a more unified and coherent, and

\footnotetext{
* Coprrigir, 1890, by James H. West.
} 
thereby a more reverent conception of the totality of Nature and of Man, and may be reconciled to the loss of that which the more credulous past held worthy of belief; for as these myths of ancient times have enriched the inagination, and stimulated the faith in an Unknown, so bave they entered into the life of the Present, which is the sum of all the Past, and have but been transformed into loftier ideals.

The establishment, within a recent period, upon a satisfactory scientific basis, of the fact of the great antiquity of man upon the earth, was primarily due to the results of investigations regarded, at the time, as of but slight consequence, and therefore, like so many other preludes to the discovery of important scientific truths, wholly undervalued, and, indeed, for a considerable time, wholly disregarded. The credit of inaugurating the line of research whereby has been ultimately demonstrated the existence of primitive races for tens, if not hundreds of thousands of years anterior to all historic records, belongs to the French scientist, M. Boucher de Perthes. Possessed by the energy and enthusiasm of a truly scientific spirit, he devoted himself from the year 1836 to 1841 to a thorough exploration of the ancient caves, peat-mosses and diluvial deposits in the vicinity of Abbeville, and in the valley of the Somme, in France. During this five-years' labor he mnearthed a large quantity of flint weapons and tools of varions kinds, evilently shaped by artificial means, having surfaces and edges roughly chipped, and obviously designed for use as spears, arrow-heads, axes, knives and hammers. 'The question immediately suggested was as to the age of these inplements. 'To this geology furnished a reply. The objects were found to be incrusted with material of a yellowish tinge, clearly not due to the substance of the ohjects themselves, but to the ferruginous natmre of the soil in which they had been imbedded. In a certain layer of the dihvium was found the character of such deposit as would have caused the incrustation, and, if the objects were imbedded in it at the time of its formation. some approximate idea could be obtained as to the age of the implements. "If," as he says in his report upon these investigations, as quoted by l'rof. Joly in his work, "Man before Metals," "they were in the bed from the herimning, the problem was solved, and the man who made the implement 
was anterior to the cataclysm to which the deposit owed its formation. In this case there was no possibility of doubt. Diluvian deposits do not, like peat bogs, present an elastic and penetrable mass" (i.e. a mass into which objects could have been forced by various external agencies), "nor do they, like the bone-caves, present a gaping chasm, into which objects might have been thrown by torrents, or into which they might have been conveyed by men or animals, but, on the contrary, each period is sharply defined. The layers are disposed horizontally, the strata differ in color and substance. If this work of human hands has remained there from the first, as irremovable as the bed itself, then it had a prior existence, and these rude stones, in all their imperfections, prove the existence of man no less surely than such a building as the Lourre itself could have done." This was evidently a true scientific induction, inferred in accordance with the well recognized scientific formula that the opposite of the proposition cannot be conceived as true.

The question as to the age of the diluvium itself makes it necessary for us to turn a few leaves of the geological record. As set forth in the subjoined table,* the periods with which we have to deal are of the Tertiary and Quaternary epochs, these having been preceded by the immensely long eras of the Primary and Secondary, in which it is not claimed that any traces of man's existence have been discovered.

Considering now the question as to the possible or probable existence of man in the several epochs of the Tertiary, it is agreed that no traces of human remains or human workmanship are discoverable in the earliest, i.e. the Eocene. The mere absence of human remains does not, however, conclude the question, for such are but rarely found in the long subsequent Pleistocene strata, whence, at the same time, thousands of flint implements have been excavated. But the argument from the character of the fauna of the period militates strongly against the probability of man's existence. Giving here the conclusions as summarized by Prof. Fiske in his interesting essay on "Europe before the Arrival of Man," we note the first appearance, in the Eocene, of the placental mammals, following the marsupials of the earlier periods, of which 
latter but few species remain. But the placental mammals of the Eocene differ so widely from the mammals of to-day as not to be recognized as related, in succession, to the

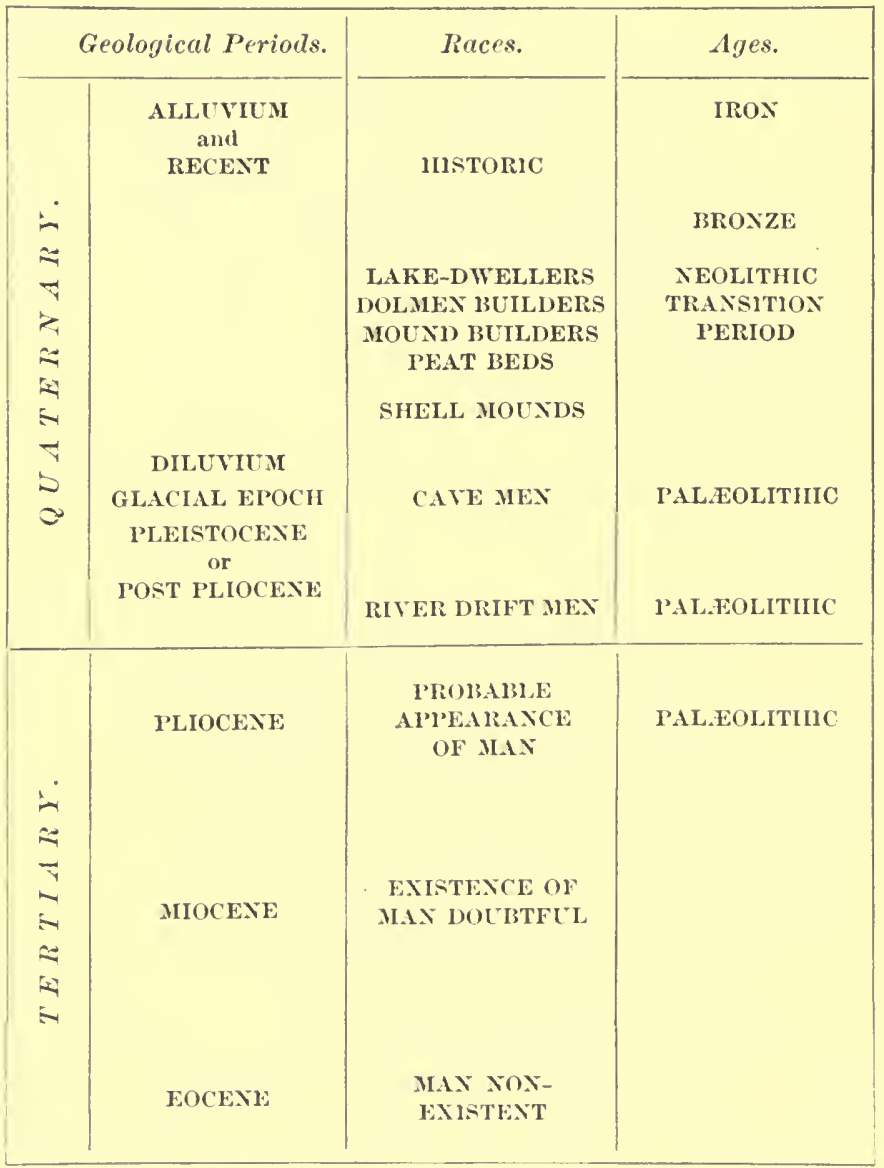

latter, except through careful and experienced scientific research and classification; and the difference consists, mainly, in their far closer relationship among themselves, in structure, than among existing orders and species. In 
the Eocene we find the ancestor of the horse, but having several toes, instead of the solid hoof. We have the progenitor of the deer and antelope species, but not presenting the special characteristics of the latter, being devoid of horus or antlers. 'The nearest approach to what was to be man is discovered in the lemur and lemuroid ape. The strange circumstance of all, however, is the resemblance, in form and structure, between the hoofed quadrupeds and the primates (i.e. the lemur and ape families). In other words, we do not find in the Eocene any of the existing species or genera, but only fauna of the fossil orders, from which present species and varieties have, by a slow evolution, differentiated.

It is therefore, argues Mr. Boyd Dawkins, with much force, in his "Early Man in Britain," altogether improbable that man, the most highly complex and specialized of all the primates, with his manifold special characteristics and adaptations of bodily function, to say nothing of his extraordinary and diversified mental processes, should have been contemporaneous with a fauna which had not, as yet, developed a single feature of physical conformation peculiar to the species now existing. 'To this conclusion add the argument from the non-existence, so far as now known, of human remains or implements, and the question of man's existence in the Eocene must be answered in the negative.

Coming now to the Miocene, or Middle Tertiary, the discussion turns mainly upon the fact, or otherwise, of the discovery of traces of man's presence. The discovery of carved flints below certain miocene deposits in France was anmounced at the Prehistoric Congress in Paris in 1867, and again at the Prehistoric Congress in Brussels in 1872. The announcement caused a wide divergence of opinion among anthropologists, which continues to the present time, some denying wholly that these carvings are the work of man, others being doubtful, some few admitting it. The question evidently awaits further exploration. The supposition of one eminent scientist, M. Gaudry, that these incisions could have been made by the great man-like ape of that period, the dryopithecus, is not generally accepted.

With reference to the Pliocene a like question has been raised as to the age of discoveries of the same and similar character. In 1844 the finding of human bones in a volcanic breccia upon the side of a mountain in France, 
upon the opposite side of which, in the same deposit, were unearthed bones of species of inammals long since extinct, was asserted to prove man's existence in the Pliocene; but the age of the deposit itself has been questioned, whether Pliocene or early Quaternary. In 1863, the discovery of carved flints in the Pliocene sands of Chartres was communicated to the French Institute; and still further, in the progress of the Geological Survey of Portugal, stone implements were found in the Pliocene beneath 1200 fcet of superincumbent rock. Without multiplying instances, for which there is not space, the consensus of scientific authority is strongly to the effect that man had appeared in the latest Tertiary epoch.*

But with the close of the Tertiary, and opening of the Quaternary, all doubt ends. In the Post Pliocene, or Pleistocene, the evidences crowd upon us, and from that period the evolution of man in physical and social conditions may be traced, not, indeed, with entire accuracy, but with reasonable certainty. Considering, for a moment, the geological character of the epoch, as necessary to account for the localities of origin and successive migrations of primeval man, we note that the conformation of the European continent was, substantially, as at present. It is asserted that, during the Pliocene, inland seas extended from the eastern portion of the Baltic to the Persian Gulf, and from the Caspian to the Arctic, thus allowing the warmer southern currents of the Indian ocean to modify the scverer climate of Scandinavia and Russia. I'rofessor Geikie claims that these seas disappeared early in the Pliocene, thereby reducing the temperature of Northern Europe. By the close of the Pliocene the climate of Northern Europe generally had become considerably colder. 'Thoughout the early Pleistocene we therefore have remarkable alternations of climate, precisely how many is unknown, but heralding the approach of the long Glacial Epoch, or ronstituting interglacial epochs, of which two at least are generally admitted. The proofs of these successive warmings and coolings are found in the curious intermixture of fossil remains in the deposits of the Pleistocene. With the remains of mammals peculiar to present tropical areas, viz., the lion, leopard, elephant, etc., we find bones of

"Further evidences are collated in Prof. L. 1). Cope's Lecture on "The Descent of Man," Brooklyn Ethieal Association "Evolution Essays," p. 163. 
the musk sheep, reindeer, arctic fox and chamois, showing that successive cold waves had forced, at one epoch, the aretic fauna far south of their present locality, and again that this was followed by a rise in temperature which permitted the animals of tropical zones to exist much farther north than at present.

It has been shown that men, prior to the Glacial Epoch, or savages perhaps rather, of probably an extremely low grade of development, without pottery, possibly in the earliest periods unacquainted with fire, existed contemporaneously with a fossil species of the rhinoceros, which at some warm period lived in the vicinity of London and was distribated extensively over Northern Europe. They were anterior in time, in France and Britain at least, to the musk sheep and the marmot, animals of the glacial and pre-glacial epochs. The flint implements of these tribes are of the roughest kind. It is claimed by some that these races were supplanted by the subsequent Cave Men; by others that they represent only an earlier and more primitive condition of the latter. 'The place of origin of River-Drift man is unknown of course, and to what periods immensely remote his ancestry extended it is still less possible even to approximate. $\mathrm{He}$ is simply the earliest of our own species whose existence is traceable, and, if belonging to essentially a distinct race from his successors, he has vanished into the night of the past, with only the most rudely chipped flints left to reveal even the fact of his having been upon the earth.

The result of the gradual refrigeration of the Northern Hemisphere was the Glacial Period of the Pleistocene, and the overlaying of all the countries now known as Finland and Northern Russia, Scandinavia and Scotland, and the American Continent as far south as the latitude of Philadelphia, with a sheet of ice many hundreds of feet in thickness, sending forth immense glaciers still farther southward. The occurrence of the Glacial Period is so well established as to have become one of the commonplaces of Geology. The proofs from the striation of rocks in the northerly and central portions of Asia, Europe and America, caused by the friction upon rock surfaces of masses of ice in motion, and now still being produced by glacial action in the Alps and elsewhere; - the fact of old river-beds existing at the foot of mountains, which have undoubtedly, in past ages, been the scene of glacial movement, and caused 
by the melting of the ice mass, - the deposit, in all countries, of boulders evidently bronglit from regions far remote northerly from the localities where deposited, and of a mineralogical character wholly different, in many instances, from that of the soil on which they rest,-are matters of ordinary information. 'The inportant result, in the history of primitive man of the ice age, in Europe certainly, was the migration from the vicinity of our present aretie clinate into the central and southern-central portions of the continent, of the race known as the cave-men, forced southerly by the exigencies of extreme cold, and displacing or exterminating the prior people of the river-drift, who liave left with us such abundant proofs of their occupation in the countless specimens of thints, knives, axes, hammers and weapons with which, and by which, their existence and name are identified. The cave man was contemporaneous with the entire glacial era, and with the geological period immediately subsequent, classed by scientists as the Dilurian or Drift. 'This brings us once more to the formation in which M. de Perthes' discoveries were first nade, and by him male available for further scientific inquiry.

The diluvian deposit was largely a direct consequence of the cessation of the glacial epoch in Europe, caused by the gradual increase in temperature and the resultant melting. of the vast ice formations, and the gradual withdrawal of the southerly line of glacial action to the remote north once more, except in lofty and therefore cold altitudes like those of the Alps, where it is still in opcration. The consequence of this general melting down of the ice-deposits was the creation of extensive river-floods, which, bearing along the great mass of foreign bodies conveyed southwarlly by the glaciers, formed what is known specifically as the diluvium of the valleys-consisting of debris from the momntains, gravels, pebbles, and scdiment of mud and sand frequently impregnated with oxide of iron (the ferruginous layers of which we have spoken), and with calcareous or chalky material. The close of the diluvian period brings us to the alluvial deposits and recent period, within which no terrestrial changes of soil or climate have been sufficient matcrially to affect the evolution of the rare.

I return now to the discoveries of M. de Perthes. With great confidence in regard to the bearing of these upon the future of primitive ethnology and archaology, he submitted 
his specimens to the Institute, with the usual consequence of arousing skepticism, and, in this case, ridicule. But he laughs best who laughs last, and prejudice and obtuseness finally yielded to scientific examination. It is not so many years indeed, since men ceased to regard these strange, but by no means unusual objects, as preternatural, if not supernatural, or "freaks of nature" as they were once termed. The ancients, indeed, classed them with the supernatural, and had called them "lapides fulminis," implying that they had fallen from the sky with the thunderbolt — and "ceraunice gemma," i.e. heavenly gems, on the theory that they had been formed on the earth by the fire of Jove; so, also, "lightning-stones." 'They were used in certain religious ceremonies by Egyptians and Romans. Even to-day they are objects of superstitious regard among some of the more ignorant of the peasantry, and kept by them carefully as having power to ward off disease or witcheraft. But even among scientists these implements had not received the attention which they deserved. As soon as investigation was commenced and interest aroused, many collections were found to have been already male, available for further study, and which have materially contributed to the advancement of prehistoric archæology.

Following Sir John Lubbock and others, the division of the age of prinitive man which has been generally approved, is that into the palæolithic, or old stone, and the neolithic, or new stone periods, - and the periods of bronze and of iron. To the palæolithic are assigned the eras of the men of the river-drift and of the cave men; but it should be here remarked that the points of transition between these various epochs, as well as the length of the periods themselves, are extremely vague and indeterminate. Old and new stone implements are, in numerous instances, found in the same locality, and neolithic and bronze objects are also frequently associated - and both these, in some cases, with implements of iron. To definitely differentiate the periods is equally impossible - the earlier extend into the later, so that any chronological arrangement, except of the most general kind, is out of the question. So far, likewise, from these epochs being contemporaneous in all parts of the world, we have numerous of the lower and some of the higher of the savage races of to-day, and some of the 
partly eivilized, in the habitual use of stone implements of the later stone age. It lias therefore been properly said that a given kind of implement indieates rather a stage of culture than a elassifieation in time. So regarded, the palæolithic are eharacteristie of the earliest man;-these, roughly lewn and ehipped, betoken an extremely remote age. The speeimens consist of axes, lanee and arrow heads, knives, serapers for preparing skins, and lrammers, all of the most primitive type, prepared almost exclusively from flint, exeept where, as in America, jade and obsidian are more readily obtained. These implements abound in great quantities, not only in the diluvian, but in the numerous bone eaves of various ages, and megalithic tombs, in peat mosses, shell mounds, barrows, erannoges and lake-dwellings.

It is to the flints discovered in the bone-eaves that we owe the second important deduction as to man's antiquity, for here we discover bones of extinct speeies of animals intermingled with palæolithic implements. If the implements are found so imbedded with these remains as to prove eontemporaneity in the date of deposit, we lave a further satisfactory scientific datum. It is now absolutely known that the principal species of animals existent during the early Quaternary - though now wholly extinet were the mammotl, the woolly rhinoceros, the cave hyena, the cave hear, the cave eat, the care lion, and the Irish elk. With the bones of these quaternary fauna, have been found associated not only flint implements, but luman remains as well, under circumstanees which preelude any reasonable doubt of the eo-existenee of man with the above enumerated species. The announcement of these diseoveries was first mate in 1828. In 1833 the eaves, of Belgium were thoroughly explored, and skulls and portions of the human skeleton were found lying not only above, but below, fossil animals. Sir Charles Iyell first opposed the theory, but after a quarter of a century argued in support of it; and when, in $18 \pi s, u p o n$ a thorough examination of the recently opened cave of Brixham, in England, an entire leg of the cave bear was found superimposed mpon an incrustation of stalagmite, which itself was fonnd superimposed npon flint instruments, the proof was deemed sufficient for the Royal Society to endorse the proposition of the existence of Quaternary man as fully established.

The bone-eaves abound in all parts of the globe, among 
the most interesting being those found in the cretaceous or chalk formation. As to the agencies by which they have become thus filled with human and animal remains, the action of river-floods does not appear to have been the sole cause, though it may have been one of the most efficient. As has been remarked, these cavities were, for a length of time unknown, utilized by primitive man, as well as by various species of now mostly extinct animals, for purposes of residence, and for temporary shelter; both probably carried or bore into them the animals upon which they subsisted or preyed. The mere juxtaposition of human and animal remains does not, of itself, demonstrate the great antiquity of the former, for, in fact, various articles of undoubtedly recent human workmanship have been found thus associated. But "doubt is no longer reasonable when the bones of animals and those of our own species, uniformly mixed, imbedded in the same sediment, and which have undergone the same alterations both in external characteristics and of chemical decomposition, are moreover covered by a thick layer of stalagmite - when objects of a completely primitive industry occupy the same deposit, with bones of extinct fauna. And finally, when we find in the diluvian strata of the valleys, manufactured objects and bones exactly like those discovered in caves of the same date, the proofs are conclusive." *

Have we any data for determining or approximating the age in the world's history of the glacial period, and thereby the time of existence of the cave men and their predecessors? It seems that we have. I give the summary of the argument as set forth by Professor Fiske, in his interesting essay on the "Arrival of Man in Europe." The conclusions there stated are those reached by Prof. Croll. The chief cause of the reduction in temperature, which ultimately produced the ice age, was an alteration in the eartl's orbit in the direction of greater eccentricity. $\dagger$ It has been shown that at least three times within the past 3,000,000 years this eccentricity has reached its maximum, with the result

* Prof. X. Joly, Man before Metals.

+ In the discussion following the lecture, Dr. P. H. van der Weyde suggested that the gradual elevation of land-areas into the region of perpetual cold, was a simpler and more reasonable explanation of the formerly extensive prevalence of glacial phenomena, which are still olscrvable in areas of high elevation. This theory would require equally immense periods of time for the deviation of these recurrent periods of glacial action, and would equally indicate the early alpearance of man. 
that the difference between the greatest and least distances from the sum has been between four and tive times as great as at present. 'That is, instead of being, as now, a difference of only $3,000,000$ niles, it was from twelve to fourteen millions. Furthermore, owing to what is known to astronomers as the precession of the equinoxes, at regular intervals of 10,500 years the winter season has oceurred and will oecur when the earth is in aphelion, or at the longest distance from the sin. If, now, these two events concur, - that is, if the greatest eccentricity of the earth's orbit happens at a time when winter occurs in aphelion,_- the earth would be in midwinter at ninety-eight millions of miles distance from the sun, instead of, as at present, ninety-one millions, and the Winter would be twenty-six days longer than summer, instead of, as now, being eight days shorter.

Working upon these data, Prof. Croll asserts that the first of these periods of great ecentricity began $2,650,000$ years ago, and lasted 200,000 years; the second began $\$ 80,000$ years since and lasted 160,000 years; the third commenced 240,000 years ago and lasted 160,000 years. This would give us, since the termination of the last glacial era (or eras), 80,000 years. But it is certain that man of the river-drift period lived in pre-glacial times, and if we accept the eonclusion that the most reeent glacial era commenced 240,000 years ago, we must allow not l'ss than 400,000 years ago as the date of the close of the Pliocene period, and the probable first appearance of man. Other theories which have been proposed to account for the Glatial Age, such as variations in the intensity of solar radiation, the movement of the earth from a colder into a warmer region of space, alteration in the axis of the marth and others, are fully stated and criticized in the twelfth ehapter" of Sir John Lubbork's "Prehistoric Man," as are also inrestigations into existing deposits and formations with a view to ascertaining the probable antiquity of the stone and bronze ages.

With the disaplexarance or final retreat nerthward of the cave men, - now representod as seems probable, if they have left any descenlants, by the Esquimaux tribes alone.me may say that the palaolithic age as a generally prevailing stage of primitive life rloses, and we observe the gradual appearance of the ground or polished stones which typify the 
neolithic period. A word, however, is necessary as to the habits and customs of palaolithic man.

Notwithstanding assertions to the contrary, the bulk of evidence indicates that Quatemary man from the most remote period was in possession of fire. According to one authority it was known to him as far back as the Niocene, but the proofs do not seem to warrant this belief. But in the case of the earliest cave men we find numerous hearths, ashes and cinders, bones wholly or partly calcined, and fragments of hand-made pottery blackened by smoke. Prehistoric man of that period cooked his food, therefore,perhaps not after our fashion, but possibly as among certain present savage tribes, by the application of heated stones, or in water heated by such means. His food was not carefully chosen, as it seems to our taste. Mammoths, the rhinoceros, beavers, dogs and foxes were on the bills of fare.* Marrow was a great dainty, as is evident from the quantity of the long bones of animals which have clearly been broken for the purpose of its extraction. Fire was probably obtained by friction in various ways, as among existing low races. Palreolithic man possessed no cereals, nor had he domestic animals or agriculture. For his sustenance he contended with the wild and ferocious animals of his time, as is evident from many skulls of beasts fractured by flint weapons. His clothing necessarily was furs and skins, to prepare which he evidently used the flint scrapers which are so abundant. P'ins of clay or bone were used to fasten the clothing, though in the so-called reindeerage rude sewing was effected by bone needles. Of social customs we have no trace, although, if we judge by analogy of existing savage tribes, both polygamy and polyandry were practised. Of the earliest men we discover no remains of dwellings. 'They contended with the cave bear and cave hyæna for shelter in the natural cave formations. It was a struggle for existence in the utmost acceptation of the phrase, and that from such an unpromising environment the race should have risen to its present high standard of social and intellectual advantage is not one of the least of the wonders that the philosophy of Evolution offers for our reflection.

* The recent discovery by II. Armand Vire, of pala olithic flint-hooks, which had evidently heen used as fish-hooks, and the prevalenee of palaolithie spearheads in the river-drift, indieate that fish was also a common food of palaolithic man. 
We must further briefly note that the numerous carvings and designs of species of animals now extinct, which have been discovered on many of their fossil bones,- - frequently exhibiting a very considerable ability in outline delineation, and superior to any thing produeed by the lowest or cven somewhat advaneed races of to-day,-are an important eontribution to the proofs of the antiquity of man, and equivalent in fact to any others which have been addueed.

We may here properly sum up the several cridences:

First - The discovery in the diluvial or drift strata, whose age in geological history is relatively well known, of rude artificial flint implements.

Second - The diseovery in bone caves of human remains and flint instruments demonstrated to be contemporancous with the remains of species of animals undoubtedly extinet, and of species also whieh have long disappeared from the region where these remains are found.

Third-Carvings of extinet species of animals upon the bones of such animals.

Fourth - The demonstration of the descent of man from some speeies of primate,- neeessitating an enormous period of time, anterior even to the Tertiary, for his progress to his earliest known or supposed appearance distinctively as Man.

It is not improbable that the very earliest races were wholly devoid of any sentiment of what we call religion, or habits of worship. The lowest tribes of which we have any aecount in historical reeords appear to have possessed some instinctive reeognition of superior powers, and we discover none in which some rite of propitiation and saerifice, or funeral eercmonial at least, has not prevailed. If primitive man exhibited any religious, or, at any rate, theistic obserrances, they must have appeared, of eourse, in forms of the lowest and most degrading fetishism, inspired only by fear. But the question must remain largely speeulative.

It some period subsequent to the disappearance of the cave men, and extending in some cases into the neolithic: are (for the chronology is very mineh disputed), oceur the phenomena of the peat deposits, the shell mounds, or kitchen middens as they are termod, and the constructions 
of the dolmen and crannoge builders of Europe and Asia, and of the mound builders of America. Some species of dolmens may be older, others more recent, than the beginning of the new stone age. It is certain that the upper sections of the peat beds have yielded bronze implements, notably a bronze shield of skilled workmanship, which brings this deposit certainly below the neolithic era. These peat beds, or peat mosses, as they are called, are most abundant, and have been studied to the best advantage in Denmark. They consist of successive layers of carbonized material, formed from trees known to be of different periods, the lowest composed of aquatic plants and pines, including the Scotch fir, which long since disappeared from the country. This gives place to various species of oak, all but one of which has disappeared - and these, in their turn, to the beech, which now grows luxuriantly in the country. The depth is from fifteen to twenty feet. Palæolitlic objects are found in the lowest deposit, which must, according to Professor Steenstrup, have been formed from ten to twelve thousand years since. Peat mosses and bogs, with corresponding remains, and imbedding the remains of extinct species of animals of the same age, are found in Ireland, France and Switzerland - in the latter containing the well-known leaf-marked coal, which, being covered by a glacial deposit, is of great antiquity, contemporaneous, in the opinion of some, with the earliest appearance of man in pre-glacial times. While it is true that, owing to the spongy, yielding nature of the material of the peat beds, we are not so well assured as to the antiquity of remains therein imbedded as in the case of the well-marked geological stratum of the diluvium, yet the researches thus far undertaken have been so carefully and impartially conducted as to make their results as worthy of confidence as similar explorations of the diluvium; and, as Professor Virchow has remarked, "If doubt was still entertained as to the coincidence of the age of the pines (now, as we have said, extinct) and the age of stone, the discovery of a flint instrument in the peat at the foot of such a pine would be conclusive."

Coming next to the shell mounds or kitchen middens, these also abound most plentifully along the coast of Scandinavia, Denmark and North Germany. They consist of remains of prehistoric cookery, oyster-shells, mussels, lim- 
pets and periwinkles, together with bones of mammals of species all at present extinct. The heaps thenselves are from one to three yards in lieight by 100 to 350 yards long and 50 to 70 wide. In these, loeated but a short distance from the shores of the Baltie, and raised about three yards above the sea level, einders, rude pottery and flint implements are found intermixed; but we discover no cereals, nor instruments of metal, though the flints are of better workmanship than those of the most remote palaolithic age. Remains of the blaekeock and the penguin, birds long since non-existent in these loealities, are also found, but no human remains. 'The age of the heaps is in dispute - some plaeing it at 7000 years, others bringing them down to the age of the dolmens. It does not seem possible to reeoncile scientifie opinion on the subject.

In the Winter of 1853-54 the waters of Lake Zurieh fell to the lowest level till then reeorded. Prof. Keller then first had his attention drawn to eertain piles driven into the bed of the lake. 'The eloser examination of these was the ineeption of a scientifie interest anong archæologists, in the investigation of these struetures, which proved to be speeially fruitful of results coneerning prehistoric man. Remains of wild and domestic animals, various forms of human skulls, implements of every deseription, in bone, flint, bronze and iron, pottery of more or less artistic workmanship, objects of ant and ornament, woven stuff's, grindmg-stones, mill-stones, grains, breads, frnit, ashes, coal - all these are fonnd. The piles are from fifteen to thirty feet in length, their diameter three to nine inehes, and they project above the surface of the water from fonr to six feet. They are sometimes placed in lines farallel with the shore, sometimes at right angles to it, and are either firmly imbedded in the mul, or supported by heaps of stone at their base. They were united by transverse beams, held in position by wooden pins. (On these heams was eonstructed a platform, of thick planks, or of split trunks of trees ronghly squared; and npon the platforms were erected ovil, circular, or rectangular huts, ten, fifteen, or more feet in dianeter, the walls being formed of verpendienlar posts fastened together by wattled branches, lined with a cement of elay. The huts were covered by a roof of bark, thatch, eane, reed, fern or noss; a trap-rloor in the platform conmunicated with the lake below. Each 
hut was surrounded by a ring of piles, and was united to the shore by a drawbridge. Such in brief was the lake dwelling. Some two hundred villages of such dwellings have been explored, and it appears that each village averaged about three hundred huts. The objects to be secured by this peculiar construction have not been satisfactorily determined, except that the tendency of scientific opinion is to consider defence against attack a principal motive.

The oldest of these structures do not antedate the neolithic age, and it seems that they existed until a short time after the arrival of the Romans, - at least, that is, into the iron age, - in the western part of Switzerland. In the east they disappear with the age of stone. Authorities differ as to the period of their earliest construction; some will have 5000 to 7000 years, others date them back to the earliest stage of the race. That they were considerably subsequent in time to the cave dwellers is, however, generally conceded. What particular race inhabited and built them is also in dispute. Experts like Professors Keller and Virchow assign them to tribes of aborigines of Keltic origin. Another argument points to an Asiatic origin, and to a sudden irruption of a new people, like similar irruptions of authentic history. The fact that, about the beginning of the neolithic age, several of the domestic animals (all of which were domesticated in Asia) appear in Europe at the same period; that also some four species of wheat, two of barley, with millet, peas, poppies, apples, pears, plums and flax, all of which are found in the lake dwellings and elsewhere, are each and all Asiatic importations, points to the sudden appearance in the history of European ethnology of a race essentially in advance of the cave dwellers in all matters pertaining to intelligence and civilization, and the life of which has never become extinct, but has subsisted and been infused into the life of present races.

This race, which diffused itself throughout Europe, is alleged to have been of a dark, olive complexion, with black hair and eyes, represented in modern Europe by the Basque people, who have long been recognized as in some respects the most peculiar people in Europe dwelling in the secluded territory lying between the Bay of Biscay and the Pyrenees, and called by the Kelts, who were the vanguard of the great subsequent Aryan immigration, Iberians, or western people. They are supposed likewise to have been 
represented by the Etruscans of the early Roman period, with an arlmixture of blood from the Arabs, the Moors of Spain and the Berber tribes of Northern Africa.

Whencesoever their origin, the earliest lake dwellers lived indisputably in the earlier stages of the new stone age. 'Their implements are highly polished, and frequently ingeniously decorated and ormamented. Many tools and utensils approaching the variety in modern use are nut, infrequently found; - flint saws with wooden liandles; harpoons and hooks; arrows; straight and curved needles, - some of the latter sharpened at both ends, with the eye in the centre; and all manufactured of bone and horn. Bone hairpins; beads of amber; horn drinking-cups; pottery; the shuttle, spindle, and loom; various woven stuffs; cords of tree-fibre; thread of flax; willow baskets; cereals, seeds, and various fruit in considerable abundance; wooden bowls and platters; combs, maces, battle-axes, spoons, bone forks ; - all indicating that with the lake dwellers modern civilization had at last dawned upon Europe. They had, moreover, domesticated nearly all of our present valuable domestic animals, including the horse. Their carpentering was ingenious. Yossibly they had commerce by barter with the Mediterranean and the Baltic, and they constructed boats of great size and strength. They clothed themselves not only in skins, but with hempen and sewn stuffs. Their deal were buried in excavations, inclosed in large stone slabs, suggesting an approach to the dolmens, or negalithic stones.

Lake dwellings were not peculiar to the ancient Helvetians. We read of them in Herodotus as existing anong the ancient Preonians. In modern times we find them anong the Cossacks, among the Papuans of New Guinea, in Borneo, the Celebes, and in Cochin Clina. Similar also were the constructions of the Aztecs of North America, and the so-called floating-islands of the Assyrians and ancient Clinese.

The dolmens, or megalithic stones, are rudely constructerl, of colossal size, consisting, in the case of dolnens proper, of huge stones placed horizontally upon other immense upright blocks, the whole either covered with earth, or left exposed. Of the latter kind, stonehenge is a well known instance. Those covered with eartl take the name also of "barrows," and "passage graves." These exposed dolmens, 
or "stone tables" as the word implies, abound especially in the plains of Brittany, in central France, and in the region of the Pyrenees. Isolated upright stones, mostly of enormous size, and known as mellhirs,-occurring sometimes singly, at other times in rows,-are equally abundant, notably those at Carnac in France, which extended a distance of a mile, and number, in all, eleven thousand, disposed in eleven rows. A single specimen measures twenty yards in length, by two in average width, and another rises to the extraordinary height of thirty feet above the ground, being imbedded tifteen below it. Covered dolmens were, quite exclusively, appropriated to purposes of burial ; - exposed dolnens and menhirs commonly to religious observances and sacrifices.

How these huge masses of stone were got together and raised is as much of a mystery as the piling of the Pyramids. Objects of both stone and metal have been discovered in the burial mounds, indicating that they are to be attributed to a period bordering on the close of the stone and opening of the bronze periods.

Who were the dolmen builders is another debated point in prehistoric archæology. By some they are supposed to have been the Kelts; by others, a race prior to the latter, whom they supplanted. That these structures are not Druidic, and that the Druids belong to a period far subsequent, is generally conceded, but scientists are at variance not only upon the question as to who built them, but also on the question whether they are the constructions of any special race, or whether different races may not have independently reached, or passed through a dolmen and tumulus building epoch.

That Anerica, no less than Europe, was the the habitat of races as primeval as the palæolithic man of Europe, has been fully established. At New Orleans a complete skeleton has been discovered, buried beneatl four successive forests, and an age of 57,000 years has been assigned to the remains. Agassiz came upon human remains in the conglomerate of a Florida reef, which he asserted to have been deposited exceeding 10,000 years ago. The caves of Brazil have yielded, as in Europe, numerous bones of man imbedded with those of fossil animals. The implements discovered are the same, subserving similar purposes, although, as lias been stated, more frequently chipped from obsidian, jade or porphyry. Likewise we find in Central America, 
Peru, and Bolivia, the huge chulpas, or burial crypts, of perpendicular stones, answering to the similar dolmens and tumulus graves of Europe, and proving a universal tendency of primitive peoples to develop correspondent ideas as to architectural work, at widely different localities.

It is to the so-called "Mounds of the American Basin" that notice and research have of late years been more particularly directed, and it is in these localities, embracing the extensive areas in the region of the junction of the Ohio and Mississippi, in the valley of the Scioto, and in Wisconsin, that Messrs. Squier and Davis, and others, have made an exhaustive study of these prehistoric phenomena. Briefly stated, these mounds, mostly designed and constructed for burial purposes, though in certain instances for purposes of religious observance, are in form most generally circular. At other times they are laid out, over extensive areas, in the form, or after the outline, of various animals, or even of such objects as pipes, etc. Arlvantage has been taken of the natural conformation of the ground to represent such figures, and the results, so far as mere size is concerned, are astonishing,- - one of them containing not less than 550,000 cubic feet, while four would exceed the largest of the Pyramids, and another one is fully 700 feet in length by 500 in width and $90 \mathrm{in} \mathrm{height,} \mathrm{and} \mathrm{is} \mathrm{estimated} \mathrm{to} \mathrm{con-}$ tain twenty million cubic feet of contents.

'There is considerable uniformity as to the relics discovered. Together with polished stone implements, we find work in eopler, and also chipped flints, nuaking it difficult to attribute the mounds to specific periods. The question is still further complicated by the fact that they have been occupied hy different tribes, if not by various races, at suecessive periods. - remains having frequently been disturbed, though not geneally molested, for the convenience of snbsequent oeerupants.

With reference to the mounds, as well as to the dolunens and barrows of Europe, the conclusion of archaologists is that they were intemled, as in the ease of the l'yramids, for places of sepulture for ehiefs of tribes, perherps also for others of distinction. Sio much labor woukd not he expended for the burial of the common people. The relative seareity of human remains indicates the purpose ahove mentioned, and the presence of altars, and other tokens and emblems of ritual and sacrifice, suggestive of the 
universally prevailing worship of the dead, or worship of deities at the tombs of the deceased, points to the same conclusion.

The period, or stage of culture, denoted by the use of bronze implements, brings us well within historic times. The date of the disuse of bronze, and the adoption of iron as the most serviceable metal for general use in the construction of tools and weapons, is as difficult of approximation as the periods of the rise and cessation of the early ages of stone, - for one reason, anong many, that the use of bronze in the manufacture of ornamental work continued far down into the iron epoch. Sir John Lubbock places the close of the Bronze age at the period of the 'Trojan war' and the mention of brass (as the word bronze is improperly translated) in Deuteromony, so much more frequently than iron, denotes that the same age among the early Hebrews had not then closed.

The object of this Essay being, particularly, an inquiry into the life and relics of more primitive races, our space has been mostly given to the discoveries and conclusions relating to the earlier old and new stone periods. Within the limits of a single paper, we can do little more than suggest, not discuss at length, the most important topics and results of prehistoric archæology. The literature of the subject is voluminous and increasing, but it is not appropriate, in a popular series, that we should enter into scientific details, nor is such treatment in fact necessary or important. 'The significance of the whole discussion for us, in this course upon Sociological Evolution, hinges upon the question of man's existence in the palæolithic age. If we establish, as a truth, the fact of man's existence upon the planet at a period remote from us by 80,000 years, or even half that time; - if we find him, at that distant age, so low in respect to habits, manners, and intelligence, that for uncounted centuries he had to take almost even chances of survival with the cave-bear and the mammoth,- frozen by glaciers or scorched with torrid heat; toilsomely shaping his rough-hewn flints wherewith barely to hold his own in the struggle for existence; - if these things be a proven fact, and if from this state have emerged the complex and elaborate civilizations, arts, commerce, industries, and immensely specialized activities of the modern centuries, the doctrine of the continuous evolution of man and of society 
receives an affirmation second only to that which it received when the genius of Darwin brought to its support the revolutionary doctrine of natural selection, with all its manifold implications. The descent of man from some one of the primates of the animal kingdom was indeed distinctly asserted by Darwin; but the proofs as to the slow, gradual melioration of the race, in respect to its progress from brutehood to manhood, was yet to be distinctly affirmed and demonstrated by the patient labors of prehistoric science. These demonstrations (for such they now are) have put the last nail in the coffin of special creationist theories, and the entire cosmos of man and nature is fully explicated as the sublime immanent working of One Power energizing in and through both Man and Nature. 


\section{THE GROWTH OF THE MARRIAGE RELATION.}

BY

C. STANILAND TAKE

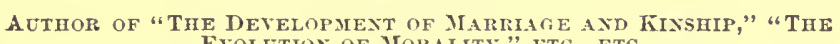
Evolution of Monalitr," ETC., ETC. 


\section{COLLATERAL READINGS SUGGESTED.}

Spencer's "Principles of Sociology"; Wake's "The Development of Marriage and Kinship"; MrLennan's "Studies in Ancient History" (on Primitive Marriage); Tylor's "Primitive Culture"; Keary's "Dawn of History"; Maine's "Early Law and Customs"; Starcke's "The Primitive Family in its Origin and Development": Snyder's "The Geography of Marriage"; Morgan's "Ancient Suciety"; Lubbock's "Origin of Civilization"; Coulange's " $\Lambda \mathrm{n}$ cient City." 


\section{THE GROWTH OF THE MARRIAGE RELATION.*}

So FAR as our experience goes, the highest product of evolution is the complicated social organism we know as a nation or State, and inarriage is the essential condition of its existence. Not necessarily, however, such a form or forms of the marriage relation as distinguish existing civilized societies. History, past as well as contemporaneous, informs us that the relation between the sexes implied in the term "marriage" may take many phases. The principles of Evolution require, however, that these various forms of marriage shall not have originated spontaneously. They are growths of the great world-tree, and, as twigs of one of its highest branches, are organically connected with each other. The branch itself was once only a twig on the parent stem, and had its origin in a simple bud, the growth of which if traced throughout will show the development of the marriage relation under all its forms, and also of society itself.

These considerations show that we must not look to the most civilized races of mankind for the earliest phase of marriage. Among them we may expect to find this relation assume a form answering to the moral and intellectual status they have reached in the course of their general progress. Thus, among the Aryan peoples, or at least those who have embraced Christianity, monogamy, or the permanent marriage of one man to one woman, subject only to the law of divorce, is miversally recognized as the only form which the marriage relation should be allowed to take. The existence of systematic monogamy is treated as evidence that any people among whom it is prevalent are far alvanced in general culture. When, therefore, we read that "a man shall leave his father and mother, and shall cleave unto his wife, and they shall be one flesh," we know that this rule cammot have been framed during the earliest age of man's existence; and we infer that it was the mar-

* Coprrigut, 1890, hy James H. West. 
riage law of a race more highly cultured than the Israelites, who were polyganists down to a late period of their history. The early Hebrews had, however, made such advances in civilization that we camnot look to them for the earliest form in which the marriage relation expressed itself. We must go beyond them to the lowest of all existing races, from whom we shall lenrn more of the namiers of primitive man than by searching the recorts of the past.

Marriage is, indeed, not linited to the human race. The idea of sex is universal thronghout the organic world, and in the animal kingdom similar phases of the marriage relation are to be met with as with man himself. 'Thus, of the man-like apes, the gorilla and the chimpanzee are polygynous, while the orang and the soko are monindrous. The orang associates with his female companion only part of the year, but some kinds of monkeys, which are sirid to be strictly monogamous, live with their mates all the year round. This consorting is evidently based on the sexual instinct, which is the true source of all marriage.

We find that the chief actions of the animal life are directed towards one or other of two great ends, the preservation of the individual or the perpetuation of the race. The former is the organic instinct, or instinct of self-presservation, and the latter the sexual instinct, or instinct of race-perpetuation. The reference to race shows what is the true object of the association between the sexes in "marriage," which necessarily supposes fitness for the relation, and a certain degree of permanence. In the absence of permanence, the institution could not take root so as to undergo the growth which the theory of evolution requires. Temporary marriages have not been unknown, even to peofles elaiming a considerable degree of eulture, but they are not so common as sone writers suppose, and they must be regarded as purely exceptional.

The marriage relation is thus based on the sexual instinct. its am is the perpetuation of the race throngh the family. and it requires a certain permanence in the association formed between the individuals conerened. These foiturest exclude from comsideration the eximples. real or supposed, of promisenity, which are said to prove that prinitive man once existed in such a sorial eondition, but which do not possess the signiticanes attiched to them by Mr. Herbert 
Spencer and other writers. Instead of promiscuity, we find that the most uncivilized peoples have certain rules which restrict the operation of the sexual instinct, and reduce its importance as a factor in the formation of the marriage relation. Those restrictions are natural or human, according to their origin, and the former may fitly be termed a natural restraint on promiscuity.

It has been found, by a study of the marriage regulations in force among varions peoples, that individuals regarded as closely related by blood are not permitted to intermarry. This rule is so widespread that I have no hesitation in asserting it to be general. It was in operation among the ancients, and it is recognized by all peoples of the present day, however low they may be in the scale of civilization. There are certain exceptions, which, however, are so few that they show how general must be the rule. This may be illustrated by the fact that the Australian aborigines have a most elaborate system of kinship, based on the division of the tribes into classes and totems, with which is associated a series of marriage regulations whose object is to prevent the intermarriage of persons who are of the same blood. All the Australian tribes have the utmost abhorrence of consanguineous marriages, and the Dieyeri, one of the most uncultured of them, profess to explain the origin of the subdivision of the tribe into families or totem groups, as intended to prevent such marriages. Moreover, it has been shown by the Hon. L. H. Morgan that a system of kinship similar to that of the Australians, though, with certain variations, is in vogue annong nearly all the non-Aryan peoples of the globe. Wherever kinship is traced preferably through either the male line or the female line, the rule that persons related through the father or throngh the mother, as the case may be, cannot intermarry, is strictly enforced. It is usually extended so as to exclude from the marriage relation persons who are nearly connected through the other parent, although not regardeed as of kin. This extension is shown where, as among nearly all the Australian tribes, marriage with a half-sister is prohibited, although she belongs to her half-brother's intermarrying group.

The rule of non-intermarriage of persons related by blood, which probably arose in the very infancy of the race, through a natural feeling against the intermarriage of 
brothers and sisters, is expressed by the term exogamy, whieh, as used by its inventor, 1)r. J. F. MeLennan, meant "prohibited marriage within the tribe or gronp," as opposed to endogamy, or "marriage within the tribe or group." It was pointed out by Mr. Morgan that exogamy is merely the rule that intermariage in the gens is mohibited, the gens eonsisting of "a body of consanguinei deseended from the same eommon ancestor, distinguished by a gentile name, and bound together by aftinities of hlood." By endogamy, then, we must understand marriage within the gens or groul' of kin, and, apart from certain practices said to be known on special oeeasions to the Anstralian aborigines and some other uncivilized peoples, it may be doubted whether the existence of real endogamy lias ever been established. 'There may be tribes eonsisting of several gentes, clans, or groups of kin, who do not allow marriage outside of the tribe, but they are not necessarily endogamous; as the members of one gens, clan, or group may intermarry with those of another sueh group belonging to the same tribe, in strict aceordance witl the principles of exogany.

The IIindoo castes were said by Dr. MeLenman to be endogamous, but they are divided into gotrams or families, and marriage is prohibited between persons of the same gotram, on the ground that the possession by its members of a common name shows that they belong to the same stoek. This is really an example of simple exogamy within what may be ealled an endogamous group. As applied by I)r. McLemuan the terms are misleading, and Mr. Herbert sipencer, applying then in the same way, erroneously supposes that exogamy has given place to endogamy as the relations of groups of men have beeone more peaceful.

The only woll authenticated exceptions to the rule against the intermarriage of recognized consinguinei, are certain eases which may be explained as having for their object the preserving of a superior strain of hlook, and which therefore proves the importance attached to bhorl relationship.

The King of Hawaii was obliged to marly the woman next in rank to himself', whatever their relationship, as rank descenderl through females and competition to the throne would thus be prevented. The Inests, who claimed deserent from the sun and regarded purity of the royal blood as absolutely neeessary. said that the kingdom should 
be inherited through both parents. Hence the eldest son of the monarch married his nearest kinswoman, whatever their relationship to each other. Unions of a similar character were made by the ancient Persians, but they were of comparatively late introduction, and owed their origin to Cambyses, the son of Cyrus, or to the priests in his interest. The actual exceptions to the rule against the intermarriage of consanguinei are thus seen to have relation to purity of blood, and, as having a special object, they tend to confirm the rule instead of disproving it. The opinion that the parental relationship is not recognized or is disregarded among the lower races has been shown to be baseless. Relationship through both parents is fully recognized with few exceptions, although kinship may be traced through only one parent.

We have now to consider the restrictions on entering in to the marriage relation due to human action, and which may be termed social restraints on promiscuity, as distinguished from the natural restraints arising from consanguinity. While the latter affect whole classes, the former may be said to affect individuals, and they arise from the claim made by parents or others to control the conduct of females belonging to the family group. This claim is asserted in various ways, such as, on the one hand, the prevention of unchastity, and on the other hand, the compulsory provision of the sexual hospitality which is general among uncultured peoples, and which anciently formed so important a feature in the temple service of the Great Goddess, as it does still in India. The parental right is asserted also in betrothal, which is very commonly practised even while the female is a mere infant. Betrothal is useful, where it is not abused in the interests of the older men of a tribe, as it operates, like marriage, to put the tubu on females who might otherwise be led to form temporary unions outside of the law of marriage.

There is a further motive in betrothal and marriage, which has reference through the female to her offspring. In the absence of any arrangement to the contrary, a woman's children wonld belong to their mother's family group. Among the early Arabs, females remained at home after marriage, whether they formed temporary or permanent unions, and as descent was traced in the female line, children were born within the tribe to which they belonged. 
With descent in the male line the same result would follow if the wife left her own tribe to live among her husband's kindred, as is customary with the Turanians. If, in this case, the husband remained after marriage with his wife's family, their offspring would form a separate group of kinsfolk within the wife's tribe. Such apparently has been the origin of the gens or totem groul among the Amcrican and Australian aborigines.

The claims of parents and others which constitute the restrictions on marriage due to human agency, are not less real and effective than those arising from the restraints due to consanguinity, on which the rule of exogamy is based. It is possible, however, that the former may not have been in operation from so early a period as the latter; seeing that in the earliest form of the marriage relation, all the nembers of a group of persons stood in this relation to all the members of an adjoining group, so that there may not have been any place for restrictions other than those arising from consanguinity.

Stating now the law in its widest form, we may say that the marriage relation may take any form that is consistent with the restrictions from time to time imposed by nuture or by man. . It is important to notice, with reference to these restrictions, that although their primary operation is to act as restraints on promiscuity, yet that they act also as inducements to marriage. Dr. Starcke, after considering certain supposed examples of promiscuity, observes * that "if marriage were decided by the sexual relations, it would be difficult to understand for what reason marriages were contracted in those communities in which an altogether licentious sexnal life is permitted to the ummarricd." As a fact, however, the restrictions above referred to tend to prevent this licentiousness, as they are intended to do, and thus indnce individuals to enter into the legitimate marriage relation. There are, however, varions active inducements which are greatly influential over the formation of that relation. Dr. Starcke remarks that a man connects himself with a woman in order that she nay keep house for him, a second motive being that of obtaining ehildren. 'These motives alone are not sufficient, howerer, and we must give the first place to the feeling, call it love or sympathy, which is the main-spring of marriage in civilized

*The l'rimitive Family in its Origin and levelopment (1889), p. 256. 
societies. There can be little doubt that sympathy is a much more important factor in the formation of the marriage relation with the lower races than is generally allowed. The desire for companionship, at least, is universal, and it is an expression of sympathetic feeling. It must be influential wherever a man leaves his own home to reside with another family to secure the hand of a woman; especially where, as is often the case, such residence entails service which amounts to considerable self-sacrifice. When a change took place, consequent on its being customary for a wife to leave the hut of her parents to reside in that of her husband, especially if this were among his kinsfolk, the desire to have some one to take charge of his household during his absence, and to cook the food supplied by his labors as a hunter or a fisherman, would acquire increased force as an inducement to marriage.

It is by the birth of children that the sexual instinct effects the perpetuation of the race which is its true aim in marriage, and we must assume, therefore, that this aim operates as a strong motive for marriage itself. We inust suppose it, indeed, to be included in the desire for companionship which is the earliest inducement for entering into the marriage relation. There is no doubt that the feeling of sympathy which underlies that desire would be increased by the birth of children, for whom real affection is entertained by one or both parents among all peoples, however uncultured. The importance of this feeling in connection with the development of the family was referred to by your President in his admirable lecture of last season on the "Evolution of Morals." He said that the long period of infancy "held the family together and necessitated a continuance of those acts of mutual forbearance and affection which cease among animals when the young are able to make shift for themselves. The mother ministered to the child, while the father gathered food and protected the family from wild beasts and savage men. Other children camc, perhaps, before the care of the mother over the firstborn could be relaxed. So, in the rude cave-dwelling, grew up the germ of the home - the earliest example of the permanent family relation."

The inducements to, or motives for, entering into the marriage relation referred to, and which may be termed internal or subjective conditions, must in course of time 
have had considerable influence over the formal development of the law of marriage. 'There are other and objective conditions, lowever, - those which constitute the external enviromment,- - which are at first the most important in relation to such development. The phase of marriage which may fit a people dwelling in the midst of plenty, may not be suited for those who are not so highly favored by natural or other circumstances; and so also with a city or agricultural population as compared with those whose lives are more unsettled. The hunting condition of life is supposed to be the most primitive, and it is not difficult to see what phase of marriage might under its influence be developed among a rude people. The men would be often away from home for a considerable time, and they would have to leave their wives behind them to take care of their households and children. They would be, nevertheless, desirous of having female companions during their absence, which would not be possible if each man had a wife to himself and the males and females were equal in number. In this case, the only plan that could be adopted would be for the men to join with their wives. Some of the women could then remain at home to take care of the families of the community, while the others would accompany the men to the hunting-ground. We have here the very simplest form of the marriage relation, and it is found in actual existence among the lowest of all human races, the aborigines of Australia. The Australian tribe was originally divided into two groups, or "classes," each of which consisted of a body of kinsfolk, male and female, tracing descent from a common female ancestor, and forbidden to marry among themselves, answering to the gens of the American aborigines. The Rev. Lorimer Fison states that, under this system, marriage is founded on the rights, not of individuals, but of the "classes," and theoretirally all the men of each group are married to all the women of the group to which they do not belong. With descent in the female line, each group may be supposed to have consisted originally of a woman and her offspring, forming two families which entered into the marriage relation with each other, and thus originated what is termed gromp-marriage. The original community would form one lange group divided into two exogamous intermarrying sub-groups; answering somewhat to the pumuluan family of the l'olynesian 
Islanders, in which several brothers had their wives in common, or several sisters had their husbands in common. The Australian system, as now seen in practice, gives every man and woman a wife or husband, and also one or more "accessory spouses," each of whom may be husband or wife to some other person. In all cases the restriction on the intermarriage of kinsfolk is strictly enforced.

The Australian system appears to me to furnish the key to all other phases of the marriage relation. These depend on the conditions under which they have been developed, but they stand in a definite relation to group-marriage. Thus, First, the group idea may be abolished on the male side, in which case we have a group of women married to a single man, (a) where the wives are kinswomen, as in the sister polygyny of the American aborigines, and (b) where the wives are strangers in blood, giving the harem or common polygyny of the East. Secondly, the group idea may be abolished on the female side, in which case we have a group of men married to a single female, (a) where the husbands are kinsmen, as in Tibetan polyandry, and (b) where the husbands are strangers in blood, as in Nair polyandry, if this can be accepted as a true phase of the marriage relation. Thirdly, with the group idea abolished on both sides, we have the intermarriage of two individuals, giving (a) individual marriage, with power for the husband, under special circumstances, to marry a second wife, or to take accessory wives - the monandry of the Turanian peoples and the so-called pairing-family arrangement of the American aborigines; and (b) the individual marriage in which a man has but one wife, and a woman but one husband, unless the marriage relation is terminated by divorce or death,- - being the monogamy of moderu civilization.

It is perhaps impossible to determine whether the primitive group-marriage was developed first in the direction of polygyny or polyandry, but as there is reason to believe that men at first left their own family groups to live in the groups to which their wives belonged, a practice which is usually associated with kinship through females, and as this is found to exist among the more primitive liuman races, many of whom also practice polygyny, we may assume that polyandry was of later development. Probably the marriage of a man to several sisters originated in a state of society where families were comparatively isolated, 
as may be the case in a sparsely populated region. If, under these cireumstances, a man nnarried into a family which had several daughters, and he was a good hunter or fisherman, he would be allowed to enter into the marriage relation with all the sisters, giving the phase of polygyny (a) which was at one time usual among the Indians of North America. The offspring of such an association would belong to their mother's family-group, and whether they had one or several fathers would be a matter of indifference in a rude society. The question of food suplly would be an important factor, and if the husband of the eldest daughter was not a good provider he would not be allowed to marry the second daughter, and possibly might not be suffered even to retain the first. The two predominant ideas in this simplest phase of polygyny are the retention of the daughters, and therefore their children, at home, and the provision of food for the supply of the general family group.

The second phase of polygyny (b), that of the harem or common polygynous family, is dependent on different ideas from the earlier phase. Here the wives are usually strangers in blood, although not necessarily so, and instead of staying at home, they go to reside in the family group of their husband. 'The external conditions with which this polygyny is associated are those of plenty, which enables a man to purchase his wives, and thus to acquire the right to their children. It is consistent with this view that marriage of the type under consideration has become prevalent especially where descent in the male line is preferred to the earlier system of female kinship, although it is practised also where this system is established. The possession of several wives may not only insure a large family, but it increases a man's social position, as he is enabled to provide more abundantly for his guests. This is the cause assigned for polygyny among the Islanders of the Pacific, as it is with many Asiatic peoples. Catlin states, in relation to some of the North American Indians, that they desire a plurality of wives owing to the advantage to he gained by having "a stoek of laborer's," by whom a man's wealth may be increased. On the other hand, among the higher races the possession of many wives is regarded as evidence of wealth, and, as Mr. Spencer remarks, monogamy is considered mean. 'The desire for increased influ- 
ence is probably everywhere an important motive for the practise of polygyny, partly through the large family which may result, and partly owing to the formation of family alliances by the chiefs, which have a real value in the absence of a central governing authority, for giving a greater coherence to society.

Referring now to the polyandrous phase of the marriage relation (a), in which a group of kinsmen are married to a single female, we find it usually associated with conditions similar to those where a group of kinswomen are married to one man. There are two essential differences, however, which are dependent on each other. Instead of the men remaining after marriage among their wife's relations, the woman leaves her home to live with her husbands, at their own home. This is due to the fact that the wife is purchased, and consequently, in this phase of polyandry, the children belong to their fathers' family group, instead of to that of their mother as in the related polygynous marriage. The Tibetans, who belong to the same stock as the Mongols, are the most pronounced polyandrists of the present day, although there are indications that the practice was at one time widely spread throughout the Asiatic continent. It is stated by MIr. Andrew Wilson that, among the Tibetanspeaking people, the choice of a wife is the right of the eldest brother, but "the contract he makes is understood to involve a marital contract with all the other brothers, if they choose to avail themselves of it." It might be thought this curious custom must be accompanied by a scarcity of women, but, as a fact, there is in Tibet a large surplus of women who are maintained in the Lama nunneries. The real explanation of its polyandry may be inferred from the effect which this practice has in "checking the increase of population in regions from which emigration is difficult, and where it is also difficult to increase the means of subsistence." Poverty appears to have been the ultimate cause of polyandry wherever this system has prevailed, although sometimes it is accompanied by a scarcity of females, due to infanticide, or to the excessive price set on them, limiting the accessible supply. The existence of polyandry among a people possessing much property is due to long continued habit, which originated at a time when they lived under much less favorable conditions.

In Ceylon, where polyandry is the most common form 
taken by the marriage relation, there are two kinds of marriage, deega and beena. 'The former is where a woman goes to live in the house or village of her husband or husbands, and the latter where she remains at home after marriage. l'olyandry of the Tibetan type is, therefore, of the deega sort. Neither this nor beena narriage is necessarily associated with polyandry, but Dr. McLennan identifies the latter with the curious custom prevalent among the Ninis of Malabar, which may be taken as an example of polyandry of the type (b) where the husbands are strangers in blood. 'This system, like the ordinary form of polygyny, is associated with plenty instead of poverty, being restricted to the ligher classes, and as there is no wife-purchase, the children follow their mothers in descent and are the heirs of their maternal uncles. According to Nair custom, a man is married to a girl of his own caste, but he leaves her immediately after the ceremony and never revisits her. Usually she continues to live with her mother, brothers, and sisters, the head of the household being the mother, and, on her death, the eldest sister. There is no male head of the family, which is perpetuated through the females, who, after their marriage, have the right to receive the visits of certain Brahmins, and of Nairs other than their nominal husbands. By this arrangement each male Nair may have a share in several wives, who answer to the "accessory spouses" of Australian group-marriage, but, as he is not allowed to associate with his own wife, he has not the privileges of the $N o$, or marital relation. That curious custom probably originated in the Nairs, who are a military caste of Sudras, taking a vow of celibacy, as was usual among the Christian knights of the Midlle Ages. At the same time, the Tair women, after their nominal marriage, were permitted, for the purpose of perpetuating the caste, to form irregular associations with the youngel Brahmins, who themselves were not permitted to marry. When the vow of celibacy was relaxed the prohibition was continued so far as a Nair's own wife was concerned, but he was allowed to visit other Nair women, the Brahmins still retaining their old privilege.

We have now to trace the origin of individual marringe, that is, the living together in the marriage relation of only two individuals, who nay be said to represent the two primitive internarlying groups. Various causes have been 
assigned for the origin of systematic individual marriage, which, before it could be exhibited in the higher phase of monogany, must pass through the lower form (a) of monan$d r y$, which allows a man under special circumstances to enter into the marriage relation with another woman during his wife's lifetime. 'There is no doubt that individual marriage may exist alongside of polygyny or polyandry. In fact, where the former of these systems is permitted, it is restricted in practice to men who are well-to-do, the majority being necessarily limited to one wife,-as in polyandrous communities they have to be satisfied with a share in one. 'There does not appear, however, to be any evidence that monandry, cxcept of this accidental kind, existed in the earliest times. The wife-purchase, which Mr. Spencer supposes to have aided at a later date in the establishment of monogamy, is, moreover, associated with the earlier systems of polygyny and polyandry. In fact it is a question how far wife-purchase was practised by the truly monogamous peoples of antiquity.

Among the causes which, with monandrous peoples, induce men to enter into the marriage relation a second time while the first wife is living, one of the most important is the desire for children. Where a wife is childless, or has no son, it is not surprising if, considering the natural object of marriage, a man marries a second wife, with or without divorcing the first one. To the ordinary reasons for desiring male offspring, was added at an early date, a superstitious one based on the necessity of having a son to perform the funeral rites. The idea that happiness in the future life was thus secured is universal among the ancient nations. It was founded on the belief, entertained also by many existing races, that the father lives again in his son. Hence, the not having a son, was always regarded as a sufficient justification for the marrying of a second wife.

Although, according to what appears to me to be the proper view of so-called "marriage by capture," it is a mere ceremony, and has to do with kinship rather than the evolution of marriage, a notice of it may be introduced here, as it is practised chiefly among peoples having systematic monandry. 'The essential element of that ceremony is stated by Dr. MeLennan, when he says, "the marriage is agreed upon by bargain, and the theft or abduction follows 
as a concerted matter of form, to make valid the marriage." He adds: "The test, then, of the presence of the symbol in any case is, that the capture is concerted, and is preceded by a contract of marriage. If there is no preceding contract, the case is one of actual abduction." * It would be thought, therefore, that cases of abduction are excluded from a consideration of "marriage by capture"; instead of which, however, Dr. McLennan bases his explanation of the ceremony on the early theft of women of foreign tribes, which he thinks became symbolized "among exogamous tribes, out of respect for immemorial usage, when friendly relations came to be established between tribes and families, and their members intermarried by purchase instead of capture." I have elsewhere given my reasons for dissenting from this conclusion, which appears not to be warranted by the facts. What is called "marriage by capture," is really "ceremonial capture in marriage." It has relation to the contract of marriage, the pre-existence of which is its essential condition, and it refers in the first place to the bride; and secondly to the offspring of the marriage itself. The latter is the most important feature, and it depends on the fact that the effect of the contract of marriage is to take away from the family group of the bride the children to be born of the marriage, and give them to the family group of the husband. The ceremony may possibly be in imitation of actual capture. If so, however, it is not evidence of a former general condition of society when women were stolen for wives, but it is rather a recognition of the fact that women captured during warfare belong to the rictors, and that their children are incorporated with the conquering people. Ceremonial capture is, indeed, often in the nature of a feigned combat between the relatives of the bridegroom and those of the bride; in which the former are successful only because this is required by the agreement previously entered into between the parties. There is another object in view, howerer, which is probably the most important motive of the whole ceremonial. It operates as a public annomeement of the marriage and of the consequences to flow from it. Where the mide's consent has not already been obtained. she usually has the opportunity of refusing to he capturerl, or of afterwarls leaving the husband rhosen for her. The consent of the bride's

\footnotetext{
* Studies in Ancient History, p. 17.
} 
friends is shown by their allowing her to be carried off, which also operates as a relinquishment of their right to her offspring, and the ceremony can at any future time be referred to as evidence of these facts, as well as of the marriage itself, if it should be called in question on either side.

Returning now to individual marriage-it may be doubted whether its enforced practice, by the force of circumstances, would lead to its general establishment on a moral basis. The substitution of systematic monogany for polygyny or polyandry is due to a subjective change, rather than an external change of conditions; although there does not appear to be any special tendency to such a system, apart from the general progress which is exhibited in the evolution of human society. The feeling of selfrespect which is probably at the root of individual marriage of the true type, is very strong among the Chinese, as it is with other peoples of a similar degree of culture, although men are allowed certain latitude which is not conceded to women. That feeling forbids women to remarry on the death of their husbands, and it must be influential over the conduct of the men themselves. Self-respect is assigned as a reason for the abandonment of polyandry by the Kandyan chiefs, and there is no doubt that it has much to do with the fact of polygyny losing its hold on the higher classes in Egypt and other Mohammedan countries, the establishment of monandry among whom may be regarded as a real moral advance.

If the derelopment of monandry is the result of a subjective change, much more must it be so with the higher phase of individual marriage in which neither the man nor the woman can enter into the marriage relation with another individual, unless released from their first tie by divorce or death. Probably there have always been examples of this higher marriage among the Chinese, whose ideas as to the requirement of a son to perform the funereal rites are shared by the Hindoos and the allied Aryan peoples of antiquity, among whom monogamy was developed. This, however, differs essentially from the monandry of the Turanian peoples, in that not only is it founded on mutual regard, with exchange of presents instead of wife-purchase, but it is placed under the sanction of religion.

Monogamy thus represents the lighest phase of develop- 
ment of which the marriage relation is capable. It places husband and wife on a footing of pcrfect equality, and they are united by a spiritual as well as a social bond, which is supposed to constitute for both of them a perpetual engagement. Marriage was to the ancients, however, something more than the uniting in heart and hand of two individuals; it was the mode provided by nature for continuing the succession of persons required to perform the rites of the religion of the hearth and of ancestors. The continuity of the family was thus regarded as the first and holiest of dutics.

Under the influence of the ideas embodied in the teaching of the Persian Zoroaster, the Jews not only acquired a purer faith, but they gradually replaced their early polygyny with monogamy. The marriage relation with then, and therefore with the primitive Christians, retained its religious sanction, and the law of marriage was expressed in the words of Genesis, "a man shall leave his father and mother, and shall cleave unto his wife, and they shall be one flesh." 'There were, however, ideas afloat in the East relative to marriage which were especially attractive to many persons in the early Christian church. In the ancient mysteries it was taught that the association of the soul with the material body was a source of spiritual impurity, from which it had to be freed. Birtl, if not an evil, was the cause of evil, and it was not going much further to assert that that to which birth was due was also evil. These ideas strongly influenced early Christianity, and its followers, expecting also an early return of Jesus to earth, and the end of the existing order of things, regarded nurriage as at least useless. St. l'aul appears to have bcen of this opinion, and, although he antlorized narriage when expedient, yet he did not look upon it as so high a state as virninity; in which he was followed by niny of the Fathers of the Church.

It would have been a misfortune for Christianity, no less than for society, if those ideas had retained their vitality. After the fire of Christian zeal had well nigh burned ont. however, nurriage was restored to its projer place as a sacred bond between two individuals, and a natural provision for the perpetuation of the race through the family. It felt, moreover, the refining influence of the emotion which, having at first been appropriated almost entirely to 
the founder of Christianity, was now shown also towards the life-partner in the cares and duties of earthly existence. The marriage relation was thus elevated and spiritualized, although it is questionable whether it was more so than with the early Aryans, to whom it was the most sacred of engagements and therefore the most difficult to be absolved from. Through the centuries which elapsed after the relrabilitation of marriage it again suffered, but in a different direction. Annong the higher classes especially it lost much of its spirituality; although it had become a sacrament of the church, and was held to be indissoluble, except in very special cases.

Since the Reformation, the Protestant sects have departed, in their ideas of the marriage relation, from the views expressed by the founder of Cliristianity. The marriage ceremony having ceased to be regarded by them as a sacrament, or even by many Protestants as an ecclesiastical office, marriage itself has gradually lost its indissoluble nature, and hence the practice of divorce for causes other than adultery has been introduced. This is reverting to what was customary in the ancient world before the establishment of Christianity, and so long as the power of divorce is not abused it is undoubtedly required by the laws of social progress. Ill-assorted marriages cannot have been "made in heaven," nor even, as the Japanese suppose, by ancestral spirits on earth; and they should be dissolved when their failure is not due to fraudulent design. The State should intervene to prevent the success of attempted fraud, but it should provide for divorce by simple, though not hasty means, in other cases, - treating the contract of marriage as it would any other contract, and giving as great facilities for setting it aside, if its terms cannot be properly carried out, as it does for the contract to be entered into.

The State should also deal with questions of marriage disability - consequent on relationship. The descriptive system, under which kinship is traced through both father and mother would, if the old rule of marriage were enforced, exclude from intermarriage all persons of kin through either parent, however distantly related. This would be carrying the objection to consanguineous unions - which seems justifiable on natural grounds*-much too

* Mr. George H. Darwin, as the result of his inguiries, came to the conclusion that "various maladies take an easy lobld of the offspring of consanguineous marriages," although they are probably as prolific as urlinary ones. 
far, and it was finally decided, therefore, in connection with the system above referred to, that any persons may intermarry provided they are not more nearly related to each other on either side than in the fourth degree.

The Christian church, however, introduced a new series of disabilities, by making affinity through marriage as much a bar as blood-relationship itself. Such questions as marriage with a deceased wife's sister or a deceased husband's brother are not for the church to decide. They should be treated as questions of social expediency, to be settled by the State, in which light should be regarded also all matters coming under the head of "social restraints" on marriage, now represented by the simple requirement of the consent of parents or guardians.

A few words may be said, in conclusion, as to the future of the marriage relation. We have seen that in the animal kingdom, and therefore with primitive man, the chief actions of life are directed toward self-preservation and the perpetuation of the race. Where these interests came into conflict the former necessarily prevailed, as the individual always preferred himself to that of which he merely formed a part. In these latter ages we may expect the same result to follow from the antagonism between self and race which always exists. It now takes, however, a different form from what it had during primitive ages,- at least when man lives for something more than the supply of mere physical wants or the gratification of the sensuous side of his nature. Ever since man's thoughts came to be elevated there has been a constant antagonism between the lower and higher principles of his being. Christianity is a phase of this conflict, concerned hitherto, however, chiefly with the emotional element in man's nature, bnt the great mental development which has taken place during recent centuries is resulting in the subordination of the emotions to the intellect. The consequence of this must be that the marriage relation will be entered into with more leliberation than formerly, and its conditions be regulated in accordance with definite principles. It is quite possible, indeed, that as a result of the development of the intellectual faculties, which constitnte the chief element in individuality, the desire to escape the cares of a family may lead to a disinclination for marriage, if even there is not a repugnance to it. 
In the interests of the race this result must be deplored; but should it occur, it may point to the conclusion that the highest evolutionary progress which mankind is capable of must be looked for in another state of existence, where, the mind not being subject as at present to material influences, its noblest faculties will attain their full development. If, however, the instinct of race continues to be sufficiently strong to induce the more intellectual class to enter into the marriage relation, but under such a sense of duty as that which led the followers of Zoroaster to address prayers to Ormuzd that he would bless the union, and give them children "renowned by merit, who would be chiefs in the assemblies," the result might be the evolution of a people superior in physical and mental constitution to any the world has yet seen. At the same time, it is conceivable that such a development of intellectual wealth might be attended with a result similar to that which has been observed in regard to the accumulation of materia? wealth, - a gradual lessening of the number of its possessors, and their final extinction, leaving the race to be perpetuated by those less abundantly endowed, mentally if not physically.

There is, however, another possibility to be contemplated. With improvement in sanitary arrangements, and in the general physical conditions under which the masses of the people live, combined with immunity from warfare, which must ultimately attend the progress of mankind in civilization, the increase in population will be so great that measures of some kind will have to be adopted to keep it within reasonable limits. Whether it will then be proper or politic to provide for the improvement of the race may be left for posterity to decide. Schopenhauer was probably right, however, when he said "could we prevent all villains from becoming fathers of families, shut up the dunderheads 'in monasteries, . . . and provide every girl of spirit and intellect with a husband worthy of her, we might look for an age surpassing that of Pericles." 



\section{THE EVOLUTION OF THE STATE}

BY

JOHN A. TAYLOR 


\section{COLLATERAL READINGS SUGGESTED.}

Spencer's "Principles of Sociology," Vols. 1 and 2, "Political Institutions," "Study of Sociology" and "Social Statics"; Fiske's "Cosmic Philosophy," "American Political Ideas" and "Beginnings of New England "; Keary's "Dawn of History"; Lubbock's "Origin of Civilization"; Coulange's "Ancient City"; Mainc's "Ancient Law," "Early Law and Customs," "Popular Government" and "Historic Institutions"; Tylor's "Early History of Mankind"; Morris's "The Aryan Race : Its Origin and Achievements"; Amos's "Scicnce of Law"; Bagehot's "Physics and Politics" and "Euglish Constitution"; Ritchie's "Darwinism and Politics"; Adams's "Village Communities"; Frecman's "IIistory of Federal Government," "Comparative Politics" and "Growtl of the English Constitution" ; Bryce's "A merican Commonwealth"; Morgan's "Ancient Society"; Howard's "Local Constitutional History of the Unitcd States"; DeLolme on "The English Constitution"; Holmes's "Constitutional History of England"; Stubbs's "Constitutional History"; Mill's "Representative Government"; Woolsey's "Political Science"; Von Holtz's "Constitutional Law." 


\section{THE EVOLUTION OF THE STATE.*}

Nearly six hundred years ago, on the banks of the most famous river in Germany, the foundations of a majestic cathedral were laid. Within a hundred years from that time, a part of the building was consecrated, and thenceforward the pilgrims to that sacred temple saw only an unfinished shrine. Within the present generation, without a change of plan,- the name of the architect lost to human knowledge,- it has been completed in the precise way in which it was designed, and presents the loftiest example of pure Gothic architecture to be found in Europe. The traveler, who stands with wondering admiration within its aisles, reflects that, when its deep foundation-stones were put in place, the art of printing was unknown, the works of Shakespeare were unwritten, Constitutional liberty was yet to be conceived of, Pope Innocent IV. was the real ruler of civilization, and the great majority of men were slaves. Yet no more surely did the germ of this magnificent structure lie perfect, yet unevolved, in the thought of this unknown master of his noble art, than did the present structure of the civilized State lie dormant in the rude elements of government which then existed.

"The roots of the present," it has been said, "lie deep in the past, and nothing in the past is dead to the man who would learn how the present comes to be what it is." The State is what we make it, - each of us,_-all of us. Of the more than a billion people who live upon the earth, each single being constitutes an independent, self-related center to which subjective unit all the phenomena of the world, including every other of the billion people, is objective. There is an inside and an outside world. The one is wrapt in subjective privacy. It is the secret penetralia of the human being. It is known only to the ego. The other is open to the perception and judgment of all mankind. To its just measurement all of history, science, art, human experience, invention and imagination contribute.

\footnotetext{
* Copraight, 1890, ly Janes H. West.
} 
Constantly, through the agres, some great soul, out of the many people, has arrested the attention of mankind by mastering all the known facts of life, and giving expression, in thought or deel, to the highest known human ideal. Such a man, in ethies, was Jesus; in literature, Shakespeare; in state-eraft, Lincoln. These were types of an unusual order of limmanity. They marked, at different ages of the world, the possibilities of manhood. It has required the long perspeetive of eighteen centuries to approximately estimate the worth of Jesus,- so long, indeed, that his human nature has been resolved by millions of his believers into the qualities of a supernatural being, -a God. These great men, and all the exceptionally strong natures of all known periods, have signally served to inciicate the heights to which our eommon human nature could attain. They constitute the exceptional beings of their time.

Now it is manifest that all problems, dealing with humanity as a whole, must take into consideration every living human being. "Society," says Thompson, our leading American Psychologist,_ "is an organic whole, of whose members each is at the same time the means and the end of all the rest." And when we inquire to what present height has the State evolved, we have to determine, not what achievements have been made possible for speeial sons of genius, but how the State deals with the average man, the world over. And in the first plaee we must clearly reeognize what the State is.

Obviously the evolution of the State is not merely the evolution of man. It deals rather with the growth of mankind in association, eonsidered solely as a governing entity. Whenever two men come together in their habitat, agreement beeomes neeessary; in other words, they must be organized, and there is founded a rudimental State. Herbert Speneer says, "Socially as well as individually, organization is indispensable to growth,- beyond a eertain point there cannot be further growth without further organization."

The State lias been defined to be "a whole people united into one body politic"; and again, as "the visible embodiment of justice under the eonditions of human society." For the purpose of this paper, the State will be considered as the seat of supreme political power, whence proeed all 
binding rules of civic conduct. This supreme political authority may find its warrant in a written code, as in the United States Constitution; it may rest upon unexpressed political postulates, like the English Constitution; or it may reside alone in the will of an absolute sovereign like the Russian Czar.

It will be seen at once that the evolution of such a political entity is something different from the growth of society or individual development. It witnesses in its present condition the latest, and therefore the highest known exposition of the governing faculty in man. Nor will it be at all certain that we shall find, in the present attainment of the State, a stage of development at all commensurate with the development of science, art, literature or invention. Indeed, we are confronted at the threshold of our inquiry by the question, has the State evolved? Is there any law of development by which succeeding stages of political institutions may be said to have been related to previous states of being?

Remembering that the trend of all evolution is from the simple to the complex, from the homogeneous to the heterogeneous, we must expect to find humanity progressing along the lines of an intelligent development, each step a cause, and each step a sequence, proceeding upward and onward toward a completer form of government. No one can, of course, expect that upon this occasion any coherent outline even, shall be suggested of the principles or laws upon which the State shall have been evolved. Little more can be done than to glance rapidly at certain epochs in State evolution, find, if we may, some connecting links between the different stages of society, and draw from these such indications as may be discerned of future tendencies. Of one thing, at the outset, the evolutionist may be sure. The law of evolution is either universal or it does not exist. The great generalization of Spencer, that things do not drift, but proceed, is as inseparable from the development of the most magnificent commonwealth as from the lowest animal cell known to the biologist. Whether we find the law or not, it is there; just as the rolling planets of the universe were held poised in the limitless spaces ages and ages before Newton discovered the law of gravitation.

Let us then consider, for a moment, some of the begin- 
nings of govermment. Without doubt its earliest form was the patriarchal. Even before the time when savages chose the tallest man for chief, the family head had exercised his petty sway. The father was an absolute power among all ancient peoples. Among the Romans he could sell his children into slavery, and sons who held the highest offices could still own no estates. Such a potentate was the unit of the rude State of lis time. The numbers of those who were considered as making up the State wert. reckoned only by such headships, and the larger authority conferred upon the leader of the State was fashioned upon the basis of family government as it then existed.

Out of these family associations came the clans, still held together by ties of blood, all worshiping a common ancestor and either contesting for the headship of the clan or agreeing by consent of the lieads of the families upon a chief. The numbers of the clan were doubtless largely increased by the fiction of adopted children, a process which imported, to the special clan, new blood, and at the same time extended its power and influence. The clan, still further evolved into the tribal State, was a form of government fitted only for nomadic peoplc, and as soon as the race advanced to the pursuits of agriculture and the formation of stable communities, locality undoubtedly became the important bond of adhesion, and a clearcr conception of the modern State began to appear. And when the boundaries of cities were enlarged, by conquest, to great territorics, the flag became the symbol of one people, and the great father or king over this land found in the head of the family the suggestion and limitation of his power.

Now, the idea upon which the father's absolute dominion over the family was based, rested upon the inability of the wife and children to control themselves, or wisely measure their own necessities; and so long as the conception of the State was simply that of a huge family, the king, whether chosen or hereditary, postulated his dominion upon the immaturity of his subjects. The subjects were cliildren, the king the father. 'The king's will was the law of the ruder State, as the father's had bcen of the family, and long before the individual man had become recognized as the true unit of the State, the old English barons were combating the allied forces of the king and 
the lower people in their revolt against the oppression of the crown. 'Thus early, it becomes us to note that the State was little more than a most inconvenient, though necessary, burden upon the race, so long as it failed to recognize manhood as the one indispensable ingredient of successful political institutions.

Such was the rule of petty kings; and whenever, by conquest, numbers of petty sovereignties were reduced to one dominion, there was developed a representation of each small kingdom or tribe by its chosen head, which, under such rulers as William the Conqueror, in England, gradually came to form an aristocracy of nobles who were destined to force the king to enlarge the freedom of the masses, in order that he might himself escape destruction. Meantime the powerful influence of the church, which before the art of printing was discovered was the sole vehicle of knowledge, was preparing the way for the voice of the penple to be lreard in the councils of the State. So that, four centuries ago, taking England as the most advanced example, the evolution of the State had reached a point where the one man power of primitive times had been largely circumscribed by the successful assaults of the common people upon the strongholds of sovereignty. And the chief agent of this result will be seen to be the barbarous, exterminating, almost endless warfare of these early centuries. Out of these rugged furrows of bloody war has blown the consummate flower of modern civilization, whose fruitage-time inust still be placed in the centuries which are to come.

At this period, the king could levy no tax without the grant of Parliament; no law could be promulgated without its assent, no man could be committed to prison but by legal warrant, the fact of guilt or innocence was determined by a public court with a jury of twelve men, and the officers and servants of the crown were subject to the same tribunal; and, for more than a hundred years previous, the kings of England had desisted from imposins taxes without consent of Parliament.

That which was at last coming to fruition was the share of the governed in the policy of the government. 'True, it was a sadly crippled share. Only within the present decade has the agriculturist laborer of England taken a direct part in the composition of Parliament. But, all through these 
pregnant centuries, the man's tone has been heard. It has pushed its way through tumbling dynasties, midst the ruins of baronial castles and the falling fortunes of kings and emperors, impelled by the irresistible laws of evolution. It has announced, with increasing force and fervor, one inevitable condition of national and individual growth to be the absolute, unqualified equality of individual human rights.

Mnch as this early recognition of the voice of the individual man may have been smothered by the usurpations of power during the succeeding centuries, it is a noteworthy fact that, long before the discovery of this continent within which representative government is supposed to have found its completest development, manhood, as the essential unit of the State, was finding place in the thoughts of the world's statesmen.

Long after this, the English corporation (evolved, as has been suggested, from the. Roman Collegia, out of which, in time, as Professor Bryce, in his remarkable book on the American Commonwealth, has shown, was to arise first the Colonial government, then the state govermment, then the Federal government, each in its turn an outgrowth of the other) was to prefigure the growth as distinguished from the drift of a State. Here, in the new land, with a diversified climate and soil, untrammeled by questions of the relations of ancient sovereignties, freed from the dominion of the one man power, was to be formulated the first written constitution known to man. And singularly enough, it was to find its substantial prototype, not in the long line of its immediate ancestry, but in the polity of ancient Greece, where, long before the white-haired Goth had invaded and subdued the swarthy Roman, the assembly of the citizens determined inportant public questions, and was the ultimate tribunal of the governed. And stranger yet, it was to promulgate in solemn terms, in its new code, the same paradox which had then existed in the streets of Athens, - proclaiming, with one breath, the equality of all men before the law, and insisting, in the next, upon the degradation and enslavement of a substantial minority of lnankind.

And now, may we not see that the State has evolved by the same processes and under the same conditions as those by means of which civilization itself has grown? One 
most important fact to be noted is, that the most signal advances made by civilization have taken place within the present century. Dr. Strong, in his widely read book on our country, has said that, "any one as old as the nineteenth century has seen a very large proportion of all the progress in civilization made by the race." And Andrew Carnegie, in his glowing laudation of what he calls the "'Triumphant Democracy," asserts that "a hundred years ago, agriculture was in little better condition all over the world than it was a thousand years before."

Taking, then, our American Commonwealth as, at its birth, expressing the highest type to which the State had then evolved, upon what shall we find its growth to have depended? Behind it lay the ancient oligarchies, and the so-called republics of Greece, the rise and temporary spread of Christianity, the darkness of the middle centuries, shrouding with obscurity all rights of man, all lights of learning, and all hopes of religion; the revival of brutal wars of conquest; age upon age of slaughtered human life, the masses held in slavery and ignorance; and at last the gradual dawning of an uplifting sense of the dignity of man. DeLolme had just given to the world his classic panegyric of the English govermment when the first President of our republic took the oath of office. "Liberty," said DeLolme, in his concluding chapter, "merely showed herself to the ingenious nations of antiquity who inhabited the South of Europe, and she has found six centuries necessary for the completion of her work." Yet when these glowing words were written, trial by personal contest had not been abolished, and no person accused of crime was allowed counsel in the English Courts.

Our republic, at its birth, stood in all essential respects for goverument by the governed. More nearly, then, perhaps, than at any time since, the wish of 'Thomas Carlyle was realized, and the individual citizen was weighed as well as counted; and to this end no single factor had more largely contributed than the town-meeting of New England. The one fundamental postulate upon which rested the theory of the State, at that time, may be said to be the right of personal representation. Prof. Stubbs has shown that, "as early as the beginning of the thirteenth century, the doctrine that the taxpayer should have a voice in the bestowal of the tax, was gaining ground, but it required 
five hundred years for its full recognition." Prof. Howard, in his recent book on the Local Constitutional History of the United States, has pointed out that "the revival of the primitive village community in the New England towns was a revival of organs and funetions on the recurrence of the primitive enviromment," and that "the selectmen of the town were the lowest representative government"; and it is obvious that the moment our early communitics began to prosper and cxtend their conquest over nature, the act of government had to be delegated. Townsmen were therefore chosen in New Haven, as long ago as 1651, in order that, in the words of their quaint resolution, "the town meetings which spend the town mueh time, may not bee so often," and, ten years before, voting by proxy had been established in Massachusetts.

More than one hundred years thereafter, the first written constitution known to history, adopted by the people, was put in praetice in Virginia; and thirteen years after this event, the Constitution under which we live, whieh Gladstone has pronounced one of the greatest products of the liuman intellect, went into effect as the express eharter of the Statc. Representative governments, then, had made possible the founding of our own state; and this, the first of rigid constitutions, was absolutely representative in all its parts. The sovereignty of the States was represented in its Senate. 'The people were directly represented in its House of Representatives, and, for the first time in the history of govermment, the department of Justice was given power to pass upon the validity of laws passed by these representative bodies.

Clearly, the State whieh we are now describing had evolved from all the attempts at govermment in the past; and the one law of growth which is apparent in any broad survey of its evolution is that the State beeame effeetive in exaet proportion as it recognized the individual dignity of its citizenship. The one inseparable accompaniment and evidence of the evolution of the State has been the eontinual uplifting and expansion of manhood as a type. This has been and is the supreme result and test of State growth. "A government is to be judged," says John Stuart Mill, "by its tendency to improve the people, and by the goodness or balness of the work it performs for them." liy manhood as a type, I mean the average being 
taken from the aggregate of every race and every clime, in every country of the world. Marcus Aurelius, standing at the threshold of the Christian era, looking forward seventeen centuries in the history of his race, said, "mankind are under one common law, and if so, they must be fellowcitizens and belong to the same body politic. From whence it will follow that the whole world is but one commonwealth."

Now, whatever may be said of ancient republics, of special reigns of special kings, the candid mind must see that the voice of this average man was heard loudest, and with more effect, in this new commonwealth, than it had elsewhere been heard in the history of the world. And it was listened to. From the time of the establishment of Christianity, the voice of the priest has been substituted for that of man. The darkness of the middle centuries, and the clanging swords of war, had stifled this power of protest; but the invention of printing gave an audience to the average man; the compounding of gunpowder shortened, by making more fatal, the wars of conquest; and out of this progression of the arts and sciences emerged the man, to be accounted for in future governments. Here, in his new environment, free from misalliance with the church, disturbed by no questions of State boundaries and perplexing balances of power, the new man founded the new State, and, in token of his different status in the new world, he was given the ballot as his scepter.

What the evolutionist has to observe, is, that the organic law, under which the great republic started upon its career, contained no new conception of human rights. Government by the governed was as old as Aristotle. It was the dream of Plato. At no time in known history had it been absent from the thoughts of men. It had simply waited for its fitting environment. Like the grain-seed in the mummy's wrappings, it throve at once when placed in proper soil and stimulated by a congenial climate. A most emphatic exposition of what an ill-adapted soil and an unfarorable climate would do for a similar endeavor was to be immediately furnished, in the abortive attempt, in France, to establish, on a like theory of government, a permanent republic. As Prof. Adams has suggested in his work on "The Democracy and Monarchy of France," Rousseau had indeed overstated the problem of a perfect form of govern- 
ment, when he declared it to be "to find a form of society in which each one, uniting himself with the whole, shall yet obey himself and remain as free as before." Yet 110 student of the French Revolution can fail to find sufficient causes for its failure in the essential limitations of its enviromment.

Here, then, was a serious challenge to posterity. Blackstone had but just proclaimed that the natural foundations of sovereignty were "wisdom to discern the real interest of the community, goodness to endeavor always to pursue that real interest, and strength or power to carry this knowledge and intention into action." The edict of the new republic set forth that all these natural foundations of sovereignty were inherent in the common citizen.

Let us consider for a moment the development of this new republic. Happily we may do so from the standpoint of a full century's experience. In seeking for the causes of what we shall find as its fruition, one of the first mistakes will doubtless be to attribute to the agency of the Constitution, itself, far more than can be justly claimed for it. With a favoring climate, a virgin soil, freedom from intestine broils, and from foreign wars either of conquest or of defence - a sturdy race of men, filled with the unconquerable resolution which characterized our early immigrants, would perhaps have given an impetus to our Western civilization which no mere form of govermment would have withstood or hindered.

A gain, it is not to be forgotten that this sacred instrument was itself a patchwork of concessions, holding within its terms a flat denial of the absolute rights of men, and made possible as the organic law only by the surrender of convictions which were not lightly held by the States of Yew York and Rhode Island, which were among the last to adopt it. Indeed, the question is now very seriously, and with great force, raised, whether we shall be able effectually to deal with evils which are manifestly grave, until we shall have deliberately revised this great Charter of our liberty.

Among the recent contributions to the literature of statesmanship, one of the strongest in its statement and in the admirable temper of its pages is a small work on 'True Democratic Government, written a few years agro by Albert Stickney. After setting forth the adrantages of a Demo- 
cratic Government, he argues with great cogency that we need to reorganize our organic law, and that a Convention should be called to that end. Whatever may be said of the perfect character of the work of our fathers, they themselves were not so vain-glorions as not to provide, in the terms of the instrument they presented for adoption, the process of amendment. And, although it is probably true, as Von Holst has declared in his history of Constitutional Law, that "the republic has been more conservative in its fundamental law than any State whatever of the European Constitution," yet it must be conceded that if we cannot, as a people, be trusted to sit in deliberation upon what the organic law of our nation should be, then we have already demonstrated the failure of a republican or democratic form of govermment. Furthermore, if we are candid with ourselves, we must see that, for some reason or other, great evils have arisen in government, which are due either to an inadequate organic law or to an imperfect administration of that law.

Let us pause for a moment to consider one of the most obvious of these. I refer to the conspicuous incapacity of any present mode of city government. No demonstration of this fact is needed. 'The public till is deemed by many to be a legitimate field for plunder. Its guardians have a market price. There is no municipal legislature in any considerable city of the Union, the character of whose working majority of membership is such as to command any large degree of confidence in either its integrity, industry or intelligence. 'The important franchises of our cities are hawked about in undiscovered places to the holders of the largest purses. Public interests lie dormant; private interests are ramprent. I'ublic office is made to produce the largest results to the smallest number. Men with polished exterior insist that they must make terms with what are called the "practical politicians," or else we shall accomplish nothing at all; and so the dispensers of patronage quietly place good men where they will do the least harm, and deliver the most important interests of the city to men who market their opportunity to the best personal advantage.

'The representation of the City of New York in the last legislature is a frightful example of incapacity and corrup. tion; - and what else could be expected when we find that 
one-third of its entire delegation were born outside the country whose important interests they were called upon to serve? So rank have these conditions become that they are attracting the attention of statesmen everywherc. So able and impartial an observer as Mr. Bryce has found it nccessary to say, "There is no denying that the government of eities is the one conspicuous failure of the United states." Nor is this failure of minor importance. When our constitution was framed, there were but thirteen cities whose population exceeded 5000, and but one with more than 40,000 inhabitants. 'To-day there are thirty exeeeding 100,000, and two exceeding 1,000,000. Ninety-seven per cent. of the population for which our fathers provided a scheme of government, lived outside the city limits; to-day less than seventy-eight per cent. inhabit the country.

Within that time, space has been nearly annihilated; and communication is almost uninterrupted. A great thought uttered at any center of the world instantly vibrates throughout Christendom. The rapid acquisition of surplus wealth fills the streets of the metropolis, and the trend of all things, in densely populated conters, is daily seen to be more and more toward eomplexity. This, with a constantly elianging enviromment, engenders problens of whieh the framers of our Constitution never dreamed. Is it strange that the machinery should need to be readapted to its new task?

But, it may be said, If the people are competent to govern; if, by the process of a natural evolution, the supreme power has been rationally devolved upon the entire citizenship, why is not an efficient appeal made to that original souree of power? Are we not justified, by the experience of the last twenty years, in replying that, while exeeptional spasms of reform have here and there worked temporaly relief from especially aggravating epochs of corruption, yet the people lawve really delegated their franchise to the active leaders of the two great political parties? My meaning is, that neither any one, nor any thousand, nor any twenty thousand eitizens of any considerable eity, can, under existing maehinery, do anything other than express a preference at the polls. Fut the ballot was given, at its origin, as a means of choosing from many, and not simply of preferring. Exaetly stated, the govermment of this and most of our eities is in the absolute eontrol of a limited 
number of men in both political parties, and any reasonably well-informed politician of either party would be competent to make up a list of less than fifty "wheel-horses" in polities, whose favor would insure his elevation to any office in the municipality. These constitute a political oligarchy, who furnish us with as poor a government as they dare to do.

Such is party municipal government, which is rightly said by Mr. Stickney, in his latest volume on "The Political Problem," to mean, "Government by organized bodies of professional electioneering agents, who betake themselves to the work of carrying elections because it pays; who are compelled by the force of eircumstances to make it pay, and who will continue so to do just so long as the work is so vast, so regular and has such large prizes."

What then are we to conclude? That in an age when rapid advances are being made in all departments of human endeavor, when science and invention and all forms of achievement are striding rapidly forward, the State is lagging in the race? Quite possibly this is true. Having delegated our right of choice, as has been suggested, to the politicians, we have reached an epoch in the evolution of the State when the art and science of government are left in abeyance, and the best thought and effort of our time are given to other pursuits.

One evidence of this is to be found, as it seems to me, in the observation that, among civilized peoples, the rights of person and property, which are essential tests of governmental efficiency, are not largely affected by particular forms of govermment. At any rate, an unprejudiced view of the conditions of society as determined by institutional forms in England and the United States would not, as I think, disclose such serious discrepancies as might be supposed to exist. It may well be doubted whether the eitizen of 'Toronto, Canada, is not quite as comfortably governed as the citizen of Brooklyn; and among civilized communities, the advantages of discoveries and inventions in science and art have been quite as efficiently availed of in one as in another form of liberal government. "Obedience is what makes government," says Edmund Burke, and "not the names by which it is called." Even in the ideal governments, many limitations were set up which this enlightened age would instantly disallow. In More's Utopia, it 
was death to talk about the govermment; while, in our modern England and America, it is almost criminal, during a certain portion of any year, to talk about anything else. In Plato's Republic, citizens were to be punished if they attempter to concern themselves with trarle. In these days of the actual republic, a vast number of our citizens find little concern in anything else.

How, then, briefly stated, has the State evolved? Begrinning with the surrender of individual indulgence to the welfare of the associated family group; rising to tribal importance by the kinship-line of demarcation; increasing th. numbers of the gens by the supremacy of conquest and by adoption; the heads of important tribes choosing jretty kings, and themselves, in turn, constituting an aristocracy of nobles; the supreme head and these allied nobles seeking, in turn, one against the other, the alliance of the masses, and, as a consequence, conceding to the average man important recognition; the average man himself tinally over-topping both kings and nobles, his speech attended to, his thought made free, his needs becoming the ultinate end of govermment.

Have we not thus epitomized the complete analogue of all that we know of evolution? Government changes from small to greater numbers, developing, as it advances, great complexity of problems. Out of the hot crucible of war the fittest form of government survives and thrives. Deeps in the still currents of the early centuries, the seed-germ of average humanity quietly awaited its favorable environment, occasionally secking the upjor sky of active being during some spasmodic episode of war, then being closed upon by inauspicious times until the fitting surroundings for its healthy growth are furnished it by the inexorable logic of events. And having thus imperfectly demonstrated the morphology of the State, we are brought to our conchusling inquiry.

What final form will the State assume, when under the full rontrol of the principles of Evolution? 'Truly this is an ambitions question. Some light might be thrown upon the problem, if we could be quite certain of the ultimate scope of governments.

'Two theories are current concerning the true functions of the State. One is, that it fulfills its office completely when it secures to the individual absolute justice-nuan- 
ing, thereby, the opportunity to exercise, to their full bent, all the faculties with which he is endowed. Another is, that the State should directly supply to the individual that which, by reason of congenital defect or unfavorable environment, he may stand in need of.

The disciples of the first theory would limit to the narrowest extent the subjects of governmental control. They would leave to individuals, or private combinations of such, the prosecution and development of all enterprises which do not involve the liberty of the person or the right of property. It is enough, say they, that the State secures the highway for its people to walk in; let it not be encumbered by even the postal-wagons of the nation. It is the old doctrine of laissez-faire, and is postulated upon the aphorisin that "all a man wants is a fair chance."

The paternal theory, on the other hand, insists that the strength of all is pledged to the assistance of those who need it; that what may be well done and with much saving of effort by the general community for all, is within the true scope of governmental function; that all the cardinal necessities of existence, such as light, heat, education, communication and transportation, not to say food, should be undertaken to be furnished by government; and some say, further, that the entire industrial scheme should go forward under the direct supervision of the State. Among the latter, Mr. Edward Bellamy, in a most ingenious, entertaining and plausible manner, has set forth the sublime satisfaction of "Looking Backward" from the twentieth century, in such attractive guise that a society has already been formed, in Boston, the natural birth-place of societies, to further the practical adoption of the views in general ontlined by him.

Perhaps these two views may be briefly defined as Anarchistic and Socialistic. Against the one it may be asserted, that it leaves without provision many hard conditions of society; and against the other, that it reduces to inane, commonplace existence the multiform activities of life as they now proceed. Both, doubtless, have in view the highest happiness of mankind; and whether we ask to what has the State evolved, or what final form will the State assume under the full control of the principles of evolntion, these two widely diverging views of the State-function suggest, with force, the great perplexities of the question. 
Let us not forget that the development of the State is but the evolution of associated manhood. It finds its most faithful prototype in the growth of a man. An infant is lying snug in the cradle. The air is carefully tempered to its feeble powers. It breathes the environment of a pure and happy household. It comes to youth and early manhood unvexed by any sombre view of nature, or the world about it. From within as from without, come only chaste thoughts of love and duty and the genial ways of sacred fellowship. Manhood is still attended with serene surroundings. 'The robust work of active life is carried forward with amazing cnergy and success; the windows of the man's mature reflection are never shut to the whitewinged messenger of honor, truth and love. His life is radiant with shining deeds of helpfulness to others, and, waking or sleeping, no evil thoughts intrude upon his presence. $\mathrm{He}$ is honest, faithful, kind, affectionate and pure as if by instinct. And when, at last, he falls into his final slumber, the estimate which men make of him is full of credit and renown.

What is it that has made this man what he is? Hc has walked his pleasant way of life, surrounded by the same great limitations as his fellows. For him no special stars have shone, no different sea has broken on the shore, no special forests waved their branches. Yet, to the making of his manhood, have contributed all the events of all the human lives which have preceded him. All deeds of deathless valor, all stainless lives of licroes in the past, all lowly suffering of humble men and women in the poor places of the world, all victories and achievements of the great in the luxurious halls of power, the joy and suffering of the rudest inhabitants of an $A$ frican jungle, have helped to make possible for him this perfect human life, and he has inherited all precious thoughts of all noble souls that have cver lived.

Now, the State is but the ontgrowth of all human development. 'To its present condition, all the men and women of the past have contributed. 'Their personal gifts and attaimments, their individnal environments, have entered into and shaped the structure of government as it now exists. If then, we may not comprehend the subtle influences that contrive for us a perfect man, how shall we be able to detcrminc the real conditions of a State under the 
full control of the doctrine of evolution? We stand between two eternities. Within the compass of the past three centuries, most of the elements we prize to day in the science of govermment have been evolved. Taking the limit of man's possession of the earth to be within the period demonstrated to us by Mr. Sampson, in his admirable lecture on "Primitive Man," four hundred thousand years were necessary to the human race before the earliest form of government was possible. Who shall say that the earthdweller of a million years to come shall not be a part of some great system of government? What prophet shall be so bold as to outline the political system which shall then infold the earth? The conception of the Universe itself is daily widening. Astronomers are piercing farther and farther the depths behind the midnight sky. Geologists and Archæologists are digging farther and farther into the heart of the world and its history. The boldest explorer of this realm which is to be, must be satisfied with what he may have the courage to say is the tendency of things.

Let me now say, however, in view of some discouraging episodes of government, that have been referred-to, that the tendency, to my mind, is forward, not backward; upward, not downward. The doctrine of evolution is of necessity optimistic. Growth without limit means continual advance; - surging and re-surging, like the tides of the ocean, but forging forward from one cycle to another. Physical cataclysms alone excepted, the march of humanity is to be perpetually toward the light. So Jesus preached, so Plato dreamed, so Milton sang, so Luther protested, so Philip Sydney fought and died, so the great of every age and clime have acted and spoken. This is the vestal fire of all the ages, which has been perpetually burning in the human heart - Progress and Victory for the human soul.

I close this paper with the suggestion that, at some time in the perhaps far distant future, the State will have evolved into an entity of purely delegated, as distinguished from representative, powers. Signs are not wanting, already, that a reversion such as Mr. Stickney has indicated to the primitive meeting, in open convention, of the citizens of a limited vicinage, will constitute the only direct political relation of the governed with the govermment.

May not the people of a given section wisely conclude that it is safer for the common interest to delegate, to a 
person known to each of them, fairly chosen in open convention and after full deliberation, those important powers which they now entrust to unknown spoilsmen, whose only incentive to action is the advancement of their private interest, and who have neither the capacity nor the inclination to further the pulblic good, and who, thereforc, permit the citizen, for instance, to be represented in Congress by some person who is amenable, not as the Constitution designed, to the people, but to those who hold the power to present him to the people as their candidate?

However this may be, the State, as an affirmative factor of evil interference with the man, belongs wholly to the past. The State which is to be will foster cvery personal light, protect every avenue of personal advancement, encourage every aspiration for personal freedom. It will gather to itself all great and noble thoughts, because it will witness the elevation of the common man. Into its complete formation will enter all lofty contemplation of the highest good to man. To its constitution all classes and conditions of mankind will contribute. Every noble endeavor, every holy instinct, and every chivalric deed of all the past, will be garncred in its perfect Statehood. It will be tolerant of human weakness, it will be helpful to human endeavor. 'T'ruth and honor will find in it an altar. Virtue will find it a shield, and vice a sword. Speech will be given audience by it. Crime will be disarmed by it. Into it will How all gracious impulses, out of it will come all ncedful courage; for it will reach its perfection at a time and in an age when men shall be exactly what they secm, and the State itself shall be the auspicious symbol of the Brotherhood of Man. 


\section{THE EVOLUTION OF LAW}

BI

RUFUS SHELDON 
COLLATERAL READINGS SUGGESTED.

Spencer"s "Principles of Sociology"; Amos's "Science of Law" and "Systematic View of the Science of Jurisprudence"; Maine's "Ancient Law," "Early Law and Customs," and "Popular Government"; Bagehot's "Plysics and Politics"; Coulange's "Ancient City" ; Pollock's "History of the Science of Politics," and "Essays in Ethics and Jurisprudence"; Lightwood's "Nature of Positive Law"; Holland's "Jurisprudence"; Morey's "Roman Law"; Muirheads's "Roman Law" (in Ency. Brit.); Wharton's "Commentaries on American Law," chaps. I., II., III. 


\section{THE EVOLUTION OF LAW.*}

Is the modern State there are two kinds of law; one made by the legislature; the other by the judges. Law made by the legislature is called statute law; that made by the judges is called the law of judicial decision. If a man agrees to serve another for a term of two years, he is not bound unless his agreement is in writing; because there is a statute to that effect. But if he agrees for a term of less than a year and for a consideration, it is a valid contract: not because of any act of legislature, but because, long ago, in England, in the time of Stephen, the spiritual courts held that a man was bound in conscience by his engagement; afterwards, the temporal courts held that he was bound in law, and have so continued to do to this day.

Statute law includes political, public and private law, the law of procedure, corporations and municipalities, ete., and a part of what is called Private law, which has to do with the rights and obligations of individuals in the ordinary affairs and business of life.

The larger part of the rules of Private law is made by the judges. That judges make law is not explicitly stated in the text-books. In fact it is not generally admitted that they have any part in law-making; the theory being that there is somewhere a store of ready-made law, consisting of rules and precedents, where the judges somehow find what they want after the lawyers have searched for it in vain, and then expound and apply it with plenty of comment and obiter dicta, but no addition.

Now, it often happens that, if any determination of right or liability is made, it must be made by the Court. Consider the first case of action brought against a parlorcar company for loss of a satchel containing jewelry entrusted to the porter without notice of contents. Here the Court gives judgrment in a case which differs from any to be found in the reports; and just in proportion to

* Copvignt, 18\%, ly James H. West. 
the difference of the circumstances from those of any previous case, is the amount of new law made. Yet the books and the ease-lawyer would have us believe that this decision was somehow implieit and potential in the judgment of the Court in a case tried before Lord Holt in 1704, in which the plaintiff brought suit against the defendant for loss occasioned by his having undertaken to haul and deliver a eask of brandy; which he did with such negligenee that it fell out of the cart and was staved, so that the brandy was spilt upon the ground, to the great loss of the plaintiff.

The thorough-going theory of the law of judicial decision is that a rule or prineiple is somewhere to be found in reports which will fit the faets of any case in trial and serve as a precedent. Yet, as Maine says, "the moment "the judgment has been rendered and reported, we slide " uneonscionsly or unavowedly into a new train of thought. "We now admit that the new decision has modified the "law. The rules applicable have - to use the very in"aceurate expression sometimes employed - become more "elastie. In fact they have been ehanged."

The growth of judicial law is a process of continuous adjustment of the rules of previously determined law to conditions ever varying. As gradually and slowly as the simple means of transport used in old times - the heavy wagon dragged through many miles of mud-develops into the long train of cars ruming on its iron track, with all the attendant complexity of commercial incidents, so, slowly and ruming parallel with it, taking up small increments along the eourse of growing eommerce, with some help from legislation, does the law of Carriers grow to a eomprehensive system adequate to the needs of a complex civilization.

And so each part of the law rapidly increases, following civilization as it advances, until at last the total becomes a vast bulk of judge-marle laws; each part very great, the whole enormous; recorded in 8,000 volumes of reports, the despair of lawyer and legislator; the result of the progressive deduction of rules and principles by a process of distinguishing, by small variation, variations from previous cases, similar, but not identical; so that when a decision is made, some increment is added to the body of the law, or substitution of new for old is made, even to such a degree that 
at last, by the slow process of distinguishing, old law is reversed.

I find no better illustration of the growth of law by variation dependent on changing conditions, than the words of Coleridge, C. J., in his charge to the jury in a case of blasphemy: "Gentlemen, you have heard with truth that these things are, according to the old law, - if the dicta of old judges, dicta often not necessary for the decisions, are to be taken as of absolute and unqualified authority, that these things, I say, are undoubtedly blasphemous libels, simply because they question the truth of Christianity. But these dicta cannot be taken to be the true statement of the law, as the law is now. It is no longer true, in the sense in which it was when these dicta were uttered, that Christianity is the law of the land. Therefore to base the prosecution of a bare denial of the truth of Christianity simpliciter et per se on the ground that Christianity is a part of the law of the land in the sense in which it was said to be so by Lord Hale and Lord Raymond and Lord Tenterden, is in my judgment a mistake. It is to forget that law grows; and that, though the principles of law remain unchanged, yet (and it is one of the advantages of the common law), their application is to be changed with the changing circumstances of the times. Some persons may call this retrogression, I call it progression, of human opinion."

Law begins when a dispute between two, about right or duty, is settled by a third person, instead of being determined by the superior strength or skill of one of the disputants, - the third party having authority to enforce the decision. In primitive times this authority rested sometimes in the tribe, sometimes, as in the Homeric era, in the assembly of warriors; in early English history, in the hundred; in a higher phase of civilization, in the state. Probably no check is at first put upon the liberty of the individual to make reprisals or take vengeance; robbery for robbery, theft for theft, killing for killing, is as natural as with animals: but when at last it works in upon the slow perception of the members of a tribe, that individual security depends upon tribal integrity, some restraint is put on the liberty of individuals to settle their quarrels ad libitum, and the parties are compelled to submit to some kind of arbitration. It is likely that, at first, ref- 
erence to arbitration was voluntary, - to a by-stander. Next, the arbitrator was some man in authority, priest or magistrate; possibly, in important cases, the chief or patriarch; obedience being still voluntary, but likely to be enforced by force of public opinion - the life of early as well as of advanced law. The next step ocours when the tribe or State assumes jurisdiction to the extent of giving the plaintiff power to compel the defendant to come before a magistrate for settlement of the dispute.

The most ancient legal proceeding of which we have record gives strong support to the theory that this was the first stage in the growth of law. This was the Legis Actio Sacramenti, the source and pattern of all later actions in Roman and Continental and old English law. The trial began with the bringing of the slave or property in dispute into court. 'Then began a feigned combat, which is thus described by Gains :

"The claimant held a wand, and, grasping the slave or thing over which he claimed dominion, said: 'This man I claim as owner, by the law of the Quirites, according to the reason that I have stated. Thus mpon him I lay my lance.' The adversary then repeated the same formula, and touched the property with a wand which represented his spear. 'This process was called the hand-grapple, and symbolized a fight for possession. The magistrate, representing the State, ordcred them to loose their hold. Then each challenged the other to stake a sum of money on the truth of his assertion. The wager accepted, issue was joined, and the money was put into the hands of the magistrate as a compensation for rendering judgment."

In some such rongh way as this the plaintiff compelled his adversary to come into court to have justice donc as fitted the times. 'This getting a man into court was the most important part of ancient law, as is witnessed by the fact that the early coles give first place and great space to the law of procedure. When the parties are in court, the magistrate must prononnce judgment according to law - that is, he must determine rights and duties by application of some rule or principle. These rules and prineiples are the substance of the law, the reason and excuse which justify the interference of the public with the will of the indivirlual.

The first appearance of substantive law is as custom, 
sanctioned and enforced by an authority which is sovereign. There are two stages in its development - 1st, the growth of custom, and, 2 d, its sanction by the sovereign, whether assembly, tribe or king.

It is true that Maine and the German school do not regard compulsion as a necessary element of the primitive customary law. But their arguments seem to go no further than to prove that ancient customs become habitual to such a degree that they become constant factors of action. This constancy is due to a conservative spirit and an apathy of thought which belong to a time when status is the prevailing condition of men. But unless personal will is somehow limited there is no Law in the legal sense; in this essay at least law connotes compulsion. It is just when the individual will begins to act in some way that conflicts with custom, that law begins. As long as pure passive custom reigns there is no law - for instinctive action does not lie in the province of will.

Just outside of the land held in common by the most primitive and rudimentary of States, - the village community, - in the wilderness, there is a spring of water. A path leads to it, used for time out of mind by every man in the community. It happens that some one builds a hut, or fences in a bit of ground, right across the path. Then the germ of law latent in every society springs into life and action. The chief, or the assembly of citizens, declares that this is a trespass upon public and private rights, and removes the obstruction: and, if the offender resists, perhaps puts him out of the law, so that any man may with impunity take his life.

Again, it is the custom of the tribe that the control of the persons and property of the family shall descend to the eldest son when the father dies. This custom, necessary for protection and preservation of the family, has its sources far back beyond memory of man or reach of investigation, in the needs and ideas of a primitive people; when it emerges into history it has been converted into customary law.

It is not necessary to go to ancient time for illustrations of the law of Custom. Although it is the first phase of legal growth, it remains always active and productive. Modem law is full of it. A very large part of what is, in strict terms, Common Law - the Common Law of Black- 
stone-consists of decisions of the Courts which hold that certain customs are binding, because they have been common throughout the land, and have prevailed from a time to the contrary of which the memory of man runueth not.

For generations custom is the only source of law. It is a characteristic of primitive commnnities, of simple structure and with small store of civil experience, that a course of condnct which has been the custom of ancestors is regarded as linding for no other reason than that it has been liabitual. Modern tests of validity, that it is reasonable, certain, etc., are not requisite. Even when the village community has become subject to a sovereign, the law of custom still prevails and is paramount; for the sovereign does not make new law; he enforces the old. No king or assembly ever enacted the law of patria protestas, which througli the long course of Roman history determined religion, morals, manners, rights and duties by an iron rulc, relaxed at last but never completely loosened; its influence co-extensive with the Roman Empire, transmitted through many a channel to this day, and still apparent in the law of primogeniture and the few remaining disabilities of women.

It is probable that among the first customs that were converted into law were many that were derived from religious ceremonial. Religion was the chief business of the family, as war was of the community (tribe). Nothing was done before the domestic hearth without offering to the Lares; no furrow was turned and no seed planted without invocation of the gods, attenderl with strictest rite and ceremonial. The battle must wait for the generals to consult the angurs - for those were the days when angmrs met withont laughing. So strict was this ritualism that the droluing of a word or the omission of a grestmre was of fatal consequence. 'The formality and pmetilionsness of the religrious rite remained when it received sanetion from the State, and became a legal obligation. De minimis non muat ler, - the law is not concerned about trifles, - is a legal maxim of modern growth. It is a natmal result of primitive conditions of thomglit and culture, snperstition, narrow experience and shallow understanding, that form shonld connt for more than substance. The reason of a cnstom soon passes out of sight and ont of mind; but thongh the reason fails, the law remains: and the ceremonial which 
was once significant of real relations, and decisive of right and duty, is reduced to mere formula and gestures of no import.

So old law becomes technical to the last degree; error in the letter kills, so that the spirit can not make alive again by amendment of course. Gains says, if you sued by Legis actio sacramenti for injury to your vines, and called them vines, you would fail; you should eall them trees, because the text of the XII. Table made mention of trees only. An old Teutonic law reads: If you sue for a bull, you will miscarry if you deseribe him as a bull; you must give him the ancient judicial designation of the leader of the herd. The fore-tinger must be called the arrow-finger; and the goat the feeder on leeks. And even as late as the time of Edward I., the rule held that "he who fails in a word, fails in his cause." This technicality, which has been called a disease of early law, is transmissible by descent, and runs far down into modern law. In England it had a most extravagant outcome in the system of special pleading so long in use.

At last it comes to pass, in progressive communities, that the iron rule of form and ceremonial can no longer be endured, and the "cake of custom" breaks at last. Social and political life have expanded and deepened, becoming manifold and complex, so that the old laws are not adequate to present needs. New rights and duties arise to which they are not suited. How shall these be fitted to the new orler of things? The fact is, they are not fitted, but new rights and duties are adjusted to the old ways, are transferred from the domain of morality to that of legality, aud are somehow forced and squeezed into the ancient formulas without thought of logic or convenience.

When the mind regards form as the essence and reason of law, it easily adapts old ceremonies to new material without perception of inconsistencies. The ceremonial law is hard to change, because it has come to be regarded as the conservative element in society. Average morality has run far in advance of positive law, but in order that the law may be brouglit to harmonize with it, the popular conscience must have a long period for action upon the public will, and through this upon State administration. 'Then begins the work of a new and unique agency for harmonizing law with social needs and ideas. This first 
instrument for the modification and improvement of law is Fiction. Old law, particularly Roman and English, is full of these devices.

One of them had a great influence, civil and social, in ancient time, and has left its traces in many parts of modern law. In Palestine, India, Greece, and Rome, there was nothing of so much social and civil importance as that the integrity of the family should continue unbroken after the death of the father. He was its head and lord; and more, for he was household priest. He alone could lawfully conduct the rites of ancestral worship. Any interruption of sacred rites was fatal in its consequences. When the father died, his office immediately passed to the oldest male descendant. In those days of private feud and tribal conflict, when men fought like kites and crows, it was likely to happen that all the males in a family would perish. But the worship of ancestors must be kept up without a day's interruption. Some remedy must be devised. There was no thought of any out of the exact line of the old ceremonial. The law was that the duty could not be delegated; it must fall upon the oldest male descendant. But there was none. 'The problem was solved by the formal adoption of a stranger as son, who immediately became such, not only by law, but also in the regard of the family and in the opinion of the community. Headship could not descend to a female. From this rule of exclusive devolution of the paternal power to a male is derived a great part of the modern law which determines the course which the property of an intestate shall follow, and also the legal relations of husband and father to wife and children.

'The fiction of adoption was extended to other transactions. The strict rule of ancient law did not permit a man to sell his land or to devise it by will. He held land and goods as trustee for his family, to the end that it might not perish out of the land. Private ownership with right to sell is an incident of arlvanced law. Of course, with change of conditions as time goes on, this rule becomes inconvenient. 'The public begin to regard it first as inconvenient, then as unjust, at last as not to be endured. Then pulblic opinion begins its influence upon the magistrates. But there is no thought of changing the old law imposed by the ancestral gorls - which declares that prop- 
erty belongs to the family; and when the family has perished that it sliall go to the gens. So the crafty and shifty magistrate invents a fiction which satisfies the unsophisticated gods with the form, and gives the substance to buyer or devisee. The proposed devisee is adopted with rigid observance of ancient form and formula, as eldest son of the family; or the vendee is so adopted; and the title of either is perfect.

For a long time, reforms in Roman and English law were brought about in this way. It is said, by competent authority, that there was a time when almost the entire law of English procedure was composed of such fictions. It is quite certain that no historic system has been without them; and it is fair to infer that they are a necessary phase of legal development. The reason is not far to seek. We find it in the conditions of a primitive people; their poverty of resource, narrow range of experience, a lack of constructive imagination, the formality and technicality of primitive ways due to the influence of a ceremonial religion, and most of all, in the mental apathy that always characterizes an age of ignorance.

Next to Fiction in the development of Law comes Equity; which, according to Sir Henry Maine, signifies "Any body of rules existing by the side of the original " civil law; founded on distinct principles, and claiming "incidentally to supersede the civil law in virtue of a su"perior sanctity inherent in these principles." This is not what modern courts would regard as a "working definition" ; for they have come to regard Equity as a fixed system, - Maine regards it as an influence.

The necessity for the action of such an influence in the modification and improvement of the law is due to the fact that, in all communities which are not stationary, the morality of the people runs in advance of the law. As civilization progresses, rights and duties multiply and become more complex; with this, morality refines, and the public conscience broadens, deepens and becomes more sensitive, so that the rigidity and formality of old law comes to be regarded as a hindrance to progress. Especially does its inadequacy in adapting form to substance, and procedure to merits, and its poverty of resource in number and kinds of remedies, begin to be felt. The sense comes that procedure and judgment should be ac- 
cording to the merits of each case considered by itself, rather than as one of a class of cases that fall under some general rule: and particularly that a man's claim slall depend for success upon application of principles of right and justice, and not upon the chance of fitting his case into some determined and arbitrary form of statement, or of referring it to some precedent.

The stock illustration of the operation of Equity given in the text-books is this: 'The Common Iaw would not discharge a man from liability upon a bond which he had signed and sealed, unless he could bring into Court as evidence of discharge a release also under sign and seal of the plaintiff. If the defendant offered to prove that he had in fact discharged himself from liability, by paynent of money or otherwise, he would not be permitted to introduce his evidence. But when the Equity Courts began to assume jurisrliction, they admitted the evidence, and, upon proof of discharge, issued an injunction forbidding the plaintiff to further prosecute his suit. 'This was sub ponu; that is, if the plaintiff persisted, he was summoned before the Chancellor and fined or imprisoned for contempt of Court. He could get no help from the Common law Courts; for the Chancellor stood next to the throne, was the keeper of the King's conscience, and had all his influence and power to aid in enforcing his judgment. Again, Common Law could not anticipate and prevent the doing of a threatened wrong, but must wait until the act was done, and then could give damages in money only. Equity compelled the offender to cone into conrt, and enjoined his wrong-doing under penalty of fine and imprisonment. Again, the old law gave to the husband absolnte ownership and control of the personal property owned before marriage by the wife. Equity compelled him to set aside in the hands of trustees a part for her exchsive use.

A brief sketrh of the growth of Equity in England will further illustrate its character. J) ring the reign of William the Conqueror and his immediate successors, the King's Court, composed of the great lords, exercised jurisdietion in the most important civil and criminal cases, leaving to the old popular County Courts a very limited anthority in local affairs. The King's Court finally broke up into three distinct Courts, afterwarts called Common law, to distinguish them from the Courts of Chaneery. 
The business of those days was fighting: there was hardly a beginning of trade and commerce; the value of all the personal property in the Kingdom was small; the rules of land law, compared with those of a later period, were few and simple; so the law of the time was crude and rudimentary. There were only four forms of action in the Common Law Courts which could be employed to maintain a right or remedy a wrong. These failing to fit the case, the plaintiff must go out of Court poorer than he went in. These four remedies, as stiff and narrow as they were simple, afforded poor showing for relief in the manifold forms of what Coke used to call fraud and covin. There was many a way by which the cruel overlord could oppress and defraud his poor tenant with impunity, because lis act could not be described in the set phrases of either of the writs of Debt, Detinue, Covenant or 'Trespass.

We read that at last some complainant, failing to get redress in the Common Law Courts, but bound to push his case, would somehow get access to the King, - coming down to London, or appearing before him on one of his circuits through the kingdom, - and would give his plaint, and pray for relief. Whereupon the King summoned the accused to make his plea, and, if found in the wrong, with off-hand justice he granted the relief asked for. There were besides, cases too difficult to be determined by the ordinary courts, which were brought before the King for decision. This kind of business grew, of course, and became so heavy a burden that he must have help, and so a Justiciary, or Chancellor, as auxiliary. In time the work increased so that it became necessary to organize a corp of assistants and subordinates. This was the origin of the famous Court of Chancery - an institution at first beneficent, remedial, and progressive, which regarded justice as of more consequence that precedent, and form as of little account when weighed against substance; but which became first conservative, then reactionary, and at last an obstacle to right and justice, so that it well deserved all the invective of Bentham and all the satire of Dickens.

The third agent in the modification and improvement of law is Legislation, which in course of time becomes a large part of the business of the State. The State is now 
mature. It has become sovereign, $\longrightarrow$ cmbodied in king, emperor, or assembly, - and supreme over its subjects to determine action, compel obedience, and regulate rights and duties. According to the theory of the English school of jurisprudence there is no limit upon its power to make law - but in fact, and in apparent support of the doctrines of the rival German school, the action of legislatures is limited by the popular conscience and will.

A distinctive characteristic of Iegislation is that it is supreme over all other methods of law-making. Its advantage is that it can make the will of the people effective much more directly and expeditiously than the other agencies. Many are the cascs in which Legislation has swept away the cobwebs of legal subtlety, simplified technical laws, and cleared from the path of progress the obstacles of precedent and form. It has abolished imprisonment for debt, removed the disability of a party to a suit to testify; has given the prisoner the benefit of counsel and the right to testify in his own behalf; has converted the wife from a figment of law appurtenant to the husband into a legal person, and is slowly bringing woman to an equality with man in civil rights.

In the progressive State the legislative function increases rapidly in scope and application, until its share in lawmaking becomes apparently, if not really, greater than that of all other sources. After lapse of time, - perhaps of a century, as in New York State; perhaps of centuries, as in England, - the bulk of this statute law becomes very great. At the same time the law of judicial decision has also been growing rapidly, with constant accumulation of additions, affirmations, reversals, and distinctions. 'There may have been - must have been - a guiding principle of growth in either case, which a master in analysis might discover; but none the less is the result in one case a thicket, in the other a jungle, the imperviousness and crucl thorniness of which it enter's into the heart of none lout a practicing lawyer to conceive. Statutes aceumulate by the myriads, with no order, no sequence except in date. no interdependence; in a word, there is nothing in print that is so utterly incoherent as a collection of statutes. And it takes thousands of volumes to contain the disjecte membre of the behemoth of Common Law - which some beaten and dis- 
gusted lawyer three hundred years ago called a "godless jumble," probably after judgment against his client.

This complexity, confusion and unwieldiness surely seems to call for some sort of correction. Not a few are of the opinion that the remedy is to be found in codification, which they regard as an advanced phase in the growth of law; while their opponents regard it as an advanced stage in the decomposition of law. A Code is a systematic body of laws enacted by the legislature. It comprises the settled principles of the law of judicial decision, and statutory law previously enacted, arranged systematically by topics, in divisions, chapters and sections, for easy reference. It also contains definitions of legal terms, rules for its own interpretation, and provisions for the future scope and application of the method of judicial decision to such cases as may arise outside of its own intent and specification. It should repeal obsolete statutes, settle disputed questions of law in the province of judicial decision, and provide for its own amendment. 'This is a long definition,-still it is incomplete.

The ancient codes, of which the Jewish, Roman, Salic and Brehon are examples, were not codes in the modern sense. They were inere undigested collections of customary laws, published for the information of the people and the government of magistrates. In the later period of Roman law, especially during the Empire, many experiments in scientific codification were made, resulting, early in the sixtl century, in the publication of the famous Justinian Codes. These are the source and model of the modern European codes, of which the most famous is the Code Napoleon. The Codes of Justinian are the domain of research and exploration for students of general jurisprudence and the philosophy of law; subjects of great importance in their possible relation to the future inlprovement of law.

The movement for codification of English law was initiated by Bentham early in this century, in his vigorous and virulent style. But English institutions are hard to change, and progress has been slow. At last however, Codification is the "burning question" in English jurisprudence. Already two or three branches of Private Law have been codified, and more are likely to follow. Lawyers, Judges and Legislators there, as here, are divided; men of great ability 
and learned in the law differ most positively, - one party insisting that Codification is the only hope for the law of the future; the other, that it would be its destruction.

Codification has fared better in the United States. The majority of the States have adopted one or more of the ordinary forms of Practice, Penal and Civil codes. Louisiana from the first has bcen governed by a Code modeled upon the Code Napoleon. It is here at lome, in the State of New York, that the main battle has been fought, with victory for the advocates of Codification in 1848, when the Code of Civil Procedure was adopted; and in 1882, when the Penal Code was enacted, - while the fight still goes on, fierce and hot, over the proposed Civil Code.

The advocates of codification claim that it is possible for a Commission of Experts in special departments to frame a general Code, made up of special Codes, constructed, if necessary, by extensions made at convenient intervals of time, that would have these advantages over the present system-or chaos of laws, as they call it: Scientific Arrangement; Accessibility ; Intelligibility ; Certainty. It is urged that Codification is necessary because law, whether statute or judicial, is not at present systematized in a scientific and plnilosophic way. Both are published in volumes that appcar from year to year, and are mere records, without system, analysis or arrangement of any sort; except so far as the so-called Revision of Statutes made in some of the States goes in that direction. 'To be sure, ponderous digests are published, but these have no legal authority. It is charged, as a defect of the law of judicial decision in its present state, that it is inaccessible to any but experts; and that an expert even must work a devious and doubtful way through a mazc of cases in order to find a case on all fours with his own, only to realize, after a search througl some liundreds of cases scattered hither and yon in some hundreds of the 8,000 volumes of reports, that case-law is what Pollock calls "chaos tempered by digests." The arlvocates of codification claim that a code would cure this defect and make the law accessible.

It is also cliarged that the law, whether statute or judicial, is unintelligible, as well as inaccessible, to any but experts, so that a man of ordinary intelligence, cven one of trained intellect, camnot without help of a lawyer ascertain 
the law that concerns his ordinary rights and duties, although it is a legal maxim that ignorance of the law is of 110 avail as a defence. It is urged that a code would cure this defect. One enthusiast suggests that such a code should be used as a text-book in our public schools, - the most important sections of law to be learned, as the Twelve Tables were learned by Roman boys. It is also charged that the law of judicial decision is defective in the quality of certainty. This appears in the great number of conflicting decisions and overruled cases to be found in the reports. Of the 154 cases reported in one volume (1883) of the reports of the Court of Appeals in New York, 32 were reversals of decisions made by the General Term. In 25 volumes of Missouri reports, 40 per cent. are reversals. Another alleged cause of uncertainty is that important questions remain unsettled, because the Courts, as some one has said, "nibble round their edges," and give judgment by indirection only.

It is objected to codification that the reduction of the law of judicial decision to statute form will give it the acknowledged defects of statute law - particularity, rigidity, and strictness in interpretation. Also, that it deprives the courts of the power to exercise the function of administering equity, of which the distinctive merit and advantage is that it does justice in each case according to the particulars of the case, - which any rigid formula of law fails to do. It is also objected that it is obvious that no jurist of one generation can anticipate the needs of the next. Law is the resultant of the moral and physical forces of civilization, which vary continually with the changing circumstances, conscience and will of the people. Any code must, therefore, be continually subjected to amendment, and be tinkered according to the varying ceprices of legislative committees, - resulting in a confusion and uncertainty much greater than that charged against the law of judicial decision.

Again, it is objected that the enactment of a code would not dispense with the necessity of further development of judicial law; for it is a well-known fact that it is impossible to draw a statute in terms so exact and definite that it will not some time require judicial interpretation to determine its meaning and application. The New York Code of Procedure has been the prolific source of thou- 
sands of decisions. It is said that there are, in English and American reports, 40,000 cases of interpretation of the Statute of Frauds.

Finally, it is objected that history shows that codification is suited only to a moribund state of the law, when it has lost its spontaneity and capacity for improvement; that codes have appeared at a period of national decline, as in the case of the Justinian Codes, or at a period of political confusion, as in the case of the Code Napolean. One writer (Best) says that codification has always been indicative of a contemporaneous state of absolutism on one side, of civic pusillanimity on the other. The great German jurist Savigny regards the French, Prussian and Austrian Codes as symbolical of the peculiar vices incident both to revolution and tyranny.

The conflict of opinion finds expression, on one side, in the language of Sir Henry Maine: "English law will continue to bear the marks of the injury that results "from the absence of creative judisprudence, until legisla"tive rearrangcment and restatement fully disclose the "stores of common sense which are at present concealed "by its defects of language and form." On the other hand, an American law-writer wails after this fashion: "If England adopts codification, it requires no gift of "prophecy to foresee that her encompassing seas will weep "upon the dripping rocks around that island a more "mournful requiem than was ever before sung over fallen "greatness and glory."

The several methods of development of law-Custom, Fiction, Equity and Legislation, and, if you please, Codification; the necessary results of the continuous interaction of State and society; different methods of adjustment of rights and duties, and all operating, when in normal action, to produce for each individual least restraint and the greatest liberty - arc best illustrated in the two great historical systems of law, the Roman and the English. There is space for only a passing notice. Their lines of development are in some respects so diverse that they have sometimes been regarded as repugnant systems. This is true rather in respect to forms and procedure than in substance. The most obvious differences are that the distinction between real and personal property, which is of such importance in English law and one of the 
greatest of obstacles, perhaps the greatest, in its progress, had no place in the Roman. At Rome, Law and Equity were administered by the same Court-in England, they were divided between two, which differed in constitution, jurisdiction, procedure, principles and, in early times, in spirit and ideals, so that for a long time they were in open and bitter conflict. In each of our original States, with the sole exception of Louisiana I believe, Law and Equity were administered in separate Courts. In 1848 the two jurisdictions in the State of New York were merged into one, by Act of Legislature. The majority of the States have followed her example, and at last, even in. old England, the home of precedent, the Law and Equity Courts were consolidated in 1873.

In the law-courts of England, questions of fact were always decided by a jury taken from the people; in Rome they were referred to an officer selected from a body of professional experts. In English practice, no decision was made upon a hypothetical case for the sake of determining a principle of law. An issue of fact or law could be joined only when a suit was brought for actual damage or relief. A great deal of Roman law consisted of the opinions of jurists upon hypothetical cases, which were made authoritative by the edict of the prætor. Law grew much more rapidly, and it was much easier to modify it, in Rome, because the judges were less conservative and had less regard for precedent. At Rome, law was studied philosphically, as a science; in England, as a profession, entpirically. Although, in literature and art, Rome was of second rate, - pupil and initator, - in law she was original and creative; without peer then, and without superior now. In one direction she made greater progress than any modern State - the philosophical study of law. Professional jurists are rare in this country and in England, and are not common on the Continent. They abounded in Rome, and Maine says that they were the means of producing results which the English practitioner lacks centuries of attaining. He adds that "the great importance of the Roman law is that in our law we approach nearer and nearer to its conclusions."

The law of any period is the resultant of countless forces, climatic, social, religious and moral, concurring through long periods of time and over wide areas of influ- 
ence. Making allowance for the fact that law lags belind morality, we find the law of any period fairly representative of the intelligence, morality and ideals of the people. The student finds many illustrations, often quaint and curious, of the varying phases of social and civil relations, and of habit, thought and belief.

Some of the primitive methods of collecting a debt strike a modern sheriff as at least unique. The first of the Twelve Roman Tables reads, _ "If you summon a man (debtor) into Court, he must go ; if he refuse, call a witness and arrest him; if he attempts flight, lay hands upon him." Observe that the plaintiff is allowed to arrest the defendant and bring him into court. The State is not represented by an officer; the summons is a private act, and the duty of the official is only to give judgment. This is a step in advance of the mode of private redress, when the parties fought it out with fists or clubs. If judgment went against the defendant he was allowed thirty days in which to satisfy it. If he failed, the plaintiff could arrest him and bring him before the magistrate, who demanded surety. If this was not given, he was adjudged to the plaintiff; was put in chains, and contined in the house of the plaintiff for thirty days. Meanwhile, the amount of his debt was proclaimed on three successive days, in the market-place. If on the third day no surety was obtained, he could be sold into slavery; or he might be put to death, and his body divided - probably pro rata - among the creditors. The words of the Twelfth Table are, _ "On the third market-day let him be cut in pieces: if any one cut too much or too little it will be no crime." Very grnesome this, - worse than the old English law of impirisomment for debt; and worse than the experience of the uncomfortable victim of modern supplementary noceedings after execution. However, retrospective pity may be suspended in view of the fact that later criticism gives a milder meaning to the text - to this effect: "Let him be soli, and the proceeds be divided ratably among the creclitor's."

The following is how they collected a lebt not long ago, in India. The process was called "sitting dharna," and is thus deseribed: "It is a fixed prineiple with the Hindoo "that to deprive a Brahmin of life, ritler ly direst violence "or by causing his death in any mode, is a crime which 
"admits of no expiation. To this principle may be traced "the practice called dharna. The Brahmin proceeds to "the door or house of the person against whom it is di" rected, or wherever he may most conveniently arrest him; " he there sits down in dharma, with poison or some instru"ment of suicide in his hand, threatening to use it if his "adversary attempts to molest or pass him. He thus com"pletely arrests him. The Brahmin fasts, and by the "rigor of etiquette the debtor also fasts; and so they "remain, until satisfaction is obtained. Failure is rare; "for if the arrested party were to suffer the Brahmin to "perish by hunger the sin would lie forever upon his head." It is said that this method of procedure "has been put "under the ban of the British law, and chiefly survives in "an exaggerated air of suffering worn by the creditor, who " comes to ask a debtor of higher rank for payment, when "he is told to wait."

In Persia the man who is to fast sows barley in front of the debtor's door, and sits down, with intent to stay till the debt is paid or the barley grown so as to give him bread. We do not know that any connection has ever been traced between this and a similar custom which formerly obtained in Ireland.

Illustration of variations of law due to influences of race and time is found in the history of the testamentary disposition of property. The idea that a man has the right to direct the course which his property shall take after his death is modern, and even now does not prevail in parts of the East. In India, the theory of the native law is that descendants receive the property of their ancestor in trust for continued performance of the rites prescribed for worship of ancestors. Essentially the same law held in early Rome, and centuries passed before fiction and equity so modified it that testamentary disposition became free. In England lands could not be devised according to the wish of a testator until the reign of Henry VIII.

The growth of Criminal law is a subject of great interest, rich in material for the investigation of the student of comparative law. There is space here for but a single point. The interference of the State in what modern law calls crimes made its appearance late in history. For generations, murder, theft and robbery were regarded as private wrongs, to be settled by the method of retaliation. 
When the State at last interfered it did no more than to compel the tribe of the injured man to accept a money compensation.

A notable generalization of comparative law has been expressed by Maine, in a significant sentence: "The move"ment of progressive Societies has been from Status to "Contract." In ancient communities State law does not reach the individual: it deals only with family relations. 'The individual was absolutely subject in life, person, and earnings, to the head of the family, no matter how old he might be. He had no personal rights; if injured he could not recover damages; his family must prosecute, and received the damages; if he injured a member of another family, his own settled by the payment of a fine. He was not a legal unit, or even a legal fraction; he was an absolute zero. It followed that in a political and a legal point of view his condition was that of status,-determined by family and tribe, with no element of individuality in it. He had no legal free-will, so could not bind himself by a promise; and therefore conld not make a contract. As he had no legal free-will, his legal status, of whatever sort, could not be changed by his own act. When contract seems to be first enforced by law it is not for the reason of the English law, that there has been some consideration; or for that of the Roman law, that it is equitable that a man shall be bound by his promise - but it was enforced because some public State ceremonial had been performed in which certain formalities in act and formulas in words had been followed with exactness; then the promisor was bound, even if his promise had been obtained by fraud or force. In the early stage of development of contract, an agreement could not be made binding by private consent or action alone. The State must give its sanction in some cercmonial. Even to-day, in some of the Indian provinces, a contract is not considered binding by the natives until it has been confirmed by the courts, representing the State.

At last, with help of Fiction, Equity and Legislation, the old patria potestas has almost died out of Western law. Stutus has passed to Contract; and the right of men - and women too - to be their own masters, and to cxtend the sphere of the artion of their will over things by private owership, and over persons by contract, is forever assured. 


\section{EVOLUTION OF MEDICAL SCIENCE}

BY

ROBERT G. ECCLES, M. D.

AdTHOR OF "The EVolution of MIND," "ThE RELATIVITY OF KNOWLEDGE," ETC. 


\section{COLLATERAL READINGS SUGGESTED.}

Spencer's "Principles of Sociology"; Gradle's "The Germ Theory of Disease"; Tyndall's "Fragments of Science"; Stillé's Therapeutics and Materia Medica"; Belfield's "Relation of MicroOrganisms to Disease "; Peters's "History of Ancient Pharmacy," (Pop. Sei. Mo., p. 95); Whewell's "IHistory of the Induetive Sciences," (Vol. I., p. 227, Vol. II., p. 261); Rodwell's "Birth of Chemistry"; Hughes's "Manual of Therapeuties": "Pharmacopœia" (Eney. Brit.), "A vicena," "Alchemy," "Pharmacopoia," "Pharnacy" (Chambers's Ency.), "Pliarmacopoia" (Jolnnson's Cyclopredia), N. Y. Medical Times (Vol. XVII., p. 158), Jour. of Am. Med. Asso. (Vol. XIII., p. 258), Druggist's Circular (Vol. XXXIII., p. 124), N. E. Druggist (Vol. I., p. 12); Flint's "Practice of Medicine"; "Michigan State Board of Health Report" (Report of Committee on Sanitary Literature, p. 122); Cruikshank's "Practical Bacteriology." 


\section{THE EVOLUTION OF MEDICAL SCIENCE.*}

How primitive man treated disease and eased pain is now mainly a matter of pure conjecture. General inferences may be drawn from the methods of modern savages and the traditions carried into historic time. Till men suffered by the mere sight of suffering in others, no effort was likely to be put forth to still the pain felt by a neighbor, or stay the ravages of disease upon him. Side by side with the development of the altruistic fellow-feeling has gone on the Evolution of Medicine.

There looms up with the dawn of history an indefinite mass of distorted facts and pure fiction from which modern Physical Science as well as modern Medical Science has been born. 'To fully realize the process by which the change went on is exceedingly difficult, owing to our inability to put ourselves, in fancy, into the queer mental states of our progenitors. It is hard for us to believe that they were as thoroughly steeped in superstition as the facts force us to acknowledge. Supernaturalism wove itself into every thought and controlled every act. The ghost-theory explained every fact of their experience. Winds and waves, falling bodies, light and darkness, disease and death, were all the direct results of the wills of ghosts. Our modern savages are in this same frame of mind, and show neither surprise nor wonder at anything that occurs. To them, our telephones and telegraphs, railway-trains, and machinery of all kinds, are as simple and understandable as is the shooting of an arrow from their bow. Their belief in magic by ghost-power is thorough, unwavering and radical. It no more occurs to them to question this than it does to us to question that twice two is equal to four. Their only cause of wonder is the occasional failure of civilized man to do some miraculous thing they think he should be able to do by his magie.

This way of thinking keeps savages, and kept primitive man, in incessant and abject terror of the forces of Nature, 
and made them the dupes of evcry miracle-monger that came along. The dangerous, and to them evil, forces were the objects of their worship. They did not consider it good policy to worship a good god, as he would be good to them anyway. The evil powers were therefore the ones propitiated at first. When a person became sick, it was taken at once to be a case of obsession. One or morc evil spirits were supposed to have taken possession of him. How to drive the bad ghosts out was the problem they set before themselves to solve.* Of course they had to resort to the priests for help in all such cases. Thus it is, that the earliest historical records tell only of ecclesiastical physicians, and their treatment consisted solely of charms, prayers or incantations, coupled of course with some rich offering to the gods. $\dagger$ With the differentiations of theology came corresponding changes in the thcory of disease and its treatment. When one good God, and a devil with a host of minor evil spirits, came to be believed in, the notion arose that sickness was due to sin. $\ddagger$ It was considered that God was meting out justice to the sick. 'Then repentance was preached as a saving grace, and prayer as the talisman to recovery. Written prayers were fastened around the diseased part, and the sign of the cross or other religious sign drawn over the same as a charm. By thus pleasing God, they were supposed to be removing themselves from the buffetings of Satan. When they failed to rally after this, they were thought to be very wicked indeed, and as God continued to curse them it was impious for man to be kind to them.

Under idolatry and fetishism, remedies of a simple character were resorted to. Under Christianity and the strict sects of the Hebrews, the resort to therapeutic measmres was considered a lack of faith in God. 'The fetish-worshiper began his use of remedies as a logical seqnence of his faith. 'The Hebrew and Christian rejected them on the same gromuls 'The former believed that there were souls to all objects, dead as well as living. Somc souls were bad and some good. Bat souls made disease, and good ones health. They held that what was eaten imparted its soul, in whole or in part, to the eater. Cowards ate the lion's

- Inblowk's origrin of Civilization, p. 19.

† American ryelopalala, worl ". Medicine."

t.Job, ('hat). 2, v. T, (hal. 15, v. 20; John, cluap. 9, v. 2.

\$James, chay. $5, v .14,15$. 
flesh to gain bravery, and his bones for strength. Weak stomachs were supposed to be cured by eating strong ones. People with short breath expected improvement from eating foxes, that were believed to have long breath. Only women were allowed to eat deer-flesh, as it made them fainthearted. New-Zealanders make baptised children swallow pebbles, to make them hard-hearted and incapable of pity.*

Thus at the very dawn of knowledge, and among all savages, the medical doctrine is that similars cure similars. When very bad spirits were supposed to be in possession of a patient, they fought them out with bad odors or very abominable doses. It was still the same "similia similibus curantur." What the Ptolemaic system and astrology were to astronomy, this doctrine has been to medicine. Every child has as natural a trend to this belief as it has to believing that the earth is flat and stationary. All barbarous and savage people in every age have harbored it as they have other superstitions. In fact, it is a strictly logical superstitious deduction. As such, of course, it must contain, somehow or somewhere, a soul of truth. It certainly has been of incalculable advantage to the race, in leading to experiments that laid the foundations of Science. Very often it must have proven successful by causing vomiting or catharsis to ensue, or a critical sweat to be established.

Upon the facts thus garnered, the philosophers began to work, and we find the disciples of Pythagoras going out and visiting the sick at their homes. Before this, when the priests held rule, the sick had to be carried to the temples where they were. All the progress made in Medical Science from this time onward was by battling priests of every kind. Each new accretion has been a survival in a most intense struggle for existence. $\dagger$ Hippocrates, in the fifth century before Christ, gives us a systematic statement of what was known up to this time, and we have only to take succeeding gains, one by one, to see how truth has always been challenged for its credentials. The worst part of the battle has been in behalf of anatomy and physiology - the corner-stones of the Science-and it continues in some countries to this day. For ages, the dissection of a human body was an act considered so sacrilegious that murder was looked upon as less heinous. There are people

* Lubbock's Origin of Civilization, p. 13.

+ Warfare of science, pp. 77 to 92 . 
living now who can remember when a man was likely to be lynched, in this conntry, if it was known that he had taken part in the dissection of a human body.

The only speck of sunshine for progressive Medicine, over a period of thousands of years, was when the P'tolemies founded and cared for the Alexandrian library, allowing luman dissections, and encouraging the importation of all sorts of remedies from every part of the earth. 'Then arose a large nmmber of able anatomists and physicians, who added extensively to human knowledge and redeemed the Art of Medicine from the region of downright superstition.* But while Egypt was thus basking in the liglit of Science, Rome was depending upon clarms and incuntations to heal her sick. At every epidemic they built a temple to pacify the supposed angry gods. Soon, however, they borrowed from their more fortunate neighbors much of their skill and knowledge. Celsus has shown us that this was really no beggarly amount. They were able to perform operations for hernia, calculus, intestinal wounds, and cataract. They could use the catheter, trephine, ligature severed arteries, and remove hemorrhoids. Theyused lead plaster for the same purposes as we do to-day, and employed opium as successfully in curing dysentery. About this time, too, some cathartics had been discoverech. A generation later, Galen compiled the merlical knowledge of the times, after which an era of darkness set in, when men's minds were frozen into set forms for twelve hundred years. Christianity, such as it then was, soon became a power in the land, and it was the sworn foe to medical progress. It was willing enough, usually, to accept acquired facts, but no new ones were allowed to be promulgated, nor efforts made to discover them. As the Bible was the only guire in matters theological, so Galen became the sole anthority in matters medical. To kare to differ from Galen was to raise a similar tempest to daring to differ from Christ. Dissecting human borlies, under l'aganism, was a misdemeanor; under Christianity it became the most horrible of (rimes. From time to time the church would rise up in arms against medical men beeause of some new discovery. Then all medicine would for a season be thenemered. The doctors were chareded with soreery and milawful rompart with the levil, crimes punishable by burning at the stake.

" I'eters' l'ietorial History of Aneient l'harmaty, l. 1R.

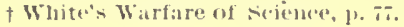


In 1243, the Dominicans solemnly interdicted every member of their order from the study of medicine. About the same time, the popes ordered all medical books from the monasteries, and forbade their study. Petrarch called the doctors, "Men who deny Genesis and bark at Christ."** 'They were called Atheists, Mohammedans, Sorcerers, Magicians, and all other titles likely to embitter the ignorant and superstitious against them. As late as 1722, the Rev. Edward Massey said that diseases are sent by Providence for the punishment of sin, and the attempt to prevent them is a "diabolical operation."

During all this dark period the only valuable gains made were borrowed from the Mohammedans. Avicenna, an Arabian, taught us how to use colchicum for gout, iron for anæmia, and rhubarb in dysentery. To him we are indebted for cassia, senna, manna, tamarinds, and camphor. We here see why doctors were called "Mohammedans," a term that then was worse than burglar or thief is to-day.

In the 15 th century, a number of bold spirits defied the popular prejudice so far as to dissect bodies privately. Some were caught and severely punished. In the 16th century, more of it still was done, in defiance of law, but privately, of course. Strange to say, however, even these men could not divorce themselves from subserviency to Galen. Whatever they found disagreeing with his description was set down as due to human degeneracy. The body not being just as Galen described it, it must have changed. Galen could not be mistaken. $\dagger$ It is ever thus, in progress from superstition to truth. The majority take the popular side, whether right or wrong. Nor can they be blamed for this. As a rule it is the side of the greatest safety. Dissentients, in defending a solitary fragment of truth, are more likely than not to discard the accumulated experiences of the race, making that fragment do duty for the whole. The men and women that are able honestly to weigh facts, and be guided solely thereby, are, in every age, few and far between. Hence it is, as a rule, safer to err on the side of conservatism than on that of so-called radicalism. In spite of this, we cannot help wishing that there had been more, and more pronommeed, radicals during the Midolle Ages.

'The theological nightmare of those times, especially in

* Il)id, pI. 100 to 108.

† American Cyclol'dia, word "Medicine." 
Christian countries, is somewhat appalling. Medical Science was held by it as in an iron vice. Escape was impossible. 'To be brought face to face with the crass ignorance, and horrible medical superstitions, then indulged in, is well, frankly, it is nauseating, and very apt to seriously disturb delicate stomachs. Nor need we go back much over a century to find it, since the awakcning is of very recent occurrence. For instance, take "Hclmont's Amulet for the l'lague," which sober, sensible - yes, sensible, as sensibility went in those days - medical men of good standing endorsed, declaring that it had "proven its efficacy in many instances" (I am quoting their own words), "particularly during the war between the Imperialists and Regulars in Hungary, where the plague raged in a terrible manner. It gained such a reputation throughout the country that all barbers and blear-eyed witches are already acquainted with its virtues." * The recipe was so highly esteemed among the leading medical men of the times that it occupied a prominent place in a Pharmacopoia of 1731, and was endorsed by the College of Physicians of the Kingdom of Prussia. Here is the delectable recipe: "Large, old frogs, caught in the montl of Junc, are hung up by their hind legs over a dish covered witl wax, which has been placed over a moderate fire. After a few days, the frogs discharge horrible fumes and slaver, which attract every kind of worms and flies. 'These stick to the wax and add their own drivel to the mess. When the frogs are dead, roast and mix them with the carefully preserved mixture of wax and drivel, and shape this compound into small rolls, or initate the shapes of frogs. One of these is scwn into a cloth, and worn in the region of the heart, suspended by a silk thread around the neck. The longer one wears these, the more certainly will he be protected from the ravages of the plaguc." †

In 166:3, Bechler's "Parnassus Medicinalis Illustratus" contained, among other equally quaint yet loathsome therapcuties, the following: "Powdered human bone in red wine will cure dysentery. 'The marrow and oil distilled from bone is good for rheumatism. l'repared liuman skull is a sure cure for the falling sickness. Moss grown on a skull is a liamostatic. Mummy dissolves coagulated blood, re-

- New Finglamd 1)ruggist, Mareh, 1889, 1. 12.

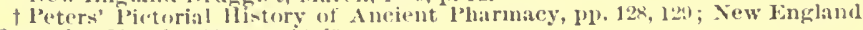
Druggist, Narch, 1880, ll]. 12, 13. 
lieves cough, etc. ... Human fat, when properly rubbed into the skin, restores weak limbs. Water distilled from human hair, and mixed with honey, promotes the growth of hair," etc. 'The druggists at this time kept in stock, for the compounding of physicians' prescriptions, the excreta of human beings and animals, spirit of human skull, spirit of huinan bones, human fat, "poor sinner's fat," wolf-liver, fox-lung, deer-spine, pike's-jaw, rabbit-hair, gallstones, scorpion and centipede ashes,*

\section{"With more of horrible and awful, \\ That even to name would be unlawful."}

To this day, a branch of the Homeopathic school prescribes just such remedies, and they can be purchased at the headquarters of the high potency homeopathic specifies, No. 13 W. 38th St., New York City. I give the address, lest some skeptical person should doubt the reliability of the statement.广 Originally, however, they were given in large doses, but now in infinitessimal ones.

At the time these remedies were so popular, the Jesuit priests introduced from South America the bark of the Cinchona tree, for the cure of malarial diseases. Protestant Europe rose up in arms against it, and stigmatized it as "Jesuit Bark." Blood-curdling stories of its poisonous and destructive effects were told, and these, in modified form, have been handed down from sire to son until the present day. Scarcely a month ago, a patient of mine refused to take quinine, because it was the poisonous extract of Jesuit bark. Ever since charms and prayers were replaced by therapeutic measures, men have striven to discover specifics for diseases. 'The majority of laymen to-day think that doctors have such specifics. In "Jesuit Bark" and its alkaloid, quinine, we have about the nearest approach ever reached to such a thing as a specific in medicine, and yet theological bigotry in disguised form causes humdreds of sufferers to refuse to use it. Doctors are compelled, in such cases, to hide the name under some foreign synonym, so that their patients shall not know that they are swallowing, in not only harmless but really useful doses, this drug. Our fathers condemned it, and lied about it, merely because Catholic Priests first brought it to notice; but they did not

* Ibid.

† Druggist's Circular, June, 1888, p. 124; Medical Advance, March, 1889, Advertisement. 
hesitate to swallow their own and other human beings' and animals' filth, or decoctions from skulls gathered from graveyards. Cinchona, in spite of theological ire, has proven itself fit, and survived; the other remedies were unfit, and only persist in modified forms and obscurc places because superstition is not yet dead in the earth.

The fetish idea that led up to such abominable forms of medical treatment, on the theory that like cures like or similar cures similar, was modified from time to time, with fashions in theological thought. 'The doctrine of "signatures" was an outgrowth of this kind. God in his goodness had not left man to grope his way in darkness in medical matters, they taught. He had put his sign on every remedy, so that anyone could easily discover it. Similar to the symptoms of the disease, or to the organ diseased, somewhere could be found a mark or appearance in the plants or things God designed we should use as cures. You will observe it is still the old formula of fetishism, of "similia similibıs curantur," but it has taken on a Christian eovering. Paracclsus was the latest champion of this form.*

Many of the old remedies, that are quite wortlless, stick by us still as fanily-lieirlooms. Blood-root, liaving a red juiee like blood, was eonsidered good for the blood. Liverwort, having a leaf like the liver, cures diseased livers. Eyebright, having a spot like an eye, cures bad eyes. Celandine, having a yellow juiee, eures jaundiee. Bug-gloss looks like a snake's liead, and therefore curcs snake-bite. Red flammel looks like blood, and cures blood taints. Hundreds to-day refuse to wear white flannel, which is in every way superior so far as liealth is eoncerned, beeause it is not "medicated." Little do they know that they are under the thrall of the silliest kind of a silly superstition.

'This notion of signatures, wild as it is, led to decided improvement in medical seience, by preeipitating a fight witl the ()rthodox disciples of Galen, and leading on to a long series of experinents in therapenties and ehemistry. The followers of Paracelsus did not confine themselves to drugs of vegetable and animal origin, but went on trying minerals as well. The Galenites, being strongest, had laws enated forbidding the use of mineral substanees in nedieine. Thm went on the f'ul that has left its mark on the

- lopular sicience Montlity, vol. 1, pp. 95 to 100. 
minds of many people to-day, making them decline to use mineral drugs if they know them as such. It is really a wonder they do not stop drinking water, every drop of which is charged with minerals. Salt, too, is a mineral. Why do they take it? 'The fact is that they could not live a second but for minerals. The mineral iron makes their blood red; the mineral lime constitutes the great bulk of their bones; the mineral phosphorus supplies the thinking power of their brains ; the poisonous mineral, muriatic acid, helps digest the food in their stomachs; the minerals soda and potash help digest the fatty parts of their food.

When antagonistic medical parties could not find theological grounds for a fight, they usually resorted to the cry of "poison!" Even now, in this 19th Century, that word has a terror to most people, worse than that of " $\operatorname{mad}$ dog." It never seems to occur to them that it is a purely relational term. Viewed one way, there is no such thing as a poison. Viewed another way, everything is poisonous. Weight for weight, and equally compressed, the oxygen of the air is the most deadly poison known to man. A troy ounce of oxygen will kill more men, and in quicker time, than a troy ounce of any other known substance, unless it is the new alkaloid lately discovered and called strophanthine.* Yet we cannot live without using it. In proper quantity it is a necessity of life. Muriatic acid is a deadly, corrosive poison, and this, too, is necessary to our existence, being supplied to our system in the form of salt. As salt, its work is not done, however. Too much heat will burn and destroy us, and too little will freeze and destroy, while the proper proportion aids healtls and life; so, too much or too little of any and all substances that exist acts in the same manner. of some we need more, and of others less, to maintain health. Within the proper amount, nothing is poisonous. Out of the proper amount, everything is poisonous.

This is the truth that has evolved out of the fight between the disciples of Paracelsus and Galen. In both of these camps, skepticism in time began to spread as to the truth of the formula that similar cures similar. Slowly there grew a tendency, never, however, definitely expressed, to a belief that the reverse was true; i. e., that Nature's method was "contraria contrariis curantur." Such was the condition of things when, in 1789, Hahnemann began his

\footnotetext{
* Popular Science Monthly, vol. 11, p. 328.
} 
translation of Cullen's Materia Medica from English into German, and when his mind reverted back to the fetishsystem of therapeutics. He believed he saw a similarity between diseasc-syintoms and the effects on healthy persons of such drugs as benefited them in such diseases.

Now began another therapeutic war, that has scarcely yet died out. The regular army never asserted any special therapeutic doctrine in opposition to homeopathy. The rebellious deserters affirmed the universality of what they were pleased to call the law of similars.* They nick-named their opponents Allopaths, although they knew the title to be false. There never has been an organized body of men believing in Allopathy, and no one knows this better than homeopathic doctors. Regular physicians to-day all know that some drugs do act as if in accordance with the homeopathic shibboleth. They also know that others act in just the contrary way. Small doses of ipecac will check nausea. That is Homeopathy. Large doses of Rochelle Salts will check constipation. That is Allopathy. Sulphur will arrest the itch. That is neither Homeopathy nor Allopathy. Regular doctors usc all these remedies, taking such as expericnce proves to be good, whatever the theory by which they act. + Homeopaths of late have been doing the same, and their very best men are pointing out the dishonesty and folly of adhering any longer to the title, since it has become merely a means of deluding the ignorant public. The future must give Hahmemann credit for sounding the death-knell of polypharmacy and excessive dosage; but he will derive no honor for reviving exclusive Homeopathy, which is merely a modificd reversion to fetishism. The progress of Bacteriology is fast putting an end to such narrowly limited views, and this is aided by the light shed by Erolution on the problems of Pathology. $\neq$

Modern therapeutics takes note of the fact that both similars and dissinilars are equally efficient, and that therefore Allopathy and Homcopathy only partially express the truth that is at once both and yet neither. Electropathy, Hydro-

\footnotetext{
* In the discussion which followed the leeture, Dr. W. S. Searle asserted tlat Iomeopatly is a scientifie system of medieine. No metlond ean claim to he seicntifie, he declared, which remains a mere undigested accummlation of empirical facts. Science only becomes such when we have discovered the underlying law which determines the character and relationship of the faets. All such laws are universal, and sucll a law of cure Homeopatliy claims to have discovercel. The prof lies in its practical results for seventy years.

t.itille's Therapeutices, vol. 1. 1). 33.

+ Anerican Saturalist, vol. 1k, pl). 1 to 9.
} 
pathy, and a host of other pathies, each contains partial views of truth, and all are taught to-day at our leading medical colleges.

At last we begin to see the great general principles governing the actions of drugs. Foster, in his Plyysiology, points out four :

"1st. By dilating the blood-vessels and increasing the blood supply.

"2nd. By acting as a direct chemical stimulus on the protoplasm.

"3rd. By exciting secretion in the cell through reflex action of the nervous mechanism belonging to the cell.

" 4 th. By acting directly on the nervous centers of that mechanism." *

To these might be added their specific effects in destroying germs, their anæsthetic effects in deadening feeling, their chemical effects in aiding digestive action, their osmotic effects in aiding secretion and excretion, etc.

Only within a century has true growth gone on at any decent rate. New and valuable drugs have multiplied through the services of chemistry, till now we can accomplish results that the men of a generation ago would view with astonishment. Within ten years some of the best discoveries for easing pain, relieving fever, and curing various forms of disease, have appeared, and most of them are prepared synthetically, in the chemist's laboratory. Had bigotry and intolerance not interfered with the progress in medicine during the long dark epoch lying between the Empiricists of Alexandria and the Scientific Physicians of the 19th Century, millions on millions of lives might have been saved, and billions on billions of hours of human agony quenched. Where we now are, they should have been, long before the time of Avicenna. $\dagger$ We would then have been where our children of a thousand years to come will be.

In this hasty retrospective view of the development of Medical Science, you will observe that only the linear path of Therapeutics has been followed. We have traced the tree from its base to its apex, only incidentally referring to

* Teters' Physiology, p. 361.

† Warfare of science, p. 44. 
some of its branches. Evolution, however, as you are aware, is differentiation. 'To early man, therapeutics was all there was of Medicine. Practically, to most people in our own day this is equally true. 'To medical men, on the contrary, the vastness of the branches is almost appalling.

Quite early, surgery began to differentiate, and cases that primitive ignorance thought to be curable by medication were found to give way only to an operation. Steadily lave such cases multiplied, and with the progress of knowledge more and more of such are discovered. Surgery itself las given off numerous branches to the care of specialists, until important facts have so multiplied that no living man can longer master them. At a very early date surgery gave birth to anatomy as a distinct branch of science, and the bad treatment this received at the hands of theology lias already been referred to. Galen tells us that the first cultivators of anatomy constituted a distinct social caste.* They never wrote out discovered facts, but kept them within their own families ly tradition. In his day, much knowledge had been acquired, thanks to the liberality of the earlier Egyptians. They had not, however, up to this time, been able distinctly to distinguish muscles from nerves in their various finer ramifications. 'They knew that the great nerves of sensation came from the brain. They knew the principal bones, muscles and viscera. 'They did not know of the solar plexus and its system of nerves.

The study of anatomy gave birth to pliysiology as a natural sequence. Errors in the former, led to the wildest kind of conclusions in the latter. Until the discovery of the relations of veins and arteries to each other and to the heart, but little that could be dignified by the title of seience was possible here. 'Through all the dark years of Galen's supremacy this discovery was not made. Mondino in 1315, came near it. Tesalius, in the middle of the 16th Century, traced them out; and for telling the world that Galen blumlered he was persecuted most mercilessly, but fortunately escaped the fate of his contemporary Servetus, part of whose heresy was the same.t Poor Servetus was a heretic to Christ as well as to Galen, and was humt at the stake therefor. Jater on, Sylvius discovered the valves of the veins, and their alsence in the arteries, while

* History of the lublurtive ficiences, vol, 2, p. 440.

tOpl. Cit., 1'1', $45,446$. 
Fabricus showed that all valves were turned toward the heart. William Harvey, at the beginning of the 17th Century, opened upon himself the flood-gates of theological abuse by making a remarkable discovery, while experimenting with these valves. He demonstrated the circulation of the blood, which in those days was an exceedingly impious suggestion, as it showed how men and animals could live without the incessant tinkering of the Almighty to keep them alive.

From this point, physiology swept grandly on, and it was aided by innumerable discoveries in the new science of Chemistry. 'The laws of digestion, respiration, secretion, excretion, reproduction, nervous and muscular action, motions of the chyle, etc., were soon discovered. On the establishment of Physiology, Pathology appeared, and the anatomical lesions of disease became a special line of study. Each new branch, as it came forward, reacted upon and aided in the advancement of all its predecessors, as well as, in time, of its successors. Inflammation, suppuration, extravisation, new formation, mal-circulation, degeneration, and kindred topics, were studied as to their causes and methods of cure. This gave rise first to Histology, and afterwards to Bacteriology, the last of which is at present making a great deal of stir in the earth.*

I have not stopped along the way to show how therapeutics begat Materia Medica and Chemistry, nor how they in turn evolved Pharmacy; but these, and many more, constitute branches from the developing tree. Beginning as an indefinite, incoherent mass of chaotic facts and fancies, slowly it has grown to its present august proportions, until it now appears as a definite, coherent mass of useful knowledge, differentiated into a large number of quite distinct and orderly departments of science.

Before the advent of the last named branch, the race had become conscious of the fact that, for some reason, cleanliness was necessary to comfort, and to freedom from diseases of a contagious character. The reason was quite unknown. Plagues and pestilences of various kinds har shown a sort of affinity for the filthy, and while the scythe of death did not cut quite a clean swathe along such a line, it succeeded quite well for an approximation. Our deluded forefathers

* Vide Cruiksliank"s Practical 13acteriology, Sternberg's Jagnin, Belfield's Micro-organisms, etc. 
for a long time failed to see this, and attributed all great epidemics to blasphemy, infirlelity, and various forms of religious heresy. Even diseases that were due to the universal unchasteness of the people wcrc charged to blasphemy, Sabbath-breaking or heresy.* "The very existencc of such a disease in an epidemic form is proof to us to-day that priests and people, high and low, rich and poor, were, on a grand scale, guilty of immorality of the worst type; and yet they blamed God for sending the disease as a punishment for their not keeping the Lord's day holy! To prove their penitence, they built hospitals and churches, dedicating them to Saints, and prayers ascended in public places for relief, while they still went on in their crime and died like rotten sheep.

The sanitary condition of their homes is scarcely creditable. The working-classes, especially, were indescribably and abominably dirty. Here, for instance, is a pen-picturc of the 16th and 17th Century homes of England, as given by the Editor of the North British Review many years ago: "In times gone by, and even later than Shakespeare's, our floors were the earth only, as in many cottages now, and we used the broom or brush littlc, and threw the garbage down, allowing it to lie and rot and become so vilc that we invented the device of covering it over with straw so that it might be trodden down, as the cattle makc the manure in the straw-yards. The earth of the floor was overweighed with putrid matter, and much of it came into the air of the room; but the formation of nitre, or saltpetre, began, and oxygen accumulated rapidly, and rendered even these houscs habitable in a way." $\dagger$ The author then goes on to tell how, after layer upon layer had been piled feet deep, and even human excreta piled in abundance in the mass, soldicrs would be sent to a village on a pleasant day to compel all the inhabitants to go into the open air while they cleaned out their pens for them. By lixiviating this mass of filth, they got the saltpetre to make their gumpowder, as pay for their labor. $\neq$ When a plague came upon thesc people or their cattle, they drew the sign of the cross on the doors, with tar, as a protection to the inhabitants.

With the development of chemical knowledge, Carbonicacid gas, carbon monoxide and sulphuretted hydrogen came

* Western I)rugrist, Jan. 15, 1890, 1. 5.

+ North I3ritisll Review, vol. 4,1 , $\$ 65$.

$\ddagger$ Ibid, 1). 47 . 
in for blame as factors in the causation of disease. Sanitary science, therefore, began its development along this line, and fortunately, although the actuating ideas proved at a later date to be in the main erroneous, they led on to actual progress. The laws of ventilation were thus discovered, and the benefits of pure air came to be appreciated. Not, however, until bacteriology evolved into a distinct department of science, did we have clear ideas as to how pure air and pure water operated in bringing us health. Then the mistakes of sanitarians, during what we may for convenience call the Chemical Era, began to be righted. We discovered that chemically and mechanically filthy air, and chemically and mechanically filthy water, may be relatively almost harmless, while air and water that, to all our tests, would seem absolutely pure, might deal death and destruction to us. The old rule that pure air and pure water are necessities for the maintenance of proper health still holds good; but we now see that there are apparent exceptions that even seem to reverse this truth. It all depends upon the nature of the germs present. These germs are minute, microscopic plants (not animals), which, like all other forms of vegetable life, require more or less decomposing materials to grow upon.* Their numbers, kinds and natures are legion. Some will grow on acid, but not on alkaline or neutral soil. Others will grow on alkaline soil only. Still others on neutral. Some grow at very high temperatures, and perish at low ones. Others are in their element at low temperatures, and die at high ones. All sorts of poisonous solutions have special kinds, capable of maintaining healthy growth within them.

Anything capable of killing bacteria of all kinds, must necessarily be of such a nature as will kill everything having life. The adaptations of all bacteria cover and go beyond every adaptation of man, so that, in all directions, man must be killed easier than bacteria are. This, remember, is only true of them as a total. Take any one kind, and man's adaptations transcend its own, so that it is much easier to kill it than man. Of the innumerable kinds known, only a comparatively small number are able to grow in or upon the human body as a soil. These have their choice of parts. Some like to grow on the skin, while others prefer mucons membranes, and still others pre-

* Gradle's Germ Theory of Disease, p. 6. 
fer other tissues of the body. Of those that are found in or upon the human body, but a small proportion are in any way responsible for disease. These we distinguish as pathogenic. Of all pathogenic micro-organisms (or, as abbreviated, microbes) those of consumption are perhaps the worst.* Now we know they exist, and sanitary science clearly points out certain duties for us to perform, for selfprotection, that are yet sadly neglected. People get consumption only by contagion from consumptives. It is not hereditary. Weak lungs are hereditary, but weak-lunged people, kcpt away from consumption-germs, will never take the disease, even if their fathers and mothers, sisters and brothers, uncles and aunts all died from it. If they breathe the confined air of the consumptive's room, they will take it; if they eat under-cooked meat from consumptive cattle, they will take it; and if they drink milk from consumptive cows they are likely to take it. If their consumptive friends spit indiscriminately around, and the sputa drys and is wafted into the air for them to breathe, they will take it. Sanitary Science demands the burning of the consumptive's spittle, the boiling of all doubtful milk, and thorough cooking of all doubtful meat, and the perfect ventilation and thorough cleaning of walls, ceilings and floors, of all rooms once occupied by consumptives, with deluges of water.

'The pathogenic microbes of typhoid-fever bear some resemblance to those of consumption. 'They develop in glands of the intestines known as Peyer's glands. The only source of contagion from such patients is in their dejecta. In country places, this disease is spread by the spores being washed through the soil from their outdoor closets down into the nndererround streams of water that supply their wells. Not only typhoil-ferer germs, but Asiatie cholera, the summer eholera of children, and a large number of minor ailinents characterized by diarreas, are fropalgated in the same way. Comntry farmers, in Watering the milk of rity customers, send these diseases into the city through this chammel. 'This is another reason why milk of unknown origin should be boiled before drinking.

In large eities, the ontrlon-closet nuisance is albated. and the bath-1oom closet takes its place. Here a system of

- ('ruikshank's liacteriologr, 1'. 1is. 
sewerage connects miles of houses together, and the germs of intestinal diseases in abundance find their way from house to house, unless the plumbers have done their work faithfully and well. I say the germs of disease do this. Scientifically, I mean the spores or seeds of such germs as develop in this manner. 'The term germs, of course, is here used as synonymous with micro-organisms. Sanitary science insists upon an arrangment of closet, bath and wash-basin pipes that will allow no back pressure of gas from the sewer to force its way into the house and carry such spores.* Sewer-gas is not always deadly or seriously dangerous. This is proven by the fact that men work in it from week to week without impairment of health. $\dagger$ It is always injurious to some constitutions, and is sometimes so to a large number of people. The less of it, therefore, that enter's a house, whether disease-laden or not, the better for the average health of the community.

Scarlet-fever germs come from milk, are carried in clothes, toys, money, books, newspapers, etc. Dogs, cats, and birds, are now charged with transmitting them. Measles, smallpox, whooping-cough, and kindred diseases, journey from patient to patient in similar ways. Bed-bugs are probably very active carriers of contagious diseases. Many investigators are strongly inclined to blame mosquitoes for transmitting intermittent and remittent fevers. You all know the sticky and transmissable character of lamp-black formed by a smoky lamp. You get it on your finger's first, and soon somebody observes a speck on your face. It is next borne to your clothing, and, whenever two surfaces toucl, if one has it, the other gets a little. Disease-microbes are like this, - an impalpable powder that every breath of air can blow and every contact of surfaces divide. Hand gives them up to hand, coat to coat, lips to lips, and even the points of the finest needles are frequently laden with and transmit them to the cloth sewn. So small are they that thousands in a single pile cannot be seen by the naked eye. As one grain of wheat will, in a season, proluce fifty grains, so one germ, multiplying rapidly every minute, will form legions in an hour. Of course,

* Michigan Board of Heal th Report, 1882, pp. 334 to 336. Ibid, pp. 213 to 217.

t In the discussion following the lecture, Mr. Charles $r$. Wingate, the Sanitary Engineer, questioned this assertion of the lecturer, and affirmed that $\mathrm{ex}$ perience proved all kinds of sewer-gas to le poisonous. Different eonstitutions, however, differed in their ability to resist these poisonous influences. 
like wheat, they do not multiply when dry, but only in proper soil, with proper temperature and moisture.

Sanitary Science seeks to cheek the growth of these germs and to destroy those already developed. To fight an invisible foe is diffieult work, but we are steadily improving in our ways of doing it. The general public are little beyond the Middle $A$ ges in their notions about how to give them battle. True, they no longer depend on phylters, charms, erosses, and prayers, for relief. 'They do, however, maintain faith in bad-smelling earbolie aeid, tar, and other equally useless and abominable so-called disinfectants.* Let every person, within hearing of my voiee to-night, learn that nothing will destroy the germs in a room, or save themselves from eontagion, so well as a deluge of water sueh as would elean a shower of lamp-black, and plenty of pure air, to blow them out of the room, while thorough dusting and sweeping, with wet brooms and dusters, is being done. You ean kill germs, that are not too dry, by any means that will kill the hardiest plants or animals. Nothing short of this is of the least avail. $\dagger$ When your disinfecting has killed every eroton-bug, bedbug, fly and plant in your room, some good has been donc in proteeting yourself and ehilhren from disease. 'To buy a few eents'-worth of earbolie aeid, ehloride of lime, l'latt's ehlorides, or any other disinfeetant, leave it open in the room, and expeet immunity therefrom, is to believe in the impossible. Sueh ideas belong to the age of magie. We but play the ostrieh in doing this, and think ourselves saved from the enemy if our heads are eovered. 'These disinfeetants are exceedingly useful as auxiliaries to floods of water, or for the preparation of strong solutions, in which to eleanse infeeted goods. $\neq$ 'To expeet any other good from them is folly.

Within the last deeade progress has been made with great rapidity. Indeed, the gain is more than in one thousand years immediately after Galen's time. A doctor who took his degree ten years agro, and who has not striv'n to keep abreast of the times, is alrealy an antiquated fossil. Ile knows nothing of the way in which the comparison of the anatomy of 1 en and animals has shown how hmolreds of diseases are due in great part to weaknesses inherent in

* Medical News, Vol. 4f, p. 14t.

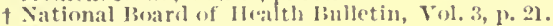

1 Merlical News, Vol. Hi, 1) 1 H. 
the race, and brought about as penalties of progress. Progress is not all a blessing. It demands its price, and sometimes a very grave one. Comparative anatomy tells us of incurable troubles, and why they are so. It points out weak and dangerous conditions, and shows how to avoid and overcome them. The non-evolutionist physician invariably overlooks these conditions, and his patients suffer accordingly. Materia Medica and Therapeutics lave become so far generalized in this decade as to show how drugs of certain qualities are composed of molecules having atoms of certain definite weights. The therapeutic qualities of drugs are functions of their atomic weights. Doctors knowing this law have a guide as to the claims of certain drugs in certain diseases. Those who do not know it must risk pure empiricism, without a guide.

Botany, too, has supplied its aid in showing how therapeutic qualities of a given type run in veins among allied species and genera of plants. 'The doctor who knows no botany is misled by pretenders who claim great things for new remedies. Every few months such discoveries are announced. A short time ago it was gleditchine. Shortly before that it was hopine. Hundreds of physicians prescribed these humbug remedies. The plants they pretended to come from belong to places in the evolutionary order that indicated positively that they were frauds. In organic chemistry we see similar generalization. Alcohols with similar properties have similar compositions. Chloral hydrate, paraldehyde, and other hypnotics, group themselves along a certain line. A knowledge of organic chemistry enables a physician to pass a fairly good judgment in advance, upon any remedy, and keeps him and his patients from being duped by advertising pretenders. Chemists lately have been working along the true lines, and making wonderful and most valuable discoveries - if we really can call them discoveries. When they know in advance what they are going to find by following a certain path, it is scarcely correct to call them discoveries, even if no living being had ever seen them before. Of course, the way they travel is dark to all senses but the mind, and much knowledge, care and skill are needed to tread the before untrodden, but predicted, path, safely.

Bacteriology has also revolutionized pathology, and he who clings to the ideas of ten years ago cannot do his 
whole duty to his patients. We now know that diseases, like everything else, are relative. There are no hard and fast lines of symptoms to any disease. We have found that the microbes do not direetly cause the symptoms in a contagious disease, but the poisons they produce. These poisons we eall ptomaines. Just as a small dose of whiskey or morphine will produce light symptoms, so a small dose of ptomaines will do the same. As the system can become accustomed to whiskey and morphine, so that large doses are scarcely able to produce any symptoms, so it can become accustomed to the piomaines of disease. As the microbes cannot develop unless the ptomaines seriously affect our bodies, to become used to their poisons is to be able to resist them. 'This is how vaccination aets. It makes your system used to the ptomaines of smallyox, so that the germs of that disease find it difficult or impossible to grow in you. This is why one attack of a eontagious disease makes us less liable to take another.* This is why, of ten persons exposed, only one seems to take the disease. Notice, I say seems to take it, - for more people take contagious diseases than we think. Doctors not alreast of the knowledge of the last ten years do not know this, and take light cases of scarlet-fever, measles, smallpox, etc., for simple eolds, or fits of dyspepsia, and foolishly treat them as such. Scirlet-fever, and the rest of these diseases, exist in all degrees of seriousness, from a simple headache to the worst anginal types. They show no exuption, nor other sign, and yet are as certainly searlet-fever as if they did. Measles may exist merely as watery eyes and impaired appetite. The victims never dream of their having such diseases.

The last decade has also shown us that diseases have a selective affinity for certiin parts of the boly, and the name given to the disease will be no criterion as to its nature. What we call Bright's disease is sometime's measles, sometimes scarlet-fever, sometimes smallpox, sometimes consumption, sometimes inmoral disease's that have centred their forces in the kidneys because they are the wak part of the patient's organism. What we call pmemonia, diphtheria, rheumatism, pereanelitis, enelocarlitis, meningitis, plenrisy, and all other local affections, may

- Inetor firalle's Cierm Theory of alisease, 1. 1in1; T. L, Agricult. lieport, $1 \times+1-2,1,29 \%$ 
be any one of a dozen troubles that happen to have attacked the special organ or part that gives the name. Every physician has seen pneumonia that was what we call an extremely bad cold; he has likewise seen cases that were la grippe, others that were scarlet-fever, still others that were measles, etc. The lungs were simply the weak organs which, in that particular patient, broke under the strain; and, because it was the lungs, we called it pneumonia. Scarlet-fever, with one patient, will give rheumatism; with another, pneumonia; with another, Bright's disease; with another, diphtheria; with another, heart-disease; with another, pleurisy; with another, inflamed glands. As no two wagons, under very heavy loads, will break down in just the same place, so no two persons with the same disease will develop the same symptoms. Expose fifty men to a ducking, on a cold day, and let them go home with wet clothes, and you will soon see how diverse the effects of the exposure will be.

The wise physician is aware of the complex problems every pathological condition presents, and governs his treatment accordingly. His patient may be likened to a ship in a storm, and surrounded by reefs and shoals. He is the pilot whose duty it is to carry that boat safely past rocks and sand-bars whereon it might be wrecked or stranded. Every rock and bar must be known to him, and the helm must be kept under his steady grasp. He cannot stay the storm; but by his skill and courage he can save the ship until it is past. The foolish old woman, or meddlesome neighbor, or the foolhardy parents, friends or guardians of a patient, who give medical advice, are ignoramuses that do not know a single danger, but believe they have a remedy, or method of holding the helm, that will stop the storm itself. The physician's remedies are to protect the life at danger-points. If the family is heir to heart-disease or rheumatism, his medicine to cure scarlet-fever is an anti-rheumatic remedy. If the danger is kidney-disease, he eases in advance the strain on the kidneys. If weak lungs or scrofulous glands "run in the blood," his "cure" for scarlet-fever is a protection to these. See that insane idiot who says, "Oh, your trouble is the same as mine, and my doctor gave me so and so; do try it!" He is asking the patient to leave himself to the tender mercies of the storm, while he holds the helm in a way to avoid a rock 
that does not exist in that family's sea. 'The stupid blunderer thinks he is staying the storm of disease - a thing 110 man has yet done, except partially in possibly two diseases only. Avoid him, if you value your own lives and the lives of your sick friends. Avoid, too, the doctor who never inquires into the disease-tendencies of your family, or the past troubles of the patient, and who has thereforc few questions to ask. A family-doctor of long standing has mastered all these facts in advance, and no longer. needs to ask; but a stranger who pretends to know without asking is a dangerous pilot.

'The proper practice of the art of medicine depends upon the Science of Medicine. The Science of Medicine is an inductive science in all its parts. The part known as diagnosis is especially so. The doctor has no magic way of finding out what ails a patient, or what his latent tenlencies are. He gets at his facts just as a detective does who wishes to run down a criminal. The more facts he gets, the more likely is he to be right in his conclusions; and the fewer he gets, the more likely is he to err. A stupid physician will make a snap diagnosis on one prominent fact, and many of this kind of doctors dejend upon the unskilled diagnoses of the patients themselves or of their friends. A single falschood, or misstated fact believed in, will lead the most skilled physician into error, and condemn the patient to the wrong treatment. 'That falsehood weakens the whole chain of facts, and cverybody knows that the strength of any chain is only the strength of the weakest link. A detective makes numerous guesses as to how a murder or a theft occurred, and finally adheres to the guess that agrees with all the facts. This guess generally is the right one. Let any person introduce misleading cues, and he will be totally unable to right himself, until he discovers that he is being deccived. It is just so with a doctor. If he is told a falsehood, he cannot possibly discover what ails the patient until he first discovers that he has been misled. No doubt an ocenlt power of getting at truth would be superior to this method, but we have discovered that the belief in occult processes is an ignorant superstition. During the dark ages, the pretense to occultism was greatest, and the evidence of knowlcdge loast. Then progress was at a standstill; now it is rushing with dizzy speed. The masses of men still be- 
lieve that doctors have some magic way of getting at a knowledge of disease, and a miraculous way of curing. 'To be able to do what nine hundred and ninety-nine out of every thousand people believe their doctors can do, would require more knowledge than could be mastered in a thousand years, with a brain as retentive as that of a child of fifteen and logical acumen as fine as that of a Newton.

Physicians are praised for things they never do, and. blamed for results of which they are innocent. Where their work is most laborious, and their mental anxiety most intense, their pay, as a rule, is abuse only, and they are denounced and vilified without mercy. Every doctor has this experience. There are no exceptions. The denser the ignorance of the patient, the greater the abuse. And yet no class of men can anywhere be shown with a less selfish record than that of the physician.

Medicine in all ages has attracted into its ranks the most self-sacrificing members of society. As a science it was born in altruism. To this day it offers the greatest opportunities of any department of life for the practice of the most ennobling graces of character. 'These constitute a primary cause of its evolution. To pass this phase unnoticed, would be to do Medical Science scant justice. Medical men stand alone in the earth among all others, striving with their whole might to extinguish their own business. They preach temperance, virtue, and cleanliness, knowing well that when the people come to follow their advice their occupations, like Othello's, will be gone. They establish Boards of Health to arrest the spread of disease, while well aware that such sanitary measures steal money from their purses. How well they succeed, is shown by official statistics. The number of deaths from contagious diseases are directly proportioned to the certainty of the doctor being called. Nobody ever fails to send for a plyysician in typhus fever. Only six persons in a million now die of this disease. Many more used to die when no effort toward its suppression was made. Whoopingcough seldom frightens patients, and neighborly old ladies of both sexes give advice. As a consequence 428 in a million die of this disease. Measles, being a little more serious, needs the doctor oftener, and only $3+1$ in a million die. Scarlet-fever is still more alarming, so that medical advice is more in demand, and 222 in a million die of 
it. Diphtheria frightens still more, thus assuring the doctor's presence oftener, and 168 in a million die.* It is thus with every disease: the fewer it kills, the more people fear it; because, if they did not fear it, they would play the fool, and give it a chance to kill more people.

If bakers, grocers, dry-goods men, carpenters, tailors, and members of all other lines of business, gave as much of their labor in charity as doctors do, poverty would instantly be wiped from the earth. Nearly one-half of their time and labor is given freely to the poor, without money and without price. All dispensary work is free. All hospital work is free. All that apply to the Society for Improving the condition of the Poor, are treated free. Every physician known to this lecturer has many families that from year to year are treated free. No one can be sick in any city in America, however poor, and not get medical care if he asks for it. Doctors do sometimes refuse to take special cases, because of the legal restrictions and responsibilities that, like Damocles' sword, hang over their heads. Such cases will be received in the dispensaries and hospitals, so that none need suffer. Let every other person, in all occupations, give nearly half his time and labor to the poor, and what a revolution it would work. Like a pair of Siamese Twins, Altruism and Medicine have always been linked together. The majority of the devoted heroes of science have been medical men. They suffered and died to redeem the race.

\footnotetext{
* New York World, quotation from St. James Gazette, Feb. 5, 1890.
} 


\section{EVOLUTION OF ARMS AND ARMOR}

BY

JOHN C. KIMBALL 


\section{COLLATERAL READINGS SUGGESTED.}

The Geologies of Lyell, Dana and Le Conte; the Botanies of Gray and Sachs; Owen's "Manual of Palæontology"; Nicholson's "Ancient Life-History of the Earth"; Darwin's "Origin of Species," chap. iii, and "Descent of Man," chap. ii ; Homer's "Iliad"; Grose's "Military Antiquities"; Mcyrick's "Critical Inquiry into Ancient Armor"; Farrar's "Military Manners and Customs"; Demmin's "History of Arms and Armor"; Boutell's Translation of Lacombe's "Arms and Armor"; Scoffern's "Projectilc Weapons"; Chesney's "Past and Present State of Firearms"; Beckman's "IIistory of Inventions," Vol. II., p. 535; Buckle's "History of Civilization," Vol. I., chap. iv, Vol. II., chap. ii ; Hallam's "Middle Ages"; Smitlı's "Wealth of Nations"; Grote's "History of Greece"; Lecky's "History of European Morals," Vol. II., pp. 262-290; Gibbon's "Decline and Fall of the Roman Empire"; Proctor's "History of the Crusades"; Scott's "Waverly" and "Ivanhoc"; Speneer's "Principles of Sociology," Part V.; Comte's "Positive Philosophy," Vols. IV., VI.; Fox's "Book of Martyrs", Proudlion's "What is Property?" Reports of the U. S. Secretaries of the Navy and of War; "The Army and Navy Jourual"; "Transactions of the Amcrican and Forcign Peace Societies." 


\section{THE EVOLUTION OF ARMS AND ARMOR.**}

Ir is a well proclaimed, though not always a well practised maxim of good citizenship, that the legislator, the reformer, the political economist, the voter, everybody who is to have anything to do with discussing and directing the affairs of society and the State, ought to have, as a preparation for it, a knowledge of history, - that is, of what other men in other days have done and have tried to do in the same great fields. Equally important is it, also, as we are now beginning to see, that such persons should have, as a requisite for their fullest intelligent action, a like acquaintance with science, and especially with those departments of science, as zoology and palæontology, which relate to what animals and plants have done, and with their great interpreter, Evolution. Human history is but the last chapter in a vast volume, many chaptered, of the world's transactions, impossible to be understood without reading in its preceding ones what our ancestors older than man have been doing; human society, as Mr. Spencer has so admirably shown in his Principles of Sociology, is but the enlargement and further development of organisms spread all through the animal and vegetable kingdoms, on which Nature has been at work for millions of years. The root and germ not only of man's body, as seen in the oldest vertebrate fossils, but of man's mind, and of all that mind does and can do both individually and socially, have existed in the world's great life-tree from the start, - must have done so, according to Evolution, - and have been contimually unfolding themselves, if not at first as flower and fruit, yet long ago as shoot and stalk. There is hardly an experiment lumanity is now trying in mechanies, art, government, labor, capital, education, sociology, and even ecclesiasticism, - some of them with its own children as the materials, - that Nature has not already tried at least the principles of, over and over, in the cruder forms of matter, and with the cheaper materials of animal and vegetable

\footnotetext{
* Copririatr, 1890, by James H. West.
} 
structure. And, such being the case, who cannot see that to study these,-which have succeeded and which have failed, and what have been the causes of their successes and failures, and what the philosophy is which lies behind them, - would save the statesman, the reformer and the citizen many a costly experiment on human beings, and would open the way for the intelligent choice of many an agency and path of progress now lying, it may be, right before their eyes, but which, as things are, they are groping for in utter blindness. or trampling down in utter contempt?

One of the great questions that is before our country to-day, and that every country has to meet, - one that involves millions of dollars and the principles, to some extent, on which is to turn the whole future of its civilization, and which in many respects is the most difficult that statesmanship has to deal with, - is what its people shall do in the way of arms and armor for their protection and defense. And it is a problem, too, that Nature, not less inperatively than nations, has had to deal with all through the past. War and the wager of battle, weapons and the wounds of conflict, are not the accident and disease of her original economy, not a human lapse and folly, but a constituent element in her very system of things. The moment she set her creatures on earth, even in their lowest forms, exposed to the clements and compelled to get their own living, most of them, by preying on each other, it became necessary, if their lives were not at once to be extinguished, to provide them with some means on the one hand of assault, and on the other of defense,- a necessity which is bound up inseparably with those two great principles on which all organic evolution is based, the struggle for existence and the survival of the fittest. Devices to meet it have played a part in her economy second only to those for alimentation itself; are a field in which she, too, as much as any statesman, has had to tax all her resourees and lay under tribute all her skill. The rocks below the earth's surface are a vast gallery in which, while the muscles, stomachs and brains of her children have perished, the arms and armor wit? which they fought have for ages been preserved, as in our musemms above its surface are the swords, shields and coats-of-mail that on human ancestors, now dust, wore to battle in their brave days of old. And 
the result of these long experiments as to what are fittest, and have helped their users to be fittest also, is not only of itself one of the most beautiful chapters in the Book of Evolution, but one that pours a great flood of practical wisdom on the problems of our time as to the true principles to be followed in securing national, social and even religious survival and supremacy.

The first effort of her Vulcan fingers was in the line of protective armor pure and simple, the encasement of animals and plants in a mere hard outside covering. It is what the exposure alone of their original protoplasm to water, sun and air, aided by the secretion of mineral matter on the surface, and intensified by the survival and reproduction of the animals and plants which had it most, would tend naturally, in strict accordance with Darwin's laws, to produce; and it is now seen to advantage in the sea-urchin and star-fish among Radiates, in the oyster and clam among Mollusks, in the turtle and alligator among Vertebrates, in the eggs of birds, and, to some extent, in the skin and hair of all animals.

It was a form, however, to which Nature could not confine herself, especially in the animal kingdom. If live things were to live, either on each other or on vegetables, they obviously must have some means of breaking through each other's hard covers and getting at their inside meat. The means came to them in the form of cilia, tentacles, suckers, claws, mouths, horns, jaws, tails, tusks, teeth, beginning, perhaps, in such mere thread-like extensions of the inner protoplasm as are now seen in the rhizopods, and culminating in the apparatus of such magnificent vertebrate carnivora as the lion and the tiger.

But such weapons alone, with only the old protoplasmic bodies to wield them, would not have been enough; would indeed have been of less value to them than even their old outside covering. To have them of any real use Nature had to develop, along with them, bones, muscles, nerves, senses, brains; and, in some of their owners, the habit and power of association, - all that constitutes a highly organized internal structure. These were organs and faculties which became, in their turn, a new species of armor still more interior; became at any rate what had the same use as armor, - the quickness of eye that could discern the 
foe, the activity of limb that could fly to it, from it and around it, the shrewdness of mind that could observe its habits and select the best points for its attack, and the instinct of co-operation that conld join forces in coping with it, differing only in their fineness from the sharpness of the tooth and the strength of the claw. And thus were introdnced the two great principles that Nature has used in all her arming, and that have played and are still playing a most tremendons part in her econony, - their distinction being not exactly that of defensive and offensive weapons, for both, when need required, could be used defensively, but that the one had its chief value in its own outside strength, while the other depended for its efficacy on qualities comnected with its possessor's inside development.

Equipped from her arsenal with the varied arms and armor which embodied, some of them one of these principles almost exclusively, and some a mingling of the two, Nature sent forth her myriad creatures into their great life-battle, world-wide in its field, where the issue has been not only which of themselves, but which of their weapons and of the principles on which their weapons were made, would prove the fittest, and best help their users to survive. During the long geologic ages they were all, and especially the outward kinds, enormously developed both in size and strength, and their underlying philosophy was tested in the severest way by contests alike with each other and with the world's equally ferocious natural elements. 'The Orthoceras, a huge cephaloid mollusk of the lower Silurian rocks, had a thick, hard, cylindrical covering, twelve to eighteen feet long and at its base a foot in diameter. The Dinichthys, a Devonian ganoid fish some thirty feet long, was protected about its head with a suit of massive articulated armor that a camnon-ball could hardly have crushed. Among the famous reptiles of the Jurassic and Cretaceons ages, - the Icthyosaur, Megalosaur, Mosasaur, Iguanodon and others, - some were fifty, sixty, and a hundred feet long, plated over with thick scales for defense, and armed for attack with claws hooked back like sickles, with long projecting tusks that shut down by each other like clasped fingers, and with sharp, glistening sabre-like teeth, sometimes four rows of them, and two hundred in number, indeed "monstrous and prodigious things worse than fables 
yet have feigned." And the age of Mammals had its Mastodon with tusks twelve and fourteen feet long, its Glyptodon with a solidified bony armor on its back nine feet across and weighing nearly four thousand pounds, its Megatherium with clawed feet a yard in length, and its Machairodus, a tiger whose open mouth was an arsenal set with natural swords.

How terrible must have been the contests of such monsters with each other, and the slaughter made by them on their weaker and less protected neighbors, - most truly "Nature red in tooth and claw with ravin"! How different the scenes of their world from the peace and repose that Miltonic poets have loved to picture as the condition of the earth "before the advent of man and sin"! The sea was alive with animal frigates, the land with self-moving Krupp cannon, the sky with literally "flying artillery." The modern question between steel plate and steel shot, tried of late by the Merrimac and the Monitor, was tried of old as a principle between ivory tooth and horny scale by many a Megalosaur and Mosasaur, carnivore and pachyderm, each increasing, as now, the force and size of the assailing weapon, as the other increased the thickness and strength of the defensive plate. The physical stuff of which a Nelson and a Napoleon, a Paul Jones and a Farragut, were afterwards made, cruised, perhaps, around the headlands of England, and marched, perhaps, across the wilds of Europe and America, ages before their day, as Dinichthys and Dinosaur, Machairodus and Megathere. Battles of Trafalgar and the Nile, of Marathon and Waterloo, deciding the fate of great animal kingdoms, were fought, to begin with, under far off Triassic and Mesozoic skies. And whether or not 'Tennyson's lines are true of the future, -

"And there rained a ghastly dew

From the nations' airy navies grappling in the central blue,"

they have been true of the past, the "airy navies" being those of such great reptile birds as the Pteranodon and Pterodactyl, the latter with a wing-spread of twenty-five feet.

What has been the result of this long, ferocious war, as related to the rarious kinds of armor used by its combatants? The records of the rocks conclusively answer. It has been the overwhelming of nearly all the races and 
orders that were provided with its massive outside varieties, and the survival and supremacy of those that have been equipped with its inner and finer forms. Orthoceras and Dinichthys, Megalosaur and Megathere, Icthyosaur and Iguanodon, monsters armed with shell and scale, tooth and claw, enormous and terrible, have all without exception gone down in the great life-battle; while those whose weapons were the finer skeleton, the keener sense, the quicker nerve, the larger brain and the stronger social instinct, faculties good for peace as well as war, - and some that apparently have had no outward fighting-apparatus at all, nothing but inner shrewdness and wisdom,- are the races that have been victorious, and survived. Even the armed ones whose descendants are still on the field, as the lion and the tiger, the eagle and the shark, have evilently held on by virtue of their quickened inner powers, rather than through their ontward strength; or else, as with the oyster and the clam, by reason of their insignificance and mimprogressiveness, rather than because of their hardened shells. And man, the one that las progressed most of all, that has become the head of the animal kinglom and the lord and master of the earth, - he is the one that, outwardly, is the most unweaponed and defenseless of all; the one whose claws are taper fingers, whose skin every mosquito can puncture, and whose armor of thought lias no size or weight whatever.

What is the reason of this result, what the underlying causes why inward development should thus prove itself more effective in the struggle for life than outside strength? They are not hard to find. 'To begin with, the animals that trusted to exterior arms and armor were less able to alap,t themselves to the ever-changing conditions of the earth and of food supply, than those whose weapons were within. The very things which protected them against one sit of elements made them often the more exposed to he wereome by another set, - as the heary fur, so warm for Winter, becomes an intolerable burden under the heats of summer. 'The endowments that were eflicient against one set of enemies. hy rason of their bulk, were inefficint against another sct ly reason of their unwielliness, - as the huge frigates, so jowerful against earh other hroadsicle to, are helpless against the lively little ram that rakes them turning round. And as the struggle went on betwern thinker 
plates on the one side and more formidable jaws, claws, teeth and limbs on the other, their weight and size became of themselves in time their owners' worst foes, sinking them in morasses, stranding them on bars, exposing them to be overwhelmed with sudden floods, and at last bearing them down to earth and to extinction by simply their own hugeness. On the other hand, with some disadvantages, the development of the animal's inner powers and parts had, in all these directions, a corresponding gain. IVhen Nature invented her backbone, and put her limbs, flesh, senses, and so many of her soft and vulnerable parts, on its outside, it looked at first like a great military mistake, - like the building of a fort and the putting of its garrison outside of its walls rather than within their protection. But what a tremendous part this very arrangement of it has acted in all her subsequent operations. The mineral matter its possessors needed to carry about was, in proportion to their size, greatly reduced by it, alike in weight and bulk. How flexible it has proved in the line of adaptations, - ranging all the way from the fish in the sea to the bịd in the air, from the snake that crawls to the man that walks, and from the uses of war to the needs of peace. What beauty and dignity it has gathered around it in man's kingly stature and in woman's queenly grace; and how fitly, in the higher conflicts of civilization, it lias become the symbol of the statesman's crowning attribute, _ his " having backbone." So with each of Nature's other steps in the same direction. What was the sharp tooth as a help, either in defense or attack, as compared with the sharp eye? What the huge limb, clumsily brought down on its object, in contrast with the quickened nerve which, in the same time, with a smaller limb, conld rain a score of blows against the selected weak parts of its victim? What the chance of the creature with the strongest claw and the widest range of wood and sea, in its contest with hunger and cold, as measured against one with the hand and mind to weave every fibre that grows into robes of warnth, turn every force of Nature into weapons of war, and lay every land that blooms under contribution for food? If the inner derelopment lost sometimes in its direct fitness for fighting, it made up for it a thousand fold by its larger fitness for peace; and as peace, even in the wildest nature, is at least one of its normal conditions, - is the time, even anong 
beasts, in which to prepare for war, _- it is not strange that what was fitted in part for each of these states should have proved, as a whole, the fittest to survive.

Beyond this, just in proportion as a live thing was protected by outward armor, either against the elements or against its foes, the stimulus for its interior development was taken away, the nourishing qualities of its food went to its outside parts, and the freedom of its circulatory system, always needed in the making of a higlly differentiated organism, was sacrificed in the interest of its harder shell. It is not improbable that the starting-point of the whole divergence between the animal and vegetable kingdoms, now so broad, was that the original protistic protoplasm out of which they both came, identical in all other respects, was a little more solidified in the one case than in the other, as it still is in their germs, - that early outsicle protection being fatal to all animal-life development. And when Naturc surrounds any creature at its birth with an encasement that is a guard without effort on its own part from all larm, as with the snail, oyster and clam, or develops its teetl, claws and bulk so enormously by inheritance that their mere display protects it from all ordinary assaults, what indncement does the creature lave for interior growth, and what sustenance have left for it even should the need arise? It is the animals whose very cxistence depends on the completeness and activity of their internal equipment, - on their quickness of motion, keenness of schse, and cumning of brain, rather than on their outside covering, - it is these that will necessarily make the most of every variation in the direction of such powers, using them more and more, and be the ones to momnt up at last from moner into man. Historically, in the animal kingdom, it is out of the lodily weakest that have come the mentally strongest. Lacking talons, they have developed tilents; mable to throttle, they have learned to think. Dingrer has been their school; difficnlty their tearher ; and, instead of yielding to the arsenal of outward weapons arrayed against them, they lave turned them into lelpers, - sharpened their wits against the very teeth of tigers, marle the frrocity of the hyena and bear contrilute to their fineness of nerve and sense, and the portion of Nature's goods that Megalosaur and Megathere consmmed with riotons living in the making of brawn, they lave used with eeonomy in the miking of hrain. 
Then, too, the imperfection of their outward armor must have had a very important influence in driving the weak into that miglitiest of all military arts, mightier than any tusk or claw or individual accoutrement,- co-operative effort. All animals even of the same species, organized to prey on each other, would naturally be foes at first, and inclined to live apart. Outward shelter meant only the continuance of this separation. What society could the oyster and the clam have with each other? What need of mutual assistance, the Icthyosaur and Megalosaur, fifty or a hundred feet long, and panoplied all over with thick plates? It was only the unprotected that would be under the necessity of overcoming their individual enmities and combining against their protected foes ; only the outwardly weak who would be apt learners of the lesson that union is strength. Once learned it became not only a mighty weapon of attack and defense, but the teacher of innumerable other things. The association it involved was a powerful stimulus to mind-development. Liking its benefits, they grew inevitably to like the benefit-givers, - that is, their associates. And thus, under the wonderful alchemy of Evolution, out of the crucible of animal hate in this seething world of ours, stirred with tusk and claw, has come, as much as there is of it, the fine gold of brotherly love, the protective arms into which all weapons are at last to merge.

As plants, in their relation to the world's great foodquestion, are necessarily the assailed rather than the assailants, being the prey of animals, but made to get their own living chiefly from unobjecting inorganic matter, their armor for the most part is naturally outward and protective rather than inward and offensive. It is what is found in the bark of trees, the rind of fruits, the shell of nuts, the beard of grains, the spines and thorns of many shrubs, and in the roughness and hardness of nearly all vegetation in its native state. And yet plants are not by any means entirely destitute of what may be called offensive arms, or wholly incapable, when assailed, of assailing in return. Species of them are found, here and there, like the sun-dew, the pitcher-plant, and the Venus fly-trap, which completely turn the tables on the animal kingdom, and, instead of being the eaten, are themselves the eaters, - catching their 
insect-victims with sticky fluids, spring-traps and imprisoning doors, the ingenuity of which the best patent, cornergrocery fly-destroyer might well emulate. Anybody who has ever tried to work himself imperiously through a tangled thicket, or to rob a blackberry-bush of its shining progeny, or to chimb a pear-tree for its juicy products, will be a not very incredulous skeptic as to the capacity of at least some plants for offensive warfare. When a forcst has been cut down and a multitude of new shoots are springing up, and one of them gets a little the start of the others, no human being in the arena of politics or society or tradc ever used his faculties more combatively, to elbow out and kick out all competitors, than such a vegetable upstart does its limbs and roots to shade out and starve out its vegetable brethren. 'The forest and the swamp have their leafy denizens that are weaponed as effectively with deadly poisons, offensive odors and biting flavors as any in the animal kingdom that wear scales and furs, or in society that wear tongues and clothes. And the small boy who has assailed the green-apple tree has, in his doubling up from it during the night afterwards, an evidence which neither he nor his mother will dispute, that the assailed orchard is not inferior to the assailed pugilist in its skill to strike back at its antagonist's most sensitive parts.

There is the same difference, also, as to the fineness, beauty and organic rank of the weapons used in the vegetable kingdom, that is found in the animal world, and the same rivalry as to which will prove the most effective in its struggle for existence. Their coarsest and ugliest forms were the ones with which Nature necessarily began. During the vast periods of palæontology the monsters of scale and claw were fully matched by those of leaf and bark. T'rees were the grass on which fei Iguanodon and Dinocere; tree-tops the grain that was reaped by Hadrosam and I)inothere. lieeds grew to be sticks of timber, and elub-mosses to be forests in size. With flowers not yet come at all, and the true woods only in a limited degree, the workl's plantforces went forth for ages to their life-battles under the hueless crylotogans as their banners and with the savage stigmaria and sigillaria trees as their lances and chubs, fought them ton, amil the thunder of volcanoes, the rising and falling of continents and the fierceness of tropic suns as we never know them now. And the coal-neasures of 
to-dlay, their ancient battle-grounds, heaped thousands of feet thick with their dead remains, testify to the ferocity of their conflicts and to the grossness and strangeness of their weapons. The weeds of our own time, rough, tough, unsightly and bitter, are looked upon as the special enemies of man's race, a part of the earth's curse for his primal sin, and as exercising their disagreeable qualties out of mere deviltry and love of mischief ; and are warred against with all the unpitying sharpness of the farmer's hoe and the gardener's hate. But weeds to begin with were the special friends of agriculture and man, the vegetable aborigines of the land and pioneers of civilization, and were armed thus with special reference to their work. When our modern earth was yet a wilderness built over the graves of its extinct geological vegetation, and incapable of nourishing any cultivated fruits, the "weeds" settled down on its great glacial furrows just plowed up, and began battling with its crude, inorganic elements to work them over through their own veins into fruitful soils. Go out on the edge of any desert to-day, and you will see some of their tribe still engaged in their old pristine war, throwing out their advanced guards and establishing their slender outposts each year a little further into the waste, too poor as yet to hoist over them the banner even of a flower, but winning what at last will wave with all Springtime's streamers and Autumn's signalhues. And who does not see that their roughness, toughness and acridness are the only possible weapons with which they could have withstood the parching drouths, elemental starvations, and fierce animal hungers, of those elder days and outer realms, and so have won for their kingdom the first stages of its struggle for life? Who, in remembrance of what they have done, and as a foregleam of that plilophyty into which mankind is some day to broaden out, will not forgive them the stained fingers and smarting palms with which, in garden and field, they resist being torn from what is so truly their own hard-won soil?

Mingled, however, with these rough and repellant weapons of the vegetable world, its finer qualities of color, form and flavor have gradually come in, - flowers on bush and tree, arching limbs and drooping boughs out in the stately woods, sweet and nourishing pulps in and around the seeds, and fragrant odors wafted on the evening gale; these, moreover, not merely as ornaments to themselves or as 
foods for other creatures, but as forces, also, which primarily they all are, in their own struggle for life,-arms and armor in the same way as arc the senses and the higher faculties that lave played such an important part in the battles of the animal kingdom.

With the finer qualities themselves, an ingenuity and skill have also been developed in their use and application, which seem sometimes to be almost human. Not a few of the arts and devices of mimicry, that are so wonderful among animals, have their counterparts in plants. How they luddle together in glorious companionship for defense against heat and cold. With what architectural wisdom they send out their roots and build up and balance their branches so as to hold and fortify their positions against gravity and wind. With what shrewdness, while some of them hide from animals and men, others find their protection by following in their steps. And when domesticated and hedged in with fences, and defended with hoes, how winningly for more of such armor, do they, as flowers, put on their brightest colors, and as fruits clothe themselves in their richest pulps.

Especially do their wisdom and care, not to say love, come out in what they do for their young. All plants, the same as all animals, seem to reach the best they are capable of in their position as parents, - sonship being apparently the axil out of which branches all good, vegetable, animal, human, and, if Christianity be true, even Divine. Unable to protect their fruit with claws and wings, like beasts and birds, they do so, while it is immature, by making its color green, like that of their leaves, so as to hide it from view, and its taste sour and bitter, so that no ordinary creature would think of putting it into its stomach. But when it is ripe, and there is need of its being scattered away from its parent stalk to find room and warmth for its own further growth, they put on it, in direct contrast with their leaves, all the bright colors of the cherry, berry, apple, peach and pear, so as to attract the attention of passers-hy, and make its outside luscions and sweet as an inducement for them to eat of it and carry it off, - at the same time wrapping its inside germ, and that germ's own special nutriment, in an armor which is proof against the digestive assaults of even a wild animal's stomach.* How

* lopular Science Monthly, vol. Xx V., p. 433. 
much is all this like the human mother keeping her darling boy inconspicuous at home during the first years of his life, but who, when the time comes for sending him out into the world to get his own living, takes off his old homespun, dresses him up in his best clothes, and puts a little money in his pocket, the sinews of war with which he is to pay his way to a new home and begin his battle of life, and beneath this, right around his leart, the armor of a Bible, or of principles and good advice, to keep him in his inexperience from being at once the world's prey. Fruits like those of the hickory-tree, whose sweetness is wholly in their meat, are provided with a bitter outside covering, which, instead of growing bright and eatable with their ripening, simply opens, when, in the frosty Autumn, they drop from their parent tree, exposing a white inside shell very conspicuous for boys and squirrels to see and gather, but at the same time a veritable fort, built with all manner of intricate casements, salient angles, and retreating walls, that only nut-crackers and the sharpest teeth can storm and break through. The cocoa-tree, having a large heavy nut whose hard shell would be liable to crack open in falling from its high limbs to the ground, wraps it up before-hand in a soft cushion-like matting, as its defense against the hard earth. And more ingenious still, the cashew-nut, growing in tropical climates and much loved by monkeys, has in its inmediate covering a pungent, acrid acid, which, touched, burns not only their tongues but also even their paws, so that not even a hmingry monkey, after one experience with its armor, can be tempted to fool with it again; but, as an allurement to secure their aid in its dispersion, it lias at the end of its stalk, and independent of the nut itself, a most delicious edible tuber, which they can have and do have at the cost only of giving the real fruit a chance to grow, - a contrivance equal to that of the old lady who presented the boy, whose integrity she was not quite ready to trust, with a roll of candy for carrying her package of sweet cakes safe to a neighbor, but at the same time wrote on its cover, "Wallop him well if you find it opened."

What is the result of Nature's experiment here as to the two ways of arming her creatures? As told in the broad pages of palaontology, it is the same as in her animal kingdom, - the gradual evolution of its inner and finer forms out of and over those which are outward and coarse; the 
weapons of swcetness, beauty, grace and use, above those of hardness, hugeness, aerid juices, and outside strength. The flowering plants have more and more eome to the front,the white lily and the fragrant rose left far behind, in thcir struggle for existenee, the old hueless, odorless eryptogams. The grains, with their great heads, have grown up over the graves of the gymnosperms, with their great bodies. 'The apple-trees, the pear-trees, and the peaeh-trees, with their rieh fruit, have elbowed out the seal-tree and the scale-tree with their tough skins. And the graceful elm, towering up over the cottage roof, looks down the climmey out of which curls up to it, as if in homage, the smoke of the carboniferous palæoxon and the old hirsute neuropteris. It is a struggle, to be sure, that is not yet over, a war whose wilder participants are very far yet from being all subdued. But the master forces, and the qualities and reasons which make them masters, are plainly to be seen. 'The industrial age of vegetation has eome in. 'The work of doing something for others has been found even among trees and shrubs a mightier weapon than any art of mere individual defense. Plants have learned, whole species of them, that it is eheaper to hire other tribes to wage their wars than it is to train up themselves to do it; learned that vegetable gold, heaped up in the orchard and the field, will turn the edge of vegetable iron hammered ont in the jungle and the fen. The honey that attraets the inseet-tribes has done for the flowering shrub, in its struggle for existence, what no hardness, driving them away, ever did; and the luseious outside of the fruit whieh feeds the birds has seeured them against foes more effeetually than any bitter rind that repelled them had the power to do. What does the cherry-tree want of a gun of its own, when it has made it for the interest of the small boy to sit patiently with one all day keeping off the too eager robins, by giving him at night a quart or two of the red balls that it spends its own energies in ripening by the thousand? What need does the wheat-field have of building fences agranst eneroaching cattle, when it has allied itself with almost ommipotent rorporations to surround its millions of acres with barbed wires, and secured dignified legislatures to build insurmountable legal posts to hold them up! How vain is it for the potato to distil a poison of its own against lugs, when out of its rich tubers it ean 
pay patient human fingers to feed them day after day with imported Paris-green? And how smilingly the serried ranks of the corn-field can straighten up their own spines and use their green blades only to parry the sunshine, while the farmer and his boy berd.their aching backs and ply their sharp hoes at their roots to drive away and put to death, as no skill in themselves could, their thousand weed-foes?

Ascending now into the kingdom of man himself, the evolution of what has played such an important part in the animal and vegetable worlds has certainly not been less prominent or less interesting in that of their head, and in his struggle for life. "Arma virumque cano,"- not umnaturally did the old Latin poet put the two together as themes to be unitedly sung; the arma perhaps logically first, as something without which man, surrounded with the savage wild, and so weak in himself, never could have been man. His earliest weapons may indeed have been the nature-given ones that he had in his brute-estate, fists, nails and teeth,the ones that, in all emergencies, he falls back upon still,mingled perhaps with the bare sticks and stones that he picked up in the woods, -

\section{"Arma antiqua manus, ungues, dentesque fuere Et lapides et item silvarum fragmina, rami,"}

as wise Lucretius has it. But when, as our great anthropoid ancestor; he came down out of his tree-life, he had, in his fingers able to grasp a club, - the fingers which his forelimbs, in grasping the tree, had developed into, - something far better with which to meet his foes than the claws with which he went up into it; and he has not been slow to use his new powers. From grasping clubs and stones he has gone on to grasping repeating-rifles and dynamite-shells. There is nochapter of human progress more interesting and impressive than that of its arms-making, unless it be that of its arms-using. All the resources of art, all the illuminations of science, have for ages been brought to bear upon it. Some of the most honored names of antiquity, though forgotten now, as those of Luno, Galen, and Andrea Ferrara, were the names of sword-makers and armorers. It was an occupation not considered unwortly of an Olympian god; and one of the most brilliant pages of Homer is the de- 
scription of a shicld, as one of the most graphic in Walter Seott is that of a sword. Kings sat at its followers' feet; the fate of empires turned on their skill ; civilization in its onward march kept time with the rise and fall of their hammers. And, though stained with blood and smoke and hate, their products have been plumed also with some of the noblest deeds of chivalry, honor, comage, self-sacrifice and manly devotion that human nature has ever reached.

But anid all thcir multiplied devices as to form and mechanism, the two methods, the two principles which ran so conspicuously through the animal and vegetable kingdoms, have been equally kept up in that of man, - on the one side a stronger outside covering, whose efficacy was chiefly in itself, as the thick garment, the bull's-hide buckler, the brazen shield, the visored helmet, the plated greaves, the glittering coat-of-mail, the massive fort, the turreted monitor, and the steel-clad ship; and on the other, something which involved, more directly, inward skill and power, as the club, the spear, the sword, the cross-bow, the catapult, the matchlock-gun, the rifle, the camon, the ram, the torpedo, and behind them all the cuming, the courage and the union instinct of man limself. And in the struggle between them here, the same as among the plants and the brutes, the result has been the supremacy of the inward over the outward, and a progress ever more towards their finer and more inward forms as the ones on which at last wholly to rely. The old Bible story of Goliath and David, - the one a giant six cubits high, ar'ned with a coat-of-mail of "five thousand shekels in weight," and a spear "like a weaver's beam," the other a rudily youth armed only with a sling and five small stones out of the brook, and his own skill, - has been the story of the ares. The barbaric nations have always relied most on outward defenses, the civilized ones on those that reguire inward skill; and rictory the world over has sided with the skill. 'The weapons with which the Roman soldhercarved his way to universal empire against all the shields, greaves, hreast-plates and forts of his foe, were the short two-edged broadsword, nineteen inches long, and the famous "pilum," four feet in length, _ himself protected only by his own stout heart and a very light defensive armor. 'The slender spears of the ancient (ireek infantry. twenty-four feet in length, and the lances at a later day of the old feudal 
cavalry, projecting ten feet beyond their horses' heads, again and again bore down in battle all the massive protective defenses that their opponents were panoplied with. The best steel-plate armor of the Middle Ages, forged with marvelous skill, and completely covering the person, was $n$ match for the arrows, five feet long, of the English yoeman, hitting the target every time an eighth of a mile off, and on the victorious fields of Crecy, Poitiers and Agincourt shooting down their mailed opponents at the distance of two hundred yards "as readily as if they were naked men." If now and then the strength of the armor caught up with that of the arms, as at a battle in Italy during the latter part of the 15 th century, where they were so nearly matched that the two opposing armies fought ferociously for seven hours without having a man killed or wounded on either side, it was only at the very next battle to have a new assailing weapon introduced to maintain the old supremacy, - as, in this case, musketry at the battle of Pavia,* before which all the gorgeous panoply of chivalry went down as completely as the fields of bearded grain before the driving summer hail. Waterloo was the last great fight in which bodily armor was used, Napoleon's cavalry wearing it, and up to that time with some success; but in the charges there made his iron-sheathed cuirassiers went down like rows of pins before the quick-moving English horse dashing in upon them with only naked swords and naked hands. The contest now is between massive forts and steel-clad ships, with ever thicker and thicker plates, on the one side, and mathematically-aimed mortars and steel-wrought rams and cannon, and projectiles themselves shot-loaded,_ cannon fired from cannon,_- with ever more and more size and force, on the other. But with mortars dropping shells from above at the rate of one a mimute into forts three or four miles away, and torpedo-boats creeping

\footnotetext{
* Beckman ; questioned, however, by Buekle and others. Mortars anil cannon for gunpowder were invented much earlier, but being made in part of wonl and even of leather were of little aecount. l'avia was, perhaps the first lattle at which troops in large numbers were armed with the more efticient musket. It took even then a quarter of an hour to load and fire one, - a striking contrast with our sixty-shot-a-minute repeating rifles. The use of the mortar was diseovered by aceident, a eluns y fellow making powder in the common houschold utensil, allowing it to explode and knock him across the room. The same ol jeetion was urged at fir-t against the n-e of all firearm $<$, and even of eross-bows, that is now made again-t dynamite-hombs, - they were too demorratic and too equalizing for honorable war. Chevalier Bavaril is said to have exclaimed with reference to them, " "est wme houte qu' um hromme de cour soit exposé it perir prr mme miseralije friquenelle." And it is a singular faet that he, the hero of a hundred knightly battles, met his own death at last by a stone shot from an arquel us.
} 
under plated frigates from below as readily as eels under a plank, and projectiles driven with smokeless powder through five inches of steel backed with fifteen of oak as easily as a boy's teeth pass through slices of bread and butter, and dynamite-guns throwing from the shore at marks two iniles off five-hundred-pound explosive-bombs that tear up the heart of old oeean itself for a hundred yards around, who can doubt the result?

It is a result, moreover, in all these cases, which has not stopped with teaehing and helping on the superiority and evolution of an ever finer and finer weapon alone. It has taught and carried with it also the superiority and evolution, behind the weapon, of an ever finer and finer man. It has done it, first of all, in the artisan who makes the weapon. Rifles that shoot sixty balls a minute, and cannon that send hundred-pound shells through twenty inches of solid oak and steel, do not grow naturally, like teeth and nails, out of the soldier's own body. 'They have to be invented and wrought out by a man baek of the soldier. They involve, in their maker, art and seience, skill of hand and skill of brain, - immense amounts of then. And what is more, they involve in him honesty and truth. There is nothing which detects cheap workmanship and base alloys quicker than the acid of war. We tolerated shordy in our shops, in our homes, in our ehurches, easily enough while peace reigned on our soil ; but when it eame to sending it to our soldiers on battle-fields, Aneriea's ontery of rage brought its dealers to a very sudien halt. Rotten timbers have small ehanee of passing the inspectioneyes that fifty-ton broadsides of iron direet against them. And when you toueh off dynamite-guns, that exert a pressure of a hundred tons to the square inch, varnish and putty and the men who make them are apt to fly very high and very far, leaving back of the soldier only solid sterel and solid workmen. Equally, too, finer armor has evolved, in the soldier himself, an ever finer and finer man. It is no longer, as it once was, physical strength alone that counts in war; no longer the more a brute the more a soldier. (inmpowder marle bodies equal, and began the proeess of having lattles turn on briins. It is a proeess that has never stopleed. With rifles like those now marle, as delicate in their machinery as ehronometers, and with camon that have to be amed at foes as mathematically as 
telescopes at stars, it is obviously impossible to trust clodhoppers with their use. New weapons involve precisely the same necessity for a more highly organized solaier that new teeth and new claws dicl of old for a more highly organized animal. It is not the fighter in the mass, as it was in ancient Greece and Rome, but the fighter in the man, that makes an army's strength. With each more intricate arm more responsibility rests on the individual soldier,* not on his captain or his corps, for its efficiency; the more need, therefore, there is of his individual training. Bayonets have had to learn not only how to thrust but how to think. Battle-fields, which hitherto have been supposed to necessitate the most absolute despotism in command, and to be the last places where personal liberty could be allowed, are having the way opened through their new weapons to taste for themselves what they have won so long for peace. And the armor which began with a sharp animal spine is mounting up step by step to that quality in the soldier's soul which can say, in all its sharpness, the grand word I.

It is not only individuals and brute races, however, but tribes and nations also, that use arms and are combatants in the struggle for existence; and as such, they are going through the same experiments as to the best ways and means of doing it that animals and individuals have tried, only on a larger scale. Originally a tribe's entire corporate body was a soldier going out to battle as one man. Every male member of it was accustomed to the use of arms alike in war and the chase. Fighting was considered to be the only employment worthy of a man; and honor and leadership and wives, and the best of everything, waited on his courage and success. But gradually nations found that, to fight well, something more was needed than brute courage and the rude weapons that each man could make for himself. Food was needed, and finer weapons, and resources to fall back upon when the struggle was long, tlie tribes which had the most of these being the ones that finally survived. And so a differentiation took place, the inevitable process in all Evolution,-_-some of the member's devoting themselves exclusively to the raising of food and clothing, and others to the manufacture of arms, and with

* See H. L. Abbott's article in March Forum (1890) on War under New Conditions. 
these, gradually, to all the employments needed for social nourishment, while a third part were trained specifically as soldiers. Thus inside the nation were started the soft industrial arts, the fluid, nutritive, growing, organizable parts of the body, and, on its outside, the hard military protective shell, - precisely the same state of things that existed in the earliest forms of individual life. And aloug these two lines, away up into the civilization of today, has been all national development, - these as methods of protection distinguishing countries in precisely the same way that they do animals and plants. On the one hand is outward military encasement, as with all the great nations of Europe, - Orthocerates and Glyptodons that stretch over vast territories; Megalosaurs and Machairoduses whose dimensions are those of States. Forts and frigates are their shells and scales; long rows of sharp sabres and glittering bayonets their teeth; vast armies their ponderous jaws; Krupp-camnon and Gatling-guns their talons and claws, and

"The bursting shell, the gateway rent asunder,

'The rolling musketry, the clashing blade, And ever and anon in tones of thunder

The diapason of the camnonade,"

the wild-beast cries with which they leap upon their foe. On the other hand is interior development, as, in some degree, with our own land, - the skeleton of a better social organization for the miting and upholding of the body as a whole, the nerves and arteries of telegraphs and railroads for the quicker and closer communication of part with part, the muscles and ligaments of industry and business for the obtaining of better nourishment, and the eyes, ears and brain of more schools, more arts and sciences and more churches, for the gathering of knowledge and the growth of mind.

Which of these methods is it the part of true statesmanship to emphasize and use? There is a tendency even in onr own land to fall back on the method of outward force. We get alarmed ever and anon at what we call our defenseless condition, - at on small army, our rotting gunboats, and our dilapidated forts. We picture to ourselves what a trrible thing it would be if some little country with a big cannon should reclare war against us ; and follow with boyish pride the excursions of onr eostly show-frigates 
into ports where our protective commercial policy has driven from the seas every flag of ours needing protection. And this very Winter the proposition is before our Congress to vote the nation's money by the score of millions for the building of a steel-clad navy that shall match those of the old world.

But if there is anything to be learned from the long experience of the mighty past, alike animal and human, is not the question's true answer largely, if not entirely, the other way, - an answer that tells us to go on as we have in part begun, and as the real genius of our country prompts, letting Germany, Russia and France follow the lead of the Dinichthys and the Megalosaur in heaping up outward armor, while we seek to develop as the man-nation of the earth by unfolding from within? It is, indeed, true that the man-animal of the earth has sbeen a fighter, - one of the worst; and that all the world's great historic nations have been fighters, and terrible ones, too; but the point to be remembered is that they have got their best means of fighting, got the real qualities which enabled them to come off victors in their fights, by cultivating the arts of peace rather than those of war. "A nation of shop-keepers!" exclaimed Napoleon, contemptuously, as he looked across the English Chamnel; but one day, in his dealings with the shop-keepers, lie found, very uncomfortably, that among their wares they had a Waterloo. How was it in the recent struggle on our own soil between the North and the South? The South was the military part of the nation. It had the most accomplished generals. Its clildren had been trained from their youth up in the use of arms; and in courage and in direct fighting qualities it certainly was not inferior to the North. But the North had the freedom, the wealth, the inventive genius, the mental training, the higher interior development, - all those qualities which are the outgrowth of peace. It called them at once into action; - where it wanted a new rifle, new war-ship, new sanitary device, called on its rear guard, back of all other rear guards, to invent it. The rear guard never failed to do so; and the result was just as certain with the first gun at Sumter, as with the last at Apponatox Court-House, - was wrouglit out by the schoolmistress and the aproned mechanic quite as largely as by the brave general and the bannered soldier. It has been said 
that the nations which shorten their swords lengthen their borders, - historically a fact. But, ultimating the same principle, we are now learning that the nations which go still further, and shorten their swords into nothing at all, lengthen their borders still more,- and at the same time lengthen their lives. Wherein is the wisdom of roting millions of dollars for forts and frigates which in a few years will be as passé as cross-bows and coats-of-mail, and when the genius that, by its other, finer inventions, is to make them so, is growing of itself in our laboratories and workslıops? It is the people hereafter who can raise Eriessons, not Napoleons, send to the field the best manhood, not the biggest mortars, boast the completest social, not soldierly organization, that can laugh at their foes. "IDamn the torpedoes!" shouted the grim old naval hero of our civil war, as he took his unarmored flagship into the hottest hell of the fight at Mobile Bay; and well the old Hartford might despise them, for within its wooden walls were ironclad hearts, and above it waved Liberty's bamner, and it was sheathed all over with a cause that gunpowder could as little blow up as it could omnipotence itself. And no matter though every sea were to be filled with explosives, and every bay with dynamite, let America carry stalwart manhood on her decks, and unfettered liberty at ler mastliead, and the sheathing of a righteous cause at her prow, and, if need demand, she can go into the hottest hell of the world's battle, exclaiming again, with the sacred profanity of her dear old Farragut, "Damn the torpedoes!"

of course this does not mean that the country should rush all at once from its policy in the past over to the opposite extreme; does not mean that in the interests of peaee it should wipe out the army and nary and beat into jlow-shares the swords it now has, or that it should abate in any dengese its reverence for the brave soldiers on its own soil, and all thongh the agres, who by their use have filled history with hreisms and the world with salvations. For prace, when it comes, will be the result of evolution, not inamufacture; and evolution here, as everywhere else, must have the root and stalk of the past on which and from which to unfold; and to eut down the armor-part of the past would be to cut down the very tree on which, as things look, its flower at last is to bloom. But it does mean that we should recognize what has been the bent and strain of 
Nature in all her kingdoms and all her ages, and ourselves work with her in the same direction. It does mean that, without destroying what now is on her armor-tree, we should join with her, so far as we do anything, in cultivating its finer industrial branches, as good alike for peace or war,- - not spend our millions in merely crowding it with bigger ones of the old type that will be of value for neither state.

It is in this way, by a simple and natural unfolding from the past, not cutting loose from it or sticking to it, that will come the supreme stage in the evolution of arms and armor, - that in which wars will be waged with no guns, no forts, no ships, no outward explosives at all; with no need, therefore, even of the arts that made them,- - but with missiles only that are forged out of mind. So far as fighting of some kind is concerned it would indeed be a fool's security for humanity to suppose that its days are over, and that peace in the sense of harmony is close at hand. Problens are before it to-day more perplexing than any that the past has ever known; passions at work in it fiercer than ever fired hearts in the jungle with rage; interests at stake with it more conflicting than any that a Marathon or Waterloo decided, - and there is no possibility of settling them without contests. It is their very greatness and intricacy, however, that are going to make it all the more a matter not of sentimental choice but of military necessity, to meet them with weapons of a corresponding substance and temper. It is a process that has already begun, a new bud that, like all buds, is springing directly from the axil of the old war-tree. The best general, even now, is not he who fights the most battles with guns, but he who so maneuvers lis army as to win victories with the fewest actual conflicts; not he who, when a battle comes, takes part himself in the deadly charge, but he who sits quietly in his tent with a map before him, directing charges with a pencil's point, and neither sees nor sheds personally a drop of blood. Literature in all ages has had its words that were half-battles; eloquence its vibrations of air that have shaken the world wider than parks of artillery; religion its love-whispers that neither Greek phalanx nor Roman legion could withstand, and before which empires have tumbled down as readily as savages before canister and grape. Paws and claws, if not yet extinct, have 
climbed up from the feet into the forehead, and from weapons that scratch and tear into weapons that think and plan. It is brains to-day, behind the cannon, that are the world's real battle-fields; ideas that are battering down strong-holds which shot and shell, armored ship and gaping mortar have knocked at in vain; ink that is solving questions of Statc that blood has only confused. And the process is bound to go on, till nations shall wage all their wars with logic and reason, diplomaey everywhere take the place of generalship, battles with powder and armies be as vulgar as those with teeth and fists arc to-day, and eivilized countries as little think of going about the world armed witl forts, and showing off frigates, as civilized individuals do now of going about society with bowieknives stuck in their belts and revolvers gleaming from their pockets. And this is what every citizen ean help along; is what every soldier should rejoice in, as he does now in the introduction of every finer and more effective weapon; is what the great poet of England, who sang so grandly the Charge of the Light Brigade, has also sung as the charge of all the ages, -

"Move upward, working out the beast, And let the ape and tiger die."

With it will come the world's real struggle to see which are its fittest nations to survive; a war more thrilling and with more chance for real heroism, generalship, and glory, than any ever waged with outer weapons and garments rolled in blood; and in it the great military nations of Europe are preparing to fail, through preeisely the same causes that overthrew the monsters of the geologic ages and that have meant failure in all time. Their vitality and food-substance are going too largely to the outside shell. Internal soeial organization is being neglected. 'They are not keejing up with the world's changing intelleetual elimate. And, continually rivalling each other in the size and strength of their armaments, they will drop down at last in the fight like the Iguanodon and Glyptorlon, overeome sinnly by their own enormous weight, leaving the great scientific, industrial and thought-using mannations to examine their bones, organize over them the new civilization, in which "the war-drum throbs no longer," and hold the luture. 


\section{"Dream not that lielm and harness Are signs of valor true: \\ Peace hath higher tests of manhood Tlian battle ever knew. \\ " Henceforth to Labor's chivalry Be knightly lionors paid; For nobler than the sword's shall be Tlie sickle's accolade."}

The lesson, however, does not stop with statesmanship. Religion is a field where precisely the same principle is at issue. What are creeds, forms and great ecclesiastical systems but the outward armor in which men have sought to protect the inward spirit of religion? What are many of the churches and denominations of the past but monsters of the theologic ages, rivaling those of geology in their fierceness? What the rack, the stake, the thumbscrew, the inquisition, and, later, all the awful imagery of eternal suffering, but the teeth and claws and jaws of the old brute-world reappearing on earth in subtler and sharper forms? Their use has no doubt been honest and natural; their hardness and cruelty have been thought a necessary means of defending and perpetuating their inside truth. But how futile they have been! How many of the old dogmas are now as dead as the old brutes! How certain are all the institutions and all the churches, whose trust is in any outward letter or outward form, sooner or later also to go! And for the same reason,_- the use of their vitality in the wrong direction ; the impossibility of anything thus hardened to adjust itself to the world's ever-changing spiritual climate, and the pressure at last on their believers, under the effort to make them ever stronger and stronger against their foes, of their own dead weight. On the other hand Christianity itself lives, the great spirit of all religion lives, because an element within it has always acted on the other principle,- refused from the start, as with Jesus, to encase itself in any words or forms, used its Divine food for inward growth, adapted itself to the world's progress, and relied, when assailed, for its real defense, on the imner weapons of reason, spiritual insight and the power of truth. When religion first started, ages since, from form to faith, from outward authority to inward insight, and from one vast body to a multitude of little sects, it did indeed seem, from the ecclesiastical standpoint, as great a mistake as 
when the animal kingdom branched off from a shell to a back-bone, and from a Megalosaur to a Microlestes. But the wisdom which has been vindicated of her children in the kingdom of animals will just as surely be vindicated of them in that of spirit. And if the friends of religion want to defend it most effectively of all, is it not plainly along the line of its interior development, rather than along that of lnilding it into creeds and fortifying it with logic, that their work should be done?

"Than tyrant's law or bigot's ban More miglity is the simplest word, The free lieart of an honest man Than crosier or the sword."

Going now a step further, does not the same principle hold good with regard to morals, right, reform, and that greatest of all organisms, society itself? These things are precious beyond all price, have grown up to their present condition through enormous toil and suffering,would mean, in their loss, what never, perhaps, could be restored; and so it is not strange that men should seek to protect and promote them with rigid precepts, with stem prohibitory laws, with great bodies of police and with all the weapons of courts, jails, scaffolds and penal legislation. It may indeed be impossible yet to abolish such things altogether, as the safeguards of society. Nevertheless, even while using them, must it not be acknowledged that they belong to the Triassic and Mesozoic rather than to human social States; are Nature's methods in the oyster and the clam, the lobster and the lion, rather than in the man; are the use for defense, of shell and scale, tooth and claw, instead of sense and soul? Whatever the good they do, their defects are the same as have been found in all outside arms and armor, from the brutes up. The moral vitality, alike of the individual and of society, goes into their prodnction and support, away from inward growth. 'The stronger and better they are made for any one period and condition of things, the less easy it is to adjust them to the world's changes, and the less fit they are for those which follow. What is the effort to put down increasing crime by increasing laws, an experiment that every unfolding social state goes through, but a renewal of the old contest between stronger scale and stronger claw, stouter 
iron-plate and stouter gun? It is a contest sure to result at last in a dead weight of legislation, too large for society to carry. Crime in it, as the assailing force, will continually get ahead, the same as in the struggle between tooth and scale in geology, between thieving and law in England a century ago, and between landlord-legislation and tenantry-violence in Ireland to-day. And even were such efforts successful, - were laws to be made so wise, and a police-force established for their enforcement so strong, as to suppress absolutely, for the time being, all vice and all crime,- how inevitably would they lead to a reliance on these agencies alone, and to a relaxation of inward culture that in the end would stop growth and turn society back towards its mollusk-state. Take the use of prohibitory laws in behalf of temperance,- whatever their value, a real value in some respects, it must be confessed that just in proportion as they are enforced, the other and finer agencies of the cause, which should act on the drunkard's moral nature to strengthen that, are liable to be dropped, leaving him, while safe from drink simply because he cannot get it, a prey all the more to other, worse vices, whose means of indulgence no laws can stamp out. What children are the weakest and surest to fall, when they grow up and go out into the temptations and trials of actual life? Those, notedly, who have been sheltered most carefully by home walls and parental care from all contact with evil, rather than those who have been strengthened inwardly, it may be in the very midst of temptation, to take care of themselves. What is the source of all Phariseeism, all hypocrisy, all obedience to the letter and not the spirit of right,-_-social states worse sometimes than open vice? It is the attempt to make people righteous by precepts rather than by principles; to protect virtue by an armor of rigid rules instead of by trusting to its own larger development; so that wisely did the old Apostle to the Gentiles exclaim: "The law worketh wrath." The truth is, there is only one sure way of arming either society or the soul against their foes,- the way taught by all the ages, from those of geology up,- that of completer inward equipment, putting nature's moral lime into the back-bone of principle, rather than into the shell of statute-books; building more school-houses and more reformatories in the place of more scaffolds and more jails; 
developing more eyes and ears, with which to see and hear the right, rather than more teeth and claws with which to put down the wrong, and organizing not so nuch a better police as a better people. It is this which is the fundamental idea of Christianity; this, what it means by its doctrine of faith as opposed to law; this, that it has come back to in all its great reformations, from that of Luther down; this, the goal at which it joins hands with science; this, very singularly, that is the real meaning to-day of a word almost too hateful for utterance,- the blossom in society of religion's most cherished teaching and the outcome in morals of Nature's divinest struggle for life. Its shortest expression, "Right its own best weapon," is a Damascus-blade that what battle-fires have tempered and battle-blows hammered out! Not poetry alone, is it, but sober fact, that "Thrice is he armed that hath his quarrel just." 'To put on "the breast-plate of righteousness," "the shield of faith," "the sword of the spirit" and "the whole armor of God," is the injunction of Hoplology not less than of Scripture. And it is as true of social safety, as of national defense, that

"Were half the power that fills the world with terror, Were half the wealth bestowed on camps and courts, Given to redeem the human mind from error,

There were no need of arsenals and forts."

The whole subject, thus looked at, is a good illustration of how, throughout the entire universe alike of matter and mind, and often amid the greatest apparent contradictions, it is possible that one increasing purpose runs. There is nothing in Natme which at first sight is more disheartening than the awful warring of its creatures one against another; provided for, as it is, in their very structure; nothing which to many persons so militates against the idea of a loving God as the awful cruelties of that strugryl. for existence into which, with no choice of theirs, all organic beings are phunged; nothing which could seem less the purpose of things, especially while the monsters of the geologie ages were being brought forth ever more and more terrible, than that the neek and the righteous should inherit the earth. Yet with the points of tooth and claw, "red in ravin," as pens, and the lolood of her myriad creatures dying in battle, as ink, she has been writing all 
the time the first pages of a philosophy under which of necessity all fighting must end; and at the very anvils of war, with her monsters, brute and human, as smiths, has been forging the weapons ever finer and finer that alone can overcome violence, and which only the righteous and the meek inheriting the earth can wield. And in all the marvels of eastern magic is there anything more wonderful, more unexpected, more beautiful, than the story that not on a tree transplanted out of Paradise, or from a seed sown in the gardens of sentiment and nourished in the hothouse of the church,- but on the rude stalk of war, rooted in the dust of slaughtered myriads, spined and petaled with the sharp points of tooth and claw, sword and bayonet, and budding in the red of battle-fields,- there should bloom at last, in the midst of a hushed and waiting earth, by strictly natural laws, the snow-white flower of universal peace,- the story that is told by Evolution in this chapter of her great book entitled "Arms and Armor"? 



\section{EVOLUTION OF THE MECHANIC ARTS.}

BY

JAMES A. SKILTON

AUthor OF "Evolution OF SOciety." 


\section{COLLATERAL READINGS SUGGESTED.}

Speneer's "Principles of Sociology"; Tylor's "Primitive Culture" and "Early History of Mankind"; Crosier's "Civilization and Progress"; Joly's "Man before Metals"; Evans's "Aneient Stone Implements in Great Britain" and "Bronzc Implements in Great Britain "; Whewell's "History of the Inductive Seienees"; Ewbank's "The World a Work-Shop, or the Relationslip of Man to the Earth"; Ward's "History of the Ancient Working People"; "The Hand, its Meelıanism and Vital Endowments as Evineing Design," Bridgewater Treatise, by Sir Charles Bell ; Adam Smith's "Wealth of Nations"; Lubboek's "Fifty Years of Seienee"; Janet's "The Matcrialism of the Present Day"; Routledge's "Discoverics and Inventions of the Nineteenth Century"; Tyndall's "Advancement of Seience" (Inaugural Address, 1876); Franklin A. Seeley's "An Inquiry into the Origin of Inventions," "The Development of Time-keeping in Grcece and Rome," and "The Genesis of Inventions." 


\section{EVOLUTION OF THE MECHANIC ARTS.*}

Is starting out with an exhilarating sense of freedom upon the broad, wild prairie of a nearly new topic, it is interesting to note that we are by no meals without compass or means of guidance. Our great Master, Herbert Spencer, from the beginning has provided a place in his system of philosophy for the mechanic arts and their evolution, by establishing and declaring the principles of their psychological genesis. Fiske and Romanes have followed Mr. Spencer; and therefore if we at any time lose our way, we have only to return to the safe starting-points these pilots have fixed for us in the new psychology.

Considering the world as a work-shop, and man as the mechanic who is to run the shop, the particular bogey by which we are met, the moment we begin to study the evolution of the mechanic arts, is the carpenter idea of Creation. Even that idea places the mechanic and mechanical principles in command of the situation at the very outset. But as there is a way of "protesting too much," so there is a way of conceding too much. At all events the evolutionist, if he would put his subject on a sound basis, must beware of this concession, as applied to the Infinite and Eternal Energy and its work, and reserve the office of the supreme carpenter and mechanic of the world to be conferred upon Man himself.

The mechanic arts, together with religion, the family, the tribe, the city, law and government — whether of status or contract - and civilization itself, ancient and modern, all had a common origin and a common expression, at the family-hearth and altar-fire, which was also a forge, located in the inclosure which was at once a house, a shop, and a sanctuary. And tracing back our American civilization to one of its origins, we find it in hundreds of New England structures still standing, that have been all of these at one and the same time, within the memory and knowledge of persons here present.

\footnotetext{
* Copvingr, 1890, 1y James H. West.
} 
Doubtless our topic omits the static side of mechanics in treatment, while it preserves it in memory, and confines itself to the dynamic side of mechanies. But we may properly take a brief glance, first, at man, the mechanic who is to run the shop, for the purpose of giving him a "Civil Service Examination" as to his qualification for his work; and, second, at the world considered as his workshop, for the purpose of taking a quasi inventory of the materials and forces with which he is to do his work.

Without man, the inechanic, the world-shop would have been useless, and would have gone to wildness and waste. Considered merely as an organized and vitalized machine, he is, in himself and alone, a most fit and rich subject for many essays. The soundest principles of construction, endurance, economy, capacity and variety are illustrated in his body, which, according to evolutionary theories, both in its individual and racial history, has been built up from a single cell, to and with which other cells have been added, integrated, differentiated and specialized, until it has become a machine of marvelous efficiency and power, operated by the consumption and at the cost of the smallest amount of material or fuel, made capable at the same time, for long periods, of making its own repairs, supplying its own local loss of substance, and to some extent of organs, keeping all its parts lubricated and in working condition. It is, in fact, a pattern piece of automatic mechanism, that is to the skilled mechanic an object of profound wonder, interest, instruction and suggestion. All other forms of animal life also have their mechanical structures and relations to the world, all of which are of profound interest and great value; and many of which show greater special powers than any that are given to man. In fact, when we consider the sizc and strength of many animals still extant, as well as of those that formerly existed, their teeth, their claws, their ferocious natures, their special superioritics, the wonder is that man and lis lineage ever survived in the contest with the wild beast and with the still stronger forees of Nature itself. Mr. Kimball has already taught us, in his admirable essay, that, notwithstanding these, and all the terrilule implements of war forged by man, and even in accordance with natural and necessary law, the meck arc to inherit the earth. But we may still be permitted to inquire a little more fully into the genesis of the title to that inheritance. 
Compelled, because of his weak and relatively helpless generic condition, not only to take to the woods, but to the trees, and to find ineans of protection and defense outside of himself and his own natural powers, man and his primordial types, by the very necessities of arboreal life, developed not only the hands, but the arms, with their co-ordidinated capacities of flexure and rigid fixture in an infinite variety of positions, the chest, the bony frame, the back, leg, and other nuscles and parts, in which largely reside the mechanical capacities of man and his other adaptations to societary life. It was the continual grasping of the limbs of trees, doubtless, that gave to the hand its opposing thumb, whereby man is able to securely hold the club, the hammer, the spear, the lever, and also the scepter of the world, of which these others are each the analogue and prototype.

The same necessities furnished man's primordial types with thumbs on the feet as well, which still appear in one stage of human embryological life, but disappear before birth. Under the influence of changed conditions resulting from the abandonment of his perch in the trees for terra firma, man, standing and walking erect, has discarded the thumbed foot, and thereby co-ordinately increased his equipment for the various motions required for the performance of mechanical functions, and for making and managing implements, tools and machinery.

Long before our ancestors had abandoned the trees, they had learned to use clubs, stones and other missiles, with the same hands and structures that enabled them to swing from branch to branch and carry on all the operations of arboreal life. From the use of clubs, spears, arrows and other sharp-pointed sticks, in war and in the chase, to the use of sticks as levers, wedges and cutting-tools of all sorts and kinds, for the purpose of upturning stones in their search for snails and other food, for digging up roots, opening shell-fish, preparing their weapons, building their places of abode, etc., etc., the progress was regular, and evidently systematic, not simply in the extermal sense, but in the co-ordinate development of brain function and mass, and the beginnings of thought and reason. Indeed, it seems clear that the enlargement of the brain of the human being, which is recognized as having been gradual, must have had its initial impulse and opportunities througl what I may 
call the mechanical life of primitive man, beginning as he did with the primaries of mechanies, under racial limitations akin to infancy and its helpless conditions. And if inan's cerebral development began with, and in any essential way was accompanied by, his advance in mechanical practice and knowledge growing out of such relations to the world, it is evident that in his continued progress and development on the earth his mechanical relations to things, both as individual man and as societary man, must be continued; or, not continuing, he must relapse toward the primary condition. Hence the necessity for artificial and scientifically adapted modes of physical exercise for those otherwise unable to obtain a uniform action and development of their bodily functions. Many men seem to forget this, and, attempting to get away from the earth and their mechanical relations thereto, seek in the office, the study, the counting-room, the pulpit, the professorial chair, to live an intellectual or brain life apart from a physical and mechanical life, with the inevitable result of a loss of power, not simply of muscle, lut also of brain, accompanied by an ummistakable tendency to perish, or to relapse into primeval conditions. Indeed, while the earlicr Gospel teaches that the meek shall inherit the earth, and the Gospel of Evolution teaches that the militant man is to give place to the industrial man, we still make the clain that the man who understands his mechanical relations to the world, and follows that understanding in practice, is that meek man to whom that inheritance belongs.

It is not alone in religion that a monastic, spiritualistic tendency prevails. All men recognize that it is necessary that trees and plants should have their roots in the earth in order to obtain therefrom their sustenance and means of life-maintenance. But some men seem to think that the law does not apply to men - that there is a degrading element in the very touch of material things. For them the old fable contains a lesson: 'The son of Mother Earth could not be overthrown so long as his fect rested upon the ground; and the first step in his overthrow consisted in lifting him from the earth, whereupon he was easily conquered. 'The same is true of civilized man considered as a son of the earth; and to maintain his position of supremaey it is absolutely necessary that his mechanical relations to the world and to things should be comprehended, maintained 
and increased in scope to the utmost. From this point of view, it appears that the "greasy mechanic" may not fall far short of becoming the true prince of the race.

But in considering man in his present bodily and perfected machine form, we have passed by the germinal conditions out of which the machine grew, with brief notice, and may therefore have missed important principles, more easily detected when the less complex, more homogeneous and total primitive conditions are carefully inspected.

Beginning with the Amøba, as it wraps itself round and gradually includes the small nutritive fragments it meets with, even before there are either prehensile or digestive organs, Mr. Spencer finds that "The fundamental attribute of matter is resistance," and that "The fundamental sense is a faculty of responding to resistance." He further says : "And while, in the environment, associated with this attribute of resistance, are other attributes severally distinctive of certain classes of bodies, in the organism there arise faculties of responding to these other attributes - faculties which enable the organism to adjust its internal relations to a greater variety of external relations - faculties, therefore, which increase the specialty of the correspondence. We see this not only in the rise of the senses that are affected by the sapid, odorous, visible, and sound-producing properties of things, but also in the series of phases through which each sense advances towards perfection. For every higher phase shows itself as an ability to recognize smaller and smaller differences, either of kind or degree, in the attributes of surrounding bodies; and so makes possible still more special adjustments of inner to outer relations." (Prin. of Psy., p. 331.) Through these processes of adjustment, and out of the fundamental faculty of responding to resistance, touch eventually develops into the five senses co-ordinately with their special organs, with limbs and other associated members, including the cerebellum and eventually the cerebrum, and the mind as a totality. The line of subsequent advancement proceeds in continuation of the antecedent, as agriculture, the arts, and social life, in the factory, the shop, the highway and the kitchen, are developed.

We cannot here follow Mr. Spencer step by step through what he calls directive changes and executive changes, the one characterizing Science and the other Art; nor 
through changes of the subjective order and developing faculty in man, interesting as it might be to do so. But, being germane to our subject, we should notice the relations of mechanisms to man in his system of psychology. $\mathrm{He}$ says: "All observing instruments, all weights, measures, scales, micrometers, verniers, microscopes, thermometers, etc., are artificial extensions of the senses; and all levers, screws, hammers, wedges, wheels, latlıs, etc., are artificial extensions of the limbs. The magnifying glass adds but another lense to the lenses existing in the eye. 'The crowbar is but one more lever attached to the series of levers forming the arm and hand. And the relationship which is so obvious in these first steps, holds throughout. 'This being perceived, a meaning becomes manifest in the fact that the development of these supplementary senses is dependent on the development of these supplementary limbs, and vice versa." (Prin. of Psy., p. 365.)

Romanes, in his diagram, places carnivora, rodents and ruminants at No. 26 in the ascending scale of animal development, opposite No. 26 in the scale of products of intellectual development, which is stated to be "Understanding of mechanisms"; monkeys and elephants at No. 27, opposite to No. 27 in corresponding scale, "Use of tools"; and birds at No. 25, corresponding to which is "Recognition of pictures, Understanding of words, Dreaming"; and he thus scales the highest capacities of each. My own birds I see every day showing understanding of mechanisms, or qualifications for the grade of No. 26, one grade above that allotted them by Romanes.

Dealing with the root principles of mind and the "correlations between muscular and mental evolution," Romanes says: "The wonderful intelligence of the Elephant may be safely considered as correlated with the no less wonderful instrument of co-ordinated movement which he possesses in lis trunk; while the superior intelligence of the Monkey, and the supreme intelligence of Man may be no less safely considered as correlated with the still more wonderful instrument of co-ordinated movement which has attained to almost ideal perfection in the luman hand.". . . "Thus the two faculties are, as it were, necessarily bound together. But here another consideration arises. They are thus bound together only up to the point at which the adaptive movements are dependent upon the machinery supplied by 
Nature to the organism itself. As soon as the power of discrimination has advanced far enough to be, not only consciously percipient, but deliberately rational, a wholly new state of things is inaugurated. For now the organism is no longer dependent for its adjustments upon the immediate results of its own co-ordinated movements. From the time that a stone was first used by a monkey to crack a nut, by a bird to break a shell, or even by a spider to balance its web, the necessary connexion between the advance of mental discrimination and muscular co-ordination was severed. With the use of tools there was given to Mind the means of progressing independently of further progress in muscular co-ordination. And so mavelously has the highest animal availed itself of such means, that now, among the civilized races of mankind, more than a million per cent. of his adjustive movements are performed by mechanisms of his own construction. Wonderful as are the muscular co-ordinations of a tight-rope dancer, they are nothing in point of utility as compared with the co-ordinated movements of a spinning-jenny. Therefore, although man owes a countless debt of gratitude to the long line of his brutal ancestry for bequeathing to him so surpassingly"exquisite a mechanism as that of the human body - a mechanism without which it would be impossible for him, with any powers of mind, to construct the artificial mechanisms which he does - still man may justly feel that his charter of superiority over the lower animals is before all else secured by this, that his powers of adjustive movement have been emancipated from their necessary alliance with his powers of muscular co-ordination."

This emancipation of man's adjustive powers from the limitations of muscular co-ordination, and their relegation to his powers of nervous organization, brings him into coordination with those instruments mentioned by Spencer, which "are artificial extensions of the senses," and those levers, serews, hammers, etc., which "are artificial extensions of the limbs." Through this new correlation comes man's power not only to understand, but to naster, the world and all it may contain. In other words, through this new relation Man becomes one member of an equation, which is the mathematical expression or co-ordination of which the other term is, practically, the whole of Nature with all its known and all its yet undiscovered wealth of jossilility. 
It is evident that we must seek for the beginnings of the meehanic arts in the brute world below man. Darwin says : "It has often been said that no animal uses any tool; but the chimpanzee in a state of nature eracks a native fruit, somewhat like a wahnut, with a stone. Rengger easily taught an American nonkey thus to break open liard palmnuts, and afterward of its own aceord it used stones to open other kinds of nuts, as well as boxes. . . A Another monkey was taught to open the lid of a large box with a stick, and afterward it used the stick as a lever to move heavy borlies. . . . In the Zoologieal Gardens, a monkey whieh had weak teeth used to break open muts with a stone; and I was assured by the keepers that this animal, after using the stone, hid it in the straw, and would not let any other monkey toueh it. Here, then, we have the idea of property; but this idea is eommon to every dog with a bone, and to most or all birds with their nests. The Duke of Argyll remarks that the fashioning of an inplement for a speeial purpose is absolutely peeuliar to man ; and he eonsiders that this forms an inmeasurable gulf between lim and the brutes. It is no doubt a very important distinction, but there appear's to me much truth in Sir J. Lubbock's suggestion, that when primeval man first used flint-stones for any purpose, he would have accidentally splintered them, and would then have used the sharp fragments. From this step it would be a small one to intentionally break the flints, and not a very wide step to rudely fashion them. . . . 'The anthropomorphous apes, guided probably by instinct, build for themselves temporary platforms; but as many instinets are largely eontrolled by reason, the simpler ones, such as this of building a platform, might readily pass into a voluntary and conseious aet. 'The orang is known to eover itself at night with the leaves of the Pandanus; and Brehm states that one of his baboons used to protect itself from the heat of the sun by throwing a straw mat over its head. In these latter habits, we probably see the first steps towarl some of the simpler arts; namely, rude architecture and dress, as they arose among the early progenitors of man."

It was in answering the question, "How did social evolution originate?" that Mr. Fiske proeeeded to make his noteworthy eontribution to the study of the subject, in which he claimed that inereasing intelligence in our early ancestors resulted in a prolongation of the period of infancy among 
their progeny - that infancy being occupied in building up the nerve and brain substance which were to be the organs of that intelligence, increasing them in mass and functional yower from generation to generation. In reaching this conclusion he mentions, but objects to, Mr. Darwin's view, "That men were originally a race of meek and mild creatures like chimpanzees, and not a race of strong and ferocious creatures like gorillas, and were accordingly forced to combine because unable to defend themselves singly." Putting the question in similar form, I venture to ask: How did the mental evolution characteristic of man originate? And to suggest as the answer, that it originated in the generic, or racial infancy and relative weakness of the early progenitors of man, long continued, and, through natural selection preserving only those who, fleeing singly to the trees, found others of their kind seeking the same refuge from common dangers which they were thenceforth to meet and combat in common, or in associated numbers, loosely organized and captained by the strongest and most intelligent of the band. The tree thus became a place of abode, in fact a home, and a house of which the leaves furnished the roof, the limbs the upper chambers, and the smaller branches the cradles for their young. It would seem that the real strength and promise of the human race have lain and still lie in relative racial infancy and weakness.

Constantly surrounded by wild beasts_-foes so much stronger than themselves - we may well, and sympathetically, understand how the mothers of that early time watched over their children by day, and especially how they mist have forbade them to be out late o' nights in the streets of their arboreal villages and cities; and, thus keeping them at home, how they cultivated from generation to generation - as we do now - what we know and appreciate as home and societary life. My own recollections of the maternal slipper do not go back so far as that; nor have my archæological studies yet qualified me to accurately describe the instrument used on such occasions by prehistoric mothers; but there is evidence to show that something was efficiently used, and that it may have had an influence in giving man his upright attitude.

It does not, then, seem to me a mere matter of fancy to consider the period of arboreal or tree-home-life as the strictly infantile part of racial development; the subsequent 
period, during which the trees ware more or less abandoned, the feet placed with the heel bearing firmly on the ground, the erect walking position assumed, and during which calves were being grown on their lcgs, as the time of adolescence; and the still later period in which we yet live, as the time of perfecting a manhood not yet perfected.

This suggestion, it appears to me, furnishes a clew to actual history ; for when we come to consider modern invention, we shall realize the absence, and the need, of a suitable explanation of its genesis as well; since the constantly recurring fact shown in these days is that inventions are not made by the strong, the rich and the powerful, but by those who are seeking to become so by growing out of their subordinated and comparatively weak individual and social position.

The history of this infancy and adolescence is chiefly written, as we may now believe, in every bone, muscle, nerve, tissue and structure of the human body, including the brain; and the history of this manhood will be found written in the moral, intellectual and social development of the race, largely in the ages to come, since we are still in a comparatively primitive stage, having as yet merely begun the work of mastering Nature.

To briefly catalogue, now, the world-shop and its contents, it may be recalled that in previous essays we have had it explained to us how, through the action of the rudimentary forces, the world not only became what we see it in its physical form, but also how it became a reservoir or storehouse of forces and materials, so disposed, arranged and adjusted as to make the earth a workshop sufficiently complete, had we been here then, to warrant us in looking abont us expectant of seeing the workman and mechanic standing near at hand, with sleeves rolled up ready for his job. Everywhere, and in everything, the earth is fairly throbbing with energy, either static, to be let loose as liy the touch of a hair-trigger, or dynamic, to be utilized anil controlled by the movement of a lever. Gravitation is an engine everywhere and at all times at work - in the solid earth, in the water, and even in the atmosphere. 'To this power is added the powers of wind, water, leat, cold, and so on to the end ; to all of which is arlded almost inexhaustible and cheaply prodnced animal power, controllable by man, and itself inlerently directed hy an intelligence only in- 
ferior to that of man, yet easily controllable by him, so long as he remains a man and does not descend to a level below the beast of the field.

As to materials for the hand of the mechanic, of minerals we have iron, and all the other metals, of the qualities of which, and of their alloys, we have only begun to dream ; coal, and other fuels, of which we are yet only intelligent enougl to get in extreme cases some ten per cent. of their dynamic capacity; innumerable rock and stone formations suitable for a variety of uses; and earths and plastic substances, capable of being softened, molded and hardened, all of which are so disposed as to be readily accessible and reducible for mechanical treatment and uses.

Next to the storehouse of minerals, stands the regetable storehouse, containing wood and timber of infinite variety. Other forms of vegetal life furnish fibrous substances for ropes, material for wicker-work, basket-work and strawplaited wares, and especially hemp, cotton and flax; to these add gums, dyes, medicines, and also a practically unlimited variety of foods already discovered and brought into use as fuel for the hmman mechanic engine; besides which, the earth contains enormous possibilities, evidently unlimited, for the production of other vegetable foods of which we now know nothing, since we have hardly begun the improvement and development of wild plants beyond their wild stage, and mostly depend upon those lianded down to us by our barbarous ancestors.

Next we have the storehouse of animal supplies, scattered, like the regetable supplies, abroad throughout the world, made accessible wherever man can live, and especially adapted to his needs in each of his many habitats. 'The animal-supplies come from the many kinds of land animals, fishes and water animals, birds, insects, worms, including the silk-worms, and all kinds of products derived therefrom. Permeating all these, in sky, air, water, solid earth, tree, plant and animal, we have that mysterious energy with which we are only now becoming acquainted - electricity; which may well seem to be a power stolen from the gods themselves, so incomprehensible, so ommipotent, so omnipresent, so all-penetrating and pervading is it.

To these make that most important addition - fire, important in its relations to the family hearth, to religion and the altar fire, but especially to the mechanic arts, and with- 
out whieh civilization, progress, soeiety and even life itself would be, for most of us, unlivable if not unthinkable. We can only glance at this subjeet, but it ought to have the adequate treatment of an entire essay, so important, so interesting and so faseinating is it. To us, as to the ancients, fire seems almost as elemental in charaeter as air, water or sunlight; but to primitive man, what a revelation it must have been! With its aid, doubtless, he first eooked his food, warmed his body, eut down small trees, divided them and their branches into elubs, pointed his weapons of war and the ehase, as well as his rudimental implements, and made his primitive boat. While, doubtless, as now, when it beeame the master, fire was terrible to him, in his hands it must at times have beeome terrible to his enemies,human, part human, or wild beasts of the forests. Seemingly, man must have lighted his first fire from the great interior earth-forge, to which aecess was had through volcanic aetion, or from natural conflagrations of eleetrical origin. Onee having knowledge of its value and power, we ean see low by meelianieal means - or frietion - he might seek it, and eventually sueceed in produeing it, under the stress of isolated sitnation, and struggle between eold and death on the one side, or lieat and life on the other.

In a leeture of brief space it is impossible to take up in detail special branehes of the mechanie arts, and show the prineiples of the evolution methods working therein. But while, as has been stated, little or nothing has been written on this subject, it eannot be said that nothing has been done to illustrate that evolution. In the National MIuseum at Washington you may find evolutionary principles applied to the eollection and arrangement of articles illustrating separate bramehes of this art, so that within a half-hour yon may see and examine original speeimens of all that has becm made and done by man in particular arts, from the carliest known periods down to the present year. In applianes eoneerned with transportation on land, you will find the band of the original transporter, which, being placed across her forehead with the two ends extending over aeross her back, was first used to seeure the burdens to be transported thereon, by the primitive or savage mother, wonan and burden-bearer (she was the original transporter); and from that article yom may follow every step of adrance up to the most perfeet loeomotive-engine and 
vestibule-train that our civilization has produced. The same is trile as to water-transportation appliances, commencing with the log-raft, and the dug-out, and ending with cuts and plans of the three-pipe steanship-flyer, which makes the trip from America to Europe inside of six days. So also in weapons of war and of the chase, fishery appliances, household implements of every kind and type, wood-working tools, metal-working tools, stone-working tools, musical instruments, and many other's.

Here we have the plan of the museum of the finture, one of the functions of which will be to put us quickly in possession of a knowledge of what has been done, and of how it lias been done, leaving us more of the precious hours of life in which to find out what can yet be done. The lesson everywhere taught in this way will be that invention and human progress are practically one.

Probably in no other place in the world is there such a store and treasure-house of facts showing that the progress of man and civilization is, and only is, along the lines of secondary evolution, or that kind of evolution to which direction is given in part by the human mind, as is to be found in the Patent Office at Washington. It is not too much to say that here are to be found counterparts to every prototype to be found in the history of primary evolution. A digest of patents in any and every branch or class of inventions, in the order of their dates, is not merely a study in evolution, it is evolution itself; for not only are new species being originated, but also new genuses, new classes, and new orders of inventions, all covered witl evolutionary earmarks. Whenever any invention is made, the first thing to be done is to obtain a list of all the patents in that and closely related classes; and, studying them backward, but with evolutionary principles in mind, we find the true relations of the new invention to the old. And only when these are ascertained, embodied in the specifications and claims, and accepted by the Office, can the respective rights of the inventor and the public be ascertained.

What, then, is the genesis of invention? At the first, brute animal strength and natnral mechanical forces are the dominant powers in the world; and what better could weakness do than escape to the trees for refuge, and, once secure there, for the time being, seck to reinforce weakness witl intelligence by taking time to think? It was wcakness 
that drove primordial man into the trees; it was also weakness that led lim to seck for the first aecessible assistanee outside of himself, which would be perhaps a eocoanut used as a missile, but more probably a club, later to become a lever, and eventually to move the world, or at least subdue and master it. Invention, then, is the initiative energy out of which man, soeiety and eivilization have grown, and without the persistenee of which they cannot continue to advance. It is certainly the basis of freedom and of peaee: in the beginning, of that kind of peace for whieh one lias constantly to fight, but in the end a peace assured, and blossoming into acknowledged freedon. The primordial club eventually becomes the seepter, and in modern times degenerates into a mere badge of soeial order, in the policeman's loeust; it also differentiates and eontinues to differentiate, until, through the lever, the inelined plane, the wheel and axle, the serew, the pulley and the wedge, it develops into all kinds of machinery and meehanism. In this differentiated form it still represents the badge of authority by whieh man reduees the forees of Nature and inferior men to obedience to his will. The pen, even more than the scepter, is our modern badge of authority. If it is true that "the pen is mightier than the sword," it is beeause the pen is, typically at least, the lever, and, like it, had its origin in the club out of whieh the sword also was developed.

Bouvier defines "Invention" to be: "l'he act or operation of finding out something new; the contrivance of that which did not before exist." But what is the naturc of the "aet of finding out"? what is newness? and what is the nature of that contrivanee which "did not beforc exist" but yet is made up of elements that have existed from the foundation of the world? By the Courts, invention, as an act, has been detined in Runsom v. Muyor of New York, to be, "the finding out, contriving, devising or eleating something new and uscful, whieh did not exist before, by an operation of the intelleet." After these simple explanations, yon find yourself floating on a wide ocean of definition, where every partieular invention is a law unto itself.

Walker, the most reeent elementary writer anl authority, says, "Novelty and utility must indeed characterize the subject of a patent, but they alone are not enough to make anything patentable; for the statute provides that things to be patenterl must he invented things, as well as new and 
useful things. The courts have therefore declared that not all improvement is invention and entitled to protection as such, but that, to be thus entitled, a thing must be the product of some exercise of the inventive faculties." Justice Matthews of the Supreme Court, dealing with a device held not to be an invention, said in 1885, it "seems to us not to spring from that intuitive faculty of the mind put forth in search for new results or new methods, creating what had not before existed, or bringing to light what lay hidden from vision; but, on the other hand, to be the suggestion of that common experience which arose spontaneously, and by a necessity of human reasoning, in the minds of those who became acquainted with the circumstances with which they had to deal." To which Walker adds: "The ideal line which separates things invented from things otherwise produced has never been completely defined nor described. There is no affirmative rule by which to determine the presence or absence of invention in every case. But there are several negative rules, each of which applies to a large class of cases." The practice universally is, to judge each case by itself. To be sure, there must be novelty, there nust be utility; but both those terms are loosely interpreted, and give us no certainty of definition.

Etymologically, to invent is to "come upon"- the word being derived from in and venire. So, to discover is to uncover. But neither of these terms fully describes or embodies the idea for which it stands. Invention is more than mere creation - it is a dual process: it involves an act of the mind in conceiving the idea, and an act or series of acts, external to the mind, either actually or amounting to an embodiment of the idea. Our word "create" means, literally, "to beget." In the account of creation in the Bible, the Greek word used in the Septuagint, which has largely influenced our English translation, is a form of the word poieo, which means to compose, as a writer or poet composes. It belongs to the order of mind, thought, and their constructions. If we were to import the word directly into our language, we should say: "In the beginning God poietised the heavens and the earth," - i. e., composed them out of the divine mind. We thus have a statement in some degree in harmony with the evolution view. This word, "poietised," would express, as it seems to me, the idea of invention, considered as an act, better than any recognized 
English word, since it involves a new mental composition and the substantial reduction of that composition to practice. In other words, invention is something more than a creation, if to create is to beget and bring into being; since the begetting and bringing into being are of the offices of the body, while invention is a function of the mind, assisted by the body only. It is also something vastly different from a mere happening, or "coming upon," the idea involved in the word now in use.

Mr. Seely suggests the word "eurematics." He has dealt with this subject in two papers read before the Anthropological Society of Washington, printed in the American Anthropologist, under the titles "T'he Development of Timekeeping in Greece and Rome," and "The Genesis of Invention." He says in the former: "My guide in this inquiry will be the principles in eurematics, that inventions always spring from prior inventions or known expedients, and that they come in response to recognized wants. . . The want may originate in some crisis or event having no apparent affinity in character with the want it engendered, or the invention that sprang to meet it. And these are not mere accidents: they are the natural course of what I venture to call the fixed laws of eurematies."

The word eurematies (eurekamatics) as thus defined has already found its way into the Century Dictionary. It does not, however, quite fit the niche prepared in this essay for the proper descriptive term. Etymologically and derivativoly it means "well-nosed,"-and carries the definition of "finding," or "discovering," as of a dog finding his prey or a buried bone, - and neither of begetting or creating, nor of composing by constructive thought or plan,- or "poietising." The word poictics, or poiematics, seems best to express the true idea, since the mind nust be the starting-point of the fixed laws of invention. and the proper word must cover or express the mental composition or construction actually required in the development of an invention, whether of a new machine, a new product, or a new art. Further, a recognised uout is primarily a recognized need growing out of relative weakness; and such a state of weakness, or relative infincy, is therefore the primary status, or base, of all invention, as it is of all mental lorecress.

Ifistorieally, it is the ontsicler who dexs the inventing, 
not the insider. It is not the man of the gruild who makes the new machine that surpasses the old, but the man whom the gnild will not admit and would destroy. 'The new invention, in fact, undermines the gulld, by displacing its machinery or method; consequently the guild is always conservative, and always the last to accept improvements or to appreciate them. The books are fnll of cases in point and proof.

Although, as Mr. Kimball has shown, the tendency of the improvement of the implements of war is to the destruction of war itself, the lever and the mechanic arts do not alone and unassisted destroy war and contention. As yet they only modify and change them into business competition and rivalry. Between great factories and little ones, the struggle for life continues. Some are equipped with old-fashioned machinery, and others with machinery containing all the latest improvements; and the old establishments find their property depreciated in value, their products more costly to make than those of their rivals, and the inevitable destiny of the old machinery is the scrapheap and that of the company the court of bankruptcy, unless at a late day it is able to recover itself by calling on the inventor for still later improvements.

Of course there can be no incentive to anyone to make inventions and improvements unless, when made, they can be hold in possession and kejt from rivals by means of a good title, or soll, subject to such title, for a proper consideration. The prineiple involved is not merely a principle of selfishness, but one of right and justice - of property in fact - which even the dog with his bone recognizes and protects, and without which we should probably to-day be still in a savage stage of society. But imperialism which is of the sword - has impressed something of its own character upon the nomenclature, the administration and the body of the patent law, thus invading the field of the mechanic arts, with the natural effect of mutilating and deforming them.

The word monopoly, implied in the patent right, is orlions because under that title kings disposed of the sole right to sell the necessaries of life to their favorites, who thereby oppressed the people. "Letters l'atent" was the name given to the doruments that sanctioned the monopoly. In seenring his patent, and in protecting it afterwards, the in- 
ventor is involved in a persistent struggle to enable him to retain possession of rights that belong to him ab initio and de jure. 'The right conferred by letters patent, as it now cxists in law and equity, is in fact merely the right to defend his right after he has armed the Government that grants the letters patent under its seal, and every man as well, for attack npon him, by disclosing the natnre of his invention and his methods of working it - it is the inventor, the creator, of civilization, against the world.

Of course, if the inventor chooses to use his invention in secret, and its secret use is valuable, he can make his own terms as to sales of products - provided his right of secrecy is not invaded by violence. But only a few inventions are of value when used in secret, and therefore in greneral that right is not protective and has no value.

The difficulties in the way of securing and protecting property rights in ideas - brain products; the fact that, notwithstanding these rights are founded as deeply as any others in the Constitution, the Govermment itself has been the great violator of these rights; that only within the last ten years the United States Conrts lave held that property in inventions could not be taken by the Government withont compensation; and that not till recently could the Govermment be brought into Court to answer for the torts of its own officers against patentees or patent property, or to answer for violation of a contract express or implied, - are important and should, with many other branches of the topic, be dealt with at length. The reasons why, and the way in which, the l'atent Office is doing more for our civilization than all the colleges and all the churches, together with important necessary improvenents in the patent law and its administration in the l'atent Othice, and in the treatmen of patents by the Courts, shonld be considered. lint the limits of this essay permit only this brief nention of these inportant sub-topies. The final conclusion of it all is, - so co-ordinated has the advance of socioty with brain action become, - that the nations which protect property in ideas will survive; all others will evidently perish.

Desiring to provile something in the nature of objectlessons for the instruetion of the Association and its guests, I plawe before you the four noble volumes of the Putent Office Girsette for 1s8s. These volumes contain 
something like 1500 pages each, or 6,000 pages in all, consisting only of what may be called the cream of invention and Patent-Office work for the year, separated from the skim-milk. These 6,000 pages contain only the claims of the patents, and one figure from the drawings of the patent intended to aid the understanding of the claims of the inventor. Including design patents, the patents for that year were upwards of 20,000 , involving an average issue of 400 patents or more per week, not counting the applications for patents not issued. These volumes are made up of weekly issues of the Patent Offce Gazette, containing from 125 to 150 pages, costing ten cents each, or $\$ 5.00$ per year. It is, as you will recognize, a marvel of cheapness, perfection and rapidity of execution, that in itself makes the Patent Office Gazette a worthy badge of the evolution of the mechanic arts, since the whole of the work is mechanical,-i. e., done by machinery. Contrast with these four volumes the volume (a small book of 519 pages) consisting of the Patent Office reports for 1851, and you will begin to obtain a glimpse of what has been done in the evolution of the mechanic arts during the last forty years.

In the year 1851,872 patents were granted; frequently now, 500 patents are issued in a single week, and on an average more than 800 are issued every two weeks. If I could set before you in a row the Patent Office reports and Gazettes, you would have the means, if inclined to philosophic speculation, of mapping or plotting out the various social, political, business, military and other cataclysms that have happened in this country during the past forty or fifty years, together with the intervals of peace and general uplift to the table-lands of national and individual prosperity. Prior to $185 \check{5}$ was the day of small things; the patents issued per year did not average 1,000. An increase in prosperity is indicated in the number and size of the volumes and the number of patents issued during 1854 , $1855,1856,185 \bar{r}, 1858$; then an ominous drop, pitching toward 1861. From this there was no recovery before 1864 . Beginning, however, in 1865 and 1866 , there was a rapid increase in the number and size of the volumes and number of patents issued, in accordance with the increase of national prosperity. From 1872 to 1879 , inclusive, the two annual volumes about equalled in size and contents one of these large quarter-yearly ones. Then, following the adoption of specie 
payments, a sudden inerease oeeurred, maintained with fluetuations of one kind and another down to the present time, the variations in the number of patents issued being latterly made up by the increased number of elaims in eaeh patent, showing improved work on the part of patent solieitors. The patents issued for 1880 in round numbers were 14,000 ; in $1881,16,000 ; 1882,19,000 ; 1883,22,000$; $1884,20,000 ; 1885$, 24,000; 1886, 22,(1000; 1887, 21,000; $1888,20,000$; and 1889, 24,158, the highest annual number yet reaehed. The number of the last patent issued in 1889 is 418,664 . The present numbering eommeneed in 1829 , prior to which 5,380 patents had been issued, commencing with only three patents issued in 1790. At the end of 1871 the number of the last patent issued was 122,303; the last number in 1881 was 251,684, the number of patents issued more than doubling in ten years. At the present rate of issue, the number of patents at the end of 1891 will again be more than doubled in ten years; or in other words, more than half of all the patents granted by the Government will have been issued within ten years; and out of about 460,000 patents issued, something like 335,000 will still be alive or unexpired.

Lack of spaee alone enables me to resist the temptation to follow up these statisties with a statement of some out of the mass of interesting facts that are involved in these few figures. As by far the larger part of these invențions are mechanical, and relate to mechanieal arts on the dynamic side, and those that relate to the arts on the statie side almost invariably touch dynamic mechanism somewhere, it becomes cvident at a mere glance that the prosperity and development of our eivilization are intimately eonneeted with the work of the inventor and the evolution of the mechanic arts. It is also evident that if our patent system should be abrogated, - the incentive to invention being therely removed,- - it would be such a disaster to civilization that we could better afford to sink one-lialf of the country to the bottom of the Atlantic Ocean.

In comparison with the great volmmes exhibited it is not much to brag about, but I am glad to be able to show you a l'atent-(office compilation, giving the names of women inventors to whom fratents had been granted by the Government, from 1790 down to July, 1sss. To be sme, an inspection of this book shows that their minds mu deeiderlly 
to bustles, lip-pads, and things of that order; but as women seem to be coming in these latter days back into contact with actual sublunary and business affairs, it may be expected that in future their influence will be felt to a much greater extent than ever before in this field of human endeavor.

It remains to consider: 1. What are the effects of Machinery and Inventions in agriculture and manufactures? 2. Have they benefited the laboring classes? 3 . What are their effects on the increase of wealth? 4. What are their effects on the progress of civilization? 5. What are their effects on the development of the human body? and, 6 . What are their effects on the development of the human mind?

Here are six distinct topics, each worthy of treatment in an entire essay, but which can receive only the attention of a few words. In considering each of them it is necessary to keep in mind the distinctions between the abstract and the relative, between what ought to be and what can be, between what is right and what the laws, the courts, the customs and the methods of society and business sanction. Here, as elsewhere and always, the first thing to seek is: The Kingdom of God, and His righteousness; whereupon you may be sure that "All these things shall be added unto you" - provided you understand the "Kingdom of God and His righteousness" to mean the supremacy of abstract, natural and divine justice — not such justice as man administers, but such as God administers and would teach man to administer. This by no means begs the question, but indicates that the true answers to the six questions depend on how much justice can be practically realized at human hands.

The answer to the first question is: That, in agriculture particularly, it depends on how the machinery is usedwhether it is used in accordance with the natural law of its use in the ultimate, divine system of things. If quickening or facilitating production by the use of machinery involves exhaustion of the soil, then the seeming benefit is a disaster, since the farmer is inevitably removing, parting with, or destroying, his capital, and will see the time when his desolated farm will drive him into exile and beggary, in punishment for his injustice - yes, his crime - committed against his land, the storehouse of the supply of life. An 
additional crime, another injustice, can be committed against land and all that concerns agriculture and its true prosperity, - nay, is being committed at this tine, - the evirlences of which are being written all over the face of the lands of our fair country, built into our cities from foundation to turret-stones, stamper indelibly upon our political, moral and religious life, formed into the very intellectual substance of our people, and co-ordinated with our entire civilization. I refer to that use of the nachincy of transportation by land and by sea, by railnoad and by steamship, through which the agricultural interests of $\mathrm{N} \times \mathrm{W}$ England, of the East, and of the ocenpying race of men and their civilization, are being destroyed, and inferior aliens in race and civilization are being put in possession in their places. Already destruction has begum to reach as far West as Michigan, where land valu's have seriously declined; and it is destined to continue its westward march across the continent, unless we promptly learn the true lesson of the use of machinery in relation to land and its products. It is this desolation of the lanrl and the masses that is enriching the few - the rilload kings.

As to mamufactures, a similar principle holds good, but with variations peculiar to that branch of industry. Thus, machinery and invention may be used in such a way as to consume and destroy wealth elsewhere and otherwise produced; but inevitably the effect of their proper use is to increase wealth - understanding that wealth neans weal; that it is not confined to movable capital; and particularly that it includes the labor of the wealth-producer, who is the mechanic, or has to do with the mechanic arts.

The answer to the second question, then, must be that inventions have benefited the laboring classes,-- nost where justice most prevails, and least where it least prevails. Consegnently, we find that in such countries even as Eng. land, it is doubtful if they have benefited the entire laboring elass affected loy the particnlar machinery and invention consinlered, though individual benefits have been realized. In America, it is certain that the cotton-gin strengthened slavery, degraded the laborer, utterly demoralized the owner of the cotton-gin, mentally, morally and politically, led up to rebellion, and still pronotes hisorder, cruelty, and, in the last analysis of cause and effect, even wholesale tyrany and mirler. An essay might well be written 
for the purpose of tracing the effects of the cotton-gin, and the absence of co-ordinately developed mechanical arts, in the South, upon the character and listory of the typical Southerner, and upon the past and future welfare of the entire country.

At this writing $I$ hear of a single typical case of benefit to the laborer, where a man known to me is now earning one hundred dollars per month as a mere attendant upon the machinery employed in making illuminating gas, who forty years ago would have done well in securing steady employment at $871-2$ cents per day. And there are many college graduates who are not earning or receiving so much. In fact, the laboring class has obtained the arvantage over all other classes - except the large capitalists - by beginning agitation and discussion years since. It is time for these other classes to take up agitation and discussion, for their salvation is now at stake. They are between the upper and the nether mill-stones.

The fifth question concerns the human body. According to the teaching of Spencer, Darwin and Romanes, already quoted, the connection between advancing brain and muscular co-ordination having been severed by machinery, and the day of a new kind of advance through mental and supplemental material, or natural mechanical co-ordination, having finally come,-chiefly in our own time,- - but little developmental change of plan or structure of the human body is to be expected or is possible, although, doubtless, rounded perfection of development, harmony and beauty of outline, as well as general increase of strength and endurance, and certainty and length of days, may be looked for.

It remains to consider the effects of machinery and inventions upon the human mind, and upon the progress of civilization in the ages to come.

Can anyone who has followed the history of the primordial germ, in its progress from a niere "faculty of responding to resistance" as its "fundamental sense," up to man with all his mental capacities, believe that the mental evolution of man is to stop now, when he has but barely entered upon that advance which is independent of muscular co-ordination? It is this emancipation of his adjustive powers which has brought him into correlation with the universe, through the additional senses, limbs 
and mental powers, conferred upon him by mechanisms. Can almost infunite development take place in mcchanisms and in the mastery of man over Nature, and man himself in his mental constitution, out of which they must grow, remain stationary or not devclop accordingly? No. Nor can any language now at command express that possible advance, for language itself has to keep step in the grand march. Only obscure mathematical formulas can embody it. Placing Nature, with its limitless capacities, on one side of the equation, we must put man on the other, with limitless answering possibilities of mental development; - for is it not the work of the human mind to realize those capacities? The equation thus formed being in the nature of a vitalized equation, no development can occur on one side of the sign of equality without rising simultaneously on the other. The nature and direction of mental advance would seem to be clear and necessary.

In dealing with the natural forces involved in the Evolution of the Mechanic Arts, the tendency must be to bring the human mind more and more into, or towards, harmony with that Infinite and Eternal Energy in and through which all forces operate, and by means of which all things have their being and their mode of action. We may therefore place a simple but perfect trust in the belief that in some day of a far distant age Man shall indeed become fit to be called a Son of God. 


\section{EVOLUTION OF THE WAGES SYSTEM.}

BY

GEORGE GUNTON

Author of "Wealth AND Progress," "The Prixciples of Soctal ECONOMICS," "THE ECONOMIO HERESIES OF

HENRY GEORGE," ETC. 


\section{COLLATERAL READINGS SUGGESTED.}

Spencer's "Principles of Sociology"; Rogers's "Six Centuries of Work and Wages"; Gunton's "Wealth and Progress"; Gronlund"s "The Co-operative Commonwealth" and "Ca Ira "; Edward Kellogg's "Labor and Capital"; Mulhall's "Progress of the World in the Nineteenth Century," and "History of Prices"; Levi's "Wages and Earnings of the Working Classes"; Grant's "History of Factory Legislation"; Brassey's "Work and Wages"; Wade's "History of the Middle and Working Classes"; Eden's "State of the Poor"; Tooke's "History of Prices"; Howell's "Capital and Labor"; Walker's "Wages Question"; Bastiat's "Economic Harmonies"; Young's "Labor in Europe and America"; C. Osborn Ward's "History of the Ancient Working People." 


\section{EVOLUTION OF THE WAGES SYSTEM.*}

Turs is essentially the era for testing systems. 'The time was, and not long since, when the laboring classes, and even the more intelligent advocates of industrial reform, regarded the capitalist as responsible for all industrial disadvantages to which they were subjected; whether it was a reduction of wages, the refusal to grant an increase of wages, or whatsoever, the individual employer or employers in general were held responsible. We have now reached the stage however where that mode of discussion is largely dispensed with. Among the more intelligent laborers, the subject is no longer discussed on purely personal grounds, but is considered from the standpoint of the constitutional tendency of existing economic and social institutions. In a word, the discussion of the industrial question has been transferred from the sphere of individual responsibility to that of economic and social law.

'This is a great advance towards a scientific consideration of the subject. It compels the laborer to look beyond the employer for the cause of the industrial hardships he encounters. Accordingly, to-day, all shades of social reformers, though they differ upon everything else, practically agree that the evils of society are due to the inherent nature of our industrial system as a system. 'The tyrannous exactions of the "heartless employer," the fraud of the "unscrupulous trader" and the vicious practices of the speculator are all pointed to as the necessary results of the present industrial organization of society - the wages system. It is held, and this view seems to be increasing, that the system of wages is a system of bondage, that the existence of wage-receivers implies the existence of capitalistic masters, that it is a system which enables the rich to grow richer by increasing the poverty of the poor. In short, that it is essentially a system of industrial servitude

* Copyright, 1890, by James H. West. 
and social degradation, differing from slavery only in nane; that it is necessarily inimical to industrial development, the growth of individual freedom and a progressive civilization. Consequently, the hand of the social reformer without regard to his constructive tenets is everywhere raised against the wages system. Whether he be Anarchist, Nationalist, Green-backer, Land Nationalizer or Socialist, the first step in his march towards the millennium is the abolition of the wages system.

It may be frankly admitted that the wages system is an essential part of the capitalistic system of production, and an indispensable feature of modern industrial methods. But is it necessarily an evil, economically or socially? is the first question to settle. If the wages system is inherently inimical to progress, nothing can justify its perpetuation. The prime question for the statesman and social philosopher to consider is human progress. All industrial conditions, social influences and institutions should be promoted or restrained according as they contribute to this end. There is nothing too sacred to be abolished in order to promote social advancement. If socialism is necessary to progress I am a socialist. I an in favor of revolution if revolution will do it. But will it do it? Is socialism necessary to progress? are questions that must be satisfactorily answered before such methods of reform can be justified. Whether or not the wages system is inimical to progress and tends to prevent the growth of indiridual and social freedom can only be determined by a eomprehensive study of the evolution of the wages system. This involves the consideration of (1) the meaning of wages and the distinctive economic characteristics of the wages system. The origin and historic development of the wages system and the influences which promoted its growth. (3) "The relition of the wages system to material improvement, individual development and a progressive civilization.

THE MEANING OF WAGES AND THE DISTINCTIVE LCONOMIO CHARACTERISTCS OF THE WAGE SYSTEM.

Wages may be defined as the price of labor or service. Since price always implies a sale, the price of labor is necessarily a stipulated amount given by unother to the laborer for his service. 'Thus wages are not, as is often assumed, what the laborer produces, nor the value of that 
product, but that which is actually and consciously given in exchange for the service per se. Therefore, for the same reason that there can be no price without exchange or sale, there can be no wages unless labor as such is bought and sold. It will be observed that this definition of wages includes the incomes not only of laborers who work by the day, by the week, or by the month, but the income of all without regard to sex or social status who sell their service as service. Wages include all stipulated incomes, whether great or small, which are received in direct payment for personal service.

The distinctive feature therefore of the wages system is that it distributes wealth in the form of fixed or previously stipulated payments. It differs from the individual selfemploying system in two ways. (1) Because the man who works for himself sells only the product of his labor, while he who works for wages sells only his labor or service. Because the amount the self-employed laborer receives is determined by the quantity he produces, while that of the wage-receiver depends entirely upon what another will consent in advance to give for his labor. It may be said that the slave-system was a stipulated-income system for the laborer. Indeed, one of the most prominent objections urged against the wages system is that it is a species of slavery. It is held that the slave worked for the master and so does the wage-laborer; the slave received what the master gave him and so does the wage-laborer. The slave did not own the product of his labor, neither does the wage laborer.

Since the wages system is the outgrowth of slavery, it naturally possesses some of the same characteristics; but it has also some radically different features, and it is these different features that distinguish it from slavery. It is true that under both systems the laborer receives his income from the employer; that under both systems the product belongs to the employer and not to the laborer. But here the similarity ceases and a new element enters the industrial relations. Under the slave system the laborer was a commodity, while under the wages system it is only his service that is bought and sold. Thus, under the wages system, instead of buying and selling laborers as under slavery, the employer buys service and sells products. By this change the price was transferred from the 
person of the laborer to his labor; thenceforth he ceased to be a commodity and became a distinct social as well as an economic factor, which constitutes a radical difference between the two industrial systems.

It is further urged that under the slave system the master was compelled to give the laborer as much of the product as would furnish him a living, and under the wages system le does no more. This is true, with the radical difference however that, under slavery, what should constitute the laborer's standard of living was determined by the arbitrary authority of the master, while under the wages system his standard of living is determined by his socral habits and new desires, which may be and are constantly increased according to the extent and complexity of his social relations. 'Thus while under both systems the laborcr's income is determined by his standard of living, in the transition from slavery to wages the standard of living was transferred from the sphere of rigid despotic authority to that of social law, where it becomes susceptible of indefinite expansion.

THF ORIGIN AND DEVELOPMENT OF THE WAGES STSTEM.

If we examine the state of society in France at the close of the ninth century, we find little but industrial and social confusion. After the death of Charlemagne, society was practically resolved into its original elements; political government and everything like social and industrial order practically disappeared. In the reorganization of society under feudalism, the center of all allegiance, authority and ambition was transferred from the emperor and petty king to the person of the feudal baron.* With the establishment of the feudal system and its more permanent social life, a greater desire for the display of wealth and social power rapidly developed among the barons and their more wealthy vassals. The ambition of every lorel to outelo his neighbors in pageantry and make the baronial hall rival the king's eastle, which was so common in the tenth and eleventh centuries, naturally stimulated the growth of new wants, tastes and social habits, the satisfaction of which necessitated the production of more wealth. As these influences extended, popmlation increased, and towns began to

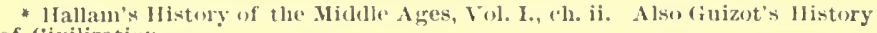
of Civilization. 
develop which naturally became the centers of industry and trade. With the growth of the towns, which became quite pronounced by the middle of the eleventl century, the social influences which had previously been confined to the lords and their vassals began to operate among the laboring classes.

Through this concentration of population and industry in the towns, several socializing influences began to operate. In the first place, in their daily occupations, domestic life and religious services, the laborers were constantly forced into more frequent and varied social relations, and these naturally tended to create among them the growth of new tastes and social habits. Under these conditions the laborers not only became familiar with and interested in each other, but they also acquired a more intimate acquaintance with and stronger desire for the use of wealth. Although the towns, including the laborers, were still the property of the barons, the new desires and wants thus developed gradually took root, and bore fruit in the character of the people, which finally became too strong for either baron or king to resist. Indeed it was by the character thus produced that the free cities were developed, where the seed of industrial and political freedom was planted which ultimately overthrew the feudal system and laid the foundation for modern civilization.

If time would permit, it would be interesting to follow the struggles of the laboring classes from the ninth to the fifteenth century, during which time they evolved from serfs, the literal property of the baron, to wage receivers with distinct industrial and social rights.* Suffice it to say that despite all the efforts of the barons and kings to oppress, plunder and enslave the laborers, before the middle of the eleventh century they began to obtain charters which not only gave them commercial privileges, but also secured to them the right of electing their own magistrates, judges, sheriffs, etc., and levying their own taxes. By these charters, which became very numerous by the twelfth century, the towns or free cities were practically transformed into little Republics. As early as 1020, the city of Leon received its municipal charter from Alfonzo V. of Spain. The charter of the city of London was granted by Henry I. in 1101, and those of Noyon, St. Quentin, Loan,

* Principles of Social Economies, lart I., ch. v. 
and Amiens by Louis VI. of France about 1110. Hallam tells us that "before the death of Henry V. (1125), almost all the cities of Lombardy and many of those of Tuscany were accustomed to elect their own magistrates and to act as independent communities in waging war and in domestic govermment." And in England, according to the same author, "From the time of William Rufus (1087 to 1100 ) there was no reign in which charters were not granted to different towns for exemption from tolls on rivers and at markets, those lighter manacles of feudal tyranny, or commercial franchises, or of immunity from the ordinary jurisdiction, or lastly of internal self-government."*

The increasing wealth and prosperity of the towns was a constant source of envy to the barons, who, we are told, "plundered them on every occasion without mercy or remorse." 'Therefore, in order to maintain their existence and the freedom and wealth they had acquired, the towns were forced to assume open hostility to the barons. As a means of swelling their numbers and sustaining themselves in this struggle, the burgesses made the towns a place of refuge and safety for all who shonld come to reside within their walls. And as an additional inducement they conferred the right of citizenship upon all who remained there one year, even though they were runaway scrfs from the neighboring baron's estate. Thus the towns not only protected the property and promoted the progress of the burgesses, but they offered protection and freedom to all who who would flee thither from the clutches of their fendal masters. By smch means they natmrally attracted to them the most energetic and characterful portion of the people. With this opportunity for improvement ancl freedom constantly held out to even serfs of husbandry, the barons were gradually compelled to provide better conditions, grant more privileges, and some freedom, in order to prevent them from fleeing to the towns. And by the middle of the fomteenth century, we are told, the villeins of England har largely berome hired laborers. In other words, the laborers had developed from serfs (slaves) into wage receivers.

since the middle of the fonrteenth century, the struggle of the laboring classes has been distinctly one for wages, as shown by the continuous legislation upon the subject

- Ilallam's History of the Mildle Ages, Yol. I., pl. 166-169 and 193; alsol Vol. II., 1. . $x$. 
since the famous statute of laborers in 1350. The first hundred years of the distinctively wage period was one of marked improvement in the condition of the laborers. Wages, which in the middle of the fourteenth century were but three pence or less a day, were doubled by the middle of the following century. Although, through canses which I cannot now stop to explain, this rise of wages was arrested* for several centuries, they were never forced back to the previous state. With the rise of the factory system, however, the same influences which produced the progress of the fourteenth century, again began to operate, and the wages system received a new impetus. And with all the disadvantages, and they are many, it must be admitted that the industrial and social progress of the laboring classes, and indeed everything that makes for civilization, has been greater than ever before.

With this evolution of industrial and municipai power came also political representation. As early as 1188 , we find, the cities of Spain acquired the right of representation in the Cortes. In England, the burgesses received a general confirmation of the:r charters, which, with many new privileges, were declared inviolable by Magna Charta in 1214. This was publicly confirmed thirty-two times before the middle of the next century, and in 1265 the burgesses obtained representation in parliament. With the growth of industrial freedom and general advancement toward wage conditions their power over the monarchy gradually increased, till, in the reign of Edward III., parliament demanded the right to appoint the king's counsellors, and finally to make and unmake kings. There is another fact worthy of note in this connection; namely, that in the same way that, with the development of the laborers from villeinage to wage receivers, and with the rise of wages and improved social conditions, their political power increased, so with the arrest of the rise of wages and social improvement, in the middle of the fifteenth century, their political power decayed. And it was not until the subsequent rise of wages under the factory system that any real revival of the political power of the masses took place.

It will thus be observed that, historically, the evolution of the wages system is an integral part of the evolution of

* Wealth and l'rogress, I'art II., ch. v. 
social freedom; that it originated in the social and industrial centers which developed character; that it was born of the very struggles for indivirual rights, and that the history of the wages system is the history of all the industrial, social, political and religious freedom modern civilization affords.

THE RELATION OF TIL WAGES SYSTEM TO MATERIAI, IMPROVEMENT, SOCIAL FREEDOM, AND A PIROGRESSIVE CIVILIZATION.

Although it is generally admitted that the wages system is superior to the slave system which preceded it, those who regard its abolition as necessary to progress insist that, instead of being fundamentally different from slavery, it is but a modified form of it, and therefore the final abolition of slavery and the establishment of industrial and social freedom involves the abolition of the wages system. Those who take this view, and they are very numerous, lay great stress upon the fact that, under the present system, the laborer is an employee. To them the very stipulation of ineome means limitation of freedom. Of all the objections urged against the wages system this is probably the most universal, and is regarded as the most fundamental. 'They think the only conditions under which social freedon is possible is where the laborer's employ themselves. This idea underlies all the impractical schemes ever attempted for introducing the social millemium. 'The scheme of early communism, the socialism (New Christianity) of Saint-Simon, Fourier and Owen, the Christian socialism of Manriec and Kingsley, the scientific soeialism of Rodbertus and Karl Marx, the land nationalization of Henry George, and the military socialism of Bellamy, are all practically based upon this assumption.

The fallacy in this position arises from a miseonception of the illea of freedom. Freedom is not a mere theoretic form, lut a sturly fart. It does not consist in the formal permission, but in the actual power, to gro or to do. Nothing ean give soeial and political freedon but wralth; the freedom that wealth afforis does not depend upon whether the laborer works for himself or for another, but it depends entirely upon how much wealth he receives. There is no power in Nature, Society, or Government that - can make a poor man free. Poverty is the essence of weak- 
ness, it is the source of slavery, and the background of all despotism. I repeat, it is not the fact that the laborer's income is stipulated that limits lis freedom, but the fact that it is small. The difference between the Pennsylvania miner and the president of the Pennsylvania Railroad is not in the form, but in the size of their incomes. A stipulated dollar gives more freedom than a stipulated cent. Let it never be forgotten, then, that it is the quantity and not the form of wealth that gives freedom.

Can the amount of wealth the laborer receives be increased under the stipulated-income wages system? I answer yes, emphatically yes! The evidence of history is conclusive upon this point. When the statute of laborers was enacted (1350), wages in England were three pence (six cents) a day, or about the same as they were and still are in Asia. Since that time they have risen many liundred per cent., and all under the wages system. And what is more, the rise in wages has increased as the wages system has become more general and permanent. Indeed, all the advantages of modern civilization, the discovery of the art of printing, the use of steam and electricity, the development of the factory system, the right of religious freedom, representative government, the development of the arts and sciences which enable the common laborer to obtain comforts, luxuries and freedom formerly unknown even to the wealtliy, have come under the wages system.

Nor is this progress in spite of the wages system, as some would have us believe. On the contrary it is largely due to it. The growth of material prosperity and intelligence among the masses was an indispensable condition to this development. The art of printing has finally given us our cheap books and the daily press, which would have been impossible without the growth of intelligence among the common people which enabled them to both purchase and to appreciate literature. Nor would the mechanical inventions of the eighteenth and nineteenth centuries and the development of the modern factory and railroad have been possible but for the increasing consumption of the products by the masses.

The wages system promoted this progress in many ways. In the first place, the stipulation of incomes tends to increase their permanence, and the certainty of getting a living. In proportion as the income of any class becomes 
stipulated it becomes less contingent and accidental. To the extent that this occurs, material substance becomes more certain and less precarions, which is the first step' towards social and intellectual development. So long as the laborer's living is uncertain, he is in a more or less constant state of anxiety and suspense which tends to make progress in the higher phases of social life impossible. Certainty of a living is the first condition to social advancement.

Another feature of the wages system is that it concentrates laborers and specializes their occupations. This is regarded as one of the worst features of the wages system, whereas it is in truth one of the best. By concentrating the laborers, it forces then into closer and more frequent intercourse with each other, which is indispensable to any appreciable degree of social development. Nothing can develop man's intelligence, character and freedom but contact with his fellow-man. It was because the free cities supplied this element that they were the nurseries of progress. It is true that in subdividing and specializing industry, the laborers become morc and more a fractional part of the productive process. But instead of this being a disadvantage it is a positive advantage. With the specialization of labor, laborers become more and more interdependent upon each other, as for instance, in the ordinary factory to-day one laborer cannot work unless they all work. 'The effect of this is to make the laborers all have a common interest. The prosperity of one is the prosperity of all.

Whatever welds people into a class, socializes them; and whatever socializes man expands and develops him. In proportion as men become interdependent with their fellowmen they become interested in them. In proportion as this process of social differentiation increases, our interests and sympathies broaden, our altruism is developed and the welfare of our neighbor becomes identical with our own. So long as man can succeed withont the aid of his fellowmen he will remain indifferent to his neighbor's welfare. The only way to insure that man will help his neighbor is to make his neighbor's well-being necessary to his own. This is precisely what the wages system does. It takes the laborer from lis isolated liand-loom or cobbler's bench, or 
his little patch of land, and puts him into the factory. When it does this, it relegates lim into a large specialized class, in doing which it makes him an inseparable part of a larger human aggregate. His interests are no longer isolated; his success is bound up with that of his fellows, and all the socializing influences of close intercourse and common interest at once set in. He then sees that he cannot fly away and leave his class, and therefore directs his efforts towards lifting that class. This is a fact which many of our leading writers and statesmen have not yet fully recognized.

It is a common thing to see the editors of the daily press advising the workingmen to save their pennies and become capitalists, - to leave their class and become employers. Such advice is very much like telling every boy that he can be president of the United States, - a thing that never was possible, and is becoming more and more impossible as the population increases. So the advice to the laborer to leave his class becomes more impracticable as civilization advances.

The tendency of industrial progress is constantly towards a relatively smaller number of employers, and more and more towards a stipulated income in the form of salaries and wages. The laborer feels this if he does not see it, and instead of trying to take wings and fly from his class, he endeavors to organize it. He sees that with the division and concentration of labor and stipulated incomes, the amount of wages, the number of hours' labor a day, the sanitary and other conditions under which he works, are not fixed separately for each laborer, but that they are regulated on a large scale for all. Consequently, in order to improve his own condition, whether by raising his wages, reducing his hours of labor, increasing the educational advantages for his children, or whatsoever, he is forced to demand the benefit for his class, as the only way of getting it for himself. This fact has brought the labor organizations into existence, which have done so much to raise the wages and improve the social and political status of the laboring classes during the present century.

There is nothing so saving to the human race, nothing that so surely promotes the advancement of civilization, as that which makes it necessary for millions to rise to- 
gether. No reform is worth fighting for, no statesmanship is worth considering, that does not tend to improve the conditions of the millions. I have no interest in any industrial or social scheme, in any civilization, or in any religion, that will save only a few. I believe in the survival of the fittest, but I also believe in making all tit to survive. Thercfore to say that the wages system is opposed to freedom because it tends to create a laboring class, is to entirely misunderstand the trend of social progress. Indeed, that is one of its most redeeming features, without which improvement among the masses would be hopeless. Wages camnot rise, nor can political frecdom or social character be developed by anything which does not increase the economic interdependence of the people, and weld them together in social classes. Whatever makes men more interdependent makes them more human, more altruistic and more frec. The savage has the minimum of interdependence; his existence mainly depends upon his muscle and upon accidents of his situation, and he is in almost perpetual terror. He has no freedom; he can travel but a very limited distance, and is in constant fear of encmies in the form of wild beasts or wild men or wild clements. In the civilized countries where the wages system is most advanced and the greatest industrial interdependence prevails, man can travel around the world in perfect safety, because under those conditions everybody has an interest in protecting the frecdom of his neighbors. 'That is why in the long run democracy is safer than despotism, because it includes more interests, more activities, more responsibilities and more reciprocal relations.

Another feature of the wages system is the tendency to promote more constant employment. Wages are an indisjensable phase of the capitalistic system of production. There is no fact more conclusively cstablished in the history of industrial progress than that with the development of the wages system, the division and specialization of labor and the interdependence of the laborers, has come the concentration of eapital in large enterprises. Nor is there any fact more conclusive than that the concentration of capital in fixed plants and large enterprises makes a marked increase in the permanenee of employment. 'That periods of industrial depression and enforeed idleness have accompa- 
nied the development of the factory-system is a fact too obvious to be questioned. 'These, however, as I have elsewhere shown,* are not inherent in the wages system, but are evils which sound economics and wise statesmanship may and should eliminate. But even with the blundering economics and blind statesmanship hitherto so prevalent, the permanence of employment has steadily increased with the development of the wages system and factory methods. For the proof of this you only need compare the statistics of able-bodied pauperisin (enforced idleness) of the sixteenth, seventeenth, and eighteenth centuries, with that of the last thirty years.

How to deal with the unemployed was the chief industrial problem that perplexed the English statesmen from the middle of the sixteenth to the first quarter of the nineteenth century. The statute books of that period bristle with enactments inflicting pains and penalties varying from the stocks to the scaffold, thousands being imprisoned, branded with red-hot irons, and not a few put to death, as the penalty for being "sturdy beggars," which condition enforced idleness made necessary. $\dagger$ Indeed, the history of the English Poor-Laws and the Act of Settlement under the Tudors and Stuarts is the history of futile attempts to deal with involuntary idleness.

With the development of the factory system and the concentration of capital, however, this evii has been steadily diminished; not from any generosity on the part of the capitalist towards the laborer, but because permanence of employment became indispensable to the success of large undertakings. As industrial establishments increased in size, involving millions of dollars, slight errors of management result in more serious losses. Indeed, it is a law of

* Prin. of Social Economics, Part IV., ch. iv (Industrial Depressions).

$\dagger$ In the first year of the reign of Edward VI. (1517) it was enacterl (chapter iii) that "if any person refuse to labor, and live idly three days, he shall be branded with a red-hot iron on the breast with letter $v$, and be adjudged slave for two years of the person who informed against him. It is further provided that the master may cause his slave to work by beating or chaining him; if the slave absconds for fourteen days he is condemned to slavery for life, and if he runs a way a second time, he can be put to deatl." It is said that "every part of the kingdom was infested with robbers and idle vagabonds who, refusing to labor, lived by plundering the peacerul inhabitants." In Elizabeth's rcign, "rogues were trussed up apace, and there was not one year commonly wherein 300 or 400 of them were not devoured and eaten $\mathrm{np}$ by the gallows in one place and other." In the reign of Henry VIII., 72,000 are said to have been put to death for these offenses. (Wade's History of England, pp. 16 and 17. See also Rogers' Six Centuries of Work and Wages, p. 419.) 
the concentration of eapital that the larger the eoneern, the smaller is the margin of profit, the greater is the risk of loss; and expertness of management is nore neeessary to suceess. Indeed, with the small margin of profits and close eompetition between large eoncerns to-day, slight mistakes may involve the loss of thousands of dollars. So true is this that in all well-established industries the eonstant employment of eapital is now praetieally indispensable to suecess. For example, in the manufaeture of eotton cloth to-day an eighth of a eent a yard will nuke the differenee between sueeess and failnre. The loss involved in the short stoppage of a large faetory will soon be more than equal to the profit of a year's business. Whatever inereases permanenee in the use of eapital necessarily inereases the eonstaney of employment. 'Thus, as the wages system and faetory methods develop, the eapitalist has to pay the penalty through loss or bankruptey for enforeed idleness; and henee permanent employment beeomes one of the features of the industrial expertness of capitalistie management. Under the individual or self-employing regime this was not the ease. When the hand-weaver failed to sell his eloth or make a living he could starve, beg, go to jail or die, as the ease might be. His poverty involved nobody else, while under the wages systen the great eapitalist, nay, the whole eommunity, is nnolved with the enforeed idleness of the laborer. This is inevitable, beeause of the dependenee of the employing elass upon the consumption of the laborers, which the eolossalizing of produetive methods has made neeessary. Thus, the inherent tendeney of the wages system is to inerease the permanenee of employment and diminish enforeed idleness.

Aceordingly, the world over, we find that permanenee of cmployment increases and enforeed idleness diminishes where the wages system is most developed and eapital most coneentrated. If you have any doubts upon this point, watch the currents of emigration. People always leave those localities and eountries where employment is the most preearious and least remunerative, and move towards those where it is most permanent and best rewarded. Hence we see that emigration cverywhere tends from those eountries where the wages system and factory methods are least developed, to those where they are most highly developed. 
It is from Bohemia, Austria, Italy, Germany, Ireland, etc., towards England and America that the laborers emigrate, and never from England or America to Continental Europe and Asia.

The wages or stipulated-income system may be properly regarded as an integral part of modern civilization, which it is absolutely impossible to abolish without returning to barbarism. If the most Utopian socialistic scheme were adopted to-morrow it could not dispense with the payment of wages without abolishing factory methods of production and returning to the self-employing hand-labor conditions of primitive society. If we are to have railroads and factories at all, it would be just as necessary to pay salaries and wages if they were owned by the government as when they are owned by private individuals. Whether we have socialism or private ownership, unless we are to abandon the economic use of iron, steam, electricity, and the achievements of modern science, we must have a wages system.

This does not imply that the poverty, ignorance and social degradation of the present industrial life is to continue. What it means is that the social progress of the future must be sought along the same general lines that it has traveled in the past; namely, towards greater specialization of labor, stipulation of income, and interdependence of social classes. The wages system does not, as is commonly assumed, imply an iron law; on the contrary it is as elastic as human wants and desires, and is capable of as much expansion as the social character of man. There is nothing in this system to prevent wages from indefinitely increasing. It is just as possible for the laborer's income to rise from the present rate to $\$ 5000$ a year under the wages system, as it was for it to increase from $\$ 20$ a year in the fourteenth century to $\$ 900$ or $\$ 1000$ a year to-day.* In fact, if the same relative increase in wages, and the social freedom it implies, takes place during the next hundred years that has occurred during the present century, the laboring classes will be better off - richer and freer-by the year 2000, under the wages system, than even Bellamy's

\footnotetext{
* The wages of compositors, earpenters, masons, lricklayers, engineers, and some other classes of neehanies, have already reached s 1000 a year in this eountry, whieh, allowing for the difference in the value of gold, is many hundred per cent. higher than the wages of the artificers as fixed by the statute of Laborers in 1350 .
} 
Utopian dream anticipates. In other words, with the wise application of economic law, the Nationalists' millennium will actually be reached quicker through the law of evolution under the wages system than by Bellamy's cthereal scheme, even if that were as scientifically correct as it is economically insane. It is of the very essence of the law of evolution, that the industrial system, which tends to centralize and socialize the laborer, to increase the economic interdependence of the capitalist, consumer and workman, and to make the material well-being of the masses the basis of business success, possesses all the possibilities of an ever-advancing civilization, and must in the nature of things be the foundation of the industrial system of the future. Manifestly, then, it is not to the abolition of the wages system, but to the influences which advance wagcs, by increasing the leisure and educational opportmnities for dcveloping the character, capacity and freedom of the laboring classes, that we must look for the industrial reforms which shall permanently promote the evolution of the highest individuality and the broadest social democracy. 


\section{EDUCATION AS A FACTOR IN CIVILIZATION.}

BY

CAROLINE B. LE ROW

Author of "English As SHe is TAught," "The Young Idea," ETC 


\section{COLLATERAL READINGS SUGGESTED.}

Spencer's "Principles of Sociology" and "Education"; Richter's "Levana"; Rousseau's "Emile"; Farrar's "Essay on Education"; Taylor's "Classical Study"; Bain's "Education as a Science"; Painter's "History of Education"; Adams's "School System"; Potter's "School and School Naster"; Randall's "First Principles of Education"; Payne's "Contributions to the Science of Education"; McCosh's "Compulsory Education"; Iruxley's "Science and Education"; Lessing's "Education of the Race"; Lubbock's "Present System of Public Sclrool Education"; Hacker"s "Scientific Basis of Education"; Everett's "Importance of Practical Education"; Dodge's "Common School System"; Huxley"s "Technical Education"; Hæckel's "Freedom in Science and Tcaching"; Fleay's "Lectures on Education"; Ham"s "Manual Training"; Palmer's "The New Education" and "Science of Education"; Mamn's "Lcetures on Education"; Peaslie's "Moral and Literary Training in the Public Schools"; Mayo's "Talks to Tcachers"; Laurie's "Comenius : his Life and Works"; Froude's "Essay on Education"; Morris" "University Education"; Boone's "Education in the United States"; Dr. Frances Emily White's "Muscle and Mind" (in Pop. Sci. Mo., July, 1889). 


\section{EDUCATION AS A FACTOR IN CIVIL- IZATION.*}

Our civilization is the result of education. The world's intellectual progress, like other phases of evolution, has encountered many obstacles, met with vexatious delays, made unexpected and astonishing strides forward. It has sought at one time to deify the body, and at another to sacrifice the body to the soul. It has been injured by its friends, aided by its foes, led men into the basest bondage as well as into the broadest freedom, and still forms the subject of bitter if bloodless controversy.

Mian was educated before books were thought of, and his development would have continued if a school-house had never been built. The stone that cut, the water that wet, the hunger which drove him to slay wild beasts, and the cold which led him to wrap himself in their skins,- - all were in turn his teachers, suggesting to him new relations and combinations, leading him to draw his crude inferences and make his clumsy experiments. It is painful and little profitable to follow the slow gropings of the human race in its efforts to reach intellectual light. These struggles are pathetically written for us in the habitations and implements left upon earth by primitive man. It is evident that from the time he began to think he has striven to think more clearly and to definite ends, growing gradually into a realization of the fact that it was possible to set in order the results of his experiments, to preserve and classify the methods by which certain desirable ends had been attained, in order that the experience of the mass might be made to benefit the individual. So came the teacher and the school, to supplement the work of Nature; but it has only lately been decided that the philosophical method in education is superior to unaided natural instinct.

Egypt, the cradle of the sciences, boasted of arts and learning while Greece was in a state of barbarism; in fact,

* Coprrigur, 1890, by James II. West. 
it was to the Egyptians that the Greeks owed their civilization. We know that Egypt was the first country to recognize the need of education, though it was intended to train men only for the special work of tlie government. History affords us no light by which we may read of Phœnicia and of Persia beyond the facts that the Persians were worshipers not only of fire and sum but of moral excellence as well, and that in Persia the State appears for the first time as an agency in promoting education. Statcments concerning Assyria and Babylon differ as much as newspapers upon the opposite sides of a political campaign. We know only what has been revealed to us by explorers among the ruins of their magniticent palaces and temples. Human thought reached a high standard in China, led by Confucius, but as the Chinese system has always been a form of communication rather than development education has never been a matter of growth. The student works always with one eye on the examiner, as all scholarship is for the sake of obtaining places in the eivil service of the empire. No girls are allowed to attend school, but to make up for this loss to the nation the boys are required to go at daybreak and remain till six o'clock at night.

Education in Rome was almost wholly military and religious, and based upon the strictest family discipline. The Romans were thoroughly utilitarian, aiming only at the education of obcdient and devoted citizens and soldiers. Strong, heroic, and disciplined men were the result of this training, although it held in contempt the graces of the intellect and the lieart. The Romans seem never to have considered education an affair of the State. Greece, though but a speck on the map of the earth's surface, occupies an immeasurable area in the empire of mind. Its name is synonymous with genius, philosopliy, and art. The age of Plato and Aristotle was the age of the beginnings of many of the sciences, while moral and ethical speculation began at that time to take definite shape. It was a saying of Cicero that Socrates "brought down philosopliy from the heavens to the earth," and the influence of Grecian thought is to-slay a mighty jower in the intellectual world.

Among the early Christians, life was considered merely a preparation for death; classical literature represented a pagan religion; ignorance and holiness were considered 
synonymous terms, and all learning except that of the priests was attributed to the Father of Lies. The mental labor of the ages appeared to have accomplished nothing, for the past was practically obliterated, and in less than four hundred years, under this devastating though conscientious influence, the race reverted to almost its original mental obscurity. But the intellectual torpor of the Middle Ages cannot be wholly attributed to the church. A state of continual conflict is not conducive to study, nor does an enslaved people ever appreciate education. Moreover, where a dead language is supreme, the mass of the people must remain in ignorance.

In the twelfth century the human mind began to stir uneasily in its heavy slumber, but it was temporarily quieted by the scholasticism which confused the awakening intellect with the foolish and fantastic speculations of monkish dialecticians. Still, this form of exercise, though merely leading the mind on a monotonous march through jungles of syllogisms and verbal quibbles, did something toward keeping the intellect from relapsing into utter stupor until it could be aroused into real activity.

But suddenly there came the shining of a great light upon a waiting world, the dawning of that intellectual day which was to make the sixteenth century an epoch in the history of human thought and aspiration. The mind a woke to intuitions concerning development according to natural laws, and to a conception and hope of independence and progress transcending the wildest dreams of the night from which it had emerged. Erasmus, Montaigne, Rabelais, Calvin and Melancthon, did much to open the long-blinded eyes, while the ink-stand thrown at the devil by Martin Luther was in reality the challenge hurled by Truth to Falsehood, and the signal for men to take up arms in the holy cause of intellectual liberty.

The common school has been called "the child of Protestantism, whose cradle was the Reformation." Comenius was the prophct - without honor - of our present educational methods. The laws formulated by him on the art of teaching, and the grades of instruction which he defined, leave little to be desired at the present day. Progressive educators of our time merely echo the words of Comenius, in which he urges the instruction of the young, "not by beating into them a mass of words, sentences, and opinions 
gathered out of books, but by opening tlyeir muderstandirg through things themselves." 'Tluus was planted, almost three hundred years ago, the germ of the idea which has since found fruition in object-lessons.

It is impossible to estimate the influence of the Jesuits upon the world's civilization. These Epicureans of Christianity, as they have been named, controlled during two hundred years over six hundred colleges and many universities, a power lasting till almost the end of the eighteenth century. 'The order disdained history, science, and philosophy, their labors being wholly directed to the propagation of the Catholic faith, and the ability to write in Iatin was their idea of all excellence. A correet notion of the tenor of their teaching can be gathered from the dictum, "We must be so attached to the Roman church as to hold for black any object which she tells us is black even when it is white, and if God should appoint for our master an animal deprived of reason we should not hesitate to render it obedience." It is only by a close study of the rules of this order that it is possible to realize the cause and progress of the terrible paralysis from which it has not yet recovered thus suffered by human consciousness.

A summary of the sixteenth century shows that the effect produced upon education by the Reformation and the Baconian plilosophy was the subjection of matters of opinion to reason, observation, and experience, and the establishment of universal instruction in order to make each human soul responsible for its own salvation. Schools were consequently multiplied and attendance made compulsory, ignorance being regarded as an evil and a menace to temporal as well as to spiritual safety.

The vital spark of the intellectual fire which warms and illumines our system of the present day was caught from the devoted Pestalozzi, who, with tardy justice, is aeknowledgred as the Father of the Common Schools. Pestalozzi, largely muractical, failing as lawyer, minister, and farmer, was possessed thromgh his eighty years of life with an affection for children which has made us his debtors for all time. His sureoss in his work with the little outcasts upon whom he experimented was remarkable. His attention was directed to the training of children as distinct from mere instruction. The hasis of his method was the development of the observing and reasoning powers - an exten- 
tion of the object-teaching of Comenius, to whose labors he acknowledged himself indebted; and, though dying overwhelmed with mortifications and disappointments, his name remains immortal among those who love their kind.

Frœbel continued the work of Pestalozzi, and like him labored less for his own time than for our day. As a child he was dubbed a dunce, and if it be true that "genius is the faculty of acquiring poverty," both he and his great master must be placed high annong the gifted ones of earth. Like him, also, Frobel was dreamy, unpractical, a blundering administrator of affairs. He made many mistakes before fixing upon his final vocation, and even this proved a failure so far as he personally was concerned. He also, a victim to great griefs, died believing that his life had been lived wholly in vain.

It is with the Kindergarten method that we associate the name of this savior of little children. To him the child was a plant and the school its nursery. Though much of the seed which he sowed fell in stony places, much also fell on good ground and has brought forth fruit abundantly. We feel a natural and profound interest in Frœbel's frankly expressed opinion that the kindergarten method could reach its fullest development only in America, whose national principle is self-government,- - perfect freedom according to law.

The pedagogy of our own century proves "how much the years teach that the days never know," and claims the proud distinction of inaugurating the attempt to organize the grand science of psycliology, the highest evolution of mental and moral philosophy, little at present understood, but alone able to furnish rules and principles upon which intellectual development can proceed. It is now for the first time conceded that all education must rest upon this scientific basis, while methods must be rationally combined; that there is, practically, no limit to this education, or to its value to the individual and the State; that education, properly understood, is preparation for "the life that now is," and that only in such preparation can there be made adequate provision for that which is to come.

So by degrees, imperceptible to each generation of men who in their brief hour of life and narrow field of labor struggled, blundered, suffered, and despaired, the human intellect has expanded through the slow centuries of 
time, governed by the law of development which produces the planet from the star-dust and controls the motion of the rolling spheres.

Horace Mann declares that, "as an imovation upon all pre-existing policy and usage, the establishment of free schools was the boldest ever promulgated since the Christian era,"-convincing words if we realize all that such establishment implied - the most practical recoguition of the brotherhood of man that could have followed the utterance of the doctrine by the Great Teacher of the world. Less than two centuries ago no system of free schools was maintained anywhere on earth. To-day there is no civilized country on the face of the globe which does not possess some of its advantages. We can almost forgive Joln Calvin for his theology in realizing our indebtedness to him for the common-school system. By Martin Luther it was introduced into Germany; by John Knox into Scotland; and, crossing the ocean in the tempest-tossed Mayflower, set firm foot upon Plymouth Rock. The school, once killed by the church, was years after rc-created by the same power grown through evolution wiser in its policy, broader in its views and aims.

One of the most important variations now proposed in connection with the public-school system is the incorporation in the course of study of mamual, industrial, or technical training. This new departure, known by all these names, meets with opposition only from the few frightened spirits who persist in looking upon it as an attempt to substitute the labors of the workshop for the legitimate intellectual training of the school. Properly it has reference only to edncation in its most comprehensive sense; the addition of practice to theory, experiment to observation, the correct eye and skilful hand to the developed brain, that the youth graduated from our schools shall be fitted not only for clerkships and professions, as is now the case, but for the skilled labor which the world so sorely needs. 'This idea, though considered so new a thing under the sun, was most eioquently advocated by Locke and Luther, and in our own country, two hundred years ago, by a Quaker - honored be his memory - Thomas Budd of Burlington, New Jersey. But the wisdom of the idea is not yet practically recognized to any great extcnt, though wherrer the experiment has been tried it has proved successful. 
A Nihilist lecturer recently stated that there are four hundred schools in Europe whose sole work is to teach the use of explosives, and there are already a few of these schools in the United States. If the Old World is thus diligently sowing the seeds of discontent and rebellion, scattering some of them on our own too prolific soil, teaching that to brute force alone can humanity look for the redress of its wrongs, how much more necessary it becomes for this new continent to show the world that not in killing each other, but in helping each other to live, is the only possible solution of our social difficulties. Unless our schools can teach respect for labor, it will never be learned; and unless it is learned, and learned practically, we may expect worse things to come upon us than any of the lamentable upheavals which of late years have disturbed and threatened society. Manual training is the logical outcome of the kindergarten principle as advocated by Frœbel, the foundation for thorough and symmetrical development. No true education is possible which ignores either of these factors, so lately recognized, so reluctantly adopted. Those who consider the name of the French nation a synonym for frivolity may yet feel considerable hope for the future of a country whose principal city is supporting one hundred and twenty-six free kindergartens, educating - body and soul, as well as brain - more than thirty thousand of its coming citizens. The application of this simple principle of political economy has been made in a few cities of our own country, and the testimony of the police concerning the consequent diminution of disorder and crime in those places proves beyond all need of argument the superiority of prevention to cure.

The only valid reason given for not including kindergarten and manual training in our school-course is the difficulty of obtaining funds for the enterprise and teachers qualified to conduct it. Few of these teachers yet exist - for they must be teachers as well as mechanics - but many are enthusiastically serving an apprenticeship. In the meantime the fact that the best educational thought of the civilized world is engrossed in the practical consideration of these reforms guarantees the hope of their ultimate adoption.

However much at variance may be our theory and our practice, it is conceded that character is the aim of cul- 
ture, and the only diversity of opinion concerns the means whereby this aim may be secured. If the only way to diminish the amount of wrong-doing is to diminish the number of wrong-doers, it becomes of the highest consequence that our youth shall be instructed in the ethical principles agreed upon by all philosophers from Socrates to Spencer. But whether this training is sufficient is a question upon which wise men radically disagree. The spirit of the Puritans, who, if a youthful historian is to be believed, "came to this country to worship God in their own way and to compel other people to do the same," is not wholly extinct among us.

The first religious difficulty concerning our schools arose as long ago as 1823 . It has become formidable since Pope Pins IX., in 1875, pronounced onr school system "a most peruicious system," and ordered that the prelates use evcry possible means to protect the flock committed to their care from all contact with the public schools. One of the leading church papers declares that " out of one hundred children educated in the public schools, ninety-six are a clear and certain gain to the devil." 'This is a fair sample of the editorial utterances of the Roman Catholic press, which calls down anathemas upon the heads of those who allow their children to attend other than parochial schools. But the ecclesiastical curse appears to carry small weight when it threatens the educational welfare of their families, and many of the Catholic elergy, though guarded in expression, are upon the side of the defiant parents.

The separation of Church and State left the school a disputed territory for both to quarrel over, and two phases of Christianity are just now on trial; bnt the fittest will survive, for the jury to decide the case is composed not of a dozen men, but of millions, upon whose intelligence, not ignorance, the verdiet is to rest. "The old-world order of things," says Holmes, " is an arrangement of locks and canals, where safety depends upon keeping the gates shnt and so holding the upper watcrs at their level; lut Ameriea trusts the whole tide of life to the great clemental influences, as the vast rivers of the continent settle their own level in obedience to the laws which govern the planet and the spheres which surronnd it." Upon those who leclare that "godless schools" are the cause of crime, 
rests the burden of proof. While a good education and a skilful handwriting may lead to forgery and to prison, there is no reason to suppose that they must do so. It is an unceasing wonder that our schools, working under so many and such great disadvantages, offer such successful resistance to the turbulent tides of ignorance and depravity threatening to overwhelm us. The very existence of the schools implies moral education, and the children who are learning the physical law that a body unsupported falls to the ground are just as surely learning the moral lesson that sin is followed by suffering.

While it is assumed that schools supported by public money for the public benefit should exclude all forms of religious teaching, it cannot yet be claimed that they are doing all that is desirable or possible in the direction of moral development. The too-commonly conceited, lawless spirit of our youth is something to be considered with fasting and prayer,-if, so be it, this kind goeth not out otherwise,- and is represented by the eager fellow who ordered to be made, for a high school, a class badge bearing the figure of the graduate and the world of knowledge he was supposed to have conquered,- the youth to be two inches high, the earth an eighth of an inch in diameter. The moral tone of the school can improve only as there is improvement in the teaching and directing force. When superficial study, love of display, and haste for results, give place - as they surely will in time - to the slow and eareful culture which, tempted to no selfishness or deceit, develops not only mind but body and soul as well, the graduates of our schools will stand erect in the stature of an emancipated and spiritualized manhood and womanhood, regarding the world and their fellow-men in that humble, teachable, and reverent spirit which characterizes the true scholar.

Crime is the costliest product of our civilization, and we pay most for what we desire least. In 1870 only four per cent. of the population of England of school-going age were under instruction, and many believe that the adoption in that year of the English Elementary Education Act saved the country from revolution. Pauperism and crime diminished in proportion as school attendance increased. In our country crime is increasing to a greater relative degree than in any other civilized country except Italy and 
Spain, nor is our prison population composed wholiy of illiterates or foreigners. In New York six millions of dollars a year are hardly sufficient to pay for police and prisons, while a little over half that sum is considered ample for schools. Germany was the first nation to discover that prevention, the moral medication which seeks to remove causes rather than symptons, is the only sane method of curing crime. If ignorance is the cause of crime, has not society as much right to place a child in school as it has in later years to put that same child in prison? The law orlains vaccination, - why not edncation? Kingsley has said that, "when the devil camnot find a knave for his purpose, he secures a fool, which answers just as well" ; and Lord Brougham, years ago, stated in the House of Lords, "If, from an early age, a proper system of instruction is pursued, it will be as difficult for a child to become a criminal as for one of your lordships to go out and rob on the public highway." "With the exceptions of Holland and Belgium, education is now compulsory in every foreign country. The monarchical governments of Europe are sagacious enough to perceive that as intelligence and opportunity for its use are rapidly increasing on the earth, it is the part of wise legislation to direct this intelligence in such a way as to insure political safety. Can this American republic afford to do less than this? Without education there can be no intelligence; without intelligence there can be no enlightened ballot, and withont the ballot there can be no preservation of the form of govermment conceded to be the lighest evolution yet attained of liberty, law, and order.

The university was the sole educational institution of the Midule Agres, when the classics furnished all there was to be learned. But the life and world of to-day is hardly that of the fathers. Gladstone is authority for the statement that from 1800 to 15.50 there was produced as much permanent wealth as during the entire eightern hundred years preceding. It is not easy to grasp this stupendons fact in all its relations to the social and intellectwal development of man. One hundred years ago there was hardly any science entitled to the name. Biology and ethnology are the growth of our own century. 'The study of chemistry has been itself transmuted during the past fifty years. Botany, geology, astronomy, as well as 
history and geography, have been greatly enlarged in scope and method. As for the social subjects clamoring for study, the number is already enormous, and constantly increasing, while there is constant discussion of the question, "Is the college a help or a hindrance to man in his preparation for the work of life?" A leading educational paper has recently declared that, "except a skinned eel or a boiled lobster few things are worse prepared for life than the average college graduate." If this be so, it is cause for thankfulness that in New England, at least, the number of persons in colleges is no larger than the number in insane asylums, though more people of the United States take a college course than those of any other country. In England there is loud complaint that the universities are not keeping pace with the progress of the people, and that a smaller number of educated men are every year coming to the front. According to President Eliot of Harvard, the ordinary American college-graduate is nearly thirty years of age before he becomes, even theoretically, self-supporting, and then is fitted only for professions already overcrowded. Certain it is that neither in school nor college will mediæval methods much longer satisfy the demands of this modern day. Evolution is reconstructing the fundamental conceptions of education as well as of philosophy and religion. Although from the magnitude of the movement its results are not readily apparent to the impatient or careless observer, this fact is practically recognized in most of our colleges to-day. Oxford and Cambridge are rising in their efforts to reach downward to the common people. Harvard and Yale are developing new and wise policies. The elective system, tried experimentally for twenty years before its permanent adoption, is now almost universally accepted. Many post-graduate courses have been added for the adaptation of studies to individual needs; and not only in the intellectual but in the moral environment of the college has evolution been steadily at work, - for, much as we deplore the riotous outbreaks which occasionally scandalize our university towns, we are soothed and encouraged by the remembrance that the old Vienua statutes found it necessary to specify that "the students shall not spend more time in drinking, gaming, and fighting than at logic and physics."

If the addition of a grammar-school training increases 
the value of a primary one; if the high-school eourse which follows furnishes still better preparation for the work of life, why should not the broader culture of the eollege render the most valuable aid of all? To do so is its intention and its aim, and, although it lias not yet reached this condition of ideal exeellence, it is not unmindful of the responsibilities of its ligh estate nor unwilling to fit itself to discharge them. To the law of natural selection, which "takes advantage of such variations as arise and are beneficial to each ereature in its eomplex relations of life," we are justified in trusting the future of our colleges as of all our schools.

The agitation eoncerning elassieal study is not of reeent date; it has existed in every eountry where the elassics form part of the school course. In Germany and Prussia the eontest has been long and bitter; lately the war has been spirited in England; it was recently revived in Scotland, and began in this eountry almost a century ago. Greek was welcomed by Christian Furope as the original of the New 'Testanent. Latin was the ground-work of education simply because it was the language of the edneated classes; it was employed for all publie business and for the service of the church, and at one time the elassics contained all the history, poetry, and philosophy of any value. The disposition to quarrel witl the classics arises solely from the assumption that they crowd out more important matters. No one denies the beauty and the power of the Greek and Latin tongues; thonsands of scholarly men enthusiastically testify to the profit and reereation of the study; but the fatal feature of the situation lies in the great difference between what classical study can do, and what it practically does do, for the majority of students. 'To be şure, Greek and Roman literature is aceessible only through the dead languages; but the opinion is steadily gaining ground that all wistom did not die with the ancients. Classical study, limited as to place and proportion, must certainly renain one of the essentials of a liberal erlucation, though the wistom of long-deal generations is not all that is required by the man of to-lay. The retention of the sturly will pove that "descent with modifieations" ohtains in the intellectual no less than in the oreanic world.

The stuly of physical problems from the standpoint 
of evolution discards the notion of a vital force to account for living phenomena. The substitution of continuity of life and growth for special creation has naturally revolutionized all that was formerly called science. Sir John Lubbock is convinced that the civilization of a people is measured by their progress in science, and, in its broadest sense, philosophy must accept the fact. Wise and experienced men, lately appointed to inquire into the condition of education in England, agree that the universal neglect of science is little less than a national misfortune, and that the study must be adopted if England desires to retain her position in the van of industrial nations. This is no less true of all other countries. At present the teaching of science, throughout the world, with the possible exception of Germany, is largely experimental, and there will be no improvement in this respect until the value of the study is definitely recognized.

Epaminondas declared, "I rule the Thebans, and $\mathrm{my}$ wife rules me; thus you see who is the ruler of Thebes." Two thousand years ago the great conqueror of Sparta was wise enough in his generation to recognize and admit a fact which the modern world has been slow to accept. It is surprising, in view of her influence upon the world, that woman's education has not always been the first concern of the State, but the church alone distinguished itself by a recognition of its necessity. When Pope suggested the idea of a college for women it was ridiculed as the chimera of an irresponsible mind. When, in this country, a little over fifty years ago, Mrs. Emma Willard petitioned the New York State Legislature for aid in establishing schools for the advanced education of women, she begged not to be misunderstood concerning the limit of her desire, as "the absurdity of sending girls to college must strike every one." A vast amount of this absurdity has been witnessed since Vassar College opened its doors to women just twentyfive years ago, and the Harvard Amnex — significant nameto-day offers to young women better advantages than young men could command in any college in the country fifteen years ago,-an example of social and intellectual evolution moving on parallel lines. Women are to-day practising at the bar in sixteen States and three Territories; nearly two hundred pulpits are regularly occupied by women; six medical colleges exclusively for women, and thirty- 
six in which they are allowed to share in the instruction given to their brothers, liave already placed three thousand women in lucrative medical practice. Austria is today the only civilized conntry of the world which debars woman from this field of professional labor. In twelve States women are eligible as county school superintendents, and in fourteen they share in school control. When the English Elementary Education Act was passed, women were at once eleeted to school-boards, onc of them receiving twenty thousand more rotes than any other candiclate. There was not even the least discussion about the matter. When Prof. Huxley resigned from the London Board he gave as a reason for so doing his belief that a woman could better fill the place. Three years later Boston elected women to the same positions, lut not with the ease which had characterized the process in England. The Supreme Court worried itself for an cutire year over the momentous question of their eligibility, and when at last it was decided that no woman could or ought to serve in such a capacity, the legislature promptly passed a law opening all school-boards to women - and both the boards and the women have so far survived it. A few other cities have followed the example set by Old and New England, while others arc gradually gaining courage to give women - the mothers of all the children and the teachers of three-fourths of them - the privilege of expressing an opinion as to how these children shall be cared for, but with painful realization of the solemu fact that in so doing they are ruming a most awful risk. The Alumm Association, formed in 1882 by the graduates of the women's colleges, has now a menbership of nearly one thousand, with branch organizations in several cities. It is arranging for home study and advaneed courses for students, investigating many important social questions, and collecting facts conccruing the results of higher education for women.

Why it is so monstrous a thing for men and women to study together, while they live and labor together in all other relations of life, is onc of the profound mysteries which science has yet to solve, but co-education, so fitr as it has been tried, has not pereeptibly undermined the founlations of soeicty. Oberliu College was brave enough to introduce this innovation in 1833, and since that time many of our best eolleges have allowed their 
doors to be cautiously set ajar for the possible entrance of women, or have thrown them wide open with hospitable invitation. At Harvard, the feminine candidate for a degree must accept in its place the certificate which testifies that her scholarship is all that could be desired, but that she is - not a man. Princeton is sure that it is a sin against Nature for a woman to take a college course, but cheerfully aids and abets the sinner by giving her a degree if she sins successfully in the college-campus. In Boston University, "a woman's a woman, but the sex is but the guinea's stamp; the brain's the gowd for a' that," and in its last catalogue the names leading four of its classes are-not those of men. It is a matter of small wonder to the logical mind that co-education is having so severe a struggle for existence, considering the immense weight of the only argument ever brought against it - the only one necessary being so convincing - namely, "Women have not brains enough to study with men. If women study with men, the women will take all the prizes: therefore women must not be admitted to men's colleges."

In all age when man lived in castles with walls three feet thick, judiciously and tastefully surrounded by moat and ditch, draw-bridge and portcullis; spending most of his not particularly valuable time in shooting arrows and pouring hot oil from the tops of his towers upon the heads of his enemies, - no one will deny that during these little neighborhood excitements, so far as woman was concerned, home was the best place for her. Later, when with axe and gun he cleared the forest and protected his cabin from wild beasts while seeking food and fuel for its inmates, it was quite according to the fitness of things that the feminine portion of the family should stay in doors to keep, the fire and to cook the food. But social safety and comfort are no longer secured by arrow, axe, and gun, but by money made in business and votes cast into a ballot-box. Women's environment is no longer that of bears and barbarians. Homemakers, - the world is sustained by them, and their office is one of the noblest on earth; but the appliances which have lightened the labor of the outside world are represented in the household also. Home will always be a good place for woman - as for man - but it is not always the best place, nor by any means the only place. Perhaps it has bcen necessary for woman's 
education to wait until the world's material interests werc in large measure provided for. But pliysical force has successfully done its work while the world has gradually been growing into a realization of the fact that for its mental and moral upbuilding the power of only one-half of the human race is only one-half sufficient. How can I refrain from referring to the fact, although so well known to you, that the discoverer of Spencer and his regenerating philosophy,--not merely the Isabella but the Columbus of this new world of thought and influence, - was a woman? Against the darkness and degradation of hundreds of centuries is to be measured woman's progress during the last fifty years, proving that this late and reluctant recognition of her brain and soul is the most advanced step yet taken by civilization and will become significant in proportion as the fogs of custom and tradition give place to the clear sunshine of logical and progressive thought. Woman stands to-day the crowning though uncompleted work of sociological evolution.

Many of the world's brilliant men and women have won their greatest distinction by their labors in the cause of education; but, singularly enough, it is only the theorists who have done this. For their disciples, who lrave tried to work out these theories, society has gencrally felt, until within a very few years, a negative contempt. One of the most imperative demands of the day is an adequate estimate of the teacher's office, and the need of preparation for those who fill it. The man who euts the hair on the outside of the child's head is supposed to lhave had sufficient training before undertaking the business; but how about the teacher to whom the child's nental and moral nature is unquestionably conficled? A carpenter who has learned his trade can earn three dollars a day while working at it. Many tcachers labor for one-thincl that sum. Logically, the man who builds your house is. worth three times the teacher who trains your child. Your louse may be blown down, or burned down, and you may build another even better than the first. Your child may break your heart and be an immense power for evil in the lives of countless of his fellow-men. What can you do about it? Nothing is more surprising among the many anomalies of education, than that, while the proper training of youtl has becin considered of parmmount inportance, the 
training of those who were to train the youth has been regarded as of no particular consequence. Although the legislators of the French Revolution may appear to us like so many reeds shaken by the wind, they were, notwithstanding, the first ones to see that for education were needed educators. To them is due the credit of the foundation of normal schools, though few are yet in existence and those few mainly the growth of the last twenty years. Education is a science, as is surgery, and why is it not reasonable to demand fitness for the work of the school-room as for that of the hospital?-more, indeed, if we are to fear less those who kill the body than those who have power to kill the soul. Public money spent for the training of teachers is capital invested at compound interest, and teaching should be made as profitable, at least, as hoeing corn. Not much longer will the teacher be allowed to tell to-day the source of a river if she must wait till tomorrow to find out where it empties; and the time is soon coming when the trustees of a district will hesitate to offer her three dollars a week for services, and charge her four dollars a week for board, for "the English-speaking race leads the world, and the teachers of that race are the ones who will decide what its future is to be."

It is true, as Carlyle says, that "our school-hours are all the days and nights of our existence, whose lessons stream in upou us with every breath we draw." Telegraph, locomotive, and steamship; social, church, and commercial relations; literary and art clubs, scientific societies, our great libraries and museums, Arctic expeditions, African explorations, geographical surveys, international expositions, - none of these forces can be overlooked in an estimate of the educational factors of civilization. Think, too, of the avalanche of matter daily falling from the press, -in such an amount and with such rapidity that even the person of entire leisure despairs of acquaintance with it, and so cheap that for ten cents apiece can be purchased the masterpieces of our own and other languages,_- evolntion indeed from the time when the eyes of the people rested only upon one book and merely the ontside of that,the bible, fastened to the altar by its heavy chain, fit symbol of the intellectual bondage of the race.

If education, both as cause and effect, can do so much for the world, it logically follows that its direction and 
development is one of the profoundest concerns of society. Yet in comparison with all that is waiting to be done, how little has been accomplished! 'Throughout all Christendom, from thousands of mines and factories, is heard "the cry of the children" for the human birthright of which they are defrauded; the vagabond and criminal classes, increasing at an appalling rate, are the despair of the legislative wisdom required to deal with them, yet compulsory education is hardly more than a name, and the best education yet devised makes only negative provision for moral development; great teachers, much as they are needed, are, as Lowell says, "rarer than great poets," and the world is blind to the fact that it can better dispense with the poet than with the pedagogue; the subjects of physical and manual as well as moral training are at present mere educational nebulæ; the supreme value of primary education is still only grudgingly conceded; higher education can hardly hold its own, to say nothing of making headway, against spirited opposition; agreement has yet to be reached as to what constitutes a liberal education and to what extent the State may be called upon to furnish it; the great mystery of heredity, whose powers and possibilities form so mighty an element in all education, is not yet penetrated; there is no work in the world carried on with such wicked waste of time and material, such enormous and reedless friction, as that of education, and it is no small matter for Americans to consider that, notwithstanding our vast expenditures for schools and our claim of superior culture, the boys and girls of this country are two years behind the youth of Europe in all important respects. In the meantine great social problens, tragic in their extent and significance, are clutching civilization, by the throat and will not relax their threatening hold until some satisfactory answer is wrung from the lips of scholars and statesmen. The aid which education can give in this emergency lies largely in the direction of industrial and scientific training. 'Through the ages, service has been considered synonymous with slavery, though the world's workers are soon to see the dawning of a better day. The mechanie's cal and blouse will not mueh longer be looked upon as the ontward and visille tokens of mental and social inferiority, for evolution is teaching r'speet for honest, wholesome human 
work. If it be true that the tree is known by its fruit, we may well believe that the leaves of this tree are for the healing of the nations whose people are cast upon our shores by every breaking wave of the Atlantic.

In every age education has been the outgrowth of the social conditions of the time, and educational ideals are always in accordance with the beliefs and principles by which nations are controlled. Civilization is but a contin. ual series of shifting conditions in need of constant organization and re-adjustment. It would be strange if this fact did not impose upon us the necessity for frequent examinations of our standards and re-arrangement in our methods of reaching them. But we are not to assume that the old methods were wholly wrong, or that new ones must necessarily be altogether right. The truth of Plato and of Paul is no less true than is that of Darwin and of Spencer. We are to prove all things, holding fast only that which is good, and rejecting even that when clearer light or broader outlook discloses something better still. Man is studying the alphabet of science and of etlics, and has not even begun to spell the first syllable of the sentences in which hereafter he may write out a little of their glory and their grandeur. He has exultingly seized upon Jove's own thunderbolts, a triumph which brings need of yet further knowledge lest they compass his own destruction. But to the evolutionist, though he does not thereby justify himself in any relaxation of individual influence or effort, no impatience or discouragement is possible. He will judge not absolutely but relatively, and be in no danger of liurrying to lame and impotent conclusions from overlooking the proportions of things or the relation of causes to effects; realizing that the present is the outcome of the past and that the present alone can inake or mar the future, he will study that past to learn what plans and methods have been failures, and why ; what others have proved successful and the reasons for the success; reading history not merely as a record of past events, but as the crystallization of the longings and endeavors of the race for a higher condition, and with the profoundest faith that what man has become is but an earnest of the better man he is to be. 



\section{EVOLUTION AND SOCIAL REFORM}

\section{THE THEOLOGICAL METHOD.}

BY

JOHN W. CHADWICK

Author of "Evolution as Related to Religlous Thought," "The FaItu of ReAson," "Charles RoBert DARWin," ETC. 
COLLATERAL READINGS SUGGESTED.

Spencer's "Principles of Sociology" and "Study of Sociology"; Thompson's "Problem of Evil" and "The Religious Sentiments of the Human Mind"; Graham's "The Creed of Science" and "The Social Problen"; Salter's "Ethical Religion"; Greg's "Creeds of Christendom"; Mosheim's "Church History." 


\section{EVOLUTION AND SOCIAL REFORM.*}

\section{THE THEOLOGICAL METHOD.}

The topic which has been assigned to me speaks volumes for your appreciation of my standing in the order of created things. Why should you think that mine should be the privilege of ushering in the great millennial dawn? For it would surely be upon us, and the remaining papers of this series would be read by its transcendent light, if I should treat successively of the different parts of the skeleton which in your syllabus of the course is denominated "Evolution and Social Reform: The Theological Method." I shall "make no bones" of setting some parts of this skeleton aside, and some of the others I shall consider with that "leaning to the side of mercy" which distinguishes the clergy from the laity in their public utterance: naturally, because they so much oftener have a chance.

There was social Form before there was social reform, and this was almost entirely theological or religious. When due allowance has been made for the over-working of a fascinating theory, M. Fustel de Coulanges's famous work, "The Ancient City," remains a splendid demonstration of the fact that religion - theological religion - was the original Founder of Society, determining its structure and its laws. Hence came, as from no other source, that "cake of custom," that definition, that authority of social forms, which was as absolutely essential to the beginnings of society as its ultimate breaking up was to its progress further on. An egg-shell is an excellent protection of the bird's incipient life, but broken it must be some day or else we have no bird. The religion of the hearth, the worship of ancestors, constituted the primitive family, established marriage and paternal authority, fixed the order of relationship, consecrated the right of property and the right of inheritance. The same religion, having formed the family, re-formed it, enlarged it, and extended it, often artificially enough. The legal fictions of antiquity were religious

* Coprright, 1890, by James H. West. 
fictions in the main. The developed and expanded religion of the hearth became the ancient city; not urbs, but civitas, the ancient civil order. Its rules, its usages, its magistracies, were all religious. The priests adjudicated every question; the pontiff was chief-justice. Law was but a phase of religion. Justice, as we understand the term, was unknown. "Our country right or wrong" was a religious doctrine then. In treaties, perfidy, in battle, massacre, were corallaries of this expanded family religion. In those good old times Socialism was the order of the day. Liberty had no existence; education was compulsory. No man was permitted to live single or to rear a child that was weak or deformed. Food and clothing were prescribed. This "cake of custom," this family religion artificially extended to a religious city, a religious state, thickened and hardened so that the wonder is that it was ever broken; but it was - about 2500 years ago. 'The priests were obliged to surrender their absolute authority, and rule only in worship, but the survivals of their original authority long lingered here and there in civic law and use. Solon "wrested the earth from religion and gave it to labor," in Coulanges's happy phrase. Aristotle says he put an end to the slavery of the people. As in mediaval Europe a baronial aristocracy succeeded the disintegration of the Empire, so was it here; and as there the people made a set of royal tyrants the instruments of their battle with this aristocracy, so also was it here. Meantime, the arts sprang up; socialism retired; personal property was created; money appeared. Over this, religion had rio power. Now plebeians could be rich, and, once rich, could be aristocrats, and so the old lines of demarcation were more and more effaced. They invaded politics. They invaded the sacramental worship. 'They became consuls, priests. Rome, become democratic, became first republican and then imperial. It was the peoplc who made the new tyrant, as they had made the old. The same tendency is observable in our modern life. Only the new tyrant, hankered for, is called Socialism. A Tyranny without a tyrant, shall we say? But no less tyrannous on this account, and the personal tyrant would come rery soon to tame the chaos that woukl certainly cusue, as Napoleon eame to tame the chaos after the wild and whirling aspirations of the French Revolution. 
It is easy to see that the relation of Religion to Society, in its primeval and pre-Christian form, was mixed of various yarn, good and ill together. The "cake of custom" which it furnished was a necessity of the social situation. That or no society at all. But it paid dear for its whistle. It was miserably artificial while it held its own. It entailed a miserable inheritance of legal and moral fictions on the emancipated Greek and Roman world. That History never repeats itself is a proverbial phrase. It is as true as our proverbial wisdom generally is, and that is something less than half. History never repeats itself exactly. It is always repeating itself in a large and general way. The immense disintegration which succeeded the downfall of the Roman Empire through its inherent weakness and the onset of the Barbarians was not unlike the original social chaos. It needed quite as much a formative principle; quite as much a new cake of custom. Christianity, ecclesiastical Christianity, responded to the need. It was the savior of society. For centuries its splendid domination secured a social order hardly if any less religious than the society and State determined by the family religion of the ancient world. For every part of life, domestic, personal, industrial, political, intellectual, æsthetic, there was a religious rule. 'The rule was often monstrous and absurd. No matter; all the same it held the fort till reinforcements could come up, the intellectual and political forces of the modern world. And as under the old régime there was a miserable inheritance from the Religion of the Hearth, so have we had a miserable inheritance from the Christianity which saved society in the Middle Ages, an inheritance of theological morality - a morality looking not to human benefit but to the imagined will or preference of God for the sanctions of the moral life. Theological morality in its palmiest days endeavored, and for the most part successfully, to elevate the importance of performing certain ceremonies and of believing certain doctrines into superiority to any actions between man and man. But hmman nature is so constituted that, although men may easily persuade themselves that intellectual error, or sacramental irregularity, is the most damnable of crimes, "the voice of conscience protests so strongly against this doctrine that it can only be silenced by the persuasion that the personal character of the heretic (or delinquent) is as repulsive as 
his creed." "Calumny," says Lecky, "is the homage which dogmatism has ever paid to conscience. Even in the periods when the guilt of heresy was universally believed, the spirit of intolerance was only sustained by the diffusion of eountless libels against the inisbeliever, and by concealment of his virtues." The heretical or sacramentally delinquent dog must have a bad name fastened on him before he could be lnung or burned or drawn and quartered with an entirely satisfied and quiet mind.

But the dis-service done by theological morality has not been by any means exhausted by its attendant persecutions. These have somehow been the nursing-mothers of political independence and industrial success. The blood of the martyrs has not been so obviously the seed of the church as it has been the seed of enterprise and wealth in soil that she has drenched with blood. Witness to this the fortumes of the Jews; of the Dutch who, having taken Holland from the sea, took her again from Philip's more rapaeious clutch; of the Huguenots who in the crypt of Canterbury Cathedral, where their descendants still have the right of worship, set up their looms and made a brave beginning of England's wonderful and magnifieent industrial life. No, the grand dis-service of the theological nethod in morality has been the absorption in the imaginary service of God of energies that would have planted the standard of humanity some furlongs further into ehaos. The survival still survives, but in our day is less a good deal than archangel ruined with the excess of glory obsemed.

One item of the schedule of particular things assigned to me for measurement and weight is "Ninetern Hundred Years of Christianity," and you are now requested to compose yourselves to a history of this succession. I hasten to arrest the stampede which I perceive is imminent, by assuring you that I shall not take up each separate year, but give you an abstract and brief chronicle, and this almost entirely with reference to that aspect of society (the industrial atsperet) to which those who follow me in this course of lertures will confine themselves. When Dr. F. E. Abbot sugroster, some twenty years ago, that Christianity is a failure, the courteous retort was at once male upon him, "It has never been tried." And this is true if by christianity we are to undrrstand the social doctrine of the Sew Testament. At least its trial, as reported in the 
New Testament, was within very narrow limits. Christian civilization has never been a trial of the New Testament Social Ideals, except here and there in isolated and sporadic ways. 'The Quakers have tried non-resistance, and the moral of their experience is that pictorially furnished by the affair in Scranton, when the Hicksites and the Orthodox contended for the possession of a meeting-house. Not a blow was struck, but there was a great deal of pushing, till, finally, the Orthodox - I must believe they were the more numerous party - pushed every living Hicksite out of doors. Moral - in any society where there is no striking, there will be a good deal of pushing. Monastic celibacy has made a very extensive and protracted trial of the "counsels of perfection" Jesus gave in his teaching upon marriage, and which Paul distinctly reinforced. With neither of them was marriage an ideal condition. It was a concession to ungovernable lust. Monastic celibacy can hardly be regarded as a success. There went along with it a great deal of industrial help. But it was essentially illogical,_-depending on the disobedient for the materials of its obedience. It said, "Marriage peoples earth, but virginity peoples heaven." But so long as marriage or illicit unions must furnish the raw material of virginity, and the former were accursed, marriage was a fortunate expedient of the average man. We have the opinion of Galton that monastic celibacy drained off the finest brains in Europe from the natural current of its intellectual development, so that the average brain at the conclusion of the Middle Ages was of less capacity than in Aneient Greece. Moreover, even if the monks and nuns had kept their foolish and unnatural vows it would have been at the expense of a pruriency of persistent thought more intolerable, says Renan, than the vices of the world.

But what is the relation of the Bible, and especially of the New 'Testament and nascent Christianity, to that Social problem which is par excellence the Social problem of the present time - the problem of Poverty and Wealth? To what extent has the New 'lestament industrial Christianity been tried. and to what extent has it succeeded, if it has not altogether failed?

Judaism has never been so painfully at odds with its arowed ideals as Christianity. In seeking wealth the Jew has always had the warrant of his Bible, clear and strong. 
For the Old Testament doctrine of wealth is frank and unmistakable. It is a blessing from the Lord. It is a sign of the divine approval - one of three sigus that are continually recurring. The other two are long life and many children. The Book of Job is the only serious protest in the old Testament against the doctrine that riches are the reward of righteousness, and even this, before it ends, seems to decide for Job's accusers and against Job himself. You will remember that in the end he had again seven sons and three daughters in the place of those whom he had lost, and twice as many sheep, oxen, camels and she-asses as he had before. We seek vainly for his wife in this enumeration; - unless - but the suggestion is unworthy, and I pass it by.

Nothing is more convineing of the gulf dividing the Old Testament and New than the difference of their views concerning poverty and wealth. In the old Testament the rich, and in the New 'Testament the poor, are approved of heaven, and known to be so by this sign. Nothing is surer than that, as between the rich and poor of his own time, Jesus was clearly for the poor. His gospel was for them. The key-note is somded in the story of his first preaching in the synagogue of his native Nazareth:

"The Spirit of the Iord is upon me,

Because he hath anointed me to preach the Gospel to the poor";

and in the beatitudes in Luke, "Blessed are the poor," he cries; and conversely, "Go to, ye rich men, weep and howl, for you have received your consolation." 'To the young man asking Jesus what he shall do to inherit eternal life, Jesus makes answer that he must sell all he has and give the proceeds to the poor. And it is evident that these precepts and examples did not vanish into the thin air and hring forth no result. Tolstoi, in his account of his religion, which he identifies with that of Jesus, takes what he likes, and leaves what he does not, with a recklessness that would make an ordinary Christian eommentator bhush. 'The mon-resistance precepts he areepts without qualification. "Judge not," he interprets literally and legally. Ergo, we are to have no conrts, no trials, no pumishments of crime. But though, in sueh a soriety as he imagines, life would surely not be worth living, a paralise of ignoranee and dirt.- edneation sepurates men, therefore no education; cleanliness separates, therefore blessed are the unwashed,- 
yet, paradoxical as it may seem, the sole function of woman in this kingdom of hell is to multiply and replenish the earth. Why did not Tolstoi avail himself of the "counsels of perfection" which Jesus uttered against marriage? Why, but because it is inevitable that, when the Bible is made an authority, it is like the Morman prophet's compass, which, when he had taken it in his hand, it did turn whichever way he would. Tolstoi is as strenuous for work as for the multiplication of children, though it is evident that Jesus and his immediate disciples gave up all work and made a common purse. "And Judas had the bag"-a phrase significant of much. He sold the Master's life for thirty pieces of silver. It is to be feared that every communistic enterprise will have its Judas soon or late, who, if he does not steal the bag, will engage in private speculation. Our first acquaintance with the early Christians after the death of Jesus finds them a socialistic body, having "all things in common," - but voluntarily, Peter reminding Ananias, who kept back part of the price, that he might have kept his money or that which he sold.

If, then, by Christianity, we mean the precept and example of the New Testament, it is evident that Christianity makes for socialism in its crudest form; for communism, with which we must not by any means confound the StateSocialism of Marx and Bellamy and Hyndman. But, then, it ought to be remembered that on the entire social and industrial ideal of early Christianity, Paul and Jesus himself included, there was the bias of a firn persuasion that the mundane order of society was very shortly to be broken up. That made a mighty difference. In 1843, if I remember rightly the year of the great Millerite excitement, a Unitarian minister, from whom I had the story, stepped into a Philadelphia hatter's store to buy a hat. Having selected one, he asked, "How much?" "Nothing," replied the hatter; and explained that he was a Millerite, and that the world was coming to an end the following day. Money was nothing to him, therefore. He had more than enough for the day. "Then," said the minister, "will you not give me ten dollars?" "Certainly," replied the man, suiting the action to the word. The next day but one my friend stepped in again, the world not having come to an end in the meantime, and paid for his hat and returned the ten dollars, nemine contradicente. The moral is plain. 
An order of society which is unobjectionable and even admirable for a world liastening to destruetion, must look quite different seen from the standpoint of a world which lias the promise of indefinite duration. It is a vice of criticism old and new that no sufticient allowance is made for the bias of the expectation, cherished equally by Jesus and his disciples, of a catastrophic ending of the mundane order of their time, and the establishment in its place of the kingdom of heaven upon earth. What Jesus and Paul might have thought of industry and property and marriage and government and slavery, and such things generally, if they had inagined such continuance of the old order as was actually unrolled, we do not know. But, knowing that their every social opinion was subject to the bias of their hope, we must neither hold them absolutely responsible for their opinions, nor go to them as if it were likely we should find in them a social rule agreeable to the continuous and stable order of the world.

The New lestament had not reached its final term, before, in Second Peter, written about 170 of our era, we hear a wail of disappointment and regret: "Where is the promise of his coming? For since the fathers fell asleep all things remain as they were from the beginning of the world." Long before that there was doubtless many a doubter, and many an Ananias who kept back part, and then the whole, of his estate from the common stock and store. It does not even appear that the Christian Commune ever got any hold outside Jerusalem. J'anl was obliged to take the Corinthian Christians in hand for not sharing even the brearl and wine of the communion-feast, some eating and drinking what they took with them and others getting nothing. Nevertheless, it was not a little that passed over from the Christianity of Jesus and his first disciples into the early and the later Christian church. The words of Paul antl Jesus about marriage died, as rules of general application, to rise again as "counsels of perfection," celibicy for those who could endure the strain; and hence, with many things co-operant to the end, the immense development of anchoritic and monastic life. And it was the monastic orders that yerpetuated the ideal, if not the practice, of poverty in the Christian church. Even before the conversion of the Roman empire the church, as an ecelesiastical institution, began to grow rich, and it grew 
enormously so as time went on. Simers and saints, departing from this life, emptied their private fortunes into its bursting coffers, either in the hope of bettering their chance of heaven or in supreme assurance of its bliss. The secular clergy growing sleek and comfortable, the regular clergy, that is to say the monks, took up the rote of poverty. These also soon attained to wealth, but in their corporate capacity; and for a monk to crave the joy of private ownership was the most heinous sin. If ever Socialism has a patron-saint it should be Gregory the Great. He was abbot of a Benedictine Monastery before he was made pope, and, falling sick, a monk named Justus saved his life by his unwearying care. Soon after, Justus falling sick and being near to death, confessed that he had three pieces of gold concealed in a flask of medicine. At once command was given, and by Gregory himself, that no one should approach the bedside of the dying man to speak a word of hope or consolation. And no sooner was he dead than his body was cast upon the dung-hill with his three pieces of gold, the whole brotherhood shouting with one voice, "Thy money perish with thee!" Here, at any rate, was Socialism that had the courage of its convictions. But private poverty immersed in corporate wealth was seen to be only a half-way poverty; and out of this perception grew the mendicant orders, taking the vow of poverty not for themselves only, but for the order also; a scheme which prospered for a time, and then the mendicants grew rich and rich and richer, till, like the Roman augurs, they could not meet in private without laughing in each other's faces at the joke. It is a significant fact that, at the beginning of the French Revolution, one-fifth of all the land in France was in the church's hands. Of other wealth it had a larger share.

The monastic ideal of poverty, in which the New Testament ideal survived, was far from being hostile to the general pursuit of wealth in the community. It was a "counsel of perfection," a rule confessedly too high for general attainment, and so it gave carte blanche to all who did not adopt it to put money in their purses and add field to field without reproach or shame. It is evident that mendicancy implied having and giving, just as the virginity that peopled heaven implied the marriage that peopled earth. 'There were never more rich men than the church found for 
her purpose, frying out their fat with an ingenious success that must be ever the despair of political committees raising money for campaign expenses in these degeneratc days. But whether it was that the impossible ideal did shame the common mind, or that this could not compete with the protected interests of the church, certain it is that those parts of Europe which have been pre-eminently distinguished for manufacturing and commercial activity and the increase of secular wealth have been almost without exception hostile to the pretensions of the Mother Church, and, in many instances, heretics and schismatics. 'This is in part explained as we explain the fortmes of the Jew in Christendom. His disabilities have been the nurses of his power. $A$ hunted creed, if it be not extirpated, has an invariable tendency to make its votaries "reserved, concentrated in their" callings, vigilant in action and in the end wealthy." Witness the fifteenth century of English history, the most prosperous in lier annals, until, in our own time, free-trade and trades-unions and the slortening of the hours of labor have conspired in the production of an unparalleled prosperity. And the energetic, the enterprising, the wealthy, were those Lollards that had sprung from Wiclif's seed. Witness the Huguenots in France, from whom the industrialism of modern England rightly dates. Witness the Dutch and Flemings, the Puritans and Qnakers. The facts incline us to accept the Old Testament interpretation that riches are the natural reward of righteousness. Of course the exceptions are many, but in the long run and the wide sweep the gravitation of wealth has been to character, to men of self-rlenying virtuc, to nen who lave sought first the Kingrlom of Gorl and his righteonsmess.

Howevor this may be, the general fact is indisputable that Christianity, which was the religion of poverty, both idcally and actually in its early stages, is in the nineteenth century pre-eninently the religion of wealth. The only possible exception to this statement is suggested by the financial successes of the Jews. But these lave been so generally thr sureesses of Christian Jews-i. c., of Jews mixed np with christians in financial matters - that it does not affect the general consideration. The wealth of the world to-day is rery largely lreaped up within Christian bomiaries, and wherever Christianity goes, there wealth accumulates and. for the nost part, men clo not ilear. lint 
the main increase has been in the most recent times, the application of machinery to labor and of steam-power to machinery, the principal factors in the increase, a comment on the threadbare fallacy that "all wealth is the product of labor" that cannot be too carefully observed. There is significance in the fact that the growth of industry and wealth has been most remarkable in quarters least subject to the control or influence of the Roman Catholic church, in quarters where the Protestant virtues, as Cardinal Newman calls them,_- personal independence and selfrespect,- have had the fullest swing. The industrialism and wealth of modern life have flourished not merely in contempt of the original church, but in part because (no thanks to her) of her fatuous opposition. The immense development of mechanical skill is eldest daughter of that scientific spirit with which the Mother Church had no community. It has come of an insatiable curiosity for which she has lad no favorable word or smile. The uttermost dis-service done by that Church to industry and wealth and labor and the general social status of mankind was through her monstrous opposition to its intellectual life. Had not the Jew and the Mohammedan kept the flame of intellectual life in Europe it seems as if it must have gone out in smoke and stench forever. The Christian branch of the Semitic stock was without flower or fruit when the Mohammedan and Jewish branches of the same stock were all abloom with promise or loaded down with intellectual fruit. "Persecution," says Lecky, "came to the Jewish nation in its most horrible forms, . . . but above all this the grandeur of that wonderful people rose supreme. While those around were groveling in the darkness of besotted ignorance; while juggling miracles and lying relics were the themes on which almost all Europe was expatiating; while the intellect of Europe, enthralled by countless superstitions, had sunk into a deadly torpor in which all love of inquiry and all search for truth were abandoned, the Jews were still pursuing the path of knowledge, amassing learning, and stimulating progress with the same unflinching confidence they manifested in their faith. They were the most skilful physicians, the ablest financiers, and anong the most profound philosophers; while they were second only to the Noors in natural science," freely appropriating their results and giving them such currency as they could 
in Western Europe. It was Jewish wealtlı that broke the arm of Christian persecution. Not till the Jew's money was absolutely indispensable to Kings and popes, for the prosecution of their crusades and wars, did the stress of persecution cease.

The system of credit and exchange which is inseparable from the industrialism of the modern world was developed by the Jews, if the letter of exchange was not of their device. They were the first to make a liberal use of this device. We are thus brought face to face with the matters of interest and usury. 'The social reformer whose panacea for all the ills which modern industrialism is heir to or has originally developed is the prohibition of interest, has the Bible, Old and New 'Testament, at his back, and equally the unanimous authority of the Christian cluurch for seventeen centuries. The last authoritative utterance of the church was in the eleventh century, and it was as hostile to usury or interest as any previous utterance. I say "to usury or" interest," for it is only the finesse of modern Christianity that has made out any difference between the two. Usury in the Bible means just interest, no more, or less; and usury meant interest all down the Christian centuries till some three centuries since. Three per cent. was as much usmry as ten, and equally disallowed. Bnt in spite of papal interdicts the giving and receiving of interest, called usury, went on, and at length all churchly opposition ceased. 'The church hardly attained unto the wistom of the schoolmistress, who said to the refractory boy, who would not budge, "Then stay where you are, for I will be minded." But it conchided to let the refractory usurers stay where they were, and say no more. Protestantism was much ahear of liomanism in its ahandonment of the futile opposition. John Calvin had some good horse sense with all lis theologieal harbarities. He was a paternalist in Geneva, if there ever was one, but he refused to prohibit interest by law. He was much less slavish in his bibliolatry than nany who succeeded him. Moreover, he was one of the very first to expose the alsurdity of Aristotle that "money" is sterile." The attitude of the chmoh in this regarl will be differently appreciated acording as one helieves all interest-taking to be wrong, or believes its giving and taking to be the happlest device of industry and commerce in the modern workl. I am myself decidedly of the last opinion. 
The principal operation of the Theological and Ecclesiastical method is not, however, to be sought in the application of specific precepts and examples of the Scriptures to the social world, but in the diffusion of a spirit of compassion and good-will and brotherhood. Nothing was more fundamental than the institution of slavery to the social structure of the pagan world. Nothing is more creditable to Christianity of the first and middle period than its opposition to this institution, an opposition by which it was ultimately destroyed. I know the gibe that it was Christians who could not be slaves in Christian eyes, not men. It somewhat dims the splendor of the church's work in this direction. But all were welcome to the church, and its recruits were largely if not mainly from the servile class. So, with its anti-slavery, there went along a social democracy which has always been the glory of the Mother Churchnot allied with political Democracy, because to this the church's doctrine of passive obedience is a fatal blow. Of social equality and fraternity the old church was a much better conservator than the reformed. It is so to this day. It is Protestantism that has rich men's churches, to which poor men cannot come. How good it is in every Catholic church in Europe to find rich and poor upon an equal footing,-it is generally footing and not sitting, - the fine lady and the peasant, the merchant and the artisan at elbowtouch! What a monstrous thing that in democratic America Catholicism contracts the aristocratic taint of pew-owning and renting, though happily as yet the poor have not been diriven out into unlovely chapels or the unlovelier streets.

Another splendid service of early Christianity to the industrial world was in its enhancement of the dignity of labor. It was a piece of happy fortune that Paul, combating the disorder and the idleness of a world expecting daily Christ's retum, said, "He that will not work shall not eat," - a copula which has lost none of its validity in the course of 1900 years. But it was the Benedictine monks who, making labor a rule of their order yet not a counsel of perfection, gave an immense enhancement to the dignity of labor in men's eyes. Nor would it be easy to exaggerate the labors of the monks as pioneers of civilization, tamers of the wildemess, founders of universities and towns, and as exemplars to the general world of sturdy industry.

You must not think that I have wilfully omitted American slavery from my consideration. Strange as it may seem, Las Casas, one of the most benevolent of Spanish Catholics, 
was the most conspicuous inaugurator of slavery in the new world. It must be confessed that the christianity which supported slavery in the United States was much inferior to that which weakened and destroyed it in the early church, and, notwithstanding frightful instances of cruelty in ancient slavery, our own of yesterday was much more debasing. Bnt though the American churches were, as James G. Birney said, the bulwark of slavery, the bulwark was one from behind which the Anti-Slavery party drew its noblest strength, from Garrison and Whittier and Green and May and Channing and Parker, down to the humblest of the rank and file. The bible strength of the Pro-Slavery party was an OldTestament custom; the bible strength of the Anti-Slavery party was the spirit of compassion and humanity which warmed the heart of Jesus with a pure and heavenly flame. There can be no doulst, I think, that Garrison was a better interpreter of Christianity than Wilbur Fisk, finding an argument for slavery in the Golden Rule;-for should we wish our neighbor to seek our liberty at the risk of endangering the safety of the Union and of the Methodist chmeh! For all the Wilbur Fisks, and there were many, it was the Puritan conscience of the Forth, which the Bible and Christianity had nourished, that broke the axe in the destroyer's hands.

"The poor ye have always with you," Jcsus said,-a prophecy that has had complete fultillment from his time to our's; but when he added, "And whenever you will you can do them good," there was a mocking echo from the experience of nineteen Christian centuries_-Good?" "Almsgiving no charity," wrote Daniel Defoe, almost the first to see that this was so. And perhaps it was not so in the order of society in which Jesus lived. Alms-giving may then lave been the only possible charity. It is certainly the rharity of the New 'Testament, and of the early and the later church to our own time. And there can be no doult that the ('hristian ('harity which provoked the Emperor .Julian to stir up the pagan leart to something like it, saying. " It is outrageous that the Christians should suplyort not only their own destitute but ours,"-there ean be no doulst that this charity was very sweet and beautiful in (omplarison with the hard indifference of the pagan world to suffering and misery. In the ages before organized chanity we must homor the spontaneous charity of men. lint of one thing we may be sure: It never yet diminished poverty. Especially when the chureh elevated mendicaney to a virtue. 
that and indiscriminate charity brought forth a dreadful brood. It was understood that porerty and mendicancy were necessary raw material for charity, and as such they were encouraged. Without poverty and mendicancy the occupation of the saintly alms-giver would be gone. Latterly it has been borne in upon us that, if charity is a necessary evil, it is an evil that cannot be too seriously deplored. Does the evil of intemperance pauperize so much? But in the reform of charity, which began within the memory of my younger hearers; in the battle with indiscriminate almsgiving; in the endeavor to help those who help themselves, to organize friendly visiting, to establish a sympathetic and humane relationship between the rich and poor, it camnot be denied or doubted that the church has furnished a full quota of the tireless laborers. Nor can it be denied that it is the spirit of Christianity, the spirit of the man Jesus, which is fundamental to their work. It was Edward Denison, a young preacher in London's miserable East-End, who was one of the first to make the startling affirmation, "Charity is a frightful evil," and who made "no direct help" and "compulsory labor for all beggary" the sine qua nons of charitable reform. It was John Richard Green, the great historian, but then a London vicar, who declared that sixpenny photographs had done more for the poor than all the charity. How so? By nourishing the home sentiment, ly strengthening the family bond. No Russian ikon so consecrating as that row of poor cartes-de-visite upon the mantelshelf,- - the old mother's in the country, the father's dead and gone, the baby's over whom the sods are green, the boys' far off in strange new lands. And it was Arnold Toynbee, another churchman eager, bold, and strong, in whose honored name 'Toynbee Hall was established to embody the idea of personal human sympathy and fellowship as the highest and the best that can entice the social helpers of our time. Sc.ientific charity is not enough. I can imagine that charity might be so scientific that a wise man would prefer the old alnus-giving way. It might pauperize more, but it would humanize more. What we want is a charity that shall be Scientific in its method, Religious in its spirit. Otherwise your scientific charity is a locomotive without fire and water, without steam. But most of all we need a vital human sympathy, sucl as Jesus felt, with every child of fiod how-ever miserable or depraved. I am persuaded that the more we know him for what he was, the more will his srmpathy and his compassion be an inspiration to our good endeavor, 
and a shame upon our shameful hesitations and withdrawals in our contact with the ignorant and poor and weak. And if the truth were known, the poor need not the rich more than the rich need the poor-to tearh them a neighborly spirit, to teach them the rudiments of generosity.

Last, but not least, I am expected-so do the syllabus and 1)r. Janes infor'm me - to say something on "the foolislmess of preaehing"; no, something about preaching as a means of social reform. The "Theological Method" is, in short, the methor of P'reaching; the method of direet religious and ethieal appeal to the individual. I should not myself think of ealling this the Theologieal method. I should prefer to call it the Ethical method or the Religious. For it is evident that we can have abundanee of direct religious or ethical appeal to the individual without any theological implications. Felix Adler and William Salter have no theology to spert: of, and they would smile or frown to hear their method called the Theologieal method; but of ethieal and religious appeal to the individual there is in them no lack. There is a theofogieal method in preaching, and it may or may not have persuasive moral force with nen. If the God whom it presents to men's imagination is a God of justiee, merey, truth and love their eontemplation of this image will be very apt to quicken in their minds and hearts those wonderful realities. But it is different when the God is different.

The effect of preaching upon social life is certainly an unknown quantity. It must be such from the nature of the rase. We camnot get at the facts. A great deal of christian preaching has had for its object, not the improvenrent of society, or even of the individual, but the salvation of souls, the improvement of men's chanees for the heavenly world. And it has endeavored to stir them up to believe rertain incomprehensible doctrines, or to arail themselves of certain sacraments, as the sure means of effecting their ctemal good. A great deal of this preaching, logically rntertainerl and carried out, would be ruinous to the social order and the individual life. It is the preaching that morality has nothing to do with salvation; that the hlood of Jesuis reanseth from all sin. "Only believe" that it is so and it is so. Estinated logrically, the dortrine of the A tone-ment is a horribly immonal doctrine; nevertheless its operation has not bren habitually immoral. But this faret goes not to the aredit of the dortrine but to the eredit of humanity, which is infinitely botter than the creeds. Men have 
not seen the doctrine; they have seen a good man suffering for humanity, a good man laying down his life for his friends, and that has touehed their hearts to finer issues.

But with all the theologieal preaehing, all the preaching of total depravity and eternal hell and the atonement and the trinity and election and predestination, and so on, there has been a great deal of moral and religious preaehing. Some of the most theologieal preaehers have been sternly ethieal. Calvin, for instance, did in no wise waste himself entirely in theological speculations. He attempted to regulate the soeial life of Geneva down to the last partieular. People should even go home and go to bed at sueh a time. A great many preaehers have been soeial reformers. 'Theodore Parker preaehed a sermon on the duties of milkmen, and Arehbishop Tillotson preaehed one on the duty of mothers to suekle their own ehildren. All the ages down, there has been a great deal of ethieal preaehing with the theologieal. The theologieal has made the more noise. It has oftener got into books. But it has not done anything like so much good as the other. That has often fallen into good ground and sprung up and borne fruit thirty, sixty and a hundred fold.

The idea of conversion has been very prominent in the Christian world. Without a conseious conversion many have insisted that no one ean have any hope of everlasting happiness or be a Christian here. Now, that preaching has effeeted a great many very real eonversions I am not in the least inelined to doubt. It has eonverted the drunkard and the lieentious from their evil ways. It has persuaded those who have stolen to steal no more. It has sent men and women home to be better husbands and wives; more kind, more tender, more thoughtful, more forgiving. But I do not believe that the best effeet of preaching has been by its eonversions - sharp turnings-round of men from bad ways to good. I believe that its best effeet has been to bathe men in an atmosphere of holiness, to induce in them a habit of noble expectation with themselves, to keep them in the constant presence of beautiful and exigent ideals, and most of all in the presenee of that ideal of tenderness and eompassion and sincerity which was embodied in the life of Jesus of Nazareth, the carpenter's son.

The Religious method of social reform, as I prefer to call it, is the method of personal character. 'The preaching of the Christian church has been one aspect of this methol. It has had many great allies,- the theatre; the novel; the 
newspaper sometimes; biographies of noble men and women, and, better still, the personal influence of such. And that for which it works is the one thing without which no social reform can have permanence or essential worth. Society will never be much, if any, better than the individuals of which it is composed. If we could have a perfect social scheme to-morrow, with men and women just as they are now, it would soon degenerate to the average level of the indiriduals of which it is composed. There must be a conspiracy of the outward and the inward. We need and must have bettèr social forms: so far the Socialist is right. We must have less governmental meddling, less interference, less protection, more local and individual responsibility: so far the Anarchist is right,- though childishly absurd in glorying in a name which has stood for lawlessness so long that the taint will stick to it forever. We must know the laws of political economy and the social structure, in order that we may obey them: and so far the Scientific method of social reform is right, and we must give to it our earnest heed. But the Religious method of social reform is greater than all these. It is the method of personal righteousness and truth and love. It is the method of men and women devoted to lofty personal ideals. Without this the other methods will not much avail. Without the others this might work a wondrous transformation. Society would hardly recognize itself if all men and women should obey the law of righteonsness so far as it is known. It would think that it was "Kingdon-come." But if with better social regulations, and fewer injurious restraints, and larger scientific knowledge, we could have a general consecration of the individual life to what it believes and knows to be the highest, then should we truly see the glow of a millennial dawn. Indiviclually it may be that we cannot do much for the better social regulation, or the lessening of interference and restraint, or the increase of scientific knowledge. But individually we can each present one man or woman to the ever-growing company of the good and true who has a right to mareh with them to certain rictory, though it may not be for us to taste the fulness of its joy. 


\section{EVOLUTION AND SOCIAL REFORM}

\section{THE SOCIALISTIC METHOD.}

BX

WILLIAN POTTS

AUthor OF "Evolution of Vegetal Life," etc. 


\section{COLLATERAL READINGS SUGGESTED.}

Spencer's "Principles of Sociology"; Chas. Booth's "Labor and Lifc of the People"; Mill's "Chapters on Socialism"; A. K. Owcn's "Integral Co-operation"; Groulund's "The Co-operative Commonwealtlr" and "Ca Ira"; Graham's "Crecd of Science" and "The Social Problem"; George's "Progress and Poverty" and "Social Problems"; R. T. Ely's "Recent American Socialism" and "History of French and German Socialism"; Moore's "Utopia"; Bcllamy's "Looking Backward", Aug. Jacobson's "IIigher Ground"; Edward Kellogg's "Labor and Capital"; T. Edwin Brown's "Studies in Modern Socialism" and "Labor Problems"; Rev. and Mrs. Sam'] J. Barnett's "Practical Socialism"; Besant's "All Sorts and Conditions of Men," "Memorial of Arnold Toynbee, and Toynbce Hall," "Rational Communism"; Dr. Schaefflc's "The Quintessence of Socialism"; Karl Marx's "Das Kapital"; Kirkup's "An Inquiry into Socialism" and "Socialism" (in Ency. Brit.); Dr. Theo. D. Woolscy's "Communism and Socialism." 


\section{EVOLUTION AND SOCIAL REFORM.*}

\section{THE SOCIALISTIC METHOD.}

Commuxism, Socialism, Nationalism, Anarchism and Nihilism are terms with which we have grown familiar within a few years. All of the movements to which these terms are applied had their origin in the old world and under conditions of society and laws wholly different from ours. As they appear on this side of the sea there is a certain element of unreality in them of which in thought we cannot readily divest ourselves, the arguments by which they are supported being so completely out of harmony with the conditions with which we are familiar.

We hear more and more of these morements in this country, mainly from three causes. First, because on the average the wage-earners are relatively much better off than formerly, and are naturally and properly anxious for a still greater amelioration of their condition; secondly, because there is a rapidly growing interest in social questions, and desire on the part of the better educated and more prosperous to find the safest and most effective means for the improvement of the position of the whole; and thirdly, because these two conditions afford the stimulus to enthusiastic and often untrained dreamers to unload their new and fantustic or old and exploded schemes upon eagerly listening ear's, or the opportunity for the soldier, or perhaps I should more properly say the sailor, of fortune to float his leaky craft for a time upon the swelling wave of popular interest. Mr. Laurence Gronlund, one of the highpriests of the socialistic movement here, writes of certain of Fourier's anticipations, "These very soon commenced to fire the American heart, and like a mighty wave they passed over the whole settled part of the United States from east to west, and, indeed, their dying embers did not expire till fifteen years later." Certainly a remarkable state of affairs. "Mr. Chairman and Gentlemen of the Board!" said a poorlaw guardian in the north of Ireland,_ "The eyes of Europe are upon us. The apple of discord has been flung in

\footnotetext{
* Coprright, 1890, by James H. West.
} 
our midst, and if it be not nipped in the bud, it will burst into a conflagration which will deluge the world."

That the advocates of most of these schemes slould at the present time seek to establish them by means of an appeal to law is a natural result of a want of knowledge of the past and, therefore, a want of knowledge of the methods of evolution. It is not seen that institutions result from the development of society, and that society is not the result of institutions. It is not realized that law s of value only as it is an expression of the sentiment of the people by whom it is established, and moreover that some things might be approved by the majority which it would be the extreme of unwisdon to put into the form of law. Statute law is useful and something requisite, but it is dangerous, and it should only be resorted to when it is necessary.

Anarchism strictly means a condition of existence without Government. As a system, if we may use such an expression, it appears to have had its origin in Russia, as dirl also Nihilism which has been practically confined to that country, and both are the result of a natural revolt from the extreme govermmental tyranny of which Russia has been always the theatre. The term Nihilism first made its appearance in one of 'Turgnéneff's novels, and its chief apostle has been Tchernycherski. It is the outcome of a feehing that practically all existing social and govermental conditions are radically wrong, and that there is no hope for improvement excepting through their utter destruction. In relation to that which is to come after this destruction, there is no common agreement.

Anarchism, or anarehy, of which Bakunin is the most pronounced prophet, is extreme Individualism. Arcording to its adrocates there should be no power above that of the individual. All action must be voluntary, and personal action must be uncontrolled. This conception comes from apprehending Government in its old sense, as something imposed from without. 'The modern idea is that Government is merely an agency of the people for sperific purposes. Some things which are necessary that social orrer may exist can only be serured by an agency acting for the whole. There are numerons other things which can be best done by such an agency without inflicting a more than counterbalancing damage, and it is mere waste and wanton 
injury to the commonweal not to use this agency to the best advantage.

It is difficult, I may say practically impossible, to separate and define distinctively the terms Communism and Socialism. Both terms are used, and have been used more particularly in the past, to indicate the governing principle of certain voluntary and local establishments, and both are used, and especially at the present time, to indicate action by the State---by the official power whatever it may be. Of both there have been and are all conceivable degrees, from Brook Farm and the Fourierite Phalansteries, to the Socialistic State of Lassalle, Karl Marx and the International.

Ebenezer Elliott, the Corn-law Rhymer, thus expresses his idea of a communist :

"What is a Communist? One who has yearnings

For equal division of unequal earnings :

An idler or bungler, or both, he is willing

To fork out his pemy and pocket your shilling."

Now this, though a perfectly true picture of a multitude of Communists or Socialists, is wholly false as regards many others.

As the line which separates Communism from Socialism cannot be discovered, so the line is frequently indistinct between these and Anarchism; or, rather, many persons consider themselves both Anarchists and Socialists, although, as I shall try to show a little later, nothing could be more incongruous if we take the modern sense of Socialism as Collectivism or Nationalism.

There are four descriptions of persons who are to be noted as together composing the body, the members of which classify themselves under these various titles: First, a large number of uninstructed persons filled with the spirit of unrest, and mainly desirous of bettering their personal condition in any way that may be handy; secondly, another large number of persons, also uninstructed, but sympathetic, who seize upon any scheme which seems to offer a prospect of promoting the general good; thirdly, a smaller number of persons, who are ready to play the demagogue for their personal advantage at the cost of any cause which they can make tributary to it; and fourthly, a small number of thinkers and students who are generally familiar with the teachings of history but are for the most part guided by their feelings. 
There is no matter in which it is so necessary or so difficult to hold one's self in eheek, as the matter of soeial reform, nor is there any field in which more harm may be done. 'The evils of the past have been so great, the sufferings of the present continue so serious, that one's sympathy becomes immediately involved, and unless he is able to loold a tight rein upon it it is sure to run away with him. 'The Socialist tells us - at least he tells me-that the soeial reformer is not a real social reformer until he is mastered by his feelings; until he has permitted himself to be swept away by his indignation and is unable to see anything but the matter before him. 'To this I reply - then is he a danger' to the people, a pest to mankind, and soeicty is bound to proteet itself against him as it is bound to protect itself against any person of unbalaneed mind. For I take it that there will be no dissent among sane persons to the statement that the intellect is the crowning factor in human nature, that upon the elearness of intelleetual ation depends human development and human progress, and that an intelleet clonded by passion is an umbalaneed intellect and dangerous to its possessor and to the eommmity, even though the passion may in the beginning have been inspired by an impulse the most benevolent; and indeed, most beeanse of this, since it is likely then to become most intense and to be most disastrous in the consequences of its Berserker rage.

Modern Communism and Soeialism had their origin in France, lout Socialism has male greatest progress in Germany. Any deductions, however, drawn from the amomint of the socialist vote in the late election for member's of the Reichstag wonld be misleading, sinee this was largely the result of a temporary combination. In France Soeialism Was a natural part of the revolt from the tyranny of the amrient régime, stimulated rather than repressed by the lanere amount of liberty aroquired through the Revolution, which led those with nutraned minds, or with minds suddenly emancipated, to believe that all things conld be obtained by means through which so much had been procured; and in Germany it has been largely the reaction against arbitrary military rule and preseriptive exaetions. The Socialism of the old days was in the main a volnutary organization of commmnities in whieh the rights of the individual were merged more on less permanently in that of 
the Community. They were practically co-operative associations of an extreme type. Of such, with certain qualifications, is the Familistère at Guise. The Socialism or Collectivism or Nationalism of to-day is absolutely antipodal to the voluntary co-operative society. The latter is what its name implies, a free partnership for the common good. On the other hand, State Socialism, which is the Socialism of Lassalle and Marx, and of their disciples in England and America as well as in Germany and France, is in its essence the apotheosis of force. I am aware that these disciples will not be disposed to admit that this statement is true, but philosophically it is absolutely incontrovertible, as I shall try to show.

Among Socialists you will find the most tender souls, hearts throbbing with good-will to all mankind. 'There is nothing exceptional or astonishing in this; it has been so in all the ages, and in the private recesses of the home it is often the finger of devoted love which touches the key to the most dreadful doom. The Inquisition was the work of those whose intentions were of the best, who wished to save mankind from eternal torment: the bloodiest wars in all history have been wars prosecuted by enthusiasts in the name of religion. Mr. Bellamy, it is said, Mr. Gronlund, Mr. George, and others, are animated by a pure desire for the good of mankind. Shall we say because of this reason, we must agree with their thought and indorse their plans? The world has been full of enthusiasts all the agres down. The world has suffered for them, it has bled for them, it has died for them. Does it make no difference whether the enthusiasm is a wise enthusiasm?- whether it is in line with the drift of the divine power, or wh ther it is athwart or against the current? Shall we say that it is enough that the leader claims to be inspired by the IIoly Ghost? and must we follow him whither he learls, though it may be into miasmatic labyrinths, into morasses from which the race, if it emerge at all, must painfully again fight its way outward to the light as in ages now long burier in the past? Alı! how large a part of the pathos of human life all the ages through do we find in the unnumbered multitudes of tender souls, crushed by the wheels of the ear of human progress in the vain effort to retard their revolution or turn them into a different path!

That system of administration which centralizes the con- 
trol of social functions must, by the necessity of the case, be absolute militarism, or be an absolute failure. And be it remenbered always that for the purpose of doing one particular thing in one particular way at one particular time and in one particular place the army is the ideal organization, and the more complete it is as a machine, the more absolutely individualities must be curbed; while for the purpose of doing an infinite variety of things in an infinite variety of ways, at all times and in all places (and this is life), the army is the worst possible icleal.

State Socialism, or Collectivism, or Nationalism, proposes in general that land and eapital shall be taken possession of by the State; that all production for distribution, and all distribution, shall be under the snpervision and control of the State; that every member of the community shall draw from the State his compensation, whatever it may be, for services performed; and that money and interest shall cease to exist. 'There may be minor qualifications of these conditions, but I think that which I have given will be acrepted by collectivists as an approximately correct statement of the end which they have in view. The more advanced and consistent of them hold that the scheme necessarily implies international union upon these matters. According to some the establishment of the Sorialistie State is to be gained by violence; according to others it is to be reached by a peaceful revolution. Areording to some the expropriation of private property is to be made at once and without compensation; according to others a compromise is to be effected upon some system of terminable anmuities, - annuities payable in goods, or orders similar to those payable for services, but terminating within a linited number of years.

Now what follows, of necessity, from this scheme? A vast centralized organization -- aceorling to some under an Emperor and State hierarehy, but aecording to most writers under a pure democracy - iunst have control of all labor and of all distribution without distinction or exeeption. And this means rastly more than can be conveyed by these works. It moans the eontrol of all varieties of employmont, the determination of what is to be produced, wherre it is to be producerl, how it is to be produered, how mureh is to be produeed; the dotermination therefore of the nomber of laborers, of where they shall labor, and at what they 
shall labor, and how long they shall labor; the control of all religion so far as it shall be manifested in institutions; the control of all instruction so far as it shall be outside of the home. For example: An unwillingness to engage in the production of food, successfully manifested, must produce famine. The teaching of doctrines contrary to the scheme in vogue would be equivalent to the spreading of anti-slavery doctrines in the South in the days before the war. To tolerate it would be to expose the State to inevitable destruction. Some systems propose to pay alike for all kinds of labor, others propose to pay in some proportion to the value of services, this value of course to be determined by the same officials who indicate the kind and extent of the labor. Mr Bellamy proposes to pay all alike, but to require shorter service in certain kinds of labor than in others. The individual becomes of necessity the servant of society, or of those who for the time being represent society, and must obey their behests. He becomes the slave of the State rather than the servant, for service may imply voluntary contract, and there is nothing really voluntary in the attitude of the individual under the proposed system. He may submit to the inevitable, but it is the inevitable and he has no choice but to submit. From a phalanstery or any local socialistic body he may escape, but there is no escape from the international socialistic State except out of the world.

If there is any way in which the socialistic State can be carried on without the exercise of this control by the authorities, I am unable to conceive it. And how are the persons to be selected who are to exercise this control? By Hopular suffrage! Imagine it if you can. Think of what is the present result of popular suffrage tempered by all that can be done to qualify it, and think of what it would be were all the interests of life dependent upon it! Our main reliance to-day is and must be upon the sturdy independence which has been fostered by our multifarious individual development, which challenges merely official authority at every point. The Socialists tell us, “Oh, but nnder our system the best men would be chosen to perform the various functions." "To this remark there is really no reply. One must simply gaze in mute despair at the speaker and feel of his own head to ascertain whether it is still upon his shoulders. 
The success of Socialism implies a tyramy as much more dreadful than any that the world has hitherto seen as our civilization is more complex than was the civilization of the past. Imagine if you can the possibility of such intellectual lives as that of Emerson, or those of which we have just heard told in this conrse of lectures,- the lives of Youmans and Gray. Imagine such a system organized a thousand years ago, and imagine it successful. Modern eivilization becomes at once an impossibility. The knowledge of the new world and of all that has come of it, nay, the very knowledge of the existence of the Western Henisphere, must be blotted out. But I am drawing too heavily upon your imagination - at icast I have reached the limit of my own. One can picture to himself the experiment attempted, but he camnot think of it as enduring for a moment. 'The very leaders of the movement would be anong the first to revolt against its decrees. Their strongest characteristic is their unwillingness to submit to the conditions surrounding them, their assurance that they are right and that the majority are wrong. Think of Ferdinand Lassalle or Karl Marx or William Morris subunitting to be ordered in all his affairs by a petty officer placed in authority over him by the multitude which he glorifies! Some of them would be burned at the stake rather than yield one jot of their independence.

I have allucled to Mr. Bellamy becanse for the moment lee is the representative of the Socialist movement in America, and he is said to hive sold more than 300,000 copies of his book. He has attempted a picture of an ideal society, as Plato in the "Repmblic," Sir "Thomas More in the "Utopia," Campanella in ". The City of the Sim," Lord Bacon in the "New Atlantis," Cabet in the "Voyage to Icaria." It is principally noteworthy for the horror with which it inspires one who cherishes the old ilea, "Give me liberty or give ne death." His fitness for the discmssion of such a problem as that which he has molertaken to treat is ammsingly illnstrated ly his management of the marriage question. He hugs himself with delight at the improvement of the race which is to result from the fact that the finest men are to mary only the finest women, wholly ohlivious of the fact that unless he revolntionizes human nature he simply leaves all the rest and residne of the rare to marry and multiply after their kind, and, if there is any 
force in his argument whatever, to intensify the evil which they represent. He has recently issued a platform of what Nationalism at present demands, including among these things Civil-Service Reform and other matters which have about as much to do with Nationalism as a system as they liave to do with Conic Sections.

The socialistic movement rests largely upon the supposition that the rich and the poor are distinct classes, permanently fixed under the present order. In certain countries in a rough sense this has been true, but only in a rough sense, and even there it is becoming less and less true. In this country it is simply nonsense. Anyone who has knowledge of the facts is aware of this. It has long been proverbial that 90 or 95 per cent. of all capitalists fail in business, and the number of families which have retained large property through several generations is extremely small.

In the city of Worcester, Massachusetts, of thirty persons who were leading manufacturers in 1840, fourteen failed and fourteen died or retired with property. Only three of the sons now have property or died leaving any. Of seventy-five of the same class in 1850 , forty-one failed and thirty died or retired with property. Only six of the sons now have property or died leaving any. Of one hundred and seven of the same class in 1860, forty-three failed and sixty died or retired with property; - of the sous only eight now have property or died leaving any. Twenty-eight out of the thirty manufacturers of 1840 began as journeymen. One hundred and sixty-one out of one hundred and seventysix manufacturers of 1878 began as journeymen. As an intelligent commentator puts it, "The truth is, that the capitalists of to-day are themselves the workingmen of twenty-five years ago, as the workingmen of to-day will be the capitalists of twenty-five years hence."

The demand of interest for the use of money is one of the matters against which Socialists and also some good people who are not Socialists most loudly inveigh. Now, simply remarking that a great part of what is called interest is merely a premium on insurance against loss of the principal, and the remainder a very small charge for a very great assistance given to the borrower, I want to call attention to the fact that not one person out of one hundred thousand has any adequate knowledge of the relation of 
the actual to the theoretical in the matter' of interest. 'The legal rate of interest in this State,-and in passing I desire to express the opinion that the fixing of a legal rate, excepting as a standard to which to appeal when there is no rate by contract, is an injury to the community, - the legal rate in this State is six per cent. per anmum. Now, it is undoubtedly the common thought that a sum of money can be invested at this rate, and allowed permanently to accumulate at compound interest. What is the fact? Supposc one dollar, one single little gold dollar, which is the sinallest of all the golden seeds which produce this crop of interest, to have been invested at the beginning of the Christian era, and allowed to compound annually at six per cent. until this day. If you will consider the sum thus accumulated as turned into gold, and this gold placed where the sun now is, it would form a solid mass extending in all directions beyond the eartl's orbit-a mass more than two hundred millions of miles in diameter. From this one dollar there would have accumulated in eighteen humdred and ninety years a sum of which the markct value of all property real and personal which exists upon the globe, or which ever conld exist thereon at any one tine, would be an almost imperceptible fraction. Now compare this with what has actually ever occurred in the way of accumnlation and you will obtain some faint conception of the relation of theory to fact. What has become of this interest then? It has been stolen, it has been lost,- it has been burned by fire, it has been drowned by water, it has been destroyed in battlc: you will find it in houses and in slopes, in pietnres and in statnes, in roads and in bridges, in the grass which covers the field, in the present grain which in the past did not exist; in the erect carriage and wide capacity of your men, in the delicate complexions, the gentle voices and manners of your women. In fine, interest is merely one slight indncenent to that habit of thrift and that effort for extended powers and opportunities which have nade the man of onr agc and race a different creature from the carcdweller and the wanlering savage. It las been one of the potent agents of human evolution, qualified and often rendered mugatory by opposing forces.

The two factors which are mainly responsilsle for the development and alvance of civilization are the accumlation of appital and the existence of eompetition. that bete moire of the sorialist. I great increase of interest-bearing 
capital greatly strengthens the position of the laborer by increasing competition among the capitalists.

The avowed object of the Socialist is of course to ameliorate the condition of the less prosperous part of mankind and to establish equality, and his main argument for the policy of Collectivism is that it will stimulate production to the highest point and greatly cheapen it, as well as equalize distribution. Equality is his ideal, not liberty. Now, I think it is sufficient to say in regard to this matter of cheap production that we have got past that star. The enormous improvements in processes which have come with the inventions of the past hundred years, together with those now in progress will, I think, within twenty-five years have forever removed from the field of debate the question of production sufficient in amount for the needs of all. The questions that remain are, (1) What shall be the character of the products, good or bad, durable or otherwise, artistic or slovenly and commonplace?- which can only be settled by individual development; - and (2) Equitable distribution in such manner as shall promote and not repress this development.

And is it true that through equality progress is to be made, and that without it the lower must remain the lower to the end of time? To me history tells exactly the opposite story.

The effort of the Socialist is directed toward the establishment of uniformity, while the whole drift of the universe is, and always has been, from uniformity toward diversity. In my judgment the proposed cure for the ills of mankind is impossible of application, and if it were possible the cure would be twenty times worse than the disease.

Mr. Henry George is not a Socialist excepting in the matter of the ownership of real estate, and in that he is prepared to make a compromise and simply take the value of land instead of taking the land itself. These are his words :

"The Stundard advocates the abolition of all taxes upon industry and the products of industry, and the taking, by taxation upon land values, irrespective of improvements, of the ammul rental value of all those various forms of natmal oplorturities embraced nnder the general term Land.

"We hold that to tax labor or its products is to discomage industry. We hold that to tax land values to their full amomint will render it impossible for any man to exact from others a priec for the privilege of ming those bomnties of Vature in which all 
living men have an equal right of use ; that it will compel every individual controlling natural opportunities to utilize them by employment of labor or abandon them to others; that it will thus provide opportunities of work for all men, and secure to each the full reward of his labor ; and that as a result involuntary poverty will be abolished, and the greed, intemperance, and vice that spring from poverty and the dread of poverty will be swept away."

Truly a consummation devoutly to be wished! I should feel more confilence in Mr. George's prophecy if I had not unfortunately read his explanation of financial crises, which seems to me the most elaboratc and consistent misstatement of an economic question which it ever entered into the mind of mau to conceive. It is a most admirable demonstration of what a courser a hobby nay becone when lie takes the bit between his teetl.

Mr. George's theory, of course, is that these crises are the result of private ownership of land, and of land specnlations. Now I camnot imagine anyone who has passed throngh two or three of these crises, and who has really been familiar with the course of events, allancing any theory so preposterous. A crisis, a lanic, is a very simple matter if you keep in view the peculiarities of human nature, which curiously cnougl are seldom taken into account by the Socialist, extreme or limited. The order is simply this: a period of commercial caln provokes the development of business enterprises; this development increases capital and stimmlates confidence; confirlence in turn begets credit and this reacts upon production; the resulting production still furtler stimmlates eredit, and strong and weak alike are indnced to spread themselves to the utmost upon the strength of public conficlence; those who liave bcen most successful and who are most shrewd now feel that it is best to make sure of what they have aequired, ant begin buying real estate whieh has long lagged behind lersonal property in the advance; its value of course rises; at the same time the system of commercial credits has reached the state of tension which is typitied by the l'rince liupert's drop of the pliysicist, of which-break off but the tiniest point - the whole mass will fly into the finest jow merchant fails, finaneial institutions stop leneling, the notes which fall due camnot be "xtended - the creelit system explodes, and the menlers of the commmnity, weak and strong alike, are involved in a eenmon ruin. 
The theory of the different relation of man to land and to other possessions is not new; it is the universal property of all civilized communities. That which is most new on the part of Mr. George and his immediate followers is the deliberate assumption and statement that the practical spoliation of the present holders of real property would be just, would be in the interest of mankind and agreeable to the gods.

The first consideration is that land cannot be increased in amount, while the race is constantly increasing in numbers. Most true; and it is likewise true that with advancing civilization land increases rapidly in productivity, while population as rapidly diminishes in rate of growth. There is not yet the slightest evidence that the one will ultimately become too small for the other. Mr. George claims that land was at one time common property, and that it has gradually fallen into private hands through more or less of fraud and violence. This is also most true, and I think that it would seriously puzzle the author to pitch upon any kind of property whatever the possession of which has not in some degree and at some time been tainted with fraud and violence. In the sense in which Mr. George's statement with regard to real property is true, the same statement is true with regard to personal property either as to the articles themselves which constitute such property, or as to some of the labor which at one time or another was involved in them, or as to the raw materials of which they are composed which at some time were a part of the land, the "natural opportunities" which Henry George says have been appropriated by fraud and violence. Indeed, according to the Scriptures, "from the days of John the Baptist until now the kingdom of heaven suffereth violence and the violent taketh it by force."

Because land was at one time in a certain sense common property (which also it is to-day) Mr. George claims that it is so now in every sense, and that the taking of the rent of land by private owners "is a fresh and continuous robbery that goes on every day and every hour." He bases the claim that the community as a whole shoula expropriate the land without compensation to the land-holder, on the doctrine of naturalright, the same doctrine upon which is largely built the theory of the various socialistic bodies. 
Now, this is merely fustian. If the theory of evolntion is true, the man primarily has a natural right to lis place on the soil simply and solely as the vegetable has a right to its place. If the oak in a fertile spot, striking its roots broadly and deeply and spreading its giant arms in air, is entitled to its position and entitled to crowd out other plants, then and for the same reason is man entitled to his. 'They obtained their right through the same rule of the survival of the fittest as the effect of universal laws, - each holds it by the right of might, and may be called upon to yield it to the same right. 'To say that in certain instancesin innumerable instances - there was violence exercised in obtaining this control, is to say that which is substantially true of all property and of every line of progress when a sufficiently comprehensive view is taken of it. If we assume a certain theory of justice to be true of all eircumstances and of all times, then is our past but a sorry one. If we adopt a certain point of view as correct let us be true to what it demands - let ns recognize the fact that the idea of equality of opportunity is the child of to-day, and, though the best beloved perhaps, to be nurtured in accordance with the demands of the principle which governs development.

With the developing man, mental and moral forces came to supplement physical forces, and law was gradually formulated, touching alike the relation of man to land and his relation to other things. When the race reached a full conception of the right of individual property it made its tirst great stride in civilization. And this was equally so in the case of the ownership of land as in the case of other things. 'The lines of change in different countries have varied but change has been steadily from the common to the individual, with ever-increasing value to the race. As I look back over the history of the past, the development of agriculture with all that has followed therefrom would be perfectly inconceivable except through the private ownership of land as that private ownership is defined and limited in cirilized countries. For it must always be borne in mind that absolute private ownership of land is recognized by no civilized people. What is called ounership of land is only a more or less extended right of use. The right of eminent domain is universally conceded as resting in the nation as a whole, but this right, it is generally understood by modern peoples, should not be exercised ex- 
cepting in the clear interest of the whole body. The community has the right of might and can be relied upon to exercise the right in establishing such rules as are necessary for its own preservation.

And now, bearing in mind that the present holders of land have acquired it precisely as they have acquired other things, through the methods established by the community as right and just, we are called upon to step in and quietly relieve them of it. Perhaps most ingeniously absurd of all is the proposition to distinguish between the land and the improvements upon it, acquired in precisely the same way. Excepting in the cities and in property similar to city property this is absolutely impossible. Moreover I can by my personal labor make land which is worth now one dollar per acre, worth a few years hence one hundred dollars per acre, without stepping my foot upon it or allowing a stick or a stone to be moved, simply by making it accessible, by building roads, and in other ways making that which was unknown and unavailable greatly useful to mankind. This increase of value, which is wholly due to $\mathrm{my}$ labor, Mr. George says is not mine, but belongs to those who would forever have left the land in its previous useless condition.

As to the matter of the "unearned increment" in the value of land, upon which so much stress is laid,- that is, the advance in value (where there happens to be an adrance) which is not the result of any action upon the part of the holder, - - since so great a man as John Stuart Mill was beguiled with it, it is no wonder that we of the commoner sort were for a time in like manner led astray. But in what respect does real estate differ in this regard from personal estate? One man buys land, giving therefor the highest price that anyone will venture and assuming the payment of all the taxes and other charges thereon including the burden of interest, with the chance of an advance or a loss, that chance being greater or less according to his shrewdness. The tide of improvement turns that way and he reaps a profit. Another man buys beans, upon which, however, he pars no taxes. There happens to be a short crop or a fire in a great warehouse; the price of beans is advanced and he reaps an enormous profit. But, says Henry George, "there is a limited supply of land." Yes, we reply, and there is a limited supply of beans. The reasons for the increment of value are of precisely the same 
cliaracter. If the people as a whole are entitled to the profit in the one case they are also in the other, and in both cases they are equally entitled to share the loss.

Now, as a matter of fact the price of agricnltural land is falling in all directions. The reports are alike from New Hampshire, Vermont, Massachusetts, Virginia, and other States. The New York assessors say that such is the condition in almost every county in this State. The same report comes from England. In the sonthern part of our own Kansas one attorney is said to have in his hands for foreclosure eighteen hundred mortgages. "Similia similibus curantur," cries Henry George in effect. "Double the taxes and save them."

'Then, as to the matter of the deduction of the value of the improvements. General Francis A. Walker writes me that, according to Henry C. Carey, "There is not a State, County, or Township in the United States whose selling price would repay the amount actually laid out in bringing the region to its existing state of cultivation and improvement." Supposing that this is not strictly so, any one familiar with country districts must be well aware that the improvements upon the land of the poor farmer are much less in value in proportion to the land than those upon the land of his rich neighior. The system proposed would therefore fall with greatest weight upon the poor. What is the case in the cities? Our ordinary observation shows us that the result would be the sime. Fortunately, however, we are not left to depend merely upon the rule of thumb. Land and buildings are not assessed separately in Brooklyn or New York, and I could, therefore, get no reliable information here firom official sources. From one only of the several real-estate dealers to whom I have applied have I obtained any figures, and an analysis of these shows a considerable excess in the proportionate valuation of improvements on the land of the walthy, as I had expected. In Massarhusetts, however, the law requires a separate assessment of land ancl improvements, at the actual value of each. 'The President of the Boind of Assessors of Boston has kindly made an examination for ne, and sends me the following results:

In the greater part of Ward 11, which is the liack Bay District, the wealthiest in the city, the proportionate value of land to the total value, of improved property, is $481-2$ 
per cent. In Ward 17, which is mainly occupred by a prospe:ous and well-to-do middle-class, the percentage of value of land to the total, in improved properties, is only 44 1-7 per cent. In Ward 13, which is oceupied almost wholly by the poor, the percentage of value of land to the total, in improved properties, is $611-3$ per cent.

Under the proposed beneficent system therefore, the very poor will be courteously called upon to surrender relatively nearly 39 per cent. more of their property than the well-to-do. "But," says the Single-tax advocate, "when unimproved land is assessed at its actual market-value the proportions in these valuations will all be changed." To this I am forced to reply, "not quite so fast, my good friend. An assessment of improved and unimproved land at actual value is no peculiarity of the Singletax system. As well characterize the author of the system as peculiarly a hatted man, because he wears a hat, as characterize the Single-tax system by any such feature. Such a method of valuation is the only proper method according to economists of various schools, and to my personal knowledge was so long before 'Progress and Poverty' was written. Moreover, this is precisely what is now done by law in the City of Boston without any such marvelous effect upon the City or State as you prophesy, and with the result of producing the figures which I have just given. Furthermore, whatever change of value might occur hereafter, the cost to those who are despoiled is the cost of their property to-day."

MIr. Henry George and his followers have yet to show that there is any conceivable practicable method by which their single tax upon land, omitting the improvements, could be collected, and that under such a system it would be any easier for a moneyless man to obtain possession of a valuable location than it is to-day.

Verily these gentlemen have the courage of their convictions: On a mere guess as to what they think might happen under a state of circumstances never yet seen in a complicated society, they are ready to bring down upon the world all that the change which I have indicated implies, to urge an act of injustice so stupendous that nothing in any way comparable with it as a deliberate proposition appears upon the pages of recorded history. They propose to deprive the owners of 
this right, on the plea that somewhere in its past history there is a taint of violence, - a point in which, as I have already shown, it resembles practically all other property, - and they propose to confer it upon whom? Upon those who first ocenpied the land and held it in common? Not at all: these, so far as our country is concerned, were the Inclians, and the Indians still remain elsewhere, having been driven from here by violence and fraud. I\%trence are these to whom the value is to be given? 'The answer must here be as in the poem, -

\section{"Out of the everywhere into the here."}

Yes, to stragglers from all parts of the known world, who have never heretofore had any right to this land, whose right if it exists is, according to Mr. George's theory, founded upon violence and fraud, the valne of the land which is to be wrung from those who have honestly acquired it is to be given. It is proposed that the change suggested by $\mathrm{Mr}$. George might be made gradually. If a man must submit to the loss of lis leg I am not sure that these is much more comfort in having it cut off say an inch at a time, once a montl, than in having it taken at one fell swool).

The question of taxation, which Hemy George claims to be such a simple one, is on the contrary a very difficult one. This is not the tmme to go into that matter, and I am not competent to handle it thoroughly if it were. But as I may be expected to suggest something I will state two principles which I believe to be absolutely somd, and express an opinion which I think worth consideration.

First Principle: Taxes shomld be so levied that their amount and effect may be clearly muderstood. 'This is not the ase with our present protective-tariff taxes. If it is best to give pecmulary encombement to certain industries - into whinh question I do not propose to enter - the only straightforward and honest way is to pay a bounty for their development and prosecution, and to obtain the necessary funds by just and equitable taxation, the character and extent of which is plain to all. If the amount amd result of all taxation were elearly understood, you may be very sure that the total would soon be rapilly reduced. We are trombled by a surplus and its consequent enormous evils simply becanse the national taxes ane levied in such a way that the payer does not know when or what he is paying. 
Second Principle: Taxes should be levied upon values easily ascertainable, and the confession of the individual taxed should not be called for. This would rule out all income taxes levied upon the individual, the income tax being theoretically perhaps the best and practically perhaps the worst tax ever conceived.

For the Opinion: I believe that the system of taxes upon real estate should be thoroughly revised, and doubtless in some instances the taxes should be greatly increased. The assessments should be as nearly as practicable upon the actual value, as experience has shown that any other system of assessments discriminates in favor of the rich and against the poor. And what further moneys may be required by the Government should be obtained from levies upon valuable franchises of all kinds, upon articles the consumption of which tends to increase the cost of government, as alcoholic drinks, and upon articles which are distinctly articles of luxury. Upon the first, because certain privileges are granted by the community, in the franchise, which either tend to the establishment of a monopoly or which enable the parties holding it to conduct a certain business with a limit to their liability thereunder (at an increased risk to the public), or both, for which privileges the Commonwealth should be compensated; upon the second, because he who dances should pay the piper; upon the third, because a tax upon luxuries does not seriously tend to hamper production, as does a tax npon necessaries. These are the economic reasons; there are others of importance into which I cannot now enter.

The taxation levied by the National Government in 1880 wholly upon personal property was about $\$ 321,000,000$. According to the census of that year, an imperfect source lut the best that we have, the total taxation of the States, Counties, Cities, Towns, etc., was $\$ 312,750,721$, which was derived from a real-estate valuation of $\$ 13,036,766,925$ and a personal valuation of $\$ 3,866,226,618$. The idiocy of the present system of taxation upon personal property will be seen from this, that in the same year the value of railroad property was returned at $\$ 5,536,419,788$, or more than forty per cent. in excess of the total amount of personal property reached by assessment. Some sapient Single-tax men class railroad property as wholly real estate, notwithstanding the fact that the total value of the real estate 
held by the railroad companies in 1850 was $\$ 103,319,845$, or less than two per cent. of their entire assets. The attempt to tax arlequately a railroad corporation on the sole ground of levying a tax upon land values is equivalent to using the extradition laws to obtain possession of the person of a man on a charge of burglary, and then trying him and punishing lim for high treason, an act which is condemned alike by international law and by the universal sentiment of mankind.

The single tax is recommended on account of its ease and simplicity. Ease is a good thing, simplicity is a goorl thing, but neither that which is easy nor that which is simple is always the best thing. 'The easiest and simplest way of getting rid of a man who annoys you is to shoot him. It is generally thought, however, that "murder is a bad habit to get into." The easiest and simplest way to get rid of troublesome theological questions is to adopt a creed which someborly has already prepared for you. 'This course, lowever, does not seem to commend itself to those who most frequent this place. It is claimed by its advocates that the simplest and easiest tax to collect is a single tax upon land values. But I think that I have shown that there is no special justification in history for sueh an exceptional burden, while it would fall with crushing weight upon those least able to bear it. Were I desirous of dis.covering one singlc measure which would most help the speculative rich at the expense of the depondent poor and most seriously damage the future of the race,- - which, thank heaven, I am not,-- I camot imagine that I could find any more potent than the proposed confiscation of land values.

'These schemes, Communism, Socialism, and Georgeism, are all artificial, mechanical, - they are not organic. You have a world infinite in its complexity, with a race infinite in its variety. You are conscious of incompleteness, of great incquality : you turn a crank (pardon me - no jun was intended) and lo! it is all changed,- the world is marle over and the millemium has arriver. When Hamlet said,

"The time is out of joint: oh, cursed spite That ever I was born to set it right!"

he seems to have felt oppressed by the weight which was thrown upon him. Not so these modern reformers. They assume the labor of performing the function in which the 
power which inspires the universe has so signally failed, with a jocund hilarity which shows their entire assurance that however it may have been with the one that preceded them, they are quite equal to the occasion.

Whatever may have been my feeling at the outset,-and I am free to say that, like most persons at this day who liave a keen interest in social questions, a keen sense of the inequalities in lumman life, the appalling, the crushing weight of circumstances upon the individual; who have an enthusiastic desire for the elevation of all, I approached the study of the question in a hopeful spirit,- I must confess that, as the result of careful study, I am driven to protest against the Socialistic proposition with every fibre of my being. I cannot imagine any movement more injurious to the interests of the race. It is the very antithesis of equitable profit-sharing, the increasing tendency and the most hopeful sign of the times, or the voluntary co-operation of intelligent individuals which is the essence of republican representative government,- that co-operation which consists in common action for the common good, founded upon a scrupulous recognition of the supreme importance of the maintenance of the most absolute liberty of each which is compatible with the good of the whole.

It is held that there are practically but two alternatives -Individualism, which means "every man for" himself and the devil take the hindmost"; and Collectivism, or every man the slave of those who can obtain the power. There is, I think, a course quite different from these, a course which is not properly to be classified as an ism at all - but if you must have a name with that termination you may if you please call it Opportunism.

This is the course which the history of the past everywhere reveals to us, and if we are to judge of the fiture by the past it is the course which the future must follow. It means in fact, that political and social action are not the result of doctrinal rules arbitrarily worked out, but the outcome of temporary conclitions which by a complication of forces produce a compound or approximate result. The development of society follows the rule of the development of organic life: there are lines of least resistance which it must follow. The thoughtful statesman or social reformer examines carefully the history of the past; he discovers that in certain directions there has been progress, and that in those directions progress has resulted in ameliorating the 
condition of the raee. He examines the present eonditions and deeides aecording to his best judgment whether upon those lines there is still room for expansion. If so, he seeks favorable opportunities for forward movement - one step at a time-acknowledging that the far futmre is far beyond his ken. and only conscious of the possibilities of the immediate present. Thus his voluntary action, itself a result of development. becomes a factor in that development and itself assists in the trend of the raee. His imagination has impressed him with the idea of equality of opportunity, and he seeks to establish that equality. He sees that all progress in the past has been the result of individual progress. He sees that that whieh encourages the development of the individual not only strengthens him but enables him to become a valuable nember of the eommunity. That which discourages that development wreeks both the individual and the community. He therefore sees that whatever changes are encouraged or permitted, the freedom of individual action should be preserved so far as that may be possible.

$A$ recent lecturer in this eourse sairl that certainty of ineome was the great desideratum. Certainty is indeerl a good thing, but it is not the best thing. It is the something beyond, the contingent, the uncertain, the prize in every package, that inspires to forth-putting, to progress. Whe in the imagination was born, then eame the man. There is no place for the imagination in socialistic schemes. It is that which inspires the schemers themselves, which gives all the vitality there is supposed to be in their sehemes, lut with the sueeess of their schemes the imagination dies.

What, then, is my scheme? I have no scheme-God forbid. I do not know whither we are going - nor do you, my good brother. We stand in reverent awe in the presence of the transcendent power which surrounds and possesses us, a power so transcendent that words eannot express or thonghts eonceive it. We touch it at every point - are a part of its extension, if I may use so crude a word-and know that nothing is which is not also a part. We feel the pulses of that life moring not in one only but in all directions, ancl ever developing greater variety, greater complexity. We surrender ourselves with serene assurance to that power. Do you call this a sublimated Fatalism? I'erhaps it is that, but if so it has none of the dangerous features of the Fatalism of the past. And whether it be Fatalism or not.- call it what you will,-it is the oondition in which you and I find ourselves and from which there is no escape. Horeover, why should we degire to escape": (Jur rearward view shows 
us an ever widening track with ever higher organization and attaimment; and if we surrender ourselves to this illimitable power we do so only in a form of words, for we are born therein, therein have our growth, and the work which is still to be done can only be accomplished through our co-operation: we have no fear of yielding ourselves to the current for we are a part of the current. Looking into the past we see dimly whence the stream has come. Regarding the present we see over its ever broadening expanse eddies around obstacles here and there, but nevertheless the current is ever flowing onward toward the golden haze which shrouds the future-and we see with absolute assurance that for that portion of the eternal power which flows through us there is only one proper application, and that is toward the removal of the obstacles which vex the current at our feet.

When I express iny dissent from this scheme or that scheme for the reconstruction of human society according to the only true and reliable method for the attaimment of millennial conditions, its advocate immediately retorts with just indignation,-_"Then you are satisfied with things as they are and wish the present conditions to continue." Satisfied with things as they are? The Time-spirit says of the present order, "An ill-favored thing, sir, but mine own," yet, unless I have sadly misjudged the course of evolution, the very fact that things are as they are is the most conclusive proof which it would be possible to have that they will be different hereafter. Satisfied with things as they are? Satisfied with misery and want and wretchedness? Satisfied with the rule of ignorance, incapacity, and corruption? Satisfied with teachings by blatant demagogues or onesided advocates? Satisfied with sophisticated foods, filthy streets, hideous buildings, squalid hovels, unfaithful labor: ers, unjust employers, devastated fields and meadows, treestripped mountains, ugliness and vulgarity and bad manners without limit? He must be a singularly constituted man who could be satisfied with these things. And it is the people who do these things or profit by them or who permit them to be done, after a race-life of probably more than 500,000 years, who - or their immediate descendants - I am asked to believe, will in one hundred years or one thousand years have suffered "a sea change into something rich and strange"; will have cast off all their old characteristies and their old ways, will have put on righteousness as a garment, will have become permeated ly a sense of beauty and comeliness, will be animated all by a common desire for the common good! And all this is to result from-what? From 
their submitting their wills to the absolute domination of a universal demoeracy composed of the material which I have indicated - represented ly such public officers as may have suceeded in procuring an clection - and compelled to surrender their volition in all inportant resperets, as to habitation, oceupation, theught and speech, to the will of these. This is to be the outcome of eivilization - this the consummation so devoutly to be wished!

I am no prophet, and I shall not attempt prophery. I only know this, that this which I have depicted will not be; and thank God for so much. I know that it will not be, because there has never been a stage in the progress of mankind or the universe which has not been absolutely at variance with such a possibility; there is not a fact in existing contitions which points to a realization of such a state of society in any positive and permanent sense.

I have pictured the shortcomings of the present with no dainty touch. Do I then feel that we have made no progress in the past? that there is no hope in the future?

I look back through the ages until I seem to see nanght but a nebulous haze. I see that haze gradually differentiating through infinite time until suns and planets are evolved, - the mineral takes organic form, the organic develops into regetable and animal, the protista ly nmmmberet stages give birth at last to primitive man. I see the growth of man frem the birth of intelleret to the era of Emerson, of Spencer, of Darwin. of Elison. Have we marle no progress? What is this panorama which I have sprearl before you? We are where we are. We have our place in the line of march. We have not yot drunk life to the lees, but with ever inereasing diversity are ever realizing a more entire oneness and mutual responsibility, and in ever increasing numbers are appresiating that bound up with the interest of each one is the interest of the whole, anel bound up in the interest of the whole is that of arch one. No pent up) Ctica can exhanst our lowers, no scheme is large coungh, claborate (nough, or sufficiently far-reaching to satisfy the aming rate. All methors are the methots of the divine, and we reach forwarel in the conficlent hope. the contilent belief, that the rave (an only attain the highest goal through the perfect acelopment of the individual soml. And

"all experience is an areh wherethromgh fileams that untraveled world whose margin fades Forever and forever when I nove." 


\title{
EVOLUTION AND SOCIAL REFORM
} III. THE ANARCHISTIC METHOD.

\author{
BY
}

HUGH O. PENTECOST

Editor of "The Twexteth Cexturx." 


\section{COLLATERAL READINGS SUGGESTED.}

Speneer's "Principles of Soeiology," "Social Staties," and "The Man versus the State"; Prudhon's "What is Property?" and "Ilée Générale de la Revolution au 19me Siècle"; Brown's "Studies in Modern Socialism"; Sumner's "What Social Classes owe to Each Other"; Mill's "On Liberty"; Lieber's "On Civil Liberty and Self-Govermment"; Huxley's "Administrative Nihilism"; Stephen's "Liberty, Equality and Fraternity"; Crosier's "Civilization and Progress"; Thompson's "Social Progress"; James"s "Anarchy"; Parsons's "Anarchism: Its Plilosophy and Scientific Basis"; Bakounine's "Gol and the State"; Andrews's "The Seienee of Soeiety"; Tchernichewsky's "What's to be Done?" 


\section{EVOLUTION AND SOCIAL REFORM.*}

\section{THE ANARCHISTIC METHOD.}

Those who accept the conclusions of Anarchism believe that it is a science; or, if you please, a philosophy supported by facts scientifically discovered and collated. It is not a religion based upon assumptions, unwarranted or contradicted by facts. It is not a system of metaphysics consisting of undemonstrable speculations. 'They freely admit that Sociology is not yet an exact science; that, strictly speaking, there is no Science of Society. But they speak of Anarchism as a science because its methods of investigation and accomplishment are scientific. In so far as it represents conclusions they have been reached scientifically. If Anarchists have a theory it is because they believe observed facts are best explained by that theory. If a theory does not well account for observed facts it is abandoned, and a new working hypothesis is sought. They do not pursue the theologic or metaphysical method in formulating their postulates.

Anarchists believe there should be no government: by which they mean no government by physical force; no government to prevent persons from thinking, saying or doing what they should be free to think, say or do; no government for the encouragement of those who invade what should be the rights of others, with the protection of such invaders; no government to authorize a few to monopolize what should be the opportunities of all; no government to compel persons to do what they should be free to refuse to do, what it is not necessary for the good of all that they should do; no government in favor of one class as against another class; no government to enrich the idle by imporerishing the industrious. They believe there should be no government that interferes with wholesome individual liberty and wealth-producing exertion. But they believe in well-ordered society, in which the wise, the just, the good will rule by precepts, principles and examples; in which healthful public opinion will utter and

*Copyrigit, 1890, by James H, West. 
morally enforce everything needful for restraint or encouragenent. They believe in government, lut not government by physical force for the injury of all, or, to use a common expression which means the same, for unjust purposes. They believe in self-eontrol and mutuality.

An Anarchist is not one who wishes to separate limself from his kind, to live independently, to lapse into the individual isolation of the Stone $\mathrm{Age}$. He is an individualist, but also a soeialist, a mutualist. He understands that eivilized men must eo-operate, that co-operation is a social neeessity. But he wishes to co-operate voluntarily; to have the privilege of declining to co-operate in one or more or all particulars; of resigning the benefits and obligations of co-operation. He values individual freedom above all other possessions, and protests against any organization of society in which it is not reeognized and respected. He does not wish another or a majority of others to decide for him what he shall or shall not do, unless he agrees beforehand to such an arrangement. If he wishes to live apart from others he desires to be allowed to do so. He believes in soeiety eomposed of individuals eaeh of whom shall be free from invasive restraints or compulsions. It should be understood that Anarehists abhor the idea of using individual liberty for the purpose of injuring others, and they believe that in soeiety rightly eonstituted there would be found effeetive methorls of dealing with those who should violate the rights or liberties of others.

It should be understood from this statement of general principles that Anarehists are not bomb-throwers-dynamiters. There are some persons who call themselves Anarchists who believe that cireumstanees might arise which would justify a resort to destructive warfare, and that good results would follow such a method. lint, in my opinion, the clearest thinkers, the most scientific anong the Anarchists, understand that what might be achieved by physical force would be subject to reversal by physieal forec, and would, therefore, lave to be conserved by physi('al force. In my opinion, the most eareful thinkers among the Anarehists understand that if some transient "tilalwave" of popular opinion. formed rapidly and by what we call aceident, or some sudken nprising of the people, inflaned by liseontent lut not elueated in eronomie prineiples, as m the case of the French lievolution, should 
enable them by political methorls or force of arms to secure control of the govermment, little or nothing would be gained and much might be lost. So that the life of even so hateful a ruler as the Czar is safe from attack by an Anarchist, because it is not the Czar but Czarism that must die before the people can be free; and no Anarchist would think of destroying the property or life of a monopolist, for it is monopolism that is aimed at, and this ean be destroyed only by education. Anarchists do not fight with bombs, but with books; nor with pistols, but with pens. They are not thugs; they are thinkers. Not powder, but persuasion, is their weapon. Not by cannon, but by convictions, do they hope to win.

Among non-Anarchists who are sufficiently well informed to understand all this, the objection is urged that Anarchism is a beautiful but utterly impracticable dream. The realization of Anarchism, it is said, would introduce the millennium; and, strange to say, this is a reason why multitudes of Christians who profess to be looking forward toward the millennium with all the fervor of religious hope regard Anarchists with aversion or contempt. It is quite true that to reach an ideally Anarchistic social state would necessitate ideally perfect individuals. But Anarchists are not idealists. They are the reverse of idealists. Every theory has its ideal of perfect consummation. But Anarchists do not expect perfection. Perfection is not necessary to the happy and relatively satisfactory working of Anarchism.

Anarchists are not dreamers, however much they may be so regarded by those who do not understand their beliefs and aims. 'They regard themselves as very rational, very practical persons. 'They believe their theories may, in many particulars, be put in practice at once; that some of them are in operation; and that wherever they are employed the results are more satisfactory than where opposite niethods are pursued. For example: Fashions are followed by the Anarchistic method. Men, without goverumental interference, wear narrow or wide trousers, and women short or long skirts. And this is a distinct advance toward Anarchism, as everyone familiar with the governmental regulations of clothing in the past knows. Men are not governmentally compelled to lift their hats to women or keep to the right on the sidewalk, but they usually do both. 
An ideal state of society in miniature may be seen in every drawing-room where ladies and gentlemen, as we call wellbred men and women, come together for social intercourse. There is no compulsion. They talk, dance, eat and drink; groups form and disperse; individuals, with freedom and polite regard for the rights of others, move about, come and go. And if one habitually disregards the proprieties of such assemblages he is not arrested and dragged to prison; he is dealt with far more effectively; he is not invited to come again; he is dropped, shunned, boycotted. 'The "four hundred" as well as the Irish peasantry know the value of the boycott.

'The New York Grocers' Association is an almost purely Anarchistic institution, and may be used as one example of many. I am informed that the wholesale grocers of New York have lost faith in the efficacy of govermmental laws for the collection of debts, and have formed an Association which has proved very satisfactory in its results, to protect themselves against loss by bad debts. 'They no longer depend upon governmental machinery. If a debtor to any grocery louse in New York exhibits signs of business weakness or lack of integrity he is visited by a representative of the Association. If this visit las no salutary effect upon him it becomes impossible for him to buy goods, except for cash, anywhere in New York. 'That is all that happens to him; but out-of-town buyers are said to be much more afraid of the Grocer's' Association than of the government. 'The staid business-men of New York who compose this Association wonld, perhaps, be shocked to know that, in one particular, they are true Anarchists; but such is the fact. 'Their Association does not serve then with ideal perfection, but it is better for them than the system of collecting debts by physical foree. And this is all that Anarchists clain for their proposed arrangement of society: that it is practicable. that it is better than government by physical force, and that it is capable of constantly approaching ideal perfection.

Let us now glance briefly at the economic principles of Anarohism.

Anarohists regard porerty as the misfortmne that causes most of the mhapuiness and crime with which the human race is aftlicted. I do not, of comse, mean that poverty which individuals might, under any social system, choose 
to suffer rather than practise virtue and self-control or labor for the production of wealth. I mean involuntary poverty; that poverty which is now, in spite of the virtue, self-control and industry of the poor, so prevalent. Many persons are skeptical concerning the existence of such poverty. It is commonly believed that no one not intemperate or thriftless need be poor. But it is only necessary to open one's eyes to see that there are millions of human beings in this and all countries who labor unceasingly only to find that their poverty increases. It is unnecessary to dwell upon a fact so patent. Everywhere children are taken from school or play to labor in factories and mines; else why the futile statutes against child-labor? Everywhere is heard the hum of sewing-machines from which hollow-chested women drop into the Potter's Field; else why all the kind-hearted charitable work among the "worthy poor"?

This social disease of poverty Anarchists believe will disappear when its causes are generally understood. And they believe its causes are much better understood by a few than the causes of small-pox or cholera are understood by any; and that they are removable. They believe that what are popularly supposed to be its causes - ignorance of what is taught in the schools, idleness, drunkenness and crimeare its effects; and that, hence, to attempt to remove it by compulsory education in the common schools, charityorganization societies, model tenement-houses and reformatories, however well-meant such attempts may be and undoubtedly are, is to necessarily fail. The cause of involuntary poverty, Anarchists believe, is the taking away from the laboring people - the producers of wealth - a large part of what they produce. This is accomplished by methods not understood without much observation and reflection but easily perceived by open-minded thinkers.

Anyone can see that there are many persons in every community who do no productive work. Such persons must be supported by what others produce, since there is no other fund from which they may draw. Beggars and tramps are a drain upon the wealth of the industrious. 'Thieves break through and steal what other's earn. Gamblers of all kinds subsist upon what others produce; and so do the inmates of poor-houses and prisons. This is plain to all. Policemen, soldiers, and high-priced govern- 
ment-officials whose services are not worth to the community what they get for them, are certainly not producers, and whether they, in part, serve good purposes or not it remains the same that producers are forcibly taxed for their support. Workers are compelled to give up their wealth to support law-makers and professional destroyers of property and life. All this is evident notwithstanding that part of it, however unfortunate, is inevitable in the present state of social development.

But besides these are other large numbers of persons who receive what they do not produce. 'Those whose incomes are wholly or partly derived from buying and selling land are regarded by Anarchists, in so far as they are dealers in land, as subsisting upon wealth produced by the labor of others. And to this class of persons belong all those who collect rents - that is, those who receive for the use of their houses, machinery or other personal effects an excess of price over and above what is required to cover compulsory taxes, insurance and necessary repairs upon such property.

'Those, also, whose incomes are wholly or partly derived from interest, or the rent of money, are regarded by Anarchists, as appropriating what other's produce. And so, too, are those who, in buying and selling or manufacturing for sale, receive as the result of such production and exchange more than what would fairly compensate them in the form of wages for their actual labor in superintending, prodncing or exchanging.

In plain words, Anarchists regard rent-takers, or landlords, interest-takers, or what Mr.J. K. Ingralls calls lendlords, and profit-takers, or trade-lords, as social parasites. Or, in other words, Anarchists believe, and think they can scicutifically prove, that anyone who receives in the process of wealth-distribution more than what represents fair wages for productive labor - that is, morc than he artually prodnees - appropriates something that shomld belong to others, and thereby helps to bind a load of inevitable poverty upon those who are thus defrauded of the fruits of their industry.

Let us look, for a moment, from the Anarchistic standpoint, at the grounds for this belief.

Land is unproduced. It is not the result of human labor. It is what is sometimes called a natural oppor- 
tunity. It is the passive factor in the production of wealth. Like air and water it is an absolnte necessity of human life. When man appeared, like the open air and water ruming in the streams or bubbling from the springs, it was free to access by lim. Anarchists believe that if, from the beginning of luman exertions upon this planet, each man had been content to possess and control only so much land as he could productively use, the supply of land free for use always would have been and now would be practically as unlimited as the supply of air and ruming water, and that, therefore, it never would have commanded a price and would not now be a thing to buy and sell. They believe that the practice of owning land that one cannot and does not wish to use, excluding others from its use, has given rise to rent, or the price of land; or, to put it in other words, that the monopoly of vacant or unused land is the cause of rent. Rent, therefore, does not represent work performed or wealth produced by the rent-taker. It represents wealth transferred from a producer to a nonproducer as the price of a privilege that should be absolutely free to all. It is evident that rent-takers, as such, are idlers. They produce nothing. If, then, they subsist it inust be at the expense of those who labor. And by just so much as they are rich others must necessarily be poor. Rent is a tribute that public opinion permits non-producers to levy upon producers by the simple contrivance of holding large quantities of land out of use.

The same reasoning applies when we turn to the subject. of interest. Rent is the product of labor paid to idlers for the use of land. Interest is the product of labor paid to idlers for the use of money. Rent is interest for land; interest is rent for money. Both are the products of nonopoly. Money is as necessary to a complicated system of trade as air, water and land are to life. If the supply of money were always equal to the demand for it as an implement of exchange, each person would always have as much of it as would represent labor directly performed or products of labor surrendered by him. 'The only use that money should have is to indicate that so much labor has been directly performed or so much wealth surrendered by the possessor of it; and its value is in that it will insure to its possessor the return of a corresponding amount of service or wealth upon demand. It is not in the least 
necessary that it shonld possess any intrinsic value other than that of the piner on which it is written or printed and the labor of writing or printing it.

If men liad been sufticiently intelligent from the start, a perfect system of money would lave grown with tle growth of society, and each person always would have liad preeisely as much money as he deserved. because he would not have parted with labor or its produets without getting a full representative equivalent in money, mnless the transaction were made by the simple process of larter, in which case exchange would be made in kind. All this will be more or less unintelligible to the average conservative person, but it will, I think, become plain to anyone who will thoughtfully real Steplien Pearl Andrews' "Science of Society," especially that portion of the work devoted to the principle therein formulaterl as "Cost the Limit of Price," the original discovery of which Mr. Andrews ascribes to Josial Warren, with whose works I am not familiar. 'To this book, the "Science of Society", I am indebted for clear and satisfactory ileas of the true nature and uses of money.

But contrary to all this men have alopted certain materials for money, the supply of which, relative to the demand, is very limited; and even when paper is used for money a very insufficient quantity is permitted to circulate. being sonetimes greater and sometimes less, but alwars under the control of persons who make their living by handling it, and by whose manipulations producers are see-sawed out of their earnings. Noney is monopolized. It is "rornered." It fropuently happens that a man has nuth valuable property lint no money. Such a man is obligel to go to those who eontrol the supply of noney and hires what he needs at rates of interest whieh could not and wonld not axist if money were not monopolized.

The point is this: Anarehists believe that as rent would not be a natmal proluct of hamoniously organized soriwty, neither would interest. 'They clearly see that interesttakel's, as such, are non-producer's, and that, therefore, what they subsist on must in some unjust way have been takin from the industrious persons who produced it.

With reagred to protits, Inarehists believe that in a fair

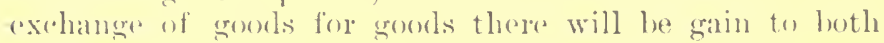
parties to the bangain hist " purefit" to neither. If I want 
your cow more than I want my own horse and you want my horse more than you want your own cow we exchange beasts. We each, by the trade, gain something, but neither makes a "profit." Profit is not as easily separable from wages as interest or rent, because what is called wages of superintendence is an uncertain quantity; but it may be, nevertheless, accurately defined as that portion of the manufacturer's or merchant's income over and above what he should receive as compensation for labor actually performed by him. And Anarchists believe that if the land and money monopolies were broken, profits would disappear. This needs further explanation, but the limits of this address do not admit of it. I must leave it for your future reflection or study, if you are not already familiar with the line of thought involved.

Anarchists believe, then, that poverty results from the existence of social parasites-persons who perform no productive labor and who are therefore, necessarily, supported out of what laborers produce. These social parasites are thieves at liberty, criminals in prison, gamblers, whether with cards, dice or stocks; sharpers, whether confidence-men or business-men; ' pauper's, whether abroad or in poor-houses; policemen, when in excess of actual need for the protection of property and life; soldiers, unless actually necessary to repel invasion; collectors of compulsory taxes; politicians and law-makers, unless we are to reject the time-honored belief of many of the wisest and best of men that government by force is, at best, a "necessary evil"; rent-takers, interest-takers and profittakers, except in so far as it can be scientifically proven that rent, interest and profits are the necessary outcome of absolutely free contracts between persons as free as individuals ever can be under any possible arrangement of society.

In my opinion, the most thoughtful Anarchists are agreed that, in any possible arrangement of society, sporadic cases of rent, interest and profits might arise, but the amounts involved would be too insignificant for serious consideration and the transactions would represent no injustice whatever. But as all these social parasites are the products of a social arrangement that legitimates rent, interest and profits, Anarchists believe that involuntary poverty is the necessary outcome of, and is completely 
accounted for by, the existence of rent, interest and profits. These, therefore, must disappear before the hmman race can be free, wealthy and happy. With their disappearance secondary causes of poverty will naturally cease.

This explains the opposition of Anarchists to government by physical force. They know that those bits of paper by which non-users hold land vacant are legal documents. They know that if laborers shonld attempt to exercise what should be their right, by taking possession of vacant land for productive use, the whole machinery of government by physical force would be brought to bear upon them, and if nothing else would avail to drive them from the vacaut land they would be shot to death by govermment powder and balls from government guns in the hands of government troops. And yet the only crime of which such laborers would be guilty would be that of trying to earn an honest living and promote the happiness of the world by increasing its wealth; their only crime would be that of wishing to apply productive labor to what we call natural materials, which, when not in legitimate use, should be free to all. They know, in short, that the man-starving monopoly of racant land is authorized and maintained by unilitary government.

They know, also, that the monopoly of money is similarly maintained by govermment. Free competition with the govermment in the manufacture and uttering of money is forcibly prevented. And becanse profits arise on account of the momopoly of land and money the govermment is the creator of rent, interest and profits, the baleful trinity in unity, more powerful than any imaginary bad god to plunge the human race into poverty and so into misery and crime.

Anarchists believe, still further, that all statute laws are necessiully partial and unjust, muless you choose to except laws against violence and theft. It is impossible to devise a statute law that will not favor some persons against others. The very "machinery of justice," as we call our judicial system, works injustice to the poor, if for no other reason, because as between a litigant with money and a litigant withont money the poor man may be lefeated by his very inalility to bear the expenses of court-procedure.

All this is very briefly and insufficiently stated, but Anarhists believe that it eam be seientifically and elab- 
orately proved that, whether government is a "necessary evil" or not, it is necessarily evil as at present constituted anywhere in the world.

It follows, then, that Anarchists desire a cessation of military government. It would not, however, convey the right idea to say that they wish to destroy the government. 'They desire that society should grow away from the necessity for government by physical force by the gradual and general acceptance of scientific principles of Sociology. The Anarchistic method of regenerating society, therefore, is that of educating the people in scientific principles of social co-operation or mutuality ; it is that of propaganda, of calling the attention of the people to facts widely observed and logically collated; of doing just what I am doing at this moment. They understand that all existing governments are the expression of the will of the people. Russia is ruled by a Czar because most of the people of Russia believe that is the best form of government for them. Public opinion prevails in Russia without the ballot as effectually as with us through the ballot. Military protection of social parasites prevails in this country because most of our people believe that the monopoly of vacant land is right and that our present money system is just and fair, precisely as they once believed that chattel slavery was a divine institution. Most of our people are firm believers in the righteousness of rent, interest and profits, and the large owners of real-estate and holders of government-bonds are commonly believed to come by their money honestly and fairly. They are not popularly regarded as monopolists who increase their riches by simply appropriating what others produce. While such beliefs exist society will remain very much as it is. Tothing can bring it into Anarchistic arrangement but a general recognition of the essential injustice of all wealth-getting except by wealth producing. Anarchists, for the present, therefore, have nothing rational to do but to clarify their own ideas, develop their science and teach their principles.

I have already explained why it would be absurd for them to wage war for their principles. They know that nothing is ever settled by being fought out; all right consummations must be thouglit out. Many Anarchists think, also, that it would be absurd for them to resort to political methods. I ballot means a bullet. The decision 
of a majority at an election holds because the army is behind it. But Anarchists, even if they were in a majority, would not wish to impose their will on a minority. In the opinion of very many Anarchists, therefore, the ballot is, for their use, a stultifying implement. But even if it were not it would not be employed by them, because they regard it as useless. They believe that when public opinion favors a violation or the ignoring of a statute law it is net necessary to rote that law off the statute-books. It will become inoperative; a dead letter, as we say. And as Anarchists can liave nothing to vote for except the abrogation of existing laws, manifestly roting, in their case, would be a work of supererogation.

For example: All Anarchists are necessarily free-traders; but most Anarchists will not vote with the Democrats, because they know that when public sentiment favors free trade custom-houses and custom officers will disappear. No army was ever yet organized that could force a nation to pay duties or do anything else against the public sentiment of that nation.

Anarchists point to the statute-books of every nation and every old State in this nation for evidence that it is unnecessary to fight or vote laws into desuetude. Multitudes of laws which have never been abrogated are absolutely inoperative. 'They are so dead that it is not worth while to expunge them from the records. I believe the old Connecticut blue-laws have never been repealed, but there is not power enough at the command of the Governor of that State or the Presilent of the United States to enforce them in the present temper of public opinion. 'There is a law in the District of Columbia providing that an offender shall be bored throngh the tongue for denying the doctrine of the Trinity, or something of that sort. But it is so paralyzed by pulblic odium that it is impossible to enforce it and unnecessiuy to abolish it.

'The New Iork Grocers' Association is a current illustration of how laws against the collection of debts will, I think, fall into disuse. Anarelists object very strongly to laws agrainst the collection of debts. They think a delot is contracted by a private aldangement with which the State should have nothing to do; that state interforence for the collection of debts tends to greatly rednce business integrity ; that commeredal morality would immerliately reareh a much 
higher than its present plane if all financial transactions were effected upon individual honor; that the dangerous, the ruinous credit-system of doing business would be desirably modified if laws for the collection of debts by force were abolished. Indeed, some Anarchists think that the abolition of laws for the collection of debts would go very far toward reorganizing society upon a just basis. But, important as this measure is, they deem it unnecessary to vote for it, because, in time, the experience of businessmen will demonstrate that such laws are futile and unnecessary, and when a law goes out of use under the action of popular opinion its disappearance produces no friction, for it ceases because no one desires it any longer.

To fight down slavery was a mistake followed by inevitable unhappy conditions until now. If slavery had been let alone until it crumbled away there would have succeeded its disappearance no sad and vexing negro-problem. 'This was the wish of Garrison and his friends, very good Anarchists, who denounced the government and burned the Constitution because they uplield chattel slavery as they sustain indirect slavery to-day, and who contemplated the use of no other than intellectual and moral weapons against the abomination. If Garrison's policy of propaganda and passive resistance had been followed, the institution of chattel slavery would not have disappeared as suddenly as it did, but it would inevitably have fallen to pieces, little by little, without leaving soldier blood and a national debt where it fell. It would have fallen without the use of a bullet or a ballot.

'The Anarchist, then, at present is simply a propagandist, by word and passive deed. He talks and writes and, as far as possible, refrains from doing those things that to him are useless and wrong. He ceases to exercise the privilege of the franchise. If he is entirely consistent he will receive nothing that he does not earn, except by gift. If he believes that it is wise for him to become a martyr for purposes of propaganda he will refuse to pay taxes and take the consequences, without physical resistance. Anarchists, however, as a rule are not what is commonly called fanatical. 'They rely more upon worls, for the present, than upon deeds. But when they become more numerous the method of passive resistance will, no doubt, be resorted to. 
For example: By general consent among a large number in a given locality, they may refuse to pay, under compul: sion, their taxes, offering, of course, to resign all claims to govermmental protection, and perlaps offering voluntarily to contribute toward the maintenance of those communal undertakings of which they alprove; or they may go upon vacant land to use it, suffering themselves to be evicted, unless public opinion sustains them; or they may attempt to circulate mutual bank or credit money. In two words, the Anarchistic method, for the present, is propaganda, but when they believe themselves to be in sufficient numbers they will probably resort to passive resistance.

Upon this presentation they may aplear to be very impractical, but if what I have so briefly said is thoughtfully considered, and if it is remembered that Anarchistic opinion as it grows will constantly be registering itself by the platform-makers and law-makers, I think the conclusion will be reached that Anarchists are not characteristically dreamers, but are sane students of history and human nature.

Let me illustrate what I mean hy a case that is before the public mind at this moment. Anarchists are opposed to capital punishment, and they observe with complacent pleasure the growing sentiment against the barbarous practice. A bill for its abolition recently passed the New York Assembly but was defeated in the Senate. The introduction of this bill in the New York Legislature exemplifies the tendency of the politicians to reflect public opinion in the making or unmaking of laws; but the facts regarding the pratice of capital punishment also show that it is a matter of no concern whatever what legislatures do or fail to do in the premises. I do not know how many murlers were committed in New York State last year, but there were only eight executions; and although there wer reported during the same year :3bit murders and homicides as having oceured in the United States, there were but ninety-eight hangings. The death-penalty is gradually abolishing itself, and whether the laws on the subject remain on the statute-looks or not, the practice of hanging in this country will soon le given up. This method of abolishing an obnoxions law is Anarehistic or evolutionary; and it should be muderstond that the Anarehistic method is always and in trery pitricular the application of, or, rather, 
conformity to, the principles of evolution in the progress of society.

From the presentation that I have made of this subject, it should be seen by the most conservative mind that Anarchism is nothing more nor less than the old-fashioned American idea that that government is best which governs least. The present apparent tendency of thought is toward the idea that that government is best that governs most State Socialism, or, as it is called in its distinctively American form, Nationalism. Between these two ideas we are slowly but surely being forced to choose. The question is immediately before us: whether government shall, little by little, increase its functions, or little by little decrease its functions; whether government shall become more centralized or society more flexible; whether the individual shall be more and more subordinated to the State or more and more free to pursue in his own way, life, liberty and happiness. Anarchists believe that the State should decrease and the individual increase; that the most harmonious society will be composed of individuals who are controlled by reason, governed by moral considerations; and that the removal of restrictions upon industry and trade, the cessation of partial, monopolistic legislation, will conduce to the development of men who will be able to sustain social relations to each other without necessity for the imaginary terrors of supernaturalism or the real compulsion of military government. Mutualism between free individuals is the doctrine of Anarchism. To rationally and peacefully decrease the powers of compulsory govermment is the method of Anarchism.

There are two questions which Anarchists are frequently called upon to answer. The first of these is: How can communal undertakings be accomplished without some govermmental authority? How can sewers and streets be made and supervised without some centralized restraining or compelling power? How could boundaries to land, and all those matters that are now defined by law,- - and disputes about which are settled in the courts,- - be determined? To all these questions Anarchists can no more give definite answers than they can tell what the fashion in hats will be in the year 2000. All they can do is to appeal to history and show that men have learned how to do many things without the aid of govermment, for the 
doing of which government was once believed to be neces. sary, and to reason with apparent warrant that men are capable of learning how to do in the future much that now seems difficult or impossible. If it is remembered that Auarchists suppose that men must learn how to do many things by voluntary association better than they are done or can be done by present methods, before they will cease to be done by governmental compulsion, the question will be answered as well as it can be in a single sentence. 'The best fire-department is that which insurance companies equip for their own interests; the best schools are private schools, else why do they continue in unequal competition with public schools? 'There is no good reason why men should not yet learn how to build the best roads and sewers and other communal works without the services of armed constables or policemen. To suppose otherwise is to strangely limit the capabilities of the human mind, which has already accomplished enough once apparent impossibilities to warrant very considerable faith in its ability to meet all future social requirements and practically solve all future social problems.

The other question to which I referred is: How long will it be before Anarchism will or may be practically realized? 'To this the Anarchist replies that it is impossible to tell. Evolution is slow up to a certain point, at which point events shape themselves with astonishing rapidity. We can never tell at just what stage of evolution we are. Unforeseen circminstances often precipitate accomplishments which apparently bclong to the remote future. But with the question, "When?" Anarehists do not much concern themselves. What is long to human life is short as a historical perior. The Anarohist is a scientist; it is for him to announce lis discovery. He is a philosopher ; it is for him to earnestly labor and patiently wait. He believes he has discovered certain sociological facts; he believes that all men will in time come to acknowledgre them as facts. For what is gained while he lives he rejoices: but if little is accomplisherl before his work is done he does not despair. He sces of the travail of his soul and is satisfied. 


\title{
EVOLUTION AND SOCIAL REFORM
}

\section{THE SCIENTIFIC METHOD.}

\author{
BY \\ DANIEL GREENLEAF THOMPSON \\ Author of "A System of Psychology," "The Problem of Evil," \\ "THE Religious SExtiMENTS OF THE HUMAN MIXD," \\ "HerberT SPENChR," ETC.
}


COLLATERAL READINGS SUGGESTED.

Spencer's "Principles of Sociology" and "The Man versus the State"; Graham's "Creed of science" and "The Social Problem"; Bagehot's "Physies and Politics"; Savage's "The Social Problem"; Crosier's "Civilization and Progress"; Ward's "Dynamic Sociology"; Gilman's "Profit-Sharing between Employer and Employee." 


\section{EVOLUTION AND SOCIAL REFORM.**}

\section{THE SCIENTIFIC METHOD.}

WHEs I looked over the assignments for the four lectures which conclude the present course, it was with a little surprise. The topics express four methods of effecting social reform, which presumably would be exhibited by their advocates and, indeed, champions. First, then, I observed that the Theological method was to be presented by Mr. Chadwick. Now, I have the greatest respect for my eminent friend's theological abilities, which I am confident we should know him to possess even if he did not often use them. I am also thoroughly satisfied of his theological learning; for it is not the empiric but the man truly learned in theology who arrives at Mr. Chadwick's conclusions and stands upon his platform. Tet there comes to memory my mental attitude of twenty years ago (which may still be that of some), when I used to attend a church in the neighborhood which, if it could not build itself upon Plymouth Rock, could at least chip off a piece for its cormerstone. In those days I did not think so much of $\mathrm{Mr}$. Chadwick in the light of a theologian as a poet, or perhaps as a humorist, when he came to discuss theological topics. But that was a long time ago, and I like to believe that during these years, when I have been deroting myself to other matters, even theology has been progressing until the best thought recognizes in Mr. Chadwick an exponent of the true Theological method, which, if knowledge and wisdom be divine, ought not to be very far away from the Scientific.

As to Mr. Potts in comnection with Socialism, I have had much more difficulty in reconciling the subject with the man. I awaited his paper with anxiety, as one waits for tidings of a friend who may have been exposed to contagious disease, not knowing with whom, in his various interests, he might have held the communications which corrupt good morals, and well-knowing that the days of sudden conversions are not yet past. He might have

* Copyright, 1890, by James H. West. 
contracted the slow malarial fever of Georgeism or the cerebro-spinal meningitis of Bellanyism - I could not know. But when I saw his lecture $I$ was at once relieved, and I ean only hope the day will soon come when Mr. Potts's Socialism will supersede other systems and become universally triumphant!

Without knowing exactly the position of Mr. Pentecost, I must confess that the line of reflection to which I have just made reference was disturbed by a ghastly suspicion. What if it were possible that these three gentlemen were selected because of the very fact that their own methods were conspicuously the opposite of those with which they were to deal? If such were the casc, exactly where would I stand with respect to the Scientific method? Perhaps as a horrible example of the unscientific; or perhaps, if I defended science, I should be thought a disguised enemy, ready to smite under the fifth rib while pretending friendly interest. Nevertheless, I shall dare assume to represent true science, and to be a sincere believer in the scientific method, though I run the risk of having some kind Socrates come up to me patronizingly but pityingly, and say : "Good friend, you are not at all scientific; you only think you are. You consider you know everything, while in reality you know nothing. With science you are very evidently unacquainted." If the courtesy of this audience spares me such a punishment, I am surc there are plenty of theologians, socialists and anarchists, who would be glanl to inflict it in the name of seience. For they all elaim to be scientific. Science is good to conjure by, and in these days we have not so mueh need of exalting her name as of detecting and exposing those who have stolen her livery to serve ignorance and seiolism.

We ought then to define our position and understand what we mean by the Seientifie method. It is Soeial lieform or improvement that we have in view, and we want to know the sieientifie method of effecting it. Why do we seek for the Scientitic mode? Why not follow an unseientific method? Because it is presupposed that the seientifie is more likely to aceomplish the desired practical "mel. What reason is there for such a presumption? The same reason that eauses us to believe we can raise figs leetter on fier-trees than on thistles; that, knowing the geography of the earth, if we steer by the sun and stars 
we shall reach our destination; that if we eat corn and wheat we shall live and thrive, but if we consume poisonous herbs we shall perish. Knowing the uniformity of Nature, and ascertaining what causes produce given effects, what ensues from the composition of causes, and what frustrates results, we are able to predict what lines of action, what conditions, are favorable to the end sought, and what are opposed. We thus see that the practical science of social amelioration is based upon a theoretical science. We must know in order that we may believe and act. The practical Scientific method must, therefore, be developed from that exact knowledge for which Aristotle and Bacon sought and which is the only sure foundation upon which to build.

The factors would seem to be simple, being only men dwelling together. But this association speedily evokes the most intricate and perplexing questions, arising from the circumstance that man is dependent upon his fellows while at the same time his interests may be antagonistic to them. Man tightly bound to man, but yet for deadly conflict, is the spectacle presented. How to transform this struggling mass of human beings in a living death, into an orderly, contented and happy community wherein the desires of all are attained and each can realize his own aims, is the problem of social improvement.

Is the solution possible? Let us study Nature. And by Nature I mean all that has been produced to human experience; that stream of events which, has proceeded from chaos and ancient night; which always is, and yet is in ceaseless flux, the perpetual contradiction of being and becoming over which the Ionic and Eleatic philosophers debated, and which the acute and imaginative Egyptians loved to symbolize in the myths of Isis and Osiris. Our field of study is the solar and stellar universe, the globe on which we dwell, the sequences of inorganic growth, and the various forms of organic life, man and his progress from the beginning. Seeing what is and ascertaining what has been, we may perhaps determine what will be. If a complete solution is not possible, an approximate one may, perchance, be reached.

Tatural forces are of two general sorts, the mechanical and the chemical. The one operate by antagonisms, the other by assimilations; the one are destructive, the other constructive; the one are characteristic of the inorganic, 
the other of the organic. As evolution has proceeded, organic life has become more complex, and hence the assimilating forces have been growing more far-reaching, more abundant, and more essential. 'This is as true of human life as it is of lower forms. In human society there is a multitude of individuals, each of whom is an organic whole, a source of life and power, having its own aspirations, purposes, and ends to fulfill. An icleal of his own greatness and glory shines before him; the world is his for achievement; everything is regarded as an instrument for his purposes; those who will submit and help are welcome, those who oppose he will dash in pieces. 'The reader of Walt Whitman's poems will find there described the type of man filled with expansiveness, initiativeness, creativeness, self-development, in whom the spirit of individualism is dominant and aggressive.

But this indivilualism receives a constant check from the fact that man does not live in isolation. The difference of sex necessitates gregariousness. Mutual interests are developed, and the indiridual finds that his own cherished objects of attainment involve the co-operation of his fellows, who are constituted precisely like himself. He cannot have their society without making concessions to their personalities. He must do at least some of the things they want in order to get the things he wants. And the more people he has communication with the more varied will be the modes of mutual yielling. The social sentiments, then, which have regard for others, grow alongsile of the selfish in the human individual, and become more complex as social intercourse is extended and the interdependence of human beings becomes more fully ustablished. The predatory appetites are weakened, their urgency becomes less, while the social interests are enlarged and the srmplathetic feelings increased in power and scope.

Thus the faet that there has been an evolutionary progress toward a mutual aceommodation of human artions and aims in a peacefully-ordered community, proves that in solution of the problem we proposed is possible, since it has bern allealy partially solved. We see how its solution has been possible, and how, if at all, its solution will be madr more complete. This we are able to understand only through a scientific observation of the facts of human nature as revealed by psychology, anthropology ant sociol- 
ogy. We note that each individual will follow out his own aims and desires, and can do nothing else, for he is both a source of power and an end unto himself. $\mathrm{He}$ will be guided by the law of his own being, established by his constitution, his training and circumstances. His ideal will always be to do what he wishes to do ; then only will he be satisfied. He can be restrained and prevented from following his chosen course, but he will elude, overeome and thwart the controlling force if he possibly canl. If the pressure be increased, his energy is crushed out and he has no more power of self-development at all.

The strong hand of government, therefore, is a most imperfect method of securing that mutual comity which is the ideal of a perfect State. It can only be administered by men acting forcibly against other men. This of itself fosters the very spirit of antagonism which it is most important to eradicate. The process is repressive of that individual expansion which is the fountain of all social progress. While governmental control is necessary to some extent, no doubt, the needs of a higher civilization demand its continual limitation within narrower bounds and its reduction to a minimum. In the nature of things the rule of man over man, whether by a monarch or the demos, is detrimental to the perfection both of the individual and of society. Its value consists in preventing chaos, in holding men together in security so as to allow the working of a much better process.

This better way is the only way of perfecting civilization. It allows the individual to have his own will in the most complete liberty, but it aims so to mould his character that his wishes and desires shall coincide exactly with the demands of social welfare. Said Emerson: "Every man takes care that his neighbor shall not cheat him. But a day comes when he begins to care that he do not cheat his neighbor. Then all goes well. He has changed his marketcart into a chariot of the sun." This is precisely the Scientific method of promoting reform,-its central, essential idea, the only thorough and successful mode, without which nothing else is of any utility and to which everything else should be held subservient.

Theoretical science thus furnishes to practical science two complementary precepts, which should guide all efforts toward social reform. The first is to keep limiting the 
sphere and diminishing the funetions of government, reducing both as fast and as far as is eonsistent with security. The other is to foster in every practieable way the formation and maintenanee of the altruistic character in individuals.

From what I have said it will suffieiently appear that the Seientific method is opposed to the Theological, so far as the latter makes obedience to authority the means of reaehing the social millennium. It makes no difference if the authority be divine. Divinity always has human interpreters and vicegerents. Divine authority is but another form of autocracy or aristoeraey, more objeetionable than the others, beeause it is less elastie, assuming that being divine it must be unchangeable. It is hence seriously obstruetive of that proeess of evolution, in the preservation of which life subsists, and in the absence of which is deeay and death to the social organism. Theology, however, is not religion. Happily, in the eourse of religious development, particularly in Christianity, the Scientifie principle has been reached, has become prominent, and its value demonstrated. The most strenuous efforts have been made in the listory of this religion to sustain the prineiple of authority, but the vitality and power of the Seientific doctrine has been so great as repeatedly and I think at last permanently to trimmph, while the blessed effeets of its practical use have given to Christianity all its success and glory.

The Scientific method is also opposed to the Anarehistic, because it recognizes that society is a growth, and knows that if at a given stage existing institutions are radically destroyed it is only by a proeess of growth that new ones can arise; that this process will be just as complicated as the preceding one, and will have to go through its various stages of imperfection before any perfeetion can be reached. First the stem, then the flower, then the fruit after its kind. Nothing can exist extept as suited to its surronnding conditions. Cataclysms in society are sometimes inevitable, because there seems to be no hope for improvenent. All the arenues are closerl up. But the virtue of the Scientific method is that it takes care to keep open the avenues for the novenent of evolntionary forces, and to render anarehic disturbances mnecessary and even impossible. 
The Scientific method has no part or lot with the Socialistic, if by the latter is meant the theory which proposes the State and its government machinery as the chief agency for guiding and training the human race to positive and progressive development, and for doing for individuals, positively, what they could not do for themselves. The reason wlyy this principle is unscientific is apparent from what has gone before. To accomplish socialistic ideals, power must be accumulated. Where? In the hands of men. Whence comes it? It is taken away from other men. Who are to use it? Men. For what purpose? 'Theoretically, for the common weal. If it is not so used, there is tyranny and greater wretchedness than before. The users of this power then must be supremely intelligent and supremely benevolent. When the amount of government we have is so largely in the hands of thieves, cutthroats and ruffians, what encouragement have we to believe that, if government had more power and more directions for its activity, matters would be improved? The answer to Socialism always is: The accumulation and exercise of power by the State is necessarily the vesting of power in individuals to be used by them over others. If the community is chiefly made up of people who are good and righteous from the social point of view, there is no need of such accumulation. If, on the other hand, the community contains any considerable evil element, increase of State functions tends to abridge the common liberty, to disturb the social equilibrium, to foster oppression, and to inaugurate a retrograde morement toward the primitive forms of "man's inhumanity to man," which made life a lurid drama of woe and wretchedness.

Having now presented what I conceive to be the Scientific method of effecting social reform, I shall not bring forward arguments to support it more than have already been indicated in the course of exposition. I shall occupy the remainder of my time with a few cautions and suggestions regarding its application. The first of these is that the Scientific method does not require a person to become either an idiot to understand or an imbecile to apply it. Because our true principle is to seek for the minimum of government, we are not required to abolish all laws and offices. Though we are to develop the altruistic character in which selfishness is to be put aside and thoughts of the 
common good to prevail, we must remember that if our neighbors became too thoroughly altruistic they might all commit suicide. Thongh such an act wonk not be withont its compensations to us, it would leave us rather lonesome, and might be otherwise inconvenient. If we are convinced that onr butcher is a wickcel man, we would not like to have him become so altruistic as to stop) killing sheep and calves, till we had learned where another butcher could be found of the old way of thinking. We do not care to have the liquor-dealer spill his liquors into the street till enough of his best whiskey is safely domiciled in our cellars. We want all lawyers to be honest and kind-hearted, but in our own cases we think the thing to be done is to bedevil and beat the other side. Beantiful as absolute altruism may be in theory, if put into practice it would either result in universal hari-kari or in a reversed form of selfish competition. Some of you may have read James De Mille's "Strange Manuscript found in a Copper Cylinder," wherein the remarkable tale is told of a land at the South Pole, whose inhabitants thought poverty and low-estate to be the most desirable objects of life. But the moment these became ends to be sought, a condition of struggle was developed, causcd by every man endeavoring to put off his wealth and his comforts mon others. Hence it becane necessary to limit and regulate altruism by law, restraining those too eager to give away their possessions for the sakc of attaining the pauper condition. If there happened to be any public occasion at which there were places of honor or vantage, a fight was apt to ensue from the circumstance that evcrybody would insist on his neighbor taking the better place. Death, too, was regarded as the greatest of boons, and self-rlestruction had to be strongly discomntenanced, veople being compensated for this prohibition by the promise of a public death as a matter of honor if they succeeded in repressing their self-denying impulses. It thins appears that we must be careful to love our neighbors only as onrselves, not better; clse rninons consequenees may cusue and the world be turned topsy-turvy.

The Scientific rnle of the application of all general principles is, Sinvey the whole tield and be sure of yonr facts. All through Nature, frustrating canses are in constant operation. There is a compounding of forces which every where modifies effects. In the social organism 
this is peculiarly true, and it takes a much more careful and judicial study to calculate effects here, than it does in the meclanical or biological world. Hence we must move cautiously and tentatively in this region. Thus it happens that the truly "practical man" is often more successful than theorists. But, though he may ridicule science, such a one it is who after all is the true scientist. He takes account of the facts. He generalizes and reasons inductively, gathering together the various lines of the operation of forces, while the doctrinaire pursues only one line deductively, falsely assuming that conditions do not change and that reaction does not modify action.

I read with much interest and with approval Mr. Potts's representation of the evil of too much enthusiasm. Loyalty to a principle, as to a person, may easily be overdone. It prevents criticism, reformation and readjustment of principles. Enthusiasm is of more value in an unscientific age, when men are too ignorant to be skilful in bringing about results, and when intellectual activities do not have free play. In former times, and now eren in many places, the king is really a god, to be thought of with awe and reverence, never to be criticized. In a thoroughly scientific community he is, as a royal personage, tawdry and contemptible. The day was when the orator who appealed fervently to the feelings governed men's minds; to-day such appeals are usually ridiculous. It must be remembered that Mohammed, fired with tremendous zeal, vainly endeavored to solve the social problem by galloping with drawn sword over three continents, cutting down all who opposed; while Buddha solved it by sitting down under a tree and groing to sleep.

If I were asked what was the Zeit-geist proper to a scientific age, I should unhesitatingly say, the eternal Mugwump-spirit. It is a great pity to have so much good activity wasted through an undiscriminating devotion to party, in politics, in religion, and even in scientific inquiry. Most people never know when to leave their party and join a better one. They cannot make the higher synthesis; they are bound by the chains of fear and prejudice. Into their olstinate adherence to their idols enters also, unconscionsly to themselves, a very dangerous form of egotism. Nothing is good except what they faror and what they are personally concerned in bringing about. Many a reform 
has been prevented because some leader has sulked and withdrawn his support when he could not become preeminent in achieving its suecess. Such men esteem themselves to be the center of the universe, but they forget that the more they indulge this thought the more the universe contracts to their vision, until at last it may chanee that they can see no farther than their hands can reach,and are as ignorant of what is really going on in the world beyond as a man of normal mind wonld be of what is transpiring in the planet Saturn.

Thus the only safety lies in constant criticism of opinions, laws, principles, courses of action, one's own not less than other people's. Beware of partisanship, be suspicious of growing loyalty to abstract principles or fanatical support of any party; avoid animosities, and look out for the pugilistic or polemical spirit when people differ from you ; above all, keep your intelligence elear by purging your soul of the lust of domination; then you are in good condition to apply the Scientific nethod to all the problems of social life; and I would not wonder if, in casc you were simply to sit down under a tree and sleep, you might see grand visions, of which you could tell, when you awoke, to the benefit of mankind.

"This is peace,

To eonquer love of self and lust of life,

To tear deep-rooted passion from the breast,

And still the inward strife."

There are four departments of activity within which social improvement is wrought out, the Industrial, the Political, the Philanthropic, the Educational. Industrial progress benefits society; every producer is a helper. Government has its office and liberty cannot yet dispense with law. Much can be accomplished hy wise charities to aid the suffering. Elucation is absolutely essential, espercially as to character; for a person's dispositions control his deeds and are largely formative of his opinions.

The relations of politics to industry just now present the most interesting and pressing questions of social reform; and here the seientific method is now-a-tays too often neglected or misapplied. 'The scientitic principle does not prohibit the interference of govermment with private action to preserve rights or to make porple secure in their enjoyment. The question always is, How can this 
best be done? How can we cure this evil without entailing a greater? The great trouble seems to be the cutting off of opportunities for men to work and earn, and the consequent hopelessness of effort. This state of things never can be helped by socialistic or nationalistic measures, which are impracticable in their nature and dangerous in their application. They are only to be relieved by remedial not revolutionary action, aiming to restrain the power of corporations, to check monopolies, to prevent frauds, to secure the workman his wages, and, as has been so well urged by Prof. Gunton, in securing a general reduction of the hours of labor, so that by increasing the social opportunities of the workingman he may become an integral part of the community and thereby better his economic situation. Assaults on the right of property are assaults on liberty and life. Holding property is not robbery, and we may still adhere to the old-fashioned doctrine that taking it away without an equivalent is robbery, for which there is no justification. "But it is necessary that I live," said the thief before the court, in extenuation of his crime. "I do not see the necessity," wisely replied the magistrate; and society will always agree with him. A restriction of property-liolding is the utmost that can legitimately be urged. Entailments and accumulations by will have been ahready limited. How far the holding of both real and personal property by one individual in his lifetime can be restricted, is a proper question for consideration, but cannot be discussed within the linnits of this paper. For ends which involve the common liberty the State powers always may be used; but we should be reluctant to permit sucli interference in industrial matters, because experience has universally shown that from this harm is more apt to result tlian good.

Passing now to our political conditions, it is to be remarked that the clice iniquity at present is the use of the powers of government and official position for private ends. Abuse of public trust for personal gain is often no bar to political preferment. It is common for those in office to think first of their own profit. One class of evils is thus presented. Another is found in the constant use of legislative functions to support private interests. To purify our governmental offices and to limit legislation to general purposes seem to be the two things of transcendent 
importance in American politics, the country over. It is hard to see low either of these desiderata is to be obtained by increasing the number of official positions and functions and creating a necessity for more legislative neasures. Rather it would seem to be the true course to abolish a great many of the offices we have, and to dispense with a considerable portion of the laws on our statute-books. The lusiness condition of the comntry is much better settled when Congress is not in session. 'Those States which have adopted for their legislatures the biemial session rule, have found it greatly to their advantage. If the legislature seldom meets there is so much less opportunity for schemes of jobbery, while people can live and justice be administered under the organic law and the general statutes which all our States have had from the beginning. So-called "private bills" are the curse of our Congressional and State legislation. 'The lower house of Congress has almost ceased to be available for the discussion and enactment of measures affecting the general welfare. It is merely a vehicle for the promotion of private schemes, and its action is the resultant of the conflict of private interests, each seeking by force, frauds or compromise the passage of its own bills. It were far better to have no legislature for an interval, than to have this unseemly strife kept up through s rveral months of each year. In executive offices, longer terms and stricter accountability will tend to create a better state of things, while the reforms in the civil service which lave been effected, and others which are proposed, are of great value for their salntary results.

Bnt it is not so much my purpose to particularize by indicating special reforms for special cases, as to remark the fact that, in Amsrica and in England at least, the practical workers for reform, and their proposed measmes, are the most scientific. In England this is illustrated in the new and simplified juclicial procedure, in the Corrupt l'ractices $A$ cet, and in the various IIome liule movenents. In onr own comntry, the three most salient reforms of to-day - Civil-service, Tariff, and Ballot-Reform - are the offspring of thoroughly scientitic thought, starting from conditions, gathering the facts, exposing the evils and their canses, and selenting thr appropriate remerly. This is very encomaging. 'Two extreme and opposite habits of mind should ilways be aroided and deprecated; the one, that of 
the theorist and doctrinaire, who has found one general principle which so possesses his mind that he can think of no other, and who applies it in season and out of season without the slightest reference to conditions. 'The other bete noire is the man who is so short-sighted that he never can see beyond his nose, who hates a theorist much more than he hates the devil, because he regards the latter as a thoroughly practical being, and whose thought never transcends the expediency of the moment. Of the two, the former state is to be preferred. It is better, I suppose, to "liteh your wagon to a star," - which may indeed drag you along roughly, not always in the road, but will still keep you moving over magnificent distances and cheer you with its light. If on the other hand you attach it to a purblind ass, the beast will take you nowhere, but will presently demolish your vehicle, and perhaps yourself, with its vicious kicks. The true method for politics is that described by Wordsworth Domisthorpe in a recently published work:- "The need should be insisted on for the thorough study of law in the concrete, and the discovery, not the manufacture, of the true statical laws which are actually operative in societies; of their tendency and of the dynamical laws of their change and development. It is by the discovery of these laws that we shall find ourselves in possession of true and useful practical guides through the labyrinth of legislation and polities. . . . The art of politics is the application of the science of nomology to the concrete, just as engineering is the application to human wants of the science of nechanics, and as navigation is one of the arts based on the science of astronomy; until we have mastered the science we shall make little progress with the corresponding art. . . 'To-day we are on the high road to Socialism; to-morrow the fates only know where we shall be. The only cure for this policy of drift is a patient and intelligent study . . . whereby middle principles of practical application are to be brought to light and the absurd fallacies of social doctrinaires put to flight forever." *

I shall not pause to speak of practical philantliropy, further than to remind you that charity never will take the place of justice, and is at best the temporary not the ultimate relief for suffering human nature. Largesse will

* "Individualism; A System of Polities," IX. 
not condone oppression, nor benevolence dispense with equity.

I pass on to say a word, in conclusion, upon what is, after all, the extreme, the fundamental practical method of improving society, namely, the Educational. To this we are always obliged to return. "To cure the soul," says Plato,- "that is the first thing." "He that doeth my will," said Jesus, "shall know of the doctrine"-riglit action will bring knowledge. But on this vast theme my limits will allow me to tonch only two or three points, which seem just now to demand consideration.

The first of these relates to the importance of a special institution, namely, the public-school system, and the increasing of its opportmities as well as its efficiency. The scientific ground for public education is that of security to the State. 'To educate at public expense is by far the most economical way in which social order can be promoted. Schools cost less and are much more efficient than penitentiaries. If properly conducted, and if the system be soconstituted as to secure a practically universal education as far as the conrse goes, the community will be spared much trouble and the process of renovating humanity will go on much faster. At the present time there is a disposition in many quarters to dispense with or curtail public-school education. 'This has appeared on both seientific and religious grounds. No more fatal error could be committed. The day when public schools are abohished in any American community will be a dark day. To educate the young person in claracter and in knowledge, particularly that knowledge which relates to lis duties as a eitizen, is the one thing of paramount interest to the State, which it never can afford to neglect; for upon such education, that cannot safely be left to private effort, depends the maintenance of the common freedom which in its turn is the safergurd of individual liberty and the surety of individual development.

'The secont line of educational effort which I propose to indicate looks to the broaking down of the barrier between business and social life. A man naty rob and steal in business ways below Fourternth street, when above that line he is bound in honor to prefer lis neighbor. Business is war, and it is not good business principle to "live and let live." So long as the humanities are kept ont of the 
counting-house or the store, good morals, good citizenship, good character cannot be depended upon. The co-operative idea, when divested of its socialistic tendencies, is certainly worthy of encouragement and should be constantly applied to industrial life. This would involve, in addition to what I have before suggested, some system of profit-sharing, and above all a greater permanence and certainty of tenure in employment, so that the laborer be not regarded as a machine but as a person, be provided for in case of sickness, and be not subject to dismissal on a day's notice, irrespective of faithful service, at the supposed interest or maybe the whim of an employer. Beyond this, when we come to the relations of those more nearly equal in business life, if we cannot have sympathy it is surely not too much to expect honesty (which in these days seems to be going out of fashion), and a state of morals wherein a lie is not considered, as it has been styled, "an intellectual mode of meeting a difficulty."

The third and last suggestion I have to offer is another caution. It is said that "Knowledge is power," thereby implying that it is not itself the ultimate end of human life, but is of value because it gives a wider field and a greater effectiveness to action. The strongest desires and aspirations are satisfied only in an activity which is forever creating. Knowledge, indeed, is often an end in itself, because learning is a process of activity which selects and forms new objects, not before present, to the mind; but it is only under the stimulus of ideals which by contrast produce a felt insufficiency of present conditions, a dissatisfaction with what is, that the process of self-development goes on to its fullest consummation. This creative instinct must be exercised, or it will become atrophied, and then growth ceases and decadence begins. We must therefore consider that, good as science is, it is in the art-impulse and its products that we behold, after all, the source and the end of individual and social progress. It is in the unknown, which furnishes possibilities of knowing, the unachieved which presents possibilities of achievement, that we find the moving cause of our exertion to know and to do. It is necessary to ascertain what is, and see things as they are; but if we become accustomed to the thought that scientific observation and experiment upon phenomena presented is the only worthy object of mental activity, we shall be in 
great danger of drying up the fountain of all intellectual and moral vitality. The greatest discoveries of science, themselves, never could have been made without the ideals of art, which set the goal for science to reach; and human life never has been made better save under the inspiration of some ideal of perfection, which is a product of intellectual creativeness. Let us, then, not make the mistake of despising art, whose aim is to eliminate the painful and disagreeable and to produce that which does not perish in the using. Nor should we seek to reduce all art to science, according to the doctrine of M. Zola in literature; but rather leave room for the movement of the creative spirit, which loves to cast off the trammels of the earthy, to soar aloft with ethereal wings, to enter the limitless, to burst into the unknown and filch therefrom something precious for science to work upon and reduce to orderly relations. Our life in the actual must needs occupy us most: but it is in the sphere of the possible, not yet realized, that we find the renewing and strengthening atmosphere, breathing which the blood is sent more swiftly through our veins, rendering us buoyant and able for the tasks before us. While, therefore, we shoukd respect the work of science, and insist on true science, within its own domain, let us not forget that he who is the anthor of a great artistic creation, clothing matter with mind and moulding Nature to express an idea, not only enriches the world with the production of his genius, but also excmplifies that man may walk with the gods, that he is himself a creator and finisher; and even suggests that deatl and nothingness are after all but names which only indicate a vast reservoir of being without beginning or end, wherein lies concealed and from which shall spring forth, eternally and exhaustlessly, an everchanging and never-ending life. 


\section{ASA GRAY: HIS LIFE AND WORK}

BY

MRS. MARY TREAT

Author of "Home Strmies in Nature," "My Garden Pets," "THRough A Microscope," ETC. 
COLLATERAL READINGS SUGGESTED.

"In Memoriam-Asa Gray"'(University Press, 188s); "Sketch of Asa Gray," in Am. Journal of Science, Vol. 35, Mareh, 18s:: Article, "Asa Gray," in "Appleton's Cyclopadia of Biography," also article in "Ameriean Cyclopædia." 


\section{ASA GRAY: HIS LIFE AND WORK.*}

Now and then a man arises whose life and works are of such magnitude that he shapes the intellectual growth of a nation or a civilization, moulding and turning thought into a new channel. Charles Darwin, like Copernicus, advanced such revolutionary doctrines. As Copernicus taught the world the now received system of astronomy, so Darwin has taught the origin of species by Natural Selection. Before Copernicus the world did not move-it was permanent, fixed, central. So before Darwin the species which exist on the earth were regarded as permanent and fixed, each having been produced by a special creation. But this belief is fast disappearing, and we are living to see Darwin's teachings recognized - not by the slow process by which the Copernican system came to be accepted, but with rapid strides due to the advanced thinkers of our time, who see and grasp the "new thought" as men could not do in the time of Copernicus.

Copernicus drew upon himself and his theory the condemmation of the Church of Rome, which was not obliterated until 1821, two liundred and eighty-seven years after it was issued! And Galileo, who followed Copernicus a century later, was imprisoned in the cells of the Inquisition for teaching the heretical doctrine that the earth moves. Surely the world has advanced during the past four centuries, so that in our time "lieresy" simply meets with disapproval and ridicule.

It is not so many years since the Darwinian theory was first promulgated, that we cannot remember the fierce opposition and ridicule with which it was received, both by the pulpit and the press. 'Then, it needed courage and boldness to be its adrocate. In this country, one of its earliest disciples was Asa Gray, who bravely stepped to the front of the battle and made havoc in the ranks of Darwin's

\footnotetext{
*Coprright, 1890, hy James H. West.
} 
opposers, until, largely through his influence, there came to be a wide-spread recognition of the doctrine of Evolution among the leading representatives of biological science. Indeed, we may say that at the present time this recognition is practically universal.

Asa Gray was born on the 18th of November, 1810, in Oneida County, New York, a few miles south from Utica. He was the eldest of eight children, and from his earliest years a wide-awake, active child, energetic and studious, wimning the prize of a spelling-book before he was three years of age. When six and seven years old he was the champion speller in the district sehool. Following him along in his boyhood we learn that, when eleven years of age, having exhausted the district-school at home, he was sent to a grammar-school in Clinton, where he staid two years, and then entered Fairfield Acadeny, where he remained until his father desired him to leave the Academy and enter the Fairfield Medical School. This was in the winter of $1826-27$. He finished his nedical course and received his degree of Doetor of Medicine in the spring of 1831.

While in this Medical Sehool - in the winter of $182 \pi-28$ - his attention was aroused in botany by reading an article in the "Edinborough Eneyclopedia." He soon obtained Eaton's Botiny, which he studied with increasing interest through the Winter, and longed for Siring that he might test his knowledge in consulting the flora around him. When spring came we can imagine sonething of the delight with which he hailed his first treasure, the little Claytonin Virginica, which he found no difficulty in assigning to its proper place. A new world was now opened around hin, and from this time on he saw not as others see. Things were revealed to him that were blindly passed by the world at large. So he became eyes to the blind and a neclium of knowledge to many loving followers.

Although he received his degree of Doctor of Medicine, and no doulst would have been a shiming light in the workd of medical science hat he chosen the career of physieian, lis heart was not there; it was set on the trees and flowers, the growing things aroumb him, and his far-reaching mind grasped the hidden seerets of Nature which he unveiled to eountless numbers of disciples.

In 1834 he became romected with 1)r. John Torrey, 
which resulted in a close relationship and a life-long friendship. For a time he studied botany under Dr. 'Torrey, but he soon made such rapid strides that he was no longer under but with him in united labor. Together they botanized in northern New York and in the Pine-barrens of New Jersey. In the same year he became Dr. Torrey's assistant in the Chemical Laboratory in the College of Physicians and Surgeons in New York City. But he remained in this Medical School only a year or so, as it was not on a sufficiently flourishing financial basis to warrant Dr. Torrey in continuing to employ an assistant. Torrey was instrumental, however, in securing for him the appointment of Curator in the Lyceum of Natural History in New York, so that his botanical work was continued under the inspiring influence of Dr. Torrey for the next four or five year's.

In his twenty-fifth year he issued two volumes on the grasses and sedges, each describing a hundred species, and illustrated by dried specimens. Among the grasses was one new to science, Pancicum Xanthophysum, which was the first of the thousands of unkwown species afterward named by him. In 1836 he began his contributions to the American Journal of Science, which he continued for more than fifty years, and he also became one of the editors of this journal, which place he filled for thirty-five years. About this time $(1835-36)$ he commenced the preparation of the "Elements of Botany," which he published in 1836. This work was characterized by such a vigorous style and breadth of treatment that it at once attracted the attention of scientists, and paved the way for universal recognition by the great botanists of Europe whom he visited in 1838. This visit was made necessary to enable him to go on with the "North American Flora," of which he was, at that early age, joint author with Dr. Torrey. Young as he was, hearts were opened and hands held out to him by such men as Robert Brown, De Candolle, the elder Hooker, Lambert, Bentham and Lindley, at that time the leading botanists of Europe. He also met the younger Hooker, then a medical student in Glasgow, and here the foundation was laid for their life-long friendship. Hooker, no less than Gray, was destined to become one of the leading scientists of his time - a great explorer and author, and President of the Royal Society. He also followed 
lis illustrious father as Inireetor of the Royal Gardens at Kew, which position he still holds.

In this brief sketch it will be impossible to follow $\mathrm{Dr}$. Gray elosely in his travels, or to enmerate the great men he met during the year he remained abroad. But he returned home full of inspiration, with enlarged views, and well equipped for the work he had in hand. In the American Journal of Science (April, 1841) he published a very interesting article, giring an account of the herbaria he examined during this visit, eommeneing with that of Limnæus, which is told in sueh a happy manner that it camnot fail to interest all lovers of good realing. In 1\$42, the Fellows of Harvard College offered him the Fisher l'rofessorship of Natural History, which liad just then been founded under the will of Dr. Fisher. At the time of Dr. Gray's appointment there was no botanieal library and no herbarium in the College, and the botanical garden was harlly more than a name. What are they to-day the magnificent library, the great herbarimm, and the garden! Had Dr. Gray done nothing nore for the alvancenent of seienee than the building up of these, this alone would have made hin inmortal.

'The same year that he was made Professor in thr College he published his botanical text-book, "Structural and Systematic Botany," which was by far the most comprehensive and valuable work on botany that hat appeared in our combry. It has passed through six cilitions, each improved and almost wholly re-written. The last edition, published in 1879 , was entirely re-written. In 1848 his "Manual of the Botiny of the Northern United sitates" was minted. For more than thirty years this book has been without a rival. It lias been the text-book for all lotanists in the Eastern, Midile, and Northern States east of the Mississippi. It is so plain and simple in its language that anyone with a natural love of plants needs uo other instructor to enable him to berome well-rersed in the flora of these regrions. The influence that this book has wrought in schools ant anomg the people, in arousing an interest in hotany, is byond ealeulation. It has passed thromgh five editions and sereral issues. In the first adition he expresses his gratiture to Dr. Torrey in the following inscription: 
To

JOHN TORREY, M.D.,

Corresponding member of the Linnaan Society, \&c.,

THIS VOKUME IS DEDICATED BY THE AUTHOR,

In grateful acknowledgment of the friendship which has honored and the comnsel winich lias aided him

from the commencement of his botanical pursuits.

The last edition was published in 1867. This also bears testimony of his continued love and hearty friendship for Dr. Torrey, in the following dedicatory note:

To

JOHN TORREY, L.L.D.

Almost twenty years have passed since the first edition of this work was dedicated to you,-more than thirty, since, as your pupil, I began to enjoy the advantage of being associated with you in botanical pursuits, and in a lasting friendship. The flow of time has only deepened the sense of gratitude due to you from your attached friend,

Cambridge, May $30,1867$.

Asa Gray.

This was characteristic of Asa Gray — he was a steadfast friend, giving and wimning affection wherever he went, always acknowledging the helpfulness of others, and often magnifying such assistance.

His "Field, Forest, and Garden Botany," published in 1868 , is an admirable guide for the beginner for determining the common cultivated plants as well as the native ones. In order to bring it within the compass of a conmon-school text-book, it was necessary to condense the descriptions of the wild plants, and to leave ont altogether the most rare and obscure ones. This is no detriment to the beginner,rather an advantage, when he has the Manual to follow. Even with all its condensation it contains descriptions of 2650 species, belonging to 947 genera. And the "Lessons in Botany and Vegetable Physiology," which preceded it, with over three hundred original illustrations from Nature by Isaac Sprague, has nften been re-written and improved until made so perfect that seemingly no other book could be made that would be so admirably adapted to our needs.

We must not overlook two other charming little books, "How Plants Grow," first published in 18.58, and "How Plants Behave," in 1872. 'These were written for young people; but many grown people have greatly enjoyed them and drawn inspiration from their pages. 
But the greatest of all of Ir. Gray's botanical works is his "Synoptical Flora of North Anerica," two parts of which lave been published,_- "the first in 1878 , being the first part of Vol. II., (iamopetalie after Compositæ, that is, the portion immediately following the second volume of the 'Flora' of 'Torrey and Gray; and the seeond, in 1884, covering the ground (Caprifoliacea to Composite inclusive) of the second rolume of 'Torrey and Gray's 'Flora.' The middle half of the entire Flora is thus completed. These volumes contain eight hundred and fifty closely printed pages, and it required ten years of excessive and hardly interrupted labor to complete them. 'They are masterpieces of clear and concise arrangement and of compactness and beauty of method. There will hardly be found in any work of descriptive botany a greater display of learning, clearness of rision and analytical powers; and few works of systematic botany have ever treated of a broader field." *

When we consider how mnch of the work on nearly all of these edueational books - with the exeeption of the "Flora"-was accomplished while Dr. Gray serupulously performed all of his college duties, we get some idlea of the magnitude of the man.

His writings and influence have done as mnch toward the advancenent of general science, and especially toward the growth of the doctrine of Evolution, as his text-books have done for the advancement of botany. One of his earliest papers, showing the tendency of his mind in the direction of evolution, was his observations upon the "Relations of the Japanese Flora to that of North America." I will quote what his colleague, l'rofessor C. S. Sargent, says of this work:

In 18.5t he pulblisherl the "Botany of the Wilkes Fxploring Experlition," a large quarto volnme, aecompanied by a folio atlats containing a hmolred magniticent plates ; and in 1s.5e he read his paper, afterwarl published in the "Nemoirs of the American Academy of Arts and scienees." nuon the "Liagnostic C'haracters of Certain New species of Plants, collected in Japan by Clanrle's Wright, with olservations upon the lielations of the Japanese Flora to that of North America, and of other parts of the northern temperate zone."

This is Professor Gray's nost remarkalble contrilmtion to scirnce. It at once raised him to the very highest rank among pliblosophi-

* From a sketele of 1)r. Gray in the New Iork sum of January 3, 18kf, lyy l'rofensior ('. s. Sirgent. 
cal naturalists, and attracted to him the attention of the whole scientific world. In this paper he first points out the similarity between the floras of Eastern North Anerica and Japan, a fact he had long suspected, and then explains the peculiar distribution of plants through the Northern Hemisplere, by tracing their direct descent through geological periods from ancestors which flourished when there was a tertiary vegetation. This theory of geographical distribution, now generally adopted by all naturalists, was further elaborated in his lecture upon "Sequoia and its IIistory," delivered in 1872 before tle American Association for the Advancement of Science, and still later in a lecture entitled "Forest Geography and Arclixology," delivered in 1878 before the Harvard Natural History Society.

'These studies of the Hora of Japan had doubtless greatly modified Professor Gray's opinion mpon the origin of species, a subject which was just then beginning to deeply interest the intellectual world. He, like the younger De Candolle and Hooker, was now ready to admit the doctrine of the local origin of vegetable species, and to discard the lyppothesis of a double or multiple origin, at that time and long afterward adlered to by many botanists. 'That is, he believed that two similar or closely allied species of plants, the one, for example, growing in New England and the other in Japan, were descended from one common although remote ancestor, and that they were not, as Schouw and Agassiz insisted, created separately and independently in the regions where they now exist.

Dr. Gray more than any other man in Anerica has made the doctrine of Evolution what it is to-day ; and he has made Darwin better understood and appreciated than all other writers combined. And yet he did not wholly agree with Darwin in some particulars. In a letter to Dr. Gray, Mr. Darwin says, "I grieve to say that I camnot go as far as you do about design. I camnot think the world as we see it is the result of chance, and yet I cannot look at each separate thing as the result of design." But Dr. Gray was so deeply grounded in the Christian faith that nothing could swerve him. He believed that the Darwinian theory of the origin of species was entirely reconcilable with the conception of a Divine Power governing the universe. He believer "that each variation has been specially ordained or lerl along a beneficial line."

In the closing paragraph of an address delivered before the Anerican Association for the Advancement of Science, in 1872 , on "Sequoia and its History," he touches the keynote of his religious belief. Ifter quoting Miss Frances Power Cobbe's regrets that we no sooner find ont how anything is done, than our first thought is that God did not do 
it, he agrees with her that this conclusion is unworthy"nay more, deplorable." 'Then follows these brief, vivid words: "Through what faults or infirmities of dogmatism on the one hand and skepticism on the other it came to be so thought, we need not here consider. Let us hope, and I confidently expect, that it is not to last; that the religions faith which survived without a shock the notion of the fixity of the earth itself, may equally ontlast the notion of the fixity of the species which inhabit it; that in the future even more than in the past faith in an order which is the basis of science will not - as it cannot reasonably be dissevered from faith in an Ordainer, which is the basis of religion."

In 1876 Dr. Gray brought together his various papers on Evolution and kindred subjects, which had appeared in the American Joumal of Science, the Nation, and the Atlantic Nonthly, and published them in a book, under the title of "Darwiniana." In the preface to this book he defines his religious belief in a short, clear passage, where it stands to remind us that one of the greatest men of the age found no difficulty in hamonizing the "new thought," or Evolution, with Christianity: "I am scientifically and in my own fashion a Darwinian, philosophically a convinced theist, and religiously an acceptor of the creed commonly called the Nicene, as the exponent of the Christian faith."

II contributions to Evolution, and his views on the subject, are better known to the workl at large than "his rank and position as a teacher of natural science." He was a born teacher. He drew students to him by his kindly, genial nature. His interest in their work was a remarkable trait in his character. His correspondents felt his friendly influence permeating their lives, giving them fresh impulse and inspiration in their work. Fven students whom he hal never met were cordially and most heartily given any assistance in his power, in the way of suggestion and even in mapping ont methods of work for them to follow. During all the years of his busy life, helpful, suggestive letters were written with his own hand, encouraging students to go on with their work and publish its results. lint for him, the work of many a botanical stulent would never have been known.

Having areess to some of his lotters to a correspondent, I have been looking them over with a view to griving a few 
extracts to illustrate his manner of guiding and instructing. The correspondent had a little plat of ground under observation, which had never been disturbed by man further than in the cutting away of the underbrush and part of the trees; Dr. Gray was given a list of the herbaceous plants that were growing on the spot, and here is his reply :

Your letter of the 12th, so full of interest, was followed this evening by the box, which I wait for daylight before opening. But I will not delay most hearty thanks for your very kind attention to my requests. I am dreadfully pressed with work now, being on the eve of completing a new lecture-room and cabinet, laboratory, etc., here in the Garden, and many things and various workmen have to be looked after, so that I camnot sit down till night, and then am tired enough. . . .

Your lawn flora is very interesting. Now, you would do a good thing if you would keep a record of this, and next year note any changes-i.e., any overcome, or any new-comers. And so on year after year. I anticipate many clianges. But as it is, it illustrates Darwin's remark upon the advantages of diversity. You have vastly more vegetation on the space than could be if restricted to one or few species.

There are a good many plants on your lawn which I would gladly have in our Garden. ... .

Yo, I have not Xerophyllum, nor the lovely Pyxidanthera. I tried both once, and lost them, but I long to try again. Will you help me to them in early Spring? What did your Penn Yan friend do to make Pyxidanthera grow?

Writing of these plants brings back most vividly my pinebarrell botanizing of 30 to 35 years ago !. . .

The above letter was soon followed by another, slowing his interest in the correspondent's observations on Droser It was understood between Dr. Gray and his correspondent that either could nese what the other had written about Drosera and otiner plants. In one of the letters before me Dr. Gray says, "You can use anything that I say about Drosera for publication, and I want the same privilege."

. . About the Drosera longifolia (which the species you describe certainly is). The folding of the blade of the leaf itself around the insect, which I understand you to describe, is very interesting, and I have copied your statement for publication. . . .

I wish I had a pencil-sketch of this fly-catching. . . .

I am preparing a new edition of "How Plants Grow,"-with three new chapters, - viz.,

IIow Plants move, climb, and take positions.

How Plants employ Insects to work for them.

How certain Plants capture Insects. 
This leads me to ask, Have you any butterflies or moths witl orchid pollen-masses attached to head or eye? . .

Platanthera Ciliaris,-how I wanted it last Summer ! If you could find it $110 w$ - roots, even, would deliglit me. . . .

More than a year after the above letter was penned, we find his interest still continued in Irosera :

Thanks for the plints which eame in nice order. . . .

In Spring, as soom as they ean le foumc, I waint some bullos of 1)roserafiliformis, and that you slomld also make some ohservations which Darwin wants to be made. But he will write to you.

'Two years later he writes about another insectivorous plant :

Thanks for yours of Dee. 2. . .

The Tribune will be glad to lave your artiele about Bladderwort, pending. As usual, Darwin is aliead of your. Jut he has pulblished nothing yet, only lints liave appeared - and lie will be pleased that you lave lit on it. If you prepare an article for the Tribune I wonkd have some drawings male to show the bladders in wood-cuts.

Alwas rall on mo, if I 'an aill in any way. Dear I)r. IIooker (Kew) lias lust his wife surlelemly.

Still later, he is interested in the Florida Pinguiculus, and writes under date of March 6 , 1st:

Those Pingmirulus aromed you are such nice thiners for their way of cross-fertilizing that l lope you are studying them and seeing what insects do it. . .

Again on Marclı 16, 18\% :

Well, if that little IIymenopter is the right one, lis tongne will be lomg (anougle to reach from the top of the spur (bottom of sac) down to the nectar. Dlease eateh and send nue one or two, or nore, and I vill find his name.

l'ray work up an article on thrse I'in!mirulu.

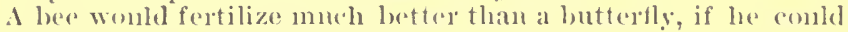
grot in - is you will see on lookinge.

What do you say? Slatl I send you the "l)arwiniana" look,

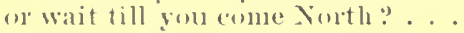

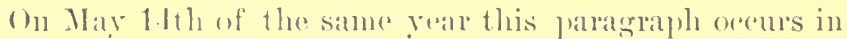

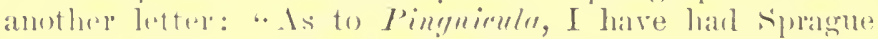
make goon ontline-skotulues and dissections to slow the most, and harr laid thrm up for future usp - yoms and perhaps mine. . . 'The printer kreps me awfully busy."

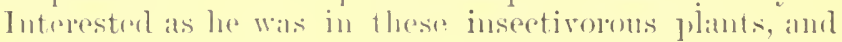

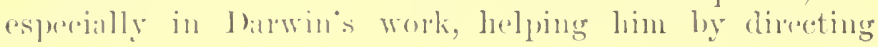


observations on this side of the water and furnishing him directly with material for his fortheoming work on "Insectivorous Plants," yet when the book appeared he was for" a long time too busy to read it:

\section{Herbarium of Harvard University,}

Botanic Garden, Cambrilge, Mass., 29 July, 1875.

Fou will hardly credit it - that $I$ have had J)arwin's book for a fortnight and have not yet found time to read over twenty or thirty pages. That shows you how busy I am, and with much less interesting work - but work that is both necessary and pressing.

We can now better understand why Asa Gray was so universally honored and loved by such a wide circle of students and botanists, as well as by many distinguished men in other departments of science. With all his multifarious work, he was ever the kind helper and teacher. Professor Sargent tells us that "he was a foreign member of the Royal Society of London; he was a foreign member also of the Institute of France, one of the 'immortal eight'; and long ago he was welcomed into all the less exclusive bodies of European sarants. He served the American Acadenry of Arts and Sciences as its President, presided over the American Association for the Adrancement of Science, and was a regent of the Smithsonian Institution." On his serenty-fifth birthday the botanists of our comntry united in sending him messages of affection and esteen, accompanied by a silver vase. The Botanical Gasette of December, 1855, tells the story of the presentation, and gives a description of the vase as follows:

The vase "is about eleven inches high, exclusive of the ebony perlestal, which is surrounded by a hoop of hammered silver, bearing the inseription,

\section{November eighteenth, 1885 \\ ASA GRAY \\ in token of the universal esteem of American Botanists.}

"The lower part of the vase is fluted and the upper part covered with flowers. The place of homor on one sirle is held by Gra!gia Polygaloides, and on the other by Shortia galacifolia. On the Graygin side of the prominent plants are Aquilegia Canadensis, Centanter Americrna, Jeftersonir diphylla, Rudbeckir speciosa, and Mitchella repens. On the Shortin sirle there are Lilium Grayi, Astor Bigelori, solidago serotina and Epigare repens. The lower part of the handles rums into a cluster of Dioncel leaves, which clasps the body of the vase, and their upper parts are covered with 
Notholcena Grayi. Adlumia cirrhosa trails over the whole background, and its leaves and flowers crop ont here and there. The entire surface is 'oxidized,' whieh gives greater relief to the decorations. The vase was designed by I. E. Jenks, and the chasing was done by $\mathrm{Wm}$. J. Austin, both with Bigelow, Kennard \& Co. The heartiest praise has been bestowed npon tho design and the workmanship by all who have seen it.

"By the request of the committee, greetings in the form of cards and letters had been sent by those who gave the vase. These were placed on a simple but elegant silver plate and accompanied the gift. The inscription on the plate reads :

\section{Bearing the Greetings of}

One humdred and eighty Botanists

of North America, to

ASA GliAY,

On his Seventy-fifth Birthday,

November 18th, 1885.

"The expressions of affection and respect which are contained in letters to the committee as well as those which were presented to the good Doctor, together with the united and hearty response to the Committee's suggestion, all testify how miversal is the esteem and how deep is the affection for this genial man, whom we have thus delighted to honor."

\section{The following response was sent by Dr. Gray:}

\section{IIerbarium of Harvard University,}

Cambridge, Mass., November 19, 1885.

To J. C. Arthur, C. R. Barnes, J. M. Coulter, Committee, and to the nmmerous Botanical Brotherhood represented by them :

As I am quite unable to convey to you in words any arlequate idea of the gratitication I received on the morning of the 18 th inst., from the wealth of congratulations and expressions of esteem and affection which welcomed my seventy-fifth birthday, I can do no more than to render to each and all my heartiest thanks. Among fellow-botanists, more pleasantly comected than in any other pursuit by mutual giving and receiving, some recognition of a rather uncommon amiversary might natmally he expected. But this full flow of benediction from the whole length ancl brealth of the land, whose flora is a common study ami a common delight, was as mexpeeted as it is touching and memorable. Equally so is the exquisite vase which accompanied the messages of comgratulation and is to eommemorate them, and upon which not a few of the flowers associated with my latume or with my special stuclies are so deftly wromglit by art that of them one may almost say, "The art itself is nature."

The gift is gratefully received, and it will preserve the memory to those who come after us of a day made by you, dear brethen and sisters, a very haply one to

lour's affectionitely,

ANA (IIRA). 
Dr. Gray's correspondence with Darwin dates from 1855, commencing with a request of Darwin for a list of American Alpine plants. From this time on their correspondence continued, and their friendship was close and intimate until Mr. Darwin's death, as is shown in "Darwin's Life and Letters," and also in Dr. Gray's printed writings.

In 1855, Dr. Gray's portrait was made in bronze by St. Gaudens, and presented to Harvard University. But one of the best pictures that has been left to us was taken while he was on a botanical excursion in tile Rocky Mountains. It represents a group of botanists in camp on Veta Pass, 9000 feet above the sea. Dr. Gray sits on the ground beneath the trees, with uncovered head, holding evidences of his work in a well-filled botanical press. Sir Joseph Hooker is by his side, with freshly gathered plants in his hand. Mrs. Gray is at the table dispensing tea to Dr. Hayden, Dr. Lamborn, Stevenson, and other distinguished members of the party. It is a vivid, life-like scene - a picture cherished by many.

But Asa Gray's memory will be perpetuated and cherished without the aid of pictures,-it is forever associated with natural objects more enduring than the monumental shaft. The loftiest peak of the Rocky Mountains bears his name, and many lowly plants in the vales commemorate it, breathing it anew in their annual resurrection. These will keep his memory fresh through the ages to come. His work and deeds can never die. Our own poet of Nature has said of 'Truth, "The eternal years of God are hers." All the labors and all the thouglits of Asa Gray were consecrated to the discovery and service of the Truth - and by this loving constancy of devotion they are assured an immortality of beneficent influence. 


\title{
ABSTRACT OF THE DISCUSSION.
}

\author{
Miss Eliza A. Youmaxs:-
}

Ix Mrs. Treat's admirable account of Prof. Gray's intelleetual career sle has given the simple faets eoneerning the times at which his various works were publislied, and the exalted estimatc put nyon them both at home and abroarl. The "Yorth Ameriean Flora," however, she prononnecs his most important work, and her account of his labors upon it seems to require further explanation. The first volume, she says, appeared in 1840 , the second in 184:3, and the next instalment not until 1878 , after an interval of thirty-five years. As its diseontinuanee dates from the time of his acceptanee of the Fisher Professorship of Natural History in IIarvard College, and its resumption inmediately followed his releatse from official duties, whieh, I learn, took place in 1873 , giving him tive years for the preparation of the volume of 1878 , the quite natural inferenee would be that his official work left him no time to give to the preparation of the "Flora." But we are deharred from this eonclusion by the detailed and emphatic statements of Mrs. Treat coneerning the vast anomnt of labor he did outside his eollege duties. His text-books and manuals were all done in the evening, and at odd hours; and his labors as a critic eonsumed a great deal of time. He was so familiar with all sides of the seientifie questions bearing upon his speeialty, so just and discriminating and eatudid, that his opinions, eriticisms and anlvice were eagerly sought for. His Reviews, Book-notices, and Bingraphical sketehes are almost endless.

In the introduetion to the two volnmes of the "Seientifie Paper's of Asa Gray, selecterl by Charles sprague Sargent," the (ompiler says: "The selection of articles of his for re-publieation has been an cmbirassing and difticult task. The amount of material at ny disposal has been overwhelning; and desirable as it might be to republish it all, it hats not been possible to do so within reasonable limits. More than eleven hundred bibliographieal notiees and longer reviows were published by Prof. (iray in different periodiealis, and it was necessiny to exclude a momber of fatrers of neraly as great interest as those which are closene." "lourly, thon, it was not lack of time that kept I)r. (iray from Eoing ou with the "Flora." Why then, in the name of Botaniest seience if not of eommon sense, dirl not prof. Gray, during these yeir's, spend the time saved from oflieial dnties in carrying on the great work on which his heart was set; which le ahone of all men was by nature and enlture so fitted to exerente, and whicll was so stremionsly callerl for loy the worlel of scienese? Why was its resimption pestponed till the later yeats of life, so that his eress were not permitted to beland its timil areomplishonent? Aecordine fo Mrs. Treat, "he had earrinel it on to the conchusion of the midelle laslf of the entive Floril," and there it is left for other hamels to tinish. (1), may we not reasonably ask, why was it 
postponed at all? It was evidently not in the plan of Mrs. Treat's paper to raise questions or to answer them. But I have in $\mathrm{my}$ possession an explanation of this seeming difficulty. It was given by that great scientific explorer and life-long friend of Prof. Gray, sir Joseph Hooker, and it furnishes matter for serious reflection. In the summer of 1871 , just two years before Prof. Gray was relieved from college duties, and while men of science were impatient and, aggravated at his situation, Mr. E. L. Youmans, who was then in London busy in establishing the "International Scientific Series," received a note from Dr. Hooker asking him to come over to Kew and dine with him, as he was quite alone. Mr. Youmans was on the lookout for eminent scientists to write books for the series, and while at dinner the talk ran upon men of this class. The next day Mr. Youmans gave an account of his visit in a letter to his New York correspondent, and the pertinence to this subject of Dr. Hooker's remarks, as reported in this letter, will, I think, justify the liberty I take in repeating them here.

The allusion to Prof. Gray's situation was suggested by the talk concerning Mr. Spencer. Dr. Hooker and Mr. Youmans had been discussing one and another great man, when Dr. Hooker said: "Spencer is the mighty thinker among them; and he is all riglit now. The recognition of hi'; genius is complete. What a lucky thing it was that he failed in getting an official appointment when he began his philosophy. Had he succeeded we never should have heard of the philosophy. The things are absolutely incompatible. No man can do great original work and be hampered with the cares of a position. The thing is impossible. The work must have the whole man. That is why I have tried to get Gray free. You Americans don't know how mucl of a man Gray is; but he is hampered with students' work and is not able to keep an assistant. When you were working for spencer on the other side, I was working for Gray here. I thought I had got it arranged. I obtained a promise from Peabody to give money enough to relieve Gray and let him go on with original work: but when he got over there, they worked at him and defeated all the good of the plan."

Happily, two years later, Gray was made free, and began again his "North American Flora," which is at every step and in all its details a work of original research. There is only now and then a man who is capable of carrying on original investigations in any branch of science. Successful research implies an accurate acquaintance with pre-existing knowledge in the field to be explored. It demands keen logic and cool judgment, and not these alone. People with great learning, fine reasoning powers and high judicial faculty are not so very rare. But the original investigator, the discoverer of principles and of laws, must have, joined with these weighty elements, the gift of a lively imagination. Prof. Gray was such a man, and Dr. Hooker and Mr. Bentham, along with him - the great leaders and originators in botanical science in our day - are men of this order. Let me give you an cxample of the estimate put upon this faculty by a botanist who knows.

Prof. Sachs, in his masterly sketch of the development of botany from 1530 to 1860 , says: "I have made it my chief object to 
discover the first dawning of scientific ideas, and to follow them as they developed into comprehensive theories. But the task is a very difficult one, for it is only witl great labor that the historian of botany succeeds in picking the real thread of scientific thought out of an incredible chaos of empirical material. It has always been the chief hindrance to a rapid advance in Botany that the majority of writers simply collected facts, or if they attempted to apply them to theoretical purposes, did so very imperfectly. I have therefore singled out those men as the true heroes of science, of our story, who not only establisherl new facts, but made a speculative use of empirical material" ; and he describes this speculative process in gifted minds as "an ever-deepening insight into the relationship of all plants to one another; into their outer form and inner organization, and into the plyysiological processes dependent on these conclitions."

Prof. Gray's original work proves him to have been one of these true heroes of the botanical story. He was a scientific theorizer. Ife conld make a speculative nse of faets. He was a deep thinker seeking always for the most comprehensive points of view. For instance, Mrs. Treat says that his most remarkable contribution to science was a paper prepared in 1859 upon the "Diagnostic characters of certain new species of plants collected in Japan by Charles Wright; with observations upon the relations of the Japanese Flora to that of North America and other parts of the northern temperate zone." "This paper," she says, "at once raised him to the very highest rank among philosophieal naturalists, and attracted to him the attention of the whole seientific workl."

Here, certainly, was very different work from that required in making text-books and teaching college students. It called into action his highest powers. He was dealing with the relationships of widlely separated patches of our North American Flora and the Flora of eastern Asia, between which he had discovered an maceountable likeness. And then he also formd a likeness hetween these existing Floras and that of the 'Tertiary epoch. Think of the vast stores of aceurate knowledge repuired to establish these relationships! But the man of inagination does not stop with the facts. 'The why and the how are ever pressing for answers, and liere (ommes in the seientific inagination. Mrs. 'Treat says: "He explained the peenliar distribution of plants throngli the Northern hemisplere by trating their descent through geological periods from eommon ancestors that flourished in the Tertiary epoeh in high latitudes." And this was done before 1)arwin. No wonler that men of science abroad were impatient at the sight of this mental grant grinding in the class-room and spending his precions leisure in celitorial drudgery or the manufacture of text-bonks, however perfect.

'Tluere is another aspect of the situation which makes it seem still more ageravating. This man's work had been acemmulating for a lomelred rears. Nut only land lie come to an unexplored (ontinent, hut the pinciples hy which its Flora conld be natmally clissed were not estahlished mutil his time; and he had an important land in their establishment. From the time of linnieus, thinking botanists had heen hewildered and defeated 
by the contradiction betwcen the dogma of the fixity of species and the aspects prescnted by the discovered facts of the vegetal world. Such natural groups of plants as mosses, ferns, Conifera, Umbiliferæ, Compositæ, Labiate, lapilionaces, were recognized. These groups were seen and felt, as we see and fecl the groups of birds, reptiles, etc., in the animal world. Even Limneus believed in a natural system of classification founded on constitutional rescmblances. Here and there, while artificial classification held the ficld, a few European botanists of decper insight pondered over the natural relationships of plants, and by the comparative study of mature forms arrived at the science of morphology, which was soon greatly advanced by the microscope; and the anatomy and physiology of plants were also studied with efiect. A long series of relationships among plants was worked out with great clearness, but they were all characterized by that mysterious word "affinity," and here thought mostly ended. The idea of the symmetry of plants was reached by these decper students; and mingling metaplyysics with objective studies, the notion of types in the vegetal world was conceived. By the help of thcological conceptions, the plan of creation, it was thought, had been discovered by Naturalists, who readily took the next step of regarding the objects of Nature as the thoughts of the Creator-a view made familiar to us thirty or forty years ago by Prof. Agassiz.

Owing to this state of things plilosophical botany made slow progress, and only the most gifted minds could evolve correct principles available in classification. Prof. Torrey was a man of the required stamp, but he came a little too soon. Prof. Gray's study of Japanese vegetation brought him to conclusions concerning the fixity of species that made him onc of Darwin's most able advisers in the ycars preceding the issue of the "Origin of Species." With the Flora of a continent to be studied in the light of recent discovery it seems doubly deplorable that the thirty-five most productive years of Prof. Gray's life should not have been spent in original research under the most favorable conditions.

Prof. Gray's case is only one of many in which men of great powers, anxiously seeking to use them to the world's advantage, have been compelled to spend their lives in drudgery, and to die with their great work unaccomplished. The world must continue to suffer the loss of such knowledge as Asa Gray might have added to its stock. And the need of some method of discovering master-minds, and presenting them as candidates for support to those who are anxious to contribute to the advance of knowledge, is forcibly suggested by this history.

Dr. Lewis G. JAXEs :-

The nature of Dr. Gray's eontribution to the doctrinc of Evolntion may perhaps be best understood by taking a single example, explanatory of his theory of the geographical distribution of plints. It is found that the nearest cxtant relations of the great sequoias, or red-wood trees, - two varieties of which are now found in California, and mowhere clse in the work, - are the sonthern cypress, found in the swamps and cverglades of our Southern Atlantic States, and a similar tree of the cypress family, now 
found only in Northern Clina and Japan. A species of yew, the Torreya, lus also a similar distribution, the members of its family being found only in the red-wood distriets of Califormia, in the swamps of Florida, and in Northern Clrina. The old theory was that these trees were created, or originated in the neigliborhood of their present labitats, thus constituting several independent stocks. Dr. Gray maintained, however, that these trees originated from a single stock, in Arctic Latitudes, when the climate was warmer and the continents were not separated as now by wide expanses of sea. By glacial action, or otherwise, they were puslied southward in different localities, and the hardiest, most adaptable stoeks survived in the localities where they are now found. 'This theory, now generally aceepted by lutanists, was subsequently confirmed by the diseovery of fossil red-wood trees in the Aretic regions.

Dr. Gray lield that the doctrine of Evolution was compatible with the belief that Nature-the naterial universe-is the outcome of mind rather than that mincl is the product of material conditions. He held that the whole process of organic evolution involved the idea of design, was an adaptation of means to ends. He did not think, however, that it was necessary for the believer in Christianity to assume the responsibility of attempting to harmonize evolution witl the natural science of Genesis. "IVith the rise and development of astronomy, physies, geology, and later of biological seience," he said, "the tables were turned; and now many religious beliefs-or what were taken for such-are controlled and molified by scientific beliefs, none more so than in the matter of 'Biblical Creation.' The result, I smppose, is that no sensible person now believes what the most sensible persons believed formerly." ()n the ground of natural science, he held, "Seientific belict must needs control the relicrious." * He thougrit, lowever, that molern natural seience, in any of its demonstrated results or well-estallished beliefs, was not necessarily antagonistic to the Christian religion.

Dr. Janes also spoke of Dr. Gray's kindness of heart and friendslip for children, mentioning some instances.

\section{M1r. James A. ShiltoN :-}

The essay of the evening and its discussion by Miss Youmans have given me the unique experience of uniting the interest and enjoymont of this prosent moment with the remembered fascoinitions of a sort of pre-adamite or ante-flelurian age, speaking in regard to the exolution of botanical seience.

It was my privilege, before I was half through my teens, in an interval of rest from over-study, and between the prepiratory school and the university, to earn the degree of Bachelor if Fatural sience in the first institution established in the [nited States for the especial study of Botany and the other Natural seienees-and thereupon to practically almost abandon the further pursuit of those sciences; only taking them up arain in the most general way as required from time to time while watching the development of the new seience and philosopliy since the publication of the "Orierin of species" in 18.9. "Tlie butanical system tanglit in that institution was that of Limneus. So it

" Discusion before "Evangelical Alliance," sept. 11, $18,2$. 
comes abont that I am able to speak to you from personal experience and observations of the state of scicntific knowledge as taught in the days before the coming of the flood of light which we are now enjoying, and also of one of the early teachers of 'rofessor Gray, his life and methods.

In May, 1810, at Catskill, N. Y. Professor Amos Eaton, a graduate of Williams College of 1799 , made, it is believed, the first attempt in this country to deliver a popular course of lectures on botany, compiling a small elementary treatise for the use of his class, in what he called "The Botanical Institution," the first botanical text-book in English published in this country; those previously used being in the Latin languagc. In 1817 he delivered lectures on botany, mincralogy and gcology to volunteer classes of the students of Williams College, at Williamstown, Mass. 'The first edition of his Manual of Botany was published by graduates of Williams College in 1817, and gave a great impulse to the study of botany in New England and New York. The eighth and last edition of this work was published in 1840, under the title of "North American Botany," a large octavo volume of 625 pages, and containing descriptions of 5267 species of plants.

Between 1817 and 18:4, Professor Eaton also delivered courses of lectures on branches of natural history, but particnlarly on botany, bcfore the Members of the Lcgislature at Albany, on the special invitation of Governor De Witt Clinton; in the Lenox Academy, Mass.; at Northampton under the patronage of Governor Strong of Massachusetts; in the Medical Collcge at Castleton, Vermont, in which he was appointed Professor of Natural History in 1820; in the City of Troy, N. Y., and in many other places. Ifis lectures in Albany resulted in the initiation of that great work, "The Natural History of New York," the naturalists engaged in which were largely his pupils-among them James Hall and Ebenezer Emmons. That work has not only been the pattern for the scientific surveys of other States, but men who studied under him have been engaged in such survcys in many of the States. In 181s he first published his "Index to the Geology of the Northern States," which was the first attempt at a general arrangement of the geological strata of North America. In 1818-19 the City of Troy - tlien little more than a village, but scttled by the advance guard of that New England emigration which las since covered the Western States-liad a Lyceum of Natural History and the most cxtensive collection of American gcological specimens to be found in this country. With Albany, it containcd a notable number of leaders in science. Among them were Professor II cnry, the Becks, and many more, but in the early days Professor Eaton was easily the leader in all branches.

In 18:4 Professor Eaton, by the aid of the Patroon, Steplen Van Rensselaer, of Albany - a man of broad views and public spiritestablished in the City of Troy a School of Science then called the Rensselaer School, which eventually became a school of all branches of engineering, is now known as the Renssclaer Polytechnic Institute, was the model at some remove of the Brooklyn Polytechnic Institute, and has turned out, as its biographical record shows, a larger number of the successful working scientific men and engineers of our day and generation engaged in applying seience in the work of the world than any other institution in the country, possibly more than all the literary 
colleges put togrether; anong whose names are to be found those of the men who designed and built the Blooklyn Bridge, and of miny otlers who are now engaged in tle great engineering works of the country. From 1824 to May 6,1842 , the day of lis death, Professor Eaton was at the lead of this institution. And between 1810 and $1841 \mathrm{in}$ aldition to other labors, lhe wrote various works on botany, chemistry, zoology, geology, and kinclred topies, to the mumber, ineluding the different editions, of about forty publications in all.

His biography has never been more than sketched in outline, but it is to be doubted whether any single American lias, thromel his work, his pupils, his metlods, and the stimulus lie direetly gave to others, done more for the eause of seience, and of combined seience and practice in the United States, than Professor Eaton did. Neither, owing to cireumstances which there is no time liero to explain, lias adequate justice been done to the metlods by and through which he produced the marked effects to be traced to him, except in tle minds of a few. 'Those methods, in a word, eonsisted in bringing the student into direct contaet witl tle aetual tling to be studied, in relegating the text-book to a seeondary position, and in bringing the mincls and loands of teacher and pupil into immediate co-operative relations. II divicled his classes into seetions of eight, with the most competent memler as its captain or leader. The pupils assisted in prepiring and arranging the ohjeets and meehanisms to be employed, wherempon the l'rofessor leetured to the entire elass; in chemistry performing all the experiments, and in all the other branches going through with all the manipulations and illustrations with the actual objects in hand; whereupon the subject was taken up in turn by eacli seetion and by every member of each section, all of them, with the other members, eonstituting a eritical andience, lecturing upon it in turn and going througl all tle neeessary manipulations, experinents, demonstrations and ilnstrations. After the lecture on botany the class was usually dismissed with the direction to start for the fields with botanical cans, and incled to find and hring back the greatest possible number of new plants. 'Tlirough the lorg list of years, I still vividly recall the eagre joy of that work, and remember low, from libll-tops and other points of vantage, I planmed botanical campaigns, studied topography, hal,itat and enviromment, and thereby somglit to discover the hiding-plices of partionlar plants we wished to capture; and how we scorncd fatigne, olstacles aud lagrards in their pursuit. 'The stmelents were expected on their retmin, after the first few lessoms liad loeen given, to find for themselves the genus and species of the plants they bromglit in. Where they fomel themselves purzled and could inot be lielped ont by their fellows, they were experted to rely $m$ poul the Professor for the names of gemus and speries.

The principle of the tixity of speries was of comrse formally tanght. Innt the total tearhing-that is, the teathing of the Professors, the looks, ond that of the fields and the plants themselves included - resnlted. not simply in the relixing of our belief in it, nor simply in the alceptance of the e(onvenient worl "variation" as cxpressive of the artual differences foumd in specimcus eviclently of the same gemm. lunt not answeriner to all the dretals of resciption given in the luoks for amy particular species. Although a mere child I distinctly renenber that 
notwithstanding the reiterated declarations of the Professors and of the text-books, my own mind would not accept the doctrine of the fixity of species. For, my experience was that in attempting to find the genus and the species of the plant in hand, the case was a rare and exceptional one where the entire description of any species would everywhere fit any specimen; and I well remember that when compelled to resort to the Professor-for that reasoll, and because $I$ attempted to adhere to the principle of the fixity of species-sometling like heat, if not indignation, would flasl through me when the Professor gave me a specific name over whicl I had long puzzled in vain and which I had perhaps rejected because of the defective description. From that time, the Summer of 1845 , till the publication of the "Origin of Species," I carried a skeptical mind on the subject, and when tliat book was published, although I could only get access, in the South, through brief reviews, through the information contained in newspaper scraps, and-I may say - througl orthodox sermons and their struggles with the "monkey problem," to what it contained, I promptly accepted the principle taught by Darwin in that book, basing that acceptance largely upon the facts of my long past experience, and upon the satisfactory explanation offered by him of ny early difficulties in the study of botany. It is to be remembered, we had Lamarck, and the "Vestiges of Creation," and that discussion was active and liad already undermined many old theories.

Further, in the home into which I was born, geological and palaontological specimens were everywhere and to a large extent the playthings of my childhood. The more recent tracing of the history of plant-life from fossil forms down to living forms by Professor Gray has been mentioned in the essay of the evening. Botany as well as geology and palæontology were constant topies in that household as far back as I can remember; and as early as 1845 certainly, probably before, I distinctly remember tracing the genus Equisetum back as far as its gigantic fossiliferous forms found in the Coal Measures. Perliaps I may be permitted to go a step further. By this time of day I suppose I am recognized in this Association as a thorough believer in Evolution as taught by both Darwin and Spencer. I first learned of spencer by taking up one of his books of essays in a bookstore in Albany in the Winter of 1862-6:3, not long after Professor Youmans had brought about his introduction to America. Before the first page was finished my mind was caught. As I read on - still standing - I soon began to hear my nind saying: Ilere he is at last-the thinker, philosopher and leader for whom I have looked so long in rain! Seeing other books bearing his name on the same table, I rapidly glanced through them, and soon found the programme of the system of Plilosophy he was to write and the list of what he had already written. Among these was the title of his essay on Population, printed in a Mestminste Reriew of 15\%2. Being myself already an anti-Malthusian, I immediately concluded that an examination of that essay wonld establish his position as a thinker, for me. It was not yet an hour since I had picked up the essays. Proceeding directly to the State Library I obtained the copy of the Reviek, and found my hopes and expectations confirmed in the first sentence. From that day $I$ have been an earnest Spencerian. And that I have been so, I believe is due primarily to Professur Eaton, to the Rensselaer Institute established by him, 
to Professor George II. Cook, now of New Jersey, his suecessor, to the 'roy Jyeeum, to my own father, who was my constant teacher in natural and biologieal science, and to the eombination of all these that lial been brought to bear upon me as early as the Summer of 1845, if not before, and certainly before the work of Professor Gray liad much of it been done or become mueh known.

From these statements it will appear that the ideas now dominant in the seientific world, as to the unfixity of speeies, were in the air, or eoming, so to speak, long before Darwin or Gray had either written, published or reached their final conclusions. While, then, I would not minify the magnifieent aehievements of such men as Darwin, Gray, and otler modern lights, I do not believe it just, and for myself I do not propose, to be guilty of ignoring the laborious workers in natural science, in this country, on whose work recent builders have built as upon a foundation. Now when we are celebrating the praises of Professor Gray, I ask you not to forget the labors of such pioneers as Professor A mos Eaton. Mrs. Treat says, you will remember, that after reading the article in the "Edinburgh Encyelopedia," it was Eaton's Botany he first obtained and studied with interest, and that by its aid the little Claytonia Virginica was the first treasure le captured and identified in the early Spring. How many of us can understand and enter into his earnest welcome of that cheerful flower !

I am glad to be able to say that in an early number the Popular Science Monthly will do for Professor Eaton what it has done for so many other seientific men, in preserving their names and labors from threatened oblivion.

Doubtless, if Professor Gray could have been with us to-night le would have stood in my place to say, mueh better than I liave done or ean do, words of cordial reeognition and appreciation on behalf of his old teaeher, Professor A mos Eaton.

\section{Mr. William Potts :-}

I desire merely to take this oceasion to emphasize the fact, so well illustrated by the experience of Dr. Gray, that the ininute and seientifie study of botany in no way interferes with the natural love of tlowers and plants for their beanty. On the contrary, the more we know about flowers, the more we study them scientifically, the nore we love them and appreciate their beauty. 'The contrary idea, sometimes expressed hy those ignorant of the facts, is entirely false, and should be conclemned by us.

\section{Dr., Robert G. Eccies :-}

Dr. Eceles said he had first been introdueed to Professor Gray about ten years ago, by P'rofessor E. L. Youmans, in D. Appleton \& Co.'s office. Ilis last meeting with him was at MeGill College, Montreal, during the neetings of the $A$ merican $\Lambda$ ssociation for the Advancement of science. On an excursion to (ottawa at the same tune a favorable opportunity was presenterl of studying Professol (rray's disposition and learning from lim low he harmonized his religion with evolution. At several points visited all the guests were asked to register. While men with one title invariably 
affixed that to their names, Professor Gray with characteristic modesty signed his name simply "Asa Gray," althougli he could almost have filled the page with the initials of lis honorary and other degrees as well as those of the learned Societies to which he belonged.

When questioned in the most elcmentary facts of botany by people not familiar with that science, he would patiently explain the matter to them with evident pleasure. The contrast between lim and a number of other prominent members of the Association, who had been seen by Dr. Eccles snubbing honest but illposted inquirers after facts, was pronounced and startling. During the trip to Ottawa he disclosed how he reeonciled his Presbyterianism and Evolution, the subject being raised by reference to a discussion on Darwinism the day preceding in the Biological Section. He pointed out that in the growth of a plant or trce from its seed to full maturity a struggle for existence among its cells, buds, leaves, branches, flowers, etc., is incessantly going on. In spite of this warfare every seed produces a tree or lierb after its kind. Like playing with loaded dice that must turn up the proper sides every time in spite of shaking, in the molecular warfare the winning party is invariably pre-destined in its very strueture. In the warfare among organisms and in society the same eonditions are found. "Fitness" may be diabolical, or it may be beneficent. Somehow in the great average it always comes out beneficent. Evolution is God's will made manifest in matter. The side championed by right and good always wins in the end.

Dr. Gray was a most voluminous writer. A list of the titles and headings of lis books and magazine contributions has been published, and forms a pretty large oetavo volume in itself. Darwin was indebted for much, and perluaps for a majority of his most telling botanieal faets, to Dr. Gray. A great deal of the material in his "Climbing Plants," was the work of the latter. The Compositæ are the most difficult plants a botanist can study. Here Gray was monarch and peerlcss. In his contributions to plant distribution he showed himself at onee a master botanist, a philosopher and a naturalist. Others had walked blindly over the same facts and fields and did not sce that every flower told the tale of its own past history, and the history of its kind, by the place where it is found. Where plants of a common or kindred kind are now, tells of thcir past wanderings when the facts arc all considered. Dr. Gray made this discovery. To Gray Darwin first imparted his idca of Natural Seleetion. Dr. Eceles thought it strange that the cssayist of the evening forgot to mention this, the most important fact in a course of leetures on Evolution in eomnection with his life. Especially important is it because of its bearings on the history of the doctrine of Natural Sclection. Darwin and Wallace each claimed priority in advocating this principle, and thcse rival claims were forever set to rest by a letter from Darwin to Gray that was read at a mceting of the Linnæan Society when the two champions first gave forth their ideas publiely. This was on July 1st, 1858. Darwin's letter was written a year before. But even this celebrated epistle was not the first. On July 20 th, 1856 , Darwin wrote to Gray :- 
"I have come to the heterodox conclusion that there are no such things as independently created species, that species are only strongly defined varieties. . . I assume that species arise like our domestic varieties with much extinction."

This is the first word ever known to have been penned in this world on the now well-known principle of "survival of the fittest."

While Gray treated this doctrine fairly from the first, it was not to be expected that he would immediately give adlierence thereto. His friends, Agassiz and Dana, bitterly opposed it, while he held his mind in the true scientific attitude of suspended judgment. His lieart from the first told lim there must be sometling in it. In 1880 he liad so far transcended his seruples that at New Haven he publicly said : "Natural selection by itself is not a hypothesis nor even a theory. It is a truth, a catena of facts and direct inferences from facts." It is a sad pity that he did not live to complete some of the work he had begun. The "Synoptic Flora" lies incomplete, to the sorrow of many a botanist

At the banquet on his seventy-fifth birthday, when the silver vase was presented to him, every botanist in Ameriea felt that, like the great Rocky Mountain peak bearing his name, here was one who transcended them all in the knowledge of their favorite Sclence. It was then Lowell wrote of him :

$$
\begin{aligned}
& \text { "Just fate! prolong his life, well spent, } \\
& \text { Whose indefatigable lowrs } \\
& \text { Have heen as gaily innocent } \\
& \text { And fragrant as his flowers." }
\end{aligned}
$$




\title{
EDWARD LIVINGSTON YOUMANS
}

\section{THE MAN AND HIS WORK}

\author{
BY \\ JOHN FISKE \\ Acthor of "Cosmic Philosophy," "Excursions of ax Evolutionist," \\ "The Destixy of Mas," Etc.
}




\section{COLLATERAL READINGS SUGGESTED.}

"Biographical sketch of E. L. Youmans," in Popular Science Monthly, March, 1887; Article, "Edward L. Youmans," in " $\Lambda_{p}$ pleton's Cyclopædia of Biography." 


\section{EDWARD LIVINGSTON YOUMANS :}

\section{THE MAN AND HIS WORK.}

Ix one of the most beautiful of all the shining pages of his "History of the Spanish Conquest in America," Sir Arthur Helps describes the way in which, through "some fitness of the season, whether in great scientific discoveries or in the breaking into light of some great moral cause, the same processes are going on in many minds, and it seems as if they communicated with each other invisibly. We may imagine that all good powers aid the 'new light,' and brave and wise thoughts about it float aloft in the atmosphere of thought as downy seeds are borne over the fruitful face of the earth" (rol. iii., page 113). The thinker who elaborates a new system of philosophy deeper and more comprehensive than any yet known to mankind, though he may work in solitude, nevertheless does not work alone. The very fact which makes his great scheme of thought a success and not a failure is the fact that it puts into definite and coherent shape the ideas which many people are more or less vaguely and loosely entertaining, and that it carries to a grand and triumphant conclusion processes of reasoning in which many persons have already begun taking the earlier steps. This community in mental trend between the immortal discoverer and many of the brightest contemporary minds, far from diminishing the originality of his work, constitntes the feature of it which makes it a permanent acquisition for mankind, and distinguishes it from the eccentric philosophies which now and then come up to startle the world for a while, and are presently discarded and forgotten. The histor' of modern physics - as in the case of the correlation of forces and the undulatory theory of light-furnishes us with many instances of wise thoughts floating like downy seeds in the atmosphere until the moment has come for them to take root. And so it has

* An Aduress hefore the Brooklyn Ethical Association, March 23, 1890. Reprinted from The Popular seipre Monthly, Iay, 1890, by permission of Messrs. 1). Appleton and Company. 
been with the greatest achievement of modern thinkingthe doctrine of Evolntion. Students and investigators in all devartments, alike in the physical and in the historical sciences, were fairly driven by the nature of the phenomena before them into some hypothesis, more or less vague, of gradual and orderly change or development. 'The world was ready and waiting for Herbert spencer's mighty work when it came, and it was for that reason that it was so quickly triumphant over the old order of thought. The victory has been so thorough, swift, and decisive that it will take another generation to narrate the story of it so as to do it full justice. Meanwhile, people's minds are apt to be somewhat dazed with the rapidity and wholesale character of the change; and nothing is more common than to see them adopting Mr. Spencer's illeas without recognizing them as his or knowing whence they got them. As fast as Mr. Nipencer could set forth his generalizations they were taken hold of here and there by special workers, each in his own department, and utilized therein. His general system was at once seized, assimilated, and set forth with new illustrations ly serious thinkers who were already groping in the regions of abstruse thought which the master's vision pierced so clearly. And thus the doctrine of Erolution has come to be inseparably interfused with the whole mass of thinking in our day and generation. I do not mean to imply that people commonly entertain very clear ideas about it, for clear icleas are not altogether common. I suspeet that a good many people would hesitate if asked to state exactly what Newton's law of gravitation is.

Among the men in America whose minds, between thirty and forty years ago, were feeling their way toward some such unified conception of nature as Mr. Spencer was about to set forth in all its dazzling glory - among the men who were thus prepared to grasp the doetrine of Evolution at once and expound it with fresh illustrations - the first in the field was the man to whose memory we lave net here this evening to pay a hrief word of tribute. It is lout a little while since that noble face was lere with us and the tones of that kindly voice were franght with good cheer for us. To most of vou, I presume, the man Eilward Iivingston Fommans is still a familiar presence. There must be many here this evening who listened to the tidings of his leath two voars ago with a sense of personal bereavement. No one who knew him is likely ("ver to forget him. liut for those who remember distinetly the man it may not be 
superfluous to recount the principal incidents of his life and work. It is desirable that the story should be set forth concisely, so as to be remembered; for the work was like the man, unselfish and unobtrusive, and in the hurry and complication of modern life such work is liable to be lost from sight, so that people profit by it without knowing that such work was ever done. So genuinely modest, so utterly destitute of self-regarding impulses was our friend, that I believe it would be quite like him to chide us for thus drawing public attention to him, as he would think, with too much emphasis. But such mild reproof it is right that we should disregard; for the memory of a life so beautiful and useful is a precious possession of which mankind ought not to be deprived.

Edward Livingston Youmaxs was born in the town of Coeymans, Albany County, N. Y., on the 3d of June, 1821. From his father and mother, both of whom survived him, he inherited strong traits of character as well as an immense fund of vital energy, such that the failure of health a few years ago seemed (to me, at least) surprising. His father, Vincent Youmans, was a man of independent character, strong convictions, and perfect moral courage, with a quick and ready tongue, in the use of which earnestness and frankness perhaps sometimes prevailed over prudence. The mother, Catherine Scofield, was notable for balance of judgment, prudence, and tact. The mother's grandfather was Irish; and, while I very much doubt the soundness of the generalizations we are so prone to make about race gharacteristics, I cannot but feel that for the impulsive-one had almost said explosive-warmth of sympathy, the enchanting grace and vivacity of manner, in Edward Youmans, this strain of Irish blood may have been to some extent accountable. Both father and mother belonged to the old Puritan stock of New England, and the father's ancestry was doubtless purely English. Nothing could be more honorably or characteristically English than the name. In the old feudal society the yeoman, like the franklin, was the small freeholder, owning a modest estate yet holding it by no servile tenure, a man of the common people yet no churl, a member of the state who "knew his rights and knowing dared maintain." Few indeed were the nooks and corners outside of merry England where such men flourished as the yeomen and franklins who founded democratic New Eugland. It has often been remarked how the most illustrious of Franklins exemplified the tylical 
virtues of his elass. There was much that was similar in the temperament and disposition of Elward Youmansthe sagacity and penetration, the broad common sense, the parnest purpose veiled but not hidden by the blithe humor, the levotion to ends of wide practical value, the habit of making in the best sense the most out of life.

When Edwarkl was hut six montlis old, his parents moved to Greenfield, near Saratoga Siprings. With a comfortable house and three acres of land, his father kept a wagon-shop' and smithy. In those days, while it was hard work to wring a subsistence out of the soil or to prosper upon any of the vocations which rural life permitted, there was cloultless more independence of character and real thriftiness than in our time, when cities and tariffs have so sapped the strength of the farming country. In the family of Vincent Youmans, though rigid economy was practised, books were reckoned to a certain extent anong the necessaries of life, and the house was onc in whieh neighbors were fond of gathering to discuss questions of polities or theology, social reform or improvements in agriculture. On all such questions Vincent Youmans was apt to have ideas of his own; he talked with enthusiasm, and was also realy to listen; and he evidently supplied an intellectual stimulus to the whole community. For a boy of bright and inquisitive mind, listening to such talk is no mean source of education. It often goes much further than the reading of books. From an early age Edward Youmans seems to have appropriated all such means of instruction. He had that insatiable thirst for knowledge which is one of God's best gifts to man; for he who is born with this appetite must needs be grievously ill-mate in other respects if it does not constrain him to lead a happy and useful life.

After ten years at Greenfield the fanily moved to a farm at Milton, some two miles distant. Until his sixteenth year Edward helped his father at farm-work in the summer and attended the district sehool in Winter. It was his grook fortune for some time to fall into the hamb of a teacher who harl a genius for teaching - a man who in those days of rote-learning did not care to have things learned by heart, lnt songlit to stimulate the thinking jowers of his pupils, and who in that age of canes and ferules never found it necessary to use such means of rliscipline, beeause the fear of displeasing him was of itself all-sufticient. Experience of the methots of such a man was enough to sharpen one's disgust for the exeessive mechanism, the 
rigid and stupid manner of teaching, which characterize the ordinary school. In after year's Youmans used to say that "Uncle Good"-as this admirable pedagogue was called first taught him what his mind was for. Through intercourse and training of this sort he learned to doubt, to test the soundness of opinions, to make original inquiries, and to find and follow clews.

But even the best of teacher's can effect but little unless he finds a mind ready of itself to take the initiative. It is doubtful if men of eminent ability are ever made so by schooling. 'The school offers opportunities, but in such men the tendency to the initiative is so strong that if opportunities are not offered they will somehow contrive to create them. When Edward Youmans was about thirteen years old he persuaded his father to buy him a copy of Comstock's Natural Philosophy. This book he studied at home by himself, and repeated many of the experiments with apparatus of his own contriving. When he made a centrifugal water-wheel, and explained to the men and boys of the neighborhood the principle of its revolution in a direction opposite to that of the stream which moved it, we may regard it as his earliest attempt at giving scientific lectures. It was natural that one who had become interested in physics should wish to study chemistry. 'The teacher (who was not "Uncle Good") had never so much as laid eyes on a text-book of chemistry; but Edward was not to be daunted by such trifles. A copy of Comstock's manual was procured, another pupil was found willing to join in the study, and this class of two proceeded to learn what they could from reading the book, while the teacher asked them the printed questions-those questions the mere existence of which in text-books is apt to show what a low view publishers take of the average intelligence of teachers! It was not a very hopeful way of studying such a subject as chemistry; but doubtless the time was not wasted, and the foundations for a future knowledge of chemistry were laid. The experience of farm-work which accompanied these studies explains the interest which in later years Mr. Youmans felt in agricultural chemistry. He came to realize how crude and primitive are our methods of making the earth yield its produce, and it was his opinion that, when men have once learned how to conduct agriculture upon sound scientific principles, farming will become at once the most wholesome and the most attractive form of human industry. 
Along with the elementary studies in science there went a great cleal of niscellaneous reading, mostly, it would appear, of good solid books. A prarently there was at that time no study of languages, aneient or modern. At the age of seventeen the young man harl shown so much promise that it was decided he should study law, and he had already entered upon a more extensive course of preparation in an academy in Saratoga County when the event occurred wlich changed the whole course of his life. He had been naturally gifted with keen and accurate vision, was a good sportsman and an excellent shot with a rifle, but at about the age of thirteen there had come an attack of ophthalmia which left the eyes weak and sensitive. Perpetual reading probably increased the difficulty and hindered complete recovery. At the age of seventeen violent inflammation set in, the sight in one eye was completely lost, while in the other it grew so dim as to be of little avail. Sometimes he would be just able to find lis way about the streets, at other times the blindness was almost total, and this state of things lasted for nearly thirteen years.

This dreadful calamity seemerl to make it impossible to continue any systematic course of study, and the outlook for satisfactory work of any sort was extremely discouraging. The first necessity was medical assistance, and in quest of this Mr. Youmans came in the autumn of 18.39 to New York, where for the most part he spent the remainder of his life. Until 1851 he was under the care of an occulist. Under such circunstances, if a man of eager energy and loundless intellectual craving were to be orerwhelned with despondeney, we could not call it strange. If lie were to become dependent upon friends for the means of support, it would be ungracious if not unjust to blame lim. But Edward Youmans was not made of the stuff that acquiesces in defeat. He rose superior to ealamity, he won the neans of livelilood, and in darkness rntered upon the path to an "nviahle fame. At first he lad to resign limself to spending weary weeks over tisks that with sound eye-sight

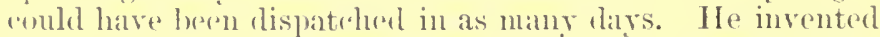
some kind of writing-marline which held his paper firmly and enabled his pen to follow straight lines at proper distances ilpart. Long practies of this sort gave his handwriting a peculiar character which it retained in later years. When I first saw it in 186.3 it seemed almost undewipherable; ; hut that was far from being the ease, and, after I lad grown used to it, I found it but little less legible than the 
most beautiful chirography. The strokes, gnarled and jagged as they were, had a method in their madness, and every pithy sentence went straight as an arrow to its mark.

While conquering these physical obstacles Mr. Youmans began writing for the press, and gradually entered into relations with leading newspapers which became more and more important and useful as years went on. He became acquainted with Horace. Greeley, William Henry Channing, and other gentlemen who were interested in social reforms. His sympathies were strongly enlisted with the little party of abolitionists, then held in such scornful disfavor by all other parties. He was also interested in the party of temperance, which, as he and others were afterward to learn, compounded for its essential uprightness of purpose by indulging in very gross intemperance of speech and action. The disinterestedness which always characterized him was illustrated by his writing many articles for a temperance paper which could not afford to pay its contributors, although he was struggling with such disadvantages in earming his own livelihood and carrying on his scientific studies. Those were days when leading reformer's believed that by some cumningly contrived alteration of social arrangements our luman nature, with all its inheritance from countless ages of brutality, can somehow be made over all in a moment, just as one would go to work with masons and carpenters and revamp a house. There are many good people who still labor under such a delusion.

Though Mr. Youmans was brought into frequent contact with reformers of this sort, it does not seem to me that his mind was ever deeply impressed with such ways of thinking. Science is teaching us that the method of Erolution is that mill of God, of which we have heard, which, while it grinds with infinite efficacy, yet grinds with wearisome slowness. It was Mr. Jarwin's discovery of natural selection which first brought this truth home to us; but Sir Charles Lyell had in 1830 shown how enormous effects are wrought by the cumulative action of slight and unobtrusive causes, and this had much to do with turning men's minds toward some conception of Erolution. It was about 1847 that Mr. Youmans was deeply interested in the work of geologists, as well as in the nebular theory, to which recent discoreries were adding fresh confirmation. Some time before this he had read that famous book, "Testiges of Creation," and, although Prof. Agassiz truly declared that it was an unscientific book crammed with antiquated and 
exploded fancies, I suspeet that $\mathrm{Mr}$. Youmans felt that anid all the ehaff there was a very sound and sturdy kernel of truth.

Among the books which Mr. Youmans projeeted at this time, the first was a compentions history of progress in diseovery and invention; but, after he had marle extensive preparations, a book was published so similar in scope and treatment that he abandoned the undertaking. Another work was a treatise on arithmetic, on a new and philosophi. eal plan; but, when this was approaching completion, he again found himself anticipated, this time by the book of Horace Mann. This was discouraging enough, but a third venture resulted in a brilliant success. We have observed the eagerness with which, as a school-boy, Mr. Yommans entered upon the study of chemistry. His interest in this science grew with years, and he devoted himself to it so far as was praeticable. For a blind man to earry on the study of a seience which is pre-eminently one of observation and experiment might seem hopeless. It was at any rate absolutely neeessary to see with the eyes of others if not with his own. Here the assistance rendered by his sister was invaluable. During most of this period she served as amanuensis and reader for him. But, more than this, she kept up for some time a course of laboratory work, the results of which were minutely described to her brother and discussed with hin in the evenings. The lectures of Dr. John William Draper on chemistry were also thoroughly diseussed and pondered.

'The conditions under which Mr. Youmans worked mate it necessary for him to consider every point with the extreme deliberation involved in framing tistinct mental images of things and processes which he could not wateh with the eyc. It was hard discipline, but he doubtless profited from it. Nature had endowed him with an unusually clear hearl, but this enfored mothod must have nute it still "learer. One of the most notable qualities of his mind was the absolute hminonsuess with which he saw things and the relations among things. It was this quality that made him so sucessful as an expounder of seientifie truths. In the course of his pondering over chemical facts which he was obliged to take at second hand, it oceured to him that most of the pupils in eommon sehools who studied chemistry were practirally no better off. It was easy enough for schools to buy text-books, but difficult for them to provide laboratories and apparatus; and it was much 
easier withal to find teachers who could ask questions out of a book than those who could use apparatus if provided. It was customary, therefore, to learn chemistry by rote; or, in other words, pupils' heads were crammed with unintelligible statements about things with queer names - such as manganese or tellurium - which they had never seen, and would not know if they were to see them. It occurred to Mr. Youmans that, if visible processes could not be brought before pupils, at any rate the fundamental conceptions of chemistry might be made clear by means of diagrams. $\mathrm{He}$ began devising diagrams in different colors, to illustrate the diversity in the atomic weights of the principal elements, and the composition of the more familiar compounds. At length, by uniting his diagrams, he obtained a comprehensive chart exhibiting the outlines of the whole scheme of chemical combination according to the binary or dualist theory then in vogue. 'This chart, when published, was a great success. It not only facilitated the acquirement of clear ideas, but it was suggestive of new ideas. It proved very popular, and kept the field until the binary theory was overthrown by the modern doctrine of substitution, which does not lend itself so readily to graphic treatment.

The success of the chemical chart led to the writing of a text-book of chemistry. This laborious work was completed in 1851, when Mr. Joumans was thirty years old. Prof. silliman was then regarded as one of our foremost authorities in chemistry, but it was at once remarked of the new book that it showed quite as thorough a mastery of the whole subject of chemical combination as silliman's. It was a text-book of a kind far less common then than now. There was nothing dry about it. The subject was presented with beautiful clearness, in a most attractive style. 'There was a firm grasp of the philosophical principles underlying chemical phenomena, and the meaning and functions of the science were set forth in such a way as to charm the student and make him wish for more. The book had an immediate and signal snecess; in after-years it was twice rewritten by the author, to accommodate it to the rapid advances made by the science, and it is still one of our best text-books of chemistry. It has had a sale of about one hundred and fifty thousand copies.

The publication of this book at once established its author's reputation as a scientific writer, and in another way it marked an era in his life. The long, distressing period of darkness now came to an end. Sight was so far 
reovered in one eye that it became possible to go about freely, to read, to recognize friends, to travel, and make much of life. I am told that his face had acquired an expression characteristic of the blind, but that expression was afterward completely lost. When I knew him it would never have oecurred to me that his sight was imperfect, except perhaps as regards length of range.

Mr. Youmans's career as a scientific lecturer now began. His first lecture was the beginning of a series on the relations of organic life to the atmosphere. It was illustrated with chemical apparatus, and was given in a private room in New York to an audience which filled the room. Probably no lecturer ever faced his first audience without some trepidation, and Mr. Youmans had not the main-stay and refuge afforded by a manuscript, for his sight was never good enough to make such an aid available for his lectures. At first the right words were slow in finding their way to those ready lips, and his friends were beginning to grow anxious, when all at once a happy accident broke the spell. He was remarking upon the characteristic instability of nitrogen, and pointing to a jar of that gas on the table before him, when some fidgety movement of his knocked the jar off the table. He inproved the occasion with one of his quaint bons mots, and, as there is nothing that greases the wheels of life like a langh, the lecture went on to a successful close.

This was the beginning of a busy career of seventeen years of lecturing, ending in 1868; and I believe it is safe to say that few things were done in all those years of more vital and lasting benefit to the American people than this broadcast sowing of the seeds of scientific thought in the lectures of Edward Yommans. They came just at the time when the world was ripe for the doctrine of Evolution, when all the wondrous significance of the trend of seientific diseovery since Newton's time was begimning to burst upon men's minds. 'The work of Lyell in geology, followed at length in 1859 by the Darwinian theory; the doctrine of the eorrelation of forees and the consegnent unity of nature; the extension and reformation of chemical theory; the simnltaneous advance male in sociological inquiry, and in the conception of the true aims and proper methods of edneation - all this made the priod a most fruitful one for the peruliar work of such a teacher as Youmans. The intellectual atmosphere was charged with ronceptions of Erolution. Mr. Iommans had arrived at such eonerptions 
in the course of his study of the separate lines of scientific speculation which were now about to be summed up and organized by Herbert Spencer into that system of philosophy which marks the highest point to which the progressive intelligence of mankind has yet attained. In the field of scientific generalization upon this great scale, $\mathrm{Mr}$. Youmans was not an originator; but his broadly sympathetic and luminous mind moved on a plane so near to that of the originators that he seized at once upon the grand scheme of thought as it was developed, made it his own, and brought to its interpretation and diffusion such a happy combination of qualities as one seldom meets with. The ordinary popularizer of great and novel truths is a man who comprehends them but partially and illustrates them in a lame and fragmentary way. But it was the peculiarity of Mr. Youmans that, while on the one hand he could grasp the newest scientific thought so surely and firmly that he seemed to have entered into the immermost mind of its author, on the other hand he could speak to the general public in a convineing and stimulating way that had no parallel. This was the secret of his power, and there can be no question that his influence in educating the American people to receive the doctrine of Evolution was great and wide-spread.

The years when Mr. Youmans was traveling and lecturing were the years when the old lyceum system of popular lectures was still in its vigor. The kind of life led by the energetic lecturer in those days was not that of a Sybarite, as may be seen from a passage in one of his letters: "I lectured in Sandusky, and had to get up at five o'clock to reach Elyria; I had had but very little sleep. To get from Elyria to Pittsburg I must take the fire o'clock morning train, and the hotel darkey said he would try to awaken me. I knew what that meant, and so did not get a single wink of sleep that night. Rode all day to Pittsburg, and had to lecture in the great Acarlemy of II The train that left for Zanesville departed at two in the morning. I had been assured a hundred times (for I asked everybody I met) that I would get a sleeping-car to Zanesville, and, when I was already to start, I was informed that this morning there was no sleeping-car. By the time I reached here I was pretty completely used up."

Such a fatiguing life, however, has its compensations. It brings the lecturer into friendly contact with the brightest minds among his fellow-countrymen in many and many 
places, and enlarges his sphere of influence in a way that is not easy to estimate. Clearly an earnest lecturer, of commanding intelligence and charming manner, with a great subject to teach, must have an opportunity for sowing seeds that will presently ripen in a change of opinion $\mathrm{Or}^{\circ}$ sentiment, in an altered way of looking at things on the part of whole eommunities. No lecturer las ever har a better opportunity of this sort than Edward Youmans, and none ever made a better use of his opportunity. His gifts as a talker were of the highest order. 'The commonest and plainest story, as told by Edward Youmans, hat all the breathless interest of the most thrilling romance. Absolutely unconscious of himself, simple, straightforward, and vehement, wrapped up in his subject, the very embodiment of faith and enthusiasm, of heartiness and good cheer, it was delightful to hear him. And when we join with all this his unfailing common sense, his broad and kindly view of men and things, and the delicious humor that kept flashing out in quaint, pithy phrases such as no other man would have thought of, and such as are the despair of anyone trying to remember and quote them, we can seem to imagine what a power he must have been with his lectures.

When such a man goes about for seventeen years, teaching seientific truths for which the workl is ripe, we may be sure that his work is great, albeit we have no standard whereby we can exactly measure it. In hundreds of little towns with queer names did this strong yersonality appear and make its way and leave its effects in the shape of new thoughts, new questions, and enlarged hospitality of mind, among the inhabitants. The results of all this are surely visible to-day. In no part of the English world has Herbert sipencer's philosophy mot with such a general and cordial reception as in the United states. This may, no doubt, be largely explained by a referenee to general causes; hut as it is almost always neressary, along with our general canses, to take into the aceount some per'sonal influenee, so it is in this rase. It is safo to say that among the agene ies which doring the jast fifty yours have so remarkally loroarlened the mind of the American people, very few have leen more potent than the gentle and snbtle but pervasive work done by Edward Yommans with his lectures, and to this has bee'n langely due the hospitable reception of Herbert speneeres ideas.

It was in 1 siog that Mr. Yommans fell in with a review of ". sipencer's Principles of l'sychology," by 1)r. Morell, in 
The Medico-Chirurgicul Rerieu. This review impressed him so deeply that he at once sent to London for a copy of the book, which had been published in the preceding year. It will be observed that this was four years before the Darwinian theory was announced in the first edition of the "Origin of Species." Toward the end of that book Mr. Darwin looked forward to a distant future when the conception of gradual development might be applied to the phenomeua of conscious intelligence. He had not then learned of the existence of such a book as the "Principles of Psychology." In later editions he was obliged to modify his statement and confess that, instead of looking so far forward, he had better have looked about him. I have more than once heard Mr. Darwin laugh merrily over this, at his own expense.

After struggling for a while with the weighty problems of this book - the most profound treatise upon mental phenomena that any human mind has ever produced-Mr. Youmans saw that the theory expounded in it was a long stride in the direction of a general theory of Evolution. His interest in this subject received a new and fresh stimulus. He read "Social Staties," and began to recognize Mr. Spencer's hand in the anonymous articles in the quarterlies in which he was then announcing and illustrating various portions or segments of his newly discovered law of Evolution. One evening in February, 1860, as Mr. Youmans was calling at a friend's house in Brooklyn, the Rev. Samuel Johnson, of Salem, handed him the famous prospectus of the great series of philosophical works which Mr. spencer proposed to issue by subscription. Mr. Johnson had obtained this from Edward silsbee, who was one of the very first Americans to become interested in Spencer. The very next day Mr. Youmans wrote a letter to Mrr. Spencer, offering his aid in procuring American subscriptions and otherwise aiding in every possible way the progress of the enterprise. With this letter and Mr. S'pencer's cordial reply began the life-long friendship between the two men. It was in that same month that I first became aware of Mr. spencer's existence, through a single paragraph quoted from him by $\mathrm{M}$ r. Lewes, and in that paragraph there was immense fascination. I had been steeping myself in the literature of modem philosophy, starting with Bacon and Descartes, and was then studying Comte"s "Philosophie Positive," which interested me as suggesting that the special doctrines of the several sciences might be organized into a general 
borly of doctrine of universal significance. Connte's work was crude and often wildly absurd, but there was much in it that was very suggestive. In May, 1860, in the old Corner Bookstorc in Boston, I fell upon a copy of that same prospectus of Mr. Spencer's works, and read it with exulting delight, for clearly there was to be such an organization of seientific doctrine as the world was waiting for. It appeared that there was some talk of Ticknor \& Fields undertaking to condnct the series in case subscriptions enough should be received. MIr. siencer preferred to have his works appear in Boston; but when in the eourse of 1860 his book on "Education" was offered to Ticknor \& Fields, they declined to publish it, which was, of course, a grave mistake from the business point of vicw. Mr. Yommans, however, was not sorry for this, for it gave him the opportunity to place Mr. S'pencer's books where he could do most to forwark their suecess.

Some years before, dnring his blindness, his sister liad led him one day into the store of Messis. 1). Appleton \& Co. in quest of a book, and $\mathrm{Mr}$. William II. Appleton hat become warmly interested in him. I believe the firm now look back to this cliance visit as one of the most anspicious events in their annals. He became by degrees a kind of atviser as regarded matters of publication, and it was largely through his far-sighted alvice that the Appletons entered npon the publication of such books as those of Buckle, Darwin, Huxley, Tyudall, Haeckel, and others of like character, always paying a royalty to the anthors, the same as to American antions, in spite of the absence of an international copyright law. As publishers of books of this sort the Appletons have rome to be pre-eminent. It is obvious enough nowadays that such books are profitable from a business point of view. But thirty years and more ago this was by no means obvious. We were very provincial. Reprints of English books, translations form French amel German. were sally behind the times. In the Comnerticnt town where I lived people would legin to wake up to the existence of some great European book or system of thought after it had beren before the world anywere fiom a tozen to fifty years. In those days, therefore, it required some boldness to molertake the reprinting of new scientifie books, and neme have reeognized mole freely than the Apuletens the importane of the part played hy Mr: Yommans in this natter. Mis work as aetrisere to a greats

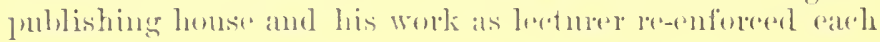


other, and thus his eapacity for usefulness was much increased.

When Mr. Spencer's book on "Education" failed to find favor in Boston, the Appletons took it, and thus presently secured the management of the philosophical series. This brought Mr. Youmans into permanent relations with $\mathrm{Mr}$. Spencer and his work. In $1861 \mathrm{Mr}$. Youmans was married, and in the course of the following year made a journey in Europe with his wife. It was now that he became personally acquainted with Mr. Spencer, and found him quite as interesting and admirable as his books. Friendships were also begun with Huxley and other foremost men of science. From more than one of these men I have heard the warmest expressions of personal affection for Mr. Youmans, and of keen appreciation of the aid that they have obtained in innumerable ways from his intelligent and enthusiastic sympatliy. But no one else got so large a measure of this support as Mr. Spencer. As fast as his books were republished, Mr. Youmans wrote reviews of them, and by no means in the usual perfunctory way; his reviews and notices were tumed out by the score, and scattered about in the magazines and newspapers where they would do the most good. Whenever he found another writer who could be pressed into the service, he would give him Spencer's books, kindle lim with a spark from his own magnificent enthusiasm, and set him to writing for the press. The most indefatigable vender of wares was never more ruthlessly persistent in advertising for lucre's sake than Edward Youmans in preaching in a spirit of the purest disinterestedness the gospel of Evolution. As long as he lived, Mr. Spencer had upon this side of the Atlantic an alter ego ever on the alert with vision like that of a lawk for the slightest chance to promote his interests and those of his system of thought.

Among the allies thus enlisted at that early time were Mr. George Ripley and Rev. Henry Ward Beecher, both of whom did good service, in their different ways, in awakening public interest in the doctrine of Evolution. In those days of the Civil War it was especially hard to keep up the list of subscribers in an abstruse philosophical publication of apparently interminable length. Mr. Youmans now and then found it needful to make a journey in the interests of the work, and it was on one of these occasions, in Novem- 
ber, 1863, that I made his aequaintance. I had already published, in 1861, an article in one of the quarterly reviews in which Mr. Spencer's work was referred to; and another in 1863, in which the law of Evolution was illustrated in connection with certain problems of the science of language. The articles were anonymous, as was then the fashion, and Mr. Youman's curiosity was aroused. 'There were so few people then who had any conception of what Mr. Spencer's work meant, that they coukl have been counted on one's finger's. At that time I knew of only three-the late l'rof. Gurney, of Harvard; Mr. George Roberts, now an eminent patent lawyer in Boston; and Mr. John Clark, now of the Prang Educational Company. I have since known that there were at least two or three others about Boston, among others, my learnea friend the Rev. W. R. Alger, besides several in other parts of the country. When we sometimes ventured to observe that Mr. Spencer's work was as great as Newton's, and that his theory of Evolution was going to remorlel human thinking upon all subjects whatever, people used to stare at us and take us for idiots. Any one member of such a small community was easy to find; and I have always dated a new era in $n y$ life from the Sunday afternoon when Mr. Youmans came to 1 y roon in Cambridge. It was the hegimning of a friendship such as hardly comes but once to a man. At that first meeting I knew nothing of him except that he was the author of a text-book of chemistry which I hat found interesting, in spite of its having been crammed down my throat by an old-fashioned memorizing teacher who, I an convinced, never really knew so much as the difference between oxygen and antimony. At first it was a matter of breathl'ss interest to talk with a man who hal seen Ilerbert Suencer. I3ut one of the immediate results of this interview was the begimning of my own correspondence with Mr. Spencer, which led to manifold results. And from that. time forth it always seemed as if, whenever any of the good or lovely things of life came to ny lot, somehow or other Edwand Youmans was cither the cause of it or at any rate intinately eoneerned with it. The sphere of his unselfish goodness was so wide and its quality so potrit that one rould not come into near relations with hin without beroming in all mamer of unsuspected ways strengthenesl and ruriehed. 
In the autumn of 1865 we were dismayed by the announcement that Mr. Spencer would no longer be able to go on issuing his works. In London they were published at his own expense and risk, and those books which now yield a handsome profit did not then pay the cost of making them. By the summer of 1865 there was a balance of $£ 1100$ against Mr. Spencer, and his property was too small to admit of his going on and losing at such a rate. As soon as this was known, John Stuart Mill begged to be allowed to assume the entire pecuniary responsibility of continuing the publication; but this, Mr. Spencer, while deeply affected by such noble sympathy, would not hear of. He consented, however, with great reluctance, to the attempt of Huxley and Lubbock, and other friends, to increase artificially the list of subscribers by inducing people to take the work just in order to help support it. But after several months the sudden death of Mr. Spencer's father added something to his means of support, and he thereupon withdrew his consent to this arrangement, and determined to go on publishing as before, and bearing the loss.

But, as soon as the first evil tidings reached America, Mr. Youmans made up his mind that $\$ 5500$ niust be forthwith raised by subscription, in order to make good the loss already incurred. It is delightful to remember the vigor with which he took hold of this work. The sum of $\$ 7000$ was raised and invested in American securities in $\mathrm{Mr}$. Spencer's name. If he did not see fit to accept these securities, they would go without an owner. 'The best Waltham watch that could be procured was presented to Mr. Spencer by his American friends; a letter, worded with rare delicacy and tact, was written by the late Robert Vinturı; and Mr. Youmans sailed for England to convey the letter and the watch to Mr. Spencer. It was a charming scene on a summer day in an English garden when the great philosopher was apprised of what had been done. It was so skillfully managed that he could not refuse the tribute without seeming churlish. He therefore accepted it, and applied it to extending his researches in descriptive sociology.

Of the many risits which Mr. Youmans made to England, now and then extending them to the Continent, one of the most important was in 1871, for the purpose of establishing 
the Interuational Scientific Series. This was a favorite scheme of Mr. Yommans. He realized that popular scientific books, arlapted to the gencral realer, are apt to be written by third-rate men who do not well understand their subject; they are apt to be chy or superficial or both. No one can write so good a popular book as the master of a sulject, if he only has a fair gift of expressing himself and keeps in mind the public for which he is writing. The master knows what to tell and what to omit, and can thus tell much in a short compass and still make it interesting; moreover, he avoids the inaccuracies which are sure to occur in second-hand work. Masters of subjects are apt, howcver, to be too much ocenpied with original research to write popular books. It was Mr. Youman's plan to induce the leading men of science in Enrope and Anerica to contribute small volumes on their special subjects to a series to be published simultanconsly in several countries and languages. Furthermore, by special contract with publishing honses of high reputation, the author was to receive the ordinary royalty on every copy of his book sold in every onc of the countries in question, thus anticipating international copyright upon a very wide scale, and giving the anthor a much more adequate compensation for his labor. 'To put this scheme into operation was a task of great difficulty, so many conflicting interests had to be considered. Mr. Youmans brilliant success is attested by that noble series of more than fifty volumes, on all sorts of seientific subjects, written by men of ral eminence, and published in England, France. Italy, Germany, and Russia, as well as in the United States.

A word is all that ran be spared for other parts of our friend's work, which deserve many words and those carcfully considered. His book on "Household sience" is not the nsual collection of scrappy comment, recipe, and apothegm, but a valuable scientific treatise on lieat, light, air, and food in their relations to every-day life. In his "Correlation of Physical Forces" he brings together the epoeh-making essays of the men who have successively established that dortrine, introducing them with an essay of his own in which its history and its philosophieal implications are set forth in a masterly mamer. In his book on the ". 'ulture demanded by Modern Life" we have a similar collection of essays witl a similar excellent 
original discussion, showing the need for wider and later training in science, and protesting against the excess of time and energy that is spent in classical education where it is merely the following of an old tradition.

As a crown to all this useful work Mr. Youmans established, in 1872, The Populur Science Monthly, which has unquestionably been of ligh educational value to the general public. It was not the aim of this magazine to give an account of every theory expounded, every fact observed, every discovery made from year to year, whether significant or insignificant. The mind of the people is not educated by dumping a great, unshapely mass of facts into it. It needs to be stimulated rather than cramined. Education in science should lead one to think for one's self. The scientific magazine, therefore, should present articles from all quarters that deal with the essential conceptions of science or discuss problems of real theoretical or practical interest, no matter whether every particular asteroid or the last new species of barnacle receives full attention or not. The Popular Science Monthly has now been with us eighteen years; its character has always been of the highest, and it must have exerted an excellent influence not only as a diffuser of valuable knowledge, but in training its readers to scientific habits of thought in so far as mere reading can contribute to such a result.

In concluding our survey of this useful and noble life, what impresses us most, I think, is the broad, democratic spirit and the absolute unselfishness which it reveals at every moment and in every act. To Edward Youmans the imperative need for educating the great mass of the people so as to use their mental powers to the best advantage came home as a living, ever-present fact. He saw all that it, meant and means in the raising of mankind to a higher level of thought and action than that upon which they now live. To this end he consecrated himself with unalloyed devotion; and we who moum his loss look back upon his noble career with a sense of victory, knowing how the good that such a man does lives after him and can never die. 


\section{ABSTRACT OF THE DISCUSSION.}

\section{Mr. Daxinl, Gireyleaf Thompsox :-}

It is my purpose only to supplement the address of the speaker of the evening by a few desultory remarks, founded partly upon personal acquaintance and partly upon facts given to me by members of Prof. Youmans' own family and by friends. Prof. Youmans was a well-known figure in our New York community, a nember of lealing clubs, a social factor and an integral part of the intellectual life of the city. He was an excellent conversationalist, and when he joined a group he speedily made limself heard and attracted attention by his emplatic manner, his incisive remarks and his droll, unique expressions. One was quite likely to hear something about Evolution from him, and if anybody was rish enougl to dwell upon the importance of the Classics in edneation he would be pretty sure to draw in his head like a turtle's into its shell after he had given Prof. Youmans a threeminutes' cliance. He was full of aneclote, and had a store of reminiscences of his acpuaintance with many eminent men of England and America, which, if they had been preserved, would have been of great interest and value.

The qualities that made him so good a conversationalist contributed to secure his success as a lecturer. He pleased his andiences, but did not always suit the fancy of the local clererymen, who in some places not only assumed to represent the Almighty in directing conduct, but also claimed to have delegated to them Ifis omniscient infallibility. In one case this earnest diseiple of science was loromgle into competitiom with a series of revival meetings. This was at Freeport, Ill., in January, 1868. I shall venture to read his own description of what occurred from a letter here, which the kindness of Mrs. Yommans permits me to use :

"There was a 'Protracted Meeting' in full blast in every chureh in town exeept the Episcopalian, and a creneral feeling of pions Christian rage at my appearance. The l'leshyterian clereryman alone, a cold-blooled but lighly intellectnal man, who had boen driven into the spiritual movement sheerly against his will. by pure competition, appointed his religious meetings at half-past six b elock, to be mit at eiglit. so as to attend the leeture. My first loeture, therefore, was malle to abont a humbed stragoleris from prayer-metings. I. of comrse, assmmed the anfignity of the wath in that lecture, and that was enough. It got abroal the next day and reverleciated throngh the town that I was an open and avowed infidel. 'Throe was a dence of a time. 1 was called upon by individuals. and offensively ratorhised as to what 1 believeri, and guestions were written by elerermen and sent in to be pomptly answereel. 'The next night it was harlly a tritle better. 'The gentlemen who had the thing in charge. sering how things were going. and determined not to be bafthed, crowded the 
house the last two miglits with the pupils of the schools, let in free - a capital arrangement, as I would always much rather talk to them than to old folks. I gave them a piece of my mind (in a dignified way), at the close of the last lecture, and it was a successful hit. I turncd the tables, and showed that it was those who betrayed their skepticism as to the safe effects of demonstrated truth who were the real infidels-'infidels,' unfaithful. At the close of the lecture a certain Mr. Mitchell, member of the Presbyterian church and president of the bank, a splendid man, the perfect image of Uncle Good, came up to the platform and collected the committee together. He then said: 'I will myself stand the expense of an immediate repetition of this course free, if Prof. Youmans will stay and deliver it.' They lost $\$ 300$ on the course. The price was $\$ 100$ for my series, but they quietly, without explanation, handed me $\$: 50-\$ 90$ apiece - which, of course, I accepted without objection."

The fact that Prof. Youmans was a good lecturer is attested by the circumstance that he conld speak two hours without wearying the audience. I will read from one more letter, which records the speaker's own estimate that he had reached the summit of his lecturing career. He writes from Fairibault:

"This is a little place of a thousand people, but they gave me a fine house last night, and $I$ in turn gave them (pardon me) a fine lecture, 'The Rise and Inflnence of Modern Science.' I happened to be in the best of trim, and they happened to have the most agreeable place to speak in. (I tumbled off the platform twice, and we all had the jolliest kind of a timc.) I spoke two hours, and a committee of gentlemen, among whom was the Chief Justice of this State and the Attorney-General, called on me this morning with enthusiastic assurances that the audience would have gladly staid two hours longer. It was the best and most telling lecture I ever gave in my life upon any subject. They gave me $\$ 100$, witl a profusion of thanks, and urged me very hard to stop and lecture again on my way back, which is now impossible. I am all right here for the future, at $\$ 100$ a night - the top of my lecturing ambition."

Prof. Youmans was a broadly educated man. It would be a mistake to suppose that his advocacy of seientific studies as against classical in the schools arose from deficiency in classical education. On the contrary, his sister tells us, in her biographical sketch in the Popular Science Monthly, how with him classical studies preceded his scientific training, and inclined his mind first toward language. After a classical education he became satisfied that more science was needed. Indecl, it was Mr. Spencer"s treatise on "Education" which first influenced his mind toward spenecrian philosophy. He had asked himself the question of that treatise, "What knowledge is of most worth?" And there he found his answer; in that answer he constructed his own work as an educator-knowledge, scientific knowledge, first in all things.

But though first a scientist, Prof. Youmans was not forgetful of other branches of literature than the scientific. He was fond of poetry. IIe was not a novel-reader, nor did he especially 
enjoy pulpit sermons. Anything making for practical value was precions in his eyes; the useless he endeavored to eliminate. l'rof. Foumans was too much of an enthusiast to become a very systematic worker. He was irregular in his labors, working all night if need be, not thinking of economy of resources. He was not eareful to take sufficient exercise, being rather indolent as regards physical exertion. Tet he sometimes chopped wood, like Mr. Gladstone; but if anyloody had asked lim to saw it I think lie would have said, "Go to!" He liked good living, but was not a drinking-man, save that he was very intemperate with ice-water. He commended himself to his wife when he married her, at his age of forty, by the fact that he never used tobacco; but he fell from this grace afterward, and became a smoker; I suppose at first only when away from her, because in his absence from her society lie felt the evil which he had not known before, and endeavored to sootle his mind as best lie conld.

Not to weary you further, if I were to characterize Prof. Youmans" work it would be to emphasize his service as an edueator. This was the purpose of his lecturing, his works, his establishment of The Popular Science Monthly. IJe wanted fir'st to know the truth, and then, he believed, if the trutl could only be applied it would make men free. So he sought to popnlarize knowledge and make it assimilable to men's minds. In this I think fie achieved a very marked success, and made a very decided impression upon American intellectual life. His own books lad this effect, and the establishment and continuance of The Popular Science Wonthly have contributed powerfully to the same result. The work of him who seizes upon, ntilizes, adapts and extends the discovery is scarcely, if at all, less important than that of the original discoverer. If it be an object to grive a force and eftieiency to truth that slaall insure its permanent hold upon the human mind, then lonor is due to him who makes it forceful. However far seientific progress has gone in America, to whatever extent empirical ionorance has been superseded, in whatever degree superstitions liave lost their force - the life-labors of Prof. Foumans must be counterl as a potent factor in the cliange. He satw his mission and he fulfilled it woll. He never despised art, but he believerl in seience as of first importance, and whether seience or art be considered, le insisted on its practical interests. Ile believed that
Not to know at large of things remote
From ns, obsenre and subtle, lout to know
'llat whiell before us lies in daily life,
Is the prine wisdom: what is more is fume,
An emptiness or lond impertinence,
Ancl remelers us in things thit most concern
Enpratised. unplepared and still to seek.

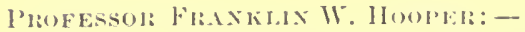

I rise to arknowleolge the debt of gratitude which I pegsonally owe to the late Prof. Youmins. More thin twenty years ago, when ocenpying the position of janitor in a Wesforn (iollege- a position which gave me alecess to the (ollewe library-I came aleross a look the reading of which marked an era in my life. The title of the hook wats. "The rulture benturled by Modern Life," 
and its author or collaborator was Mr. Youmans. I read it eagerly, especially the cliapter wlich was written by Mr. Youmans, and it strongly influenced my mind in the direction of scientific studies. Either on the advertising pages of the book, or elsewhere, about the same time, I saw a notice of Hcrbert Spencer's book on "Education" - a book which it is hardly too much to say has influenced, more than any other of the present century, the character of our educational methods.

In subsequent years, after I came to Brooklyn, I frequently had occasion to meet Prof. Youmans, and consult with him about the text-books in use in our colleges and schools. The impression produced by personal acquaintance strengthened the judgment - which I had formed from reading his books. His influence more than any other aroused in my mind broad ideas of the Universe, and started me out as an evolutionist.

The leading characteristic in Prof. Youmans' character, as it seems to me, was his hatred of pretense and shams. I remember calling on him once to consult him in regard to the compilation of a text-book on zoology. He indignantly, and in the strongest language, denounced the books then in use in the schools, declaring that it was impossible for children to be properly educated by the use of such defective tools.

Prof. Toumans, in some of the cliaracteristics of his mind and character, strongly resembled the late Horace Greelcy. Both of these men possessed admirable virtues, but both also had some noticeable defects. The defect in Prof. Youmans' cliaracter, as it appears to me, was that his mind was not broad enough to include religion in his philosophy. He was a materialist and an agnostic; whereas, in my juclgment, the study of science and of Evolution slould empliasize the fact that all Nature, the Universe itself, and the mind of man, arc but sliadows and symbols of an immanent and self-revcaling God.

\section{Mr. Garente P. Shrivis:-}

I also desire to recognize my great indebtedness to Prof. Youmans for his books and his popular lectures on scicntific subjects, which awakcned in my mind an interest in the plyysical sciences that lias never since weakened or grown dim. The most striking characteristic of his character, as it seems to me, was his wonderful faculty for simplifying the abstruse problems of scientific research, making tliem clear and plain to the most uninstructed inind, and hy the charm of his manner awakening the interest and arousing the cntlmsiasm of his auditors and readers. I cannot believe that this faculty of popularizing science is iu trutl so rare as it appears to be-though we must admit that few eminent scientific investigators have possessed it in any great degrec. In that direction must lic our progress in the future; for in order that the beneficent influence of seience may extend its sway over all the earth, the people must be instructed.

\section{Mr. George Iles:-}

While Prof. Youmans natural powers of expression were remarkable even in youth, he took pains to improve them by umemitting cultivation. Ilc well knew how much the cffectiveness of a thought depends upon clear and telliner statement, and lie drilled himself carefully in the art of making difficult things 
plain. His task of course began in reaching thoroughly clear views as to the themes of lis sturly. For this complete grasp of ideas, and facility in communicating them, lie was inclebted in no small measure to the circumstances of his early years in New York. Unfortunte as those years were in many ways they were not without their compensations. When he left the eye-infirmary, in lis nineteentl year, he went to hoard at a Mrs. Cook's, whose house was at the corner of Pearl and Hague streets. Most of lis fellow-boarders were printers, and their friemlship was soon enlisted by his intelligence and vivacity. As opportumity offered they would read to lim, and as his clooice lay among books of science lie had abundant food for reflection when left by limself. Throughout life it was his habit and pleasure to talk over witl his friends whatever interested lim, so that in those early days lie spent a good many hours explaining to the young printers about him something of the facts and principles he had been digesting; thus all uncousciously reeciving a capital training for lis future work as a scientific expositor. There can be no doult that, to a man of his impulsive temperament, blindness and solitude compelled a deptli of reflection which happier circumstances would have denied. And in teaching lessons so painfully learned to otliers nuch less informed tlıan liimself lie took his first steps in the mastery of an art in which he afterward excelled, - the difficult art of interesting every-day people in science and making its trutlss simple and clear. As a writer he was his own severest critic in this regard. Articles widely quoted for their apparent spontaneity, articles which miglit seize the pith of a controversy, or wittily prick some bubble of fallacy, were the products of liard labor. He often re-wrote parts of a manuscript a dozen times, and only surrendered it to the printer when the printer would wait no longer. His introdnetion to "The Culture Demanded ly Modern Life," perlaps lis best picce of writing, was prmed, revised and recast so much that at last searcely a sentence of the original draft remaned. When he became editor, the art lie hat so firithfully practised lie commended to others. Here is a specimen letter to a young contributor :-

\section{"My Dear sir:}

"New Yokк, May 17th, 1siti.

"Your article appears in the Jume number. As I stated to you at first, it is excellent, and will be read by many with alpreciation. lint when I looked over the proof it occurred to me that it had some faults of presentation, perlatps due to your lack of practice in putting abstanct thiugs to commom realers. Onr seientific: readers, of (oulse, will have no trouble in understanding you, and will enjoy your argument, but eiglit-tentlis of the patrons of the Monthly will get hut a partial eompreliension of it. Of course so abstract a topic as "Tle Mathematies of Evolution" may lu. expected to refuire some intellectmal foree to grasp it, and $i$ am well eontent witl your main exposition. still, I think soms serions and systematic attention on your part to the art and artifice of clear and familiar statement, which will give you access to orlinary minds, is very important. I lo not mean for a moment that your writiug is obseme, but only that your composition would be improved if you hal in your mind's eye a person of 
common intelligence and quite unacquainted with the subject you sought to explain. You would then stop and think by what handling or illustration the view, so clear to you, could be brought into his apprehension. I am speaking from the Popular Science stand point about a deficiency which marks many of our scientific writers; generally, the deeper and more thorough their science the poorer is their power of exposition. Excuse me for throwing out these suggestions, but with your unusual ability of statement and command of appropriate language, if you could study the art of getting at the mind of the multitude, as a dramatist has to study it in elaborating his points with reference to their effect upon theatre-goers, you could do very important and increasingly needed work in the field of popular and scientific education. . . . Ever and truly yours, "Mr. George Iles, Montreal."

E. L. Youmans.

\section{Dr. D. H. Cochrax :-}

Dr. Cocliran, President of the Brooklyn Polyteclmic Institute, wrote as follows, in response to an invitation to speak :

"E. L. Youmans was my very dear friend. There are very few men whom I more respected and loved, and I exceedingly regret that I am unable to hear Mr. Fiske's paper and the tributes that will be paid to his memory and worth."

\section{Rev. Johy W. ChadwiCk:-}

I will not go into the pulpit, for I think it must enjoy the fumigation which it lias received this evening at the hands of laymen. I knew Prof. Youmans rather as a free-trader than as an evolutionist - probably because I usually met him at the house of our friend Richard IIenry Manning, who was a good evolutionist but was very far gone as a protectionist, and needed light particularly on that subject. It was a characteristic of Mr. Youmans to give liglit where it was needed, and therefore he talked free-trade to Mr. Manning.

I am very glad that it has been our good fortune to have Mr. Fiske in this place, to deliver this lecture on Prof. Youmans. And I wish to express my own indcbtedness to Mr. Fiske - who in his "Cosmic Plilosophy" has made what is to my mind a clearer statement of the principles of Mr. Spencer's philosophy than Mr. Spencer has made in his own books. All who have any acquaintance with my sermons know that I have made great use of MIr. Fiske's works, by way of illustration and otherwise, for many years past. 'There are few writers whose thought has been so fruitful to my mind.

\section{Mr. Fiske:-}

I am greatly moved by the words of Mr. Chadwick, and glad to know that my work has proved suggestive to his own thought.

I notice but one point in the remarks made here this evening that appears to require correction. I cannot think that the term "materialist" can properly be applied to Mr. Yonmans. It is true that neither he nor Mr. Spencer have formulated a distinct set of views on theology. They were botls kept so busy in estab- 
lishing the principles of Evolution, in their general seientifie and philosophical bearings, that they had no time to apply them to theology; that is a task for the next generation - and I liave no doubt that in due time it will be suceessfully aceomplished.

\section{Mr. HeRBert SPExcer:-}

The following letter from Mr. Speneer was received too late to be read at this meeting, but was read at a subsequent meeting.

\section{Dear Mr. Skilton:-}

64 Avenue Road, Regent's Park, Loxnox, N. W., Mareh 1:3, 1890.

I received your telegram last night, and from the wording conclude that you wish some letter from me abont Youmans whieh Fiske may read in his leeture on the 23d. I an very glad to respond to the request, and I eannot do this better tham by giving you the following copy of a passage in my Autobiograpliy coneerning lim:

"The relation thus initiated was extremely fortunate; for I'rof. Edward L. Youmans was, of all Amerieans I have known or heard of the one most able and most willing to help me. Alike intellectually and morally, he had in the fighest degrees the traits condueive to suceess in diffusing the doctrines he espoused; and from that time to this he las devoted his life mainly to spreading thronghont the United States the doetrine of Evolntion. His love of wide generalizations had been shown years before in lectures on such topies as the correlation of the physical forces; and fom those who heard him I have gathered that, aided ly his unusual powers of exposition, the enthusiasin which contemplation of the larger trutlis of seience prodneed in lim, was in a remarkable degree communicated to his hearers. Sncl larger truths I have on many occasions observed are those whieh he quickly seizes - ever passing at once through oletails to lay hold of essentials; and, having laid loble of them, he elearly sets them forth afresh in his own way with added illustrations. Bnt it is morally even more than intellectually that he has proved himself a true missionary of advinced idras. Extremoly encretie-so encrgetic that no one las been able to eheck his over-activity he has rxpended all his powers in advancing what he holds to he the truth; and not only his powers but lis means. It has proved imposilhle fo prevent him from injuring himself in health by his exortions: and it las proved impussible to make him pay due reagred to his personal interests. So that towards the close of life lo finds limself wrorked in body and imporerished in estate by thirty yeirs of devotion to high enels. Among professad worshipers of homanity, who toald that hmman welfare shonld be the dominamt aim. I have not yet hearl of one whose saerifices (on helulf of hmmanity will hear eomparison witl those of $11 \mathrm{y}$ triend."

'llowerl the volmme containing this passage will not loe published until after my reath, I im very willing that this tribute of admination to my late friend should le made publie mow.

I am, fatithully yours,

IIEREAT SPEXTER. 
INDEX 



\section{N D E X.}

ABBEVILLE, discoveries at, 46.

Abbot, Dr. Francis Ellingwood, on agnosticism, 8 ; on Christianity, 260

Abolitionists, the, 269-270, 315, 371.

A buse of legislative functions, $327,331-332$.

Adlams, Professor, on Rousseau's theory of government, 99-100.

Adler, Professor Felix, liis ethical religion, 272 .

Adoption, 118-119.

Agassiz, Professor Louis, his theory of creation, 355; opposed to that of Professor Gray, 362; on Vestiges of Creation, 371.

Aguosticism, 9-16, 29-42.

Alger, Rev. William R., his early interest in evolution, 380 .

Alims-giving, 270-271.

Altruism, dependent on social differentiation, 226; dangers of excessive, 327-328.

America, primitive man in, 63-64.

American evolutionists, criticized by A. R. Wallace, 4 .

Amcrican slavery, 269, 270 .

Amiens, 222 .

Anceba, 195.

Anarchism, its theory of government, 105; opposed to the wages system, 218; partial wisdom of its theory, 274 ; its metlod defined, $278-279$; its scientific aspect, 303; Hugh 0 . l'entecost on, 303-318; distinguished from individualism, 304; its methols peaceful, 304-305; opposed to monopolism, 307-309; its economie principles, 308 ; opposed to land-ownership, 308-309; opposed to interest-taking, 309-310; opposed to profit-taking, 310-311; opposed to government by physical force, 312-313; opposed to voting, 313-314; in favor of free-trade, 314 ; opposed to state-socialism, 317 ; its relation to evolution, 318 ; as lelated to the scientific method, 327.

Ancestor-worship, among pre-historic races, 64, 65; as related to the evolution of law, 118 .

Ancient City, the, $25 \%$.

Andrea Ferrara, 173.

Andrews, Stephen Pearl, his Science of Society, 310.

Anti(puity of man, 46,65 .

Antoninus, Marcus Aurelius, on human brotherhood, 99.

Ape, anthropoid, man's relation to, 58 .

A ppleton, 1). \& Company, 378, 379.

A rloreal life of unan's ancestors, 199.

A ristotle, on govermment ly the governed, 99 ; science lhegan in his age, 236 ; on labor and slavery, 258; on money, 268; his exact method, 323.

A rins and armor, evolution of, 159-187.

A rmold, Mattlew, his definition of morality, 18.

A rrival of man in Europe, 54 .

Artificial exercise, why necessary, 194.

Art-spirit, its relation to social progress, $335-336$.

Aryans, their emigration to Europe, 61 ; marriage customs among, $69,83$.

A ustralian marriage customs, $72,76-77$.

BAcos, Lond, his New Atlantis, 284; his advocacy of an exact plilosophy, 323; his philosophy studied by Jolm Fiske, $3 \overline{7}$.

Bacteria, as causes of disease, $1+i-148,151$.

Bakunin, 278 .

Ballot-reform, necessity of, 332 .

Beecher, Rev. Hcnry Ward, his interest in evolution, 379 .

Bellamy, Edward, his social theory, 105; his theory compared with the wages system, 232; a form of state-socialisin, 263; his theory criticized by Willian P'otts, 281-285; its advocacy of equality of earnings, 283, 287; state-socialism in America, 317.

Berkeley, Bishop, his philosophy, 29.

Bible, its teachings in regard to disease, 134; its authority, 136; its account of creation, 205,356 ; on wealth, 261-263, $264,268$.

Biology, its relation to sociology, $22-23$.

Boston, Mass., land-values in, 2ije-293. 
Botany, its relation to medical sclence, 151 ; Asa (iray's relation to, 339-362; Laton's work on, 340, 356-360; (iray's text-books on, 341-314; value of his contrilutions to, $344-345,352-356,361$.

Bouvier, on inventions, 204.

Brahmins, tleir marriage customs, $73,80,83$.

Bronze age, 53.

Brook Farmi, 279.

Brougham, Lord Henry, on education, 24.

lirown, Robert, 34.

Bryce, Professor, on the evolution of the American Republic, 96 ; on the government of cities in the United States, 102.

liudd, Thomas, his advocacy of manual training, 240.

liullha, his method contrasted with that of Moliamined, 329.

(.ABFT, his Toyage to Icaria, 284.

Calvin, John, his advocacy of education, 237 ; his relation to the common-scluool system, 240 ; his paternalism, 268 ; his social regulations, 273 .

Cambyses, 73 .

Campanella, lis City of the Sun, 284.

Capital and labor, the relations of, $224-232,285,286,287$.

Capital punislinent, 316.

Carey, Henry C., on farm values, 292.

Carlyle, Thomas, on cliaracter in rulers, 97; on education, 251.

Camegie, Andrew, on improvements in agriculture, 97.

Catlin, on Indian marriage customs, 78 .

Cave-men, 51.

Cluadwick, Rev. John T., on the theological method in social reform, 257-274; D. ( $i$. Thompson on, 321 ; his remarks on E. L. Yonmans, 389; on the writings of Joln Fiske, 38 ! .

('baming, Rev. William Ilenry, his acquaintance with E. L. Youmans, 371.

('liarity, 270-273.

tharleinagne, 220 .

('llemistry, as related to medical science, 145 ; to sanitation, 146-150; Prof. Youmans" study of, 372; lis diagrams, 373 ; lis text-look on, 373.

Christianity, as related to agnosticism, $17-18,21$; its idea of narriage, $84-86$; a foe to niedical progress, $134,136,13 \overline{7}, 138$; its fundanental law, 186 ; its relation to elucation, 236,238 ; its two pluses on trial, 242; its social ideals, 261; its teaching concerning poverty and wealth, 261 ; its relation to the scientifie method, 326 .

('hinese, marriage among. 83.

Ciccro, his definition of leligrion, 18 ; his remark aloout Socrates, 236.

('ities, the govermment of. 101 ; the growth of, $2220-221$; when first chartered, 221.

City government, its failure, $1(11$.

Civil liluerty and the doctrine of evolution, 24.

('ivil-service 1'eform, 285, 33'2.

Clans, tluir place in social evolution, 94.

Clark, Joln, lis early interest in evolution, 380.

f'lassical studies, their value in colueation, 246.

loblue, Miss Frances I'ower, on theirm, 345-; 46.

(oclurin, Ior. I). II. on E. L. Youmans, $3 \times 9$.

Codification, 124-12ti.

ro-education, 24x-25).

(oleridge, flicf Juntice, on C'luristianity and the Statc, 112.

('omenius, his relation to modern educotional metlosk, 237 -238.

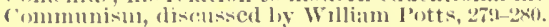

('ompertion, its allogral injustice, 2xis; freedom in competition advocated ly anarchist<, 312,314 .

Composit:?, $344,355,361$.

('ompulsoryerlucation, 244.

Comte, $\lambda$ ugruste, lis contribution to social science, 22 ; his pliblosoply characterized liv Joln Finke, $37 \%-37 x$.

fonfucius, his influenceon education, 23t;

Cook, I'rof. lieorere $11 ., 3$ औit.

fo-operation, 247, 313 .

(ope, Ior. Edward D), criticized ly A. R. Wallace, 4; on the descent of man, 5) mote.

('op'ruic'11s, 2\%, 339\%,

('oral reefs, I )arwin's eonclusions concerning eonfirmed, 5 note.

Corrolation of fliymieal forcex, $3 \times 2$.

foulanges, M. Fustel de, on the oripin of socicty, 25.

(rannoge-luilelers, 59 . 
Creation, Bible account of, 205 .

Credit system, 288.

Crime, can it be cured ly legislation? 181-185; its relation to education, 24 ; the effect of poverty, $30 \%$.

Critique of l'ure Rèason, 9.

Croll, 1'rof., on causes of glacial action, 55-56; on the duration of glacial periods, 56.

Culture demanded by Modern Life, 382, 387, 389.

DARWIx, CHARLEs RoBfrt, Wallace's resemblance to, 3; Wallace's judgment of, 3; lis theory of coral reefs contirmed, 5 note; his Descent of Man, 66 ; his law in the evolution of protective armor, 161; on the use of tools liy animals, 198; on the character of primitive man, 199; the truth of his doctrine, 253; his era, 300; his influence on civilization, 339 ; his views about design in creation, 345; his friendslip with Asa Gray, 345, 361.

Darwin, George 11 ., on consanguineous marriages, 85 .

Darwiniana, $346,348$.

Darwinism, Wallace's book on, 3 .

Dawkins, Boyd, on Early Man in Britain, 49.

De Candolle, 341,345 .

1) Foe, Daniel, on almsgiving, 270.

De Lolme, on the English constitution, 97 .

De Mille, James, his Story of a Strange Manuscript, 328.

Denison, Edward, on charity, 271.

Descartes, $3 \pi \pi$.

Descent of Man, 45, 66 .

Dharna, 128-129.

Diderot, 45.

Dinichthys, the armor of, $162,163,164,179$.

Dinocere, 168.

Dinosaur, 163.

Dinotherium, 168 .

Divine power in evolution, $345-346$.

1)olmens, $59,62,63$.

Dommisthorje, Wordsworth, on the true priuciples of legislation, 333 .

)raper, l'rof. John William, lis lectures on cliemistry, 372.

Drey, Sylvan, on agnostic religion, 21.

EAtox, 1'rof. A.mos, his works studied ly Asa Gray, 340, 357, 360; his contributions to botanical science described by James $A$. Skilton, 356-360.

Leeles, I)r. Robert $G$., on the Relativity of Knowledge, 2 ) -42 ; on the Evolution of Medical Science, 133-156; on Asa (iray, 360-361.

Edisom, Thomnas A., 300.

Education as a Factor in Civilization, 235-253.

Education, as related to civilization, 235; in Erypt, 235; of primitive man, 235; in l'ersia, dssyria, Babylon, (ireece and Rone, 236; its relation to crime, 243-24t, 307; to pauperism, 243-244; elueation in England, 243; in New York, 244 ; in (iermany, 244 ; the elective system, 245 ; education of women, $247-250$; anarchistic view of, 307,318 ; as related to the seientitic method, $334-336$; intluence of Spencer's work on, 387.

Education, Spencer's work on; how first pulblished in America, 378, 379; its influence on Prof. E. L. Ioumans, 385̃; on edlueational metloods in Ameriea, $3 \times 7$.

Eleatic philosophers, on Nature, 323.

Eliot, Hesident, on the university graduate, 245 .

Elliott, Ebenezer, lis detinition of the communist, 279.

Emersou, Railph Waldo, 45, 284, 300, 325 .

Entluusiasm, evils of undie', 281, 329 .

Eocenc epoch, no traces of man in, 47 .

Epaminondas, 247 .

Eipuisetum, $35 \%$.

Equity, legal status of, 119.

Erasnus, fis relation to edncation, 237.

Esquimaux, 56 .

Ethies, evolutionary doctrine of, $18,19,21,186$; relativity of, 41,42 ; of (hristianity, 273 .

Furope liefore man, 47-48,

Evidencies of man's antiquity, 50-55, 58 .

Evil, nature of, 19.

Evolution, the seope aut principles of its philosopley, 3-26; of marriage, 69-87; of the state, 91-108; of law, 111-130; of nedical science, 133-156; of 
arms and armor, 150-187; of the medinie arts, 191-214; of the wages system, 217-232; of elueation, 235-253; and social reform, 257-336; Asa (iray's contributions to, 3H-345, 330; Flward I. Youmans' eontriloutions to, $376-383$; I'rof. Joln Fiske on, $374,377,379,380$.

Evolution and Soeial Reform, the Theological Mothol, 25\%-274; the Soeialistie Method, 277-300; the Anarehistie Nethod, 303-318; the Seientitie Method, $321-3 * 36$.

Fxercise, artifieial, why reguired by man, 194.

FACTORY-svistey, its evolution, 222-230; its relation to wages, 230-231; to child-labor, $30 \%$.

Familistere, the, 281 .

Farragut, Aduiral, 180.

Ferrara, Anclrea, 173.

Fetishism, in medicine, 134, 140.

Feudal system, 220-223.

Fiction, in law, 118-119, 130; as related to religion, $25 \pi, 258$.

Fire, its inportanee in the meelanic arts, 201-202.

First Prineiples, Speneer's, $7-x$.

Fiske, John, his ('osmic: l'hilosophy, 6-7; on mind and matter, 15-16; on Europe before man, 47-4x; on man's arrival in Europe, 55; on theopsehology of mechanies, 191 ; om infancy as relatel to mental evolution, 199; on

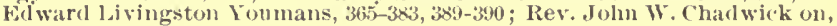
389.

Fison, Rev. Iorimer, on marriage in Australia, 76 .

Flenings, 2tid.

Flint inplements, found helow miocene deposits, 49; in uliocene deposits, 50 ; rough and polished, 5t; Armand de Vire's diseoveries, 57 note; age of, 59.

Flower, l'rofesior, on the arbitrary limitations of sense-pereeption, 13 note.

Food, of primitive man, 57 ; as related to poisons, 141 ; necessity of thorough eooking, 14k; eontagion in, 144,149 ; of plants and animals, $167-171$; as related to organization, $1 x^{2}$; it. mnlimited varjety, 201 ; the earliest eookery, $2(1) 2$.

Foster, on the aetion of llrugs, 143 .

Fourier, his communistic ideas (x)plained by fromlund, 277; his phalinsteries, 279.

Fremeli revolutiom, 20ii.

Froelel, his relation to modern educational methods, 239; to manual training, $2+1$.

(;A I.Ex, his contributions to medieal soiencr. 13f; sulsequent subsrvieney to, 137; comflict with his disciples, 1 to) : the truth resulting therefrom, 141 ; his account of the first anatmuists, 144; progress since his time, 150.

Galileo, 24, 339.

falton, Francis, his law of regression towarl medionity, 4 ; on celilaey, 261.

farrison, William ldoyl, his religions character, 270; his anarchistic views, 315.

(iaulry, M., on carvol implements, 49.

(ienesis and s.ience, Asil riray an, 35xi,

Geologrical periols, $47-48$.

fieorge, Henry, lis opposition to land-ownership, 28; ; his theory explained and eritieized by William I'otts, 287-24)4; impracticalility of his theory, 293-24.4.

filarial (eporll, 50; as related to primitive man, 51.

Gilarstone, lion. William $1 \%$, on recent increase in wealth, 24.

filyptolon, jts lony armor, 163 ; compared with militant soeieties, 178-182.

fivernment, its evolution, 92-94; its earliest form, 94; its momarehical form, 95; gralual modifications of, 95, :M; clemocratic and representative tenden-

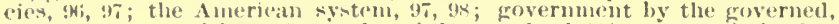
(18-100); of large ('jtion, 10)1, 1022; low it has evolved, 104; antagomistin theories, 105; anschion opposed to government by force, 304, 312, 313; its functions should le limited, $274,317,325-3266$.

Gray, l'rof. Axa, 244 ; his life and work, 33!-342; his advoeacy of 1 )irwinism, ;3.); lis carly years, 340 ; his conne(tion with 1)r. Torroy, 30)-343; his professorship) at llarvard, 342; his works an hotany, 34-345; his personal friendships, 343; lis fontributions to the doctrine of evolution, 344-345;

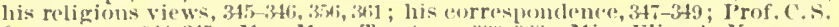

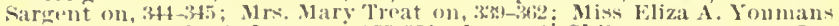

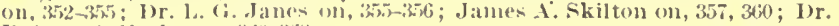

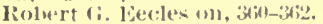


Grecley, Horace, his acquaintance with E. L. Youmans, 371 ; compared with Prof. Youluans, $38 \pi$.

freenbackers, 218 .

Green, John Richard, on cliarity, 271.

(iregory the Great, his socialisiu, 265.

Gronlund, Laurence, on Fourierism, 277; his benevolent intent, 281.

G roup-marriage, 76,77 .

G rowth of the Marriage Relation, 69-87.

Giunton, Professor George, on the evolution of the wages system, 217-232; his advocacy of reduced hours of labor, 331 .

Gurney, Professor, his early interest in evolution, 380 .

HADROSAUR, 168.

Hahnemaun, his translation of the Materia Medica, 141-142; his theory criticized by Dr. Eccles, 142 ; defeuded by Dr. W. S. Searle, $1+2$ note; why credit is due him, 142 .

Hamilton, Sir Williain, his influence on Prof. Huxley, 9.

Hauds, how they were developed, 193.

Harvey, William, his discovery of the circulation of the blood, 145.

Heilprin, Irofessor Angelo, on coral reefs, 5 note.

Heredity, discussed by Weismann and Wallace, 4; as related to education, 252.

Herodotus, on lake-divellings among the Pæonians, 62.

Hippocrates, on early medical knowledge, 135.

Holmes, Dr. Oliver Wendell, on the American idea, 242.

Homeopatly, criticized by Dr. Lecles, 135-139, 142 ; defended by Dr. Searle, 142 note.

Hooker, Sir Joseph, his acquaintance with Asa Gray, 341 ; his eminence as a botanist, 341-342; his evolutionary views, 345 ; his portrait, with Asa Gray, 351 ; his opinion of Prof. Gray, 353; his estimate of Herbert Spencer, 353.

Hooper, I'rofessor Franklin W., on Ed ward L. Youmans, 386-32 7 .

Hoplology, 186.

Howard, Professor, on the New England township, 98.

Huguenots, their relation to modern industrialism, 266.

Hume, David, his influence on Prof. Huxley, 9; his philosophy, 29.

Huxley, Prof. Thmmas H., his suggestion of the word "Agnostic," 9; his alvocacy of women on boards of education, 248 ; his friendship with $\mathcal{k}$. L. Youmans, 379; his influence in promotiug the salc of Speucer's works, 381 .

Ifyndman, his state-socialism, 263.

\section{IBERIA NS, 61.}

Ielithyosaurus, $162,164,167$.

Idealism, its philosoplyy criticized, 14, 15; Berkeley's relation to, 29; explained by Dr. Eceles, 30 et ser.: regarded as a theory, 37.

Illeuess, statutes against, 229 , and note.

Iguanodon, $162,164,168$.

Iles, Georgc, on Edward L. Youmans, 38i-3\$9.

Immortal life, 5 .

Intlividualism, 278, 297, 304, 324-325; Wordsworth Donnisthorpe on, 333.

Industrial evolution, 191-214, 220-22-, 260, 261, 330 .

Industrial training, 240-241.

Inland seas of the Pliocene, 50.

Insectivorous plants, $347-349$.

Intemperance, 288,307 .

Interest, its alleged injustice, 282, 285-286, 308-310.

Internationalism, 279,282 .

Inventions, genesis of, 203; definition of, 204; meauing of the word, 205, 206 ; evolution of, 208-210; of woluen, 210 , 211; influence on civilizatiou, 211-214; stimulated by improvement among the masses, 225 .

Ionic philosophers, on Yature, 323.

Iron age, 53 .

Isis, 323 .

JAYES, Dr. LEwIS F., 272 ; on the scope and principles of the evolution philosoplyy, 3-26; on the origiu of the marriage relation, 75 ; on Asa Gray, $355-3546$.

Japan, the flora of, $34,354,356$.

Japanese, their beiief about marriagc, 85 .

Jesus, his essential thought, 17 ; understood by the agnostic, 42 ; his anticipated return to earth as related to Cliristian views of marriage, 84 ; his exalted ethics and human nature, 92 ; his optimistic preachiug, 107 ; his doctrine 
of inward growth, 183; lis views on marriage, 261, 262, 263, 264; on poverty and wealth, 262 ; his commmnism, 263, 264; lis dishelief in the continuance of the existing social orter, 263 ; his hmmanity, 270 ; his sympathetic spirit, 271 ; his ideal life, 273 ; on right action, 334 .

Jesuits, their introduction of Cinchona, 139; their influence on edication, 238. Jews, their marriage customs, 84; their cole of laws, 123; their attitude toward 1nelical science, 134, 267; their enterprise and wealth, 260; their Old Testament ideals, 261, 262; their financial successes in Cliristian comntries, 266; their influence on modern intellectnal life, 267 ; their importance to European governments, 248.

Johnson, Rev. Sammel, his relations with llerbert Spencer and I'rof. Youmans, $3 \pi 7$.

Joly, Professor $\mathbf{X}$, on the discoveries of $\mathrm{M}$. Boncher de Perthes, $46,47$.

Julian, the Emperor, on Christian eliarity, 270.

Justiniall code, $123,126$.

KA xt, EMA 29.

Keller, Professor, on lake-dwellings, 60,61 .

Kelts, as related to the lake-d wellers, 61 ; to the dolmen-lunilders, 63.

Kepler, 2u.

Kimball, Rev. John C., on evolution of arms and armor, 159-18\%, 192.

Kinclergarten, 239,241 .

Kingsley, Canon, on education, 244 .

Kinship, among the Australians, 71 ; McLennan on, 72 ; among the Peruvians, 73; among the Iersians, 73 ; among the Tiletans, 79 ; as related to marriage by capture, $81,8 * 2$.

Kitchen-midlens, 59-60.

Knox, John, his introduction of pullic schools in Scotland, 240.

LABOR, of prmitive man, 62; man's adaptation for, 192-194, 197; inventions as related to, $212-214$; as related to slavery, $2191-220,2(69-270$ : to the wages system, 217-219, 220-232; mamal training as a preparation for, 240,241 ; as related to wealth, $291,307-308$.

Lake-dwellers, $60-62$.

Lamarck, 3-4, 359.

Land, the question of private ownership, 282, 287, 308, 309: the taxation of land-values, $287-2.4,23 \%$; relation of land-values to the value of improvements, 292-243; the freedom of vaeint land advoeated by anarihists, 308-309, 312, 313, 316; how far its restriction may bescientitically advocated, 331 .

Lassille, Ferdinand, his state-socialism, 279, 281; how he womld thrive under it, 284 .

Law, the evolution of, 111-130; how it berins, 113; custom as related to, 115; religion as related to, 116 ; fiction in, 118; equity jurisprublence, 119; leral codification. 123; anarchistic opposition to, 312 ; simplification of, necessary, $325,32 t, 327$.

Lecky, W. E. H., on heresy, 260 ; on the perscention of the Jews, $26 \pi$.

lemur, 49.

Leon, eity of, when eliartered, 221.

le kow, Miss Caroline 13., on education as a factor in eivilization, 235-253.

lewes, fieorge Henry, 37\%.

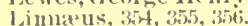

l.o:m, city of, whe'n chartered, $221-2: 22$.

lolliarcls, their eliterurise, 246 .

london, when cliartereol, 221.

bowell, James Russell, on the teacher, 252.

l.ulbork, Sir Jolım, on the arlutrary limitation of sense-perception, 13 note: on prinitive man, 53 ; on the causes of glacial astion, 5xi; on the loromze are, $65 ;$ on early superstitions, $1: 4$. 135; on min's first use of tools, $19 x$; on sejeititie progrexs as related to rivilization, 247 ; his influence in promoting tle sale of Herbert spencer's works, $3 \times 1$.

I. uno, 173.

luther, Martin. the progressive nature of his protest, 107; the legend of lis ink-stand, $23^{-}$; lois introluetion of free selools in formany, 240.

I.yell, sir ('larles, (m the age of pinitive man, int: his work on greology. 374.

IAcuarron's, its natural weapons, 10; ; eompared with the modern militant state, 17x.

Maine, sir llenry sumner, on judge-make law, 112; lis dlefinition of equity, 119 ; on codification, 126 ; on status and contract, li30. 
Magna Cliarta, 223.

Mallock, on agnosticism, 8.

Malthusianisn, 359 .

Man, carliest traces of, 46-51; cave-dwellers, 51; contemporary with extinct species, 54; his tirst food, 57; clothing, 57; his marriagre-customs, 69-87; in association, 92 et seq.; his political rights, $99-101$; his relation to the State, 106-108; his legal obligations, 111-130; his superstitions, 133-141; his struggle for existence, 173-187; his tools and work-slop, 191-214; his industrial plogress, 217-232; his intellectual growth, 235-253.

Mann, Horace, on free schools, 240 ; his treatise on arithmetic, 372.

Manning, Ricluard Henry, his acquaintance with Prof. Youmans, 389.

Ianual eqlucation, 240-242.

Marcus Aurelius, on the unity of man, 99.

Marriage, its origin and growtl, 69-87; in the animal kingdom, 70 ; among the Hebrews, 70; Australian customs, 71; definition of, 74 ; aflection its true foundation, 75; marriage by capture, $81-82$; Christian ideas about, $84-86$; Jesus' teaching about, 261, 263; Fdward Hellany on, 284.

Marx, Karl, his state-socialism, 263; discussed by William Potts, 279, 281, 281.

Materialisin, its philosopliy criticized, 12-15.

Iaxwell, Clerke, his theory of light, 13,38 .

MeLennan, Dr., his views on marriage, 72 ; on polyandry, 80 ; on marriage by capture, 81-82.

Mechanic Arts, evolution of, 191-214.

Nechanism of the human body, 19, 197.

Medical Science, evolution of, $133-156$; relation of religion to, $134-137$; an inductive seience, 154 ; its altruistic character, 156.

Medical superstitions, 138, 139.

Megalosaurus, $162,163,164,167$.

Megatherium, 163, 164, 166.

Melancthon, his relation to education, 237 .

Meta-gnosticism, 9.

Microlestes, 184.

Mill, John Stuart, on the test of good government, 98 ; on the unearned increment, 291.

Mohammed, his method of conquest compared with that of Buddha, 329 .

Mohammedans, their marriage customs, 83 ; their contributions to medical science, 137 ; to intellectual and scientific progress, 267.

Monandry, 70,83 .

Monarchy, 94, 95; as related to the wages system, 220-223.

Monasticism, 84, 194, 261, 265-266.

Iondino, 144 .

Money, its nature and uses, 309-310.

Monogany, 79, 83-84.

Monopoly, opposed by anarehism, 307-312.

Montaigne, lis relation to elucation, $23 \%$.

Moral elueation, necessity for, $243,334-33.5$.

More, Sir Thomas, his I topia, 42, 103-104, 231, 284.

Morgan, Hon. I. H., on Aryan marriage customs, 71 .

Morris, William, his state-socialism, 284.

Mosasaurus, 162, 163, 164.

Iound-builders, 6t-65.

Ingwump-spirit, the Zeit-geist of to-day, 329 .

Nalrs, their marriage customs, 80.

Nationalism, opposed to the wages system, 218; its probable results compared with those of the wages system, 232; discussed by William P'otts, 287-294; opposed by allarchism, 317; as related to the scientific method, 322, 327.

Natural selection, rlefended by A. R. Wallace, 3-5; Darwin's relation to, t6; its intlucuce on thought, 339; Darwin first announces it to Asa Gray, 361; its slow operation, 371 .

Nature, what we mean by, 323.

Neolithic age, 53.

New Ingland town-meetings, 98 .

Newton, Sir Isaac, his law of gravitation, 366 ; conpared with Herlyert Spencer, 380 .

New York Grocers' Assoriation, their anarchistic method, 306, 314-315.

Nichols, Starr 11., on agnosticisin, 8.

Nihilism, $27 \%, 278$.

Noyo1, when chartered, 221, 222.

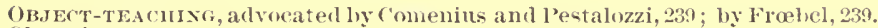

Olscssion, 134 . 
()portunisun, advocated by William l'otts, 297-298.

Urigin of Species, $3,56,35 \%, 377$.

()rthocerns, 162 .

Osiris, 323 .

P'A I.FOLITHIC AGE, 53 ,

I'aracelsus, 140.

liarker, Theodore, lis semuon on tle duties of milk-men, 273.

larty--ipirit, dangers of, $3201-330$.

l'ateint-oflice, its reeords illustrative of evolntion, 203.

l'atent riglits, 207.

l'atents, $2(x)-211$.

latriarehal system, as related to the evolution of government, 94 .

1'uul, his views of marriage, 84; on legalisul, 185; the value of lis truth, 25.3; his belief in the speedy destruction of the existing social order, 263 ; his commmnistic teachind 264 .

lentecost, Hugh $O$., on the anarehistie method of social reform, $303-318$.

l'tricles, 87 .

l'('rrin, Raymond s., his philosophy, 31.

perthes, Ibouclier de, his discoveries at Abbeville, 4t; how they were received, $52,53$.

l'estalozzi, his relation to education, 238-239.

l'harmacy, as related to medical seience, 145.

Philosophy, of evolution, its scope and principles, 3-26: eosinic philosophy, 7 ; ;ynthetic philosophy, 7 ; of the uneonditioned, 9 ; of agnostioism, 8-16; of naterialisin, criticized, 14-15; as related to ethies, 18-20; to sociology, 22-25; to the relativity of knowledge, $29-42$.

l'hysiology, of sensation, $32-333$; as related to medical seienee, 145.

l'ius IX., on tlue pulblic sehools, 242.

J'lints, protective armor of, $117-169$, 172 ; social (1ualities of, 170 .

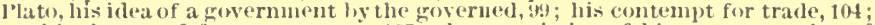
lis drean of future progres;, 197 ; characteristios of lis agr, 2:3; value of his trutl, 253; his ideal lienulilic, 104, 284; on the cure of the sonl, 334.

I'leistoeene epoch, evidenees of man's existenee in, 47 .

l'liocene epoch, evidenees of man's existenee in, 4.1 .

I"oietic:s, 2xis.

rolitics, its relation to industry, $283,330-331$; to anarchisin, 313,314 ; to grood govermme'11t, 331-3:33.

polyaudry, early evidences of, 57 ; its place in social evolution, 7!-80, 83.

polygyny, early evidences of, 57 ; its place in social evolntion, $76-7 !$.

loor-laws, 22:1.

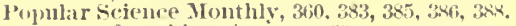

pottery, of prehistoric races, (io).

Potts, Willian, on the socialistic method, $27 \%-300$; his socialism endorsed by

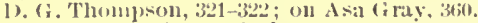

Poverty, evolution's word alout, 22; as related to the wares system, 224-2'33; primitive Christian views of, 2(i]-26t; as related to land-monopoly, 287, 288; recrarded as a sorial disease, $3316-30 x$.

l'reaching, as a motans of social reform, 272-273.

l'rimitive Cloristianity and elueation, $236-23 \%$.

Primitive man, 4i-likj.

l'rinciples of sociology, 159.

l'rofit-sharing, 297 .

l'rohibitory laws, 1 sis.

l'rotostantis 11 , as related to the marriare puestion, s.5; to medical evolntion, $13: 1$; to education, 23t;, 24t); to social reform, 2ti7-26i9.

l'sycluology, l'rinciples of, 195,$19 ;, 3 \pi 6,37 \%$.

l'terancolion, 163 .

l'terodact $y 1,10 i 3$.

l'ublie sclionls, their origrin, 240; manul training in, 240-241; I'ins IX. on, 242; secularization of necessary, 243 ; noral eflueation in, 213 ; alvoeated as an element in the scientific nethod of social reform, :334-335s.

lytlagoras, his relation to medic:al seienee, $1: 35$.

(2t A klus, their non-resistance principles, 261 ; their industrial enterprise, 267.

RABELAIS, $23 \%$.

lisces of $111+11,4 k$.

Raymond. Or. liositer W., his Ven-lamarekiom, 4.

Relativity of linowledget, 23)-42. 
Religion, its definition, 18 ; its relation to cvolution, 18-22; of primitive man, 58 ; its relation to law, 116; its relation to medical science, 133-137; to arms and armor, 183-184; its relation to the State, 257-258; to morality, 259 ; to social reform, 257-274; to charity, 271 ; to personal character, 273-274.

Rensselaer, Ste

Rent, the justice of, 289-293; its injustice alleged by anarchism, 308-309.

Representative government, its evolution, 95-101; its defects, 101-103; as related to education, 244 .

Republic, Plato's, 104, 284.

Ripley, George, his early interest in evolution, 379.

River-drift nien, 51 .

Roberts, George, his early interest in evolution, 380 .

Roman Catholicism, its views of the marriage-relation, 84,85 , 264; its relation to medical science, $136-140$; to education, $236,237,238,242$; to the public school system, 242; to wealth, $264,265,267$; to the scientific spirit, 265 ; to interest, 268; to labor, 269; to slavery, 270; its denunciation of Copernicus, 339 .

Romanes, George J., on the mechanic arts, 191; on animals as related to mechanisms, 196; on animal intelligence, 196-197; on the advancement of human intelligence, 213 .

SAMPSOX, Z. SIDNEY, on primitive man, $45-66$; on the age of the human race, 107.

Sanitary science, the growth of, 148-150.

Sargent, Professor Charles Sprague, on Asa Gray, 344-345, 349, 352.

Schopenhauer, on the improvement of the race, 87 .

Science, the foe of materialisin, 12, 14; on the nature of sense-perception, 13 , 30,31 ; on the eternity of matter, 15,16 note; of society, 22 ; its wonders, $38-40$; of arehæology, 45,60 ; its testimony to man's antiquity; 46 ; of government, 103; of medicine, 133-156; of lioplology, 186; of poieties, 206; of psychology, 239; in education, 244,247, 252; its relation to social reform, $321-336$.

Scientific Method, in social reform, 321-336; the method defined, 322-325; as distinguished from the theological method, 326 ; from the anarchistic method, 326 ; from the socialistic method, 327 ; its practicability, 327-329; it favors personal independence, $329-330$; practical suggestions relating to, $330-336$.

Scientific studies, the value of, $246-247$.

Seope and Principles of the Evolution Plilosophy, 3-26.

Searle, Dr. W. S., his defense of homeopathy, 142 .

Seely, on inventions, 206 ;

Sense-perception, the nature of, 13, 29-32.

Sequola, $345,355-356$.

Servetus, Hichael, his medical heresies, 144.

Serviss, Garrett P., on Edward L. Youmans, 388.

Sheldon, Professor Rufus, on the Evolution of Law, 111-130.

Shell-mounds, $59-60$.

Silsbee, Edward, 377.

Single-tax, 287, 296.

Skilton, James A., his meta-gnosticism, 9 ; on the evolution of the mechanic arts, 191-214; on Amos Eaton and Asa Gray, 356-360.

Slavery, of the inasses in early times, 97 ; recognized in the Constitution of the U.S., 100; of debtors, under the Roman law, 128; American, relation of inventions to, 212, 213; its relation to the wages system, 219-220; under the feudal system, $221-223$; its relation to poverty, $224-225$; a penalty for idleness in the sixteenth century, 2229 note; Aristotle on Solon's relation to, 258; the views of Jesus and Paul concerning, 264; fundamental in the Pagan world, 269; Anerican, the relation of Christianity to, 269-270; its relation to socialism, 283 ; its relation to the a narchistic nethod, 315 .

Social Reform, Evolution and, 23; the theological method, 257-274; the socialistic method, 277-300; the anarchistic method, 303-318; the scientific method, 321-336.

Socialism, as related to the evolution of the State, 104, 105; to the wages system, 218, 224, 231, 232; an early type of societary development, 258 ; its decay, 258; its nodern revival, 258; its Christian phase, 263, 264; Fregory the Great its patron saint, 265; partial wisdom of its theory, 274; discussed by William Potts, $277-300$; as related to anarchism, 304, 317-318; to the scientific method, 322,327 ; present tendencies toward, in America, 333.

Socialistic Method, $277-300$; as opposed to the scientific, 327 .

Social Statics, 377 . 
Sociology, as related to evolution, 22 ; compared with biology, 23 ; as related to prinitive man, 65 ; to natural science, 159.

Soerates, his intluence on philosophy, 236 ; lis ethical principles, 242.

Solon, his exaltation of labor, 258.

Spencer, Herbert, his Factors of Organic Evolntion eriticised by A. R. Wallace, 4; on the scope of the evolution philosophy, 6 ; on frcedom of opinions, 7,8 ; on agnosticism, 8 ; on the Unknown Cause, 8,20 ; on sociology, 9 ; on the relativity of knowledge, 10,11 ; lis definition of life, 11 ; on the personality of the Absolute, 20 ; his scienee of sociology, 22 ; influenee of his philosoply, 29 ; on promisenity in early narriage eustoms, 70 ; on exogamy and endogamy, 72 ; on monogany an $31 \mathrm{~g}$ certain races, 78 ; on wife-purchase, 81 ; on organization as related to growth, 92; on society as an or ganism, 159; on the psyehological grenesis of the mechanie arts, 191 , 195,$196 ;$ on the influence of machinery on mental progress, 213 ; his ethical principles, 242; lis regenerating plilosophy, 250 ; the value of his truth, 253; his era, 300; Sir Joseph Hooker on, 333; his relations witlı Edward L. Youmans, 346, 375-381; his letter to the Ethical Assoeiation on Edward l. Youmans, 390 .

Spontaneous generation, A. R. Wallace on, 5 .

sitareke, l'rofessor C. $\mathbf{X}$., on the motives for marriage, 74 .

siate, Evolution of the, 91-108; necessity of limiting its power, 327 .

State-socialism, as advocated by Elward Bellamy, $105,224,2633$; discussed by

William I'otts, 280-287; arlveated by Lassalle and Marx, 279, 281; olposed ly anarchism, 317 ; as related to the scientific methorl, $322,32 \overline{\text {. }}$.

Stcenstrup, I'rofessor, on the age of palaxolithie man, 59.

Stickney, Albcrt, on True Democratic Government, 100, 101; on the Political l'rolileu, 103; on govermment by' the people, 107 .

Stonelienge, 62 .

Strong, Dr., on progress in the Nineteenth Century, 97.

Stubbs, l'rofessor, on taxation ancl representation, $97,98$.

sumner, Professor William ( $\mathrm{r}$., un civil liberty, 24 , and 24 note.

sipernaturalism, in medicine, 133-13:

Sylvius, his discovery of valves in the veins, $1+4$.

TARIFF-REFORM, inefficacy of a priori theorizing about, 25 ; its effect in England, 26ti; necessity for in America, 332.

Taxation, as related to representation, 97, $3 x^{2}$ in feudal times, 22x; llenry

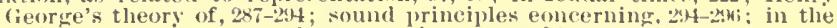
United States, 295 ; compulsory taxation opposed by anarchism, 311.

Taylor, John A., on the Evolution of the State, 91-108.

'Teliernvehevski, his advocacy of Nilhili:m, 278 .

Theolowical Methol of Social Reform, 257-274; as opposed to the scientitir, 326 .

Thonlwon, baniel Greenleaf, on society as an organism, 92; un the scientific

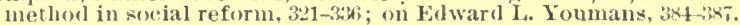

Tillotson, Archlishop, on the duties of mothers, 273.

Tolstoi, (ount Lyof $\mathrm{N}$., on marriage and labor, 263.

Torreya, 356.

Torres, Ir. John, his connection with Asa fray, 340-343; his contributions to botanieal scienre. 341,343 ; his eminence as a botanist, 341 .

Toynbee, Arnolil, 2:T.

Toynlee Hall, $2 \pi 1$.

Treat, Mrs. Miry, on Asa Gray, 339-351, 352, 354.

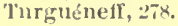

I'NFALNLD ING1:FUENT, 291

Iniversity, the, in the Mirlile Acres, 24 ; as related to nodern life, 245; l'resident Eliot on, 245 ; evolution of, 245 ; true value of, 241 ; classical studies in, 247 .

I"uknowable, the loctrine of, $9-13,20,31-34$.

I'sury, 268 . (See linterist.)

'topia, Sir Thomas More's, $42,103,104,231,2 \times 4$.

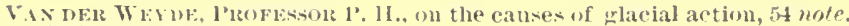

Variations, $3, \ldots x$.

Ventilation, 14\%.

Vesalins, on the anatomy of the veins and arteries, $1+4$.

Vestiges of ('reation, 355,331 .

Virelow, l'rofe-sor, on the are of thint inplement.s, 59: on the lake-(wellers, 61.

Vire, Armand de, his diseovery of tlint implements, 57 mote. 
WAGES, definition of, 218 ; as related to civilization, 231 ; equality of, under the Nationalist system, 283 .

Wages-system, evolution of, 217-232; economic eliaracteristics of, 218; as opposed to slavery, 219 ; its origin and "lowtl, 220-224; its relation to material improvement, 224-225; to social freedom, 226 ; to modern civilization, 231 .

Wake, C. Staniland, on the growth of the marriage relation, 69-87.

Walker, Gen. Francis A., on inventions, 20t-205; on agricultural land values, 292 .

Wallace, Alfred Russcl, his criticism of Lamarckism, 3; on Darwinism, 3-5; his criticism of I'rof. Cope, 4 ; on stages of organic evolution, 5.

Warren, Josiall, on money, 310 .

Wealtll, the measure of social freedom, 224; how increased by the wages system, 225; the New Testament on, 261 ; the Jewish idea about, 261-262; of the Catholie cluurch, 265 ; of Christendom, 266 ; who are its producers? 307 ; unfair distribution of, 308-311; unjust appropriation of, 313 .

Weismann, Professor, on heredity, 4 .

Whitman, Walt, his individualism, 324.

Willard, Miss Emma, on the education of women, 247 .

Wilson, Andrew, on marriage customs in Tibet, 79 .

Woman, in the marriage relation, 69-87; her rights under the law, 120, 122; increasing freedom of, 130 ; as an inventor, 210 , 211; the education of, $247-250$; in the professions, $247-248$; ler co-education witl man, 248-249.

Worcester, Mass., labor statistics from, 285.

Wordsworth, William, 45.

YouMAxs, EDWARD I., his talk with Sir Josepl 1 Hooker on Asa Gray, 353; his introduction of Dr. Eecles to Asa Gray, 360 ; his life and work, $365-390$; his education, 368-370 ; his relations witl Ḧerbert Spencer, 366, 375, 376-381, 385; his blindness, 370,372 , 388; his career as a 1opular lecturer, $374-376,384,385$; liis contributions to the spread of evolution views, 376, 378, 383; Prof. Joln Fiske on, 365-383, 389-390; Daniel Greenleaf Thompson on, 384-386; Prof. Franklin W. Hooper on, 386-387; Garrett P. Serviss on, 387; George Iles on, 387-389; his letter to Mr. lles, 388-389; Rev. Joln W. Chadwick on, 389; Dr. D. H. Cocliran on, 389 ; Herbert spencer on, 390.

Youmans, Mrs. Edward L., 379, 384.

Youmans, Miss Eliza A., her recognition of Herbert Spencer, 250; on Asa Gray, 352-355; her aid to Prof. Joumans, 372; she introduces him to I. Appleton \& Co.'s office, 378; lier biographical sketcll of lier brother, 385.

Youmans, Vincent, $367-368$.

ZoLA, M., his mechanical method, 336.

Zoroaster, his influence on Judaism, 84 ; his views of marriage, 84,87 . 



\section{PROOFS OF EVOLUTION \\ BY}

NELSON C. PARSHALL

\section{OUTLIYE OH}

1. The Growth of Evolutionary Thought.

2. The Practical Benetits of the Evolution Theory.

3. The Four Great Factors of Evolution.

4. Proofs from Geology.

5. 'Proofs from Morphology.

6. l'roofs from Embryology.

7. l'roofs from Metamorphosis.

8. l'roofs from Rudimentary Organs.
9. Proofs from Geographical Distribution.

10. Proofs from Discovered Links.

11. Proofs from Artificial Breeding.

12. l'roofs from Reversion.

13. l'roofs from Mimiery.

14. Spontalleous Generation.

15. A Summary of Evidence.

16. Language and the Moral Sense.

17. Conclusion.

"One of the most systematic, concise and comprehensive presentations in popular" form of the foundation and theory of Evolution. Excellent, . . . succint, . . interesting."-Public Opinion.

One Volume, Large Open Type, 70 pages. Price, Fine Cloth, 75 cents.

\section{FIF TH THOUSA ND.}

\section{FACTORS OF SOCIAL REFORM.}

\section{OUTLINE OF CONTENTS:}

1. Moral Education and Personal Effort as Factors of Social Reform. By Fraxcis E. A ввот, PII.D., Author of "Scientific Theism," "The way Out of Agnosticism," ete.

2. First Principles in Social Reform. By A. E. Dolbear, M.E., Ph.D., 'rofessor of Physies and Astronomy at 'Tufts College.

3. Evolution of the Wayes System. By Prof. George Guntox, Author of "Wealth and Progress," "Principles of Social Economics," "The Economic Heresies of Henry George," ete.

4. Exolution and social Iiform: I. The Theological Method. By Rev. JoHx W. CHADWICK, Author of "Evolution as Related to Religious Thought," "The Faith of Reason," "Charles liohert l)arwin," cte.

5. Erolution and Social Reform: II. The Socialistic Method. By Wintiam l'otTs, Author of "Evolution of Vegetal Life," etc.

6. Erolution and Social Reform: III. The Anarchistic Method. By IIvGI (). PENTECost, Editor of The Tuenticth (entury.

7. Evolution and Sorial lieform: I I. The Srientific Method. By DAxies, GREExLEAF Thompsox, President of the Nineteenth Century Club, and Author of "A fivstem of Psychologr," "The P'roblem of Evil," "Tlie Religious Sentinients of the Human Alind," "Herbert Spencer," etc.

"The ingenious gentlemen who propound these Essays to the world a re but a small groul of a vast army of nien and women who are debating the sane subjects. They are hringine into consideration matters of which our fathers knew nothing and of which earlier generations never dreaned. They are gathering together a vast mass of argument, controversy and disputation upon problems which sprang up for diseussion only vesterlay. Vet so great has become the connection of these matters with our actual life and historr, so close is the relation they bear to the interests of us all, that they have pervaded all our literature and public affairs, and there are to-day no political questions which are not also social questions."-.Mbany 'Times.

One Vilume, 140 pages. Price, Fine Cloth, \$1.00; Paper Covers, 60 ets.

*** For sale by all book-dealers, or sent postpaid, on receipt of price, by

JAMES H. WEST, Publisher, 196 summer Street, Bostox. 


\section{The Modern Science Essayist Popular Erolution Essays and Lectures.}

One of the most systenatic, concise and comprehensive presentations in popular form of the fomndation and theory of evolution. Excellent, . . succint, . . interesting.-Public Opinion.

Papers that are neither dull nor commonplacc.-Boston Times.

Tle suljects are very fully discussed, aul the seeker for information can scarcely find the case better statel.- New Bedforl Mereury.

A collection of essays scholarly and instructive.- Feu York Sun.

\section{Tirese Numbers Now Ready.}

1. Herbert Spencer. His life and personal characteristics; his views on education; his religions opinions; his earlier writings; the relation of his work to Darwinism and the evolution philosophy.

By Danien (ireexieaf Thompsox, author of "A System of Psychology," "The Problem of Evil," "The Scientific Method in Social Reform," etc.

2. Charles Robert Daruin. His ancestry, life, and personal characteristics; the voyage of the Beagle; disovery of natural solection; the two factors of the Darwinian theory; Darwin and Wallace; Lonis A gassiz and evolution; intluenee of loarwin's stndies on his religious opinions; evolution before Darwin; views of frethe and Lamarck.

By Jonn WT. CHAmWick, author of "The Bible of To-rlay," "The Faith of Reason," "Evolution as Relaterl to Religious Thought," etc.

3. Solar and Planetary Evolution. How suns and worlds come into being; the nelular hypothesis of Laplace and Faye; Creation or Evolution? did the material universe ever have a heginning?

By GAlRETT P'. SEIRVis, author of "Astronomy with an Opera Giass."

4. Evolution of the Eroth. The story of geology; how the world grew ; the oriler of stratification; the action of fire and water preparation of the earth for veretalle and amimal life.

By Dı. Iswa (:. JAxk. anthor of "A situly of Primitive Christianity," "The Seope and prineiples of the Evolution I'hilosophy," "The Evolntion of Morals," ete.

5. Evolution of Tegetal Life. How rloes life begin? the poblem of spontaneous gencration; mopholosy-the forms of leaves and flowers: the geomraplical distribution of phant-; methods of fertilization; dintinctions and fikenesies between plants and animals.

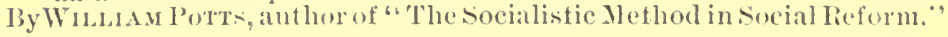

6. Evolution of thimal Liff. The evidences from geology, geomraphieal distrilontion and comparative zoolong: the problem of sperial ereation; the laws of evolution: lourwinism as modified ly liomanes; the mutalility of species: the order of zonlowieal (roolution.

by losstrea W. liavmoxi, Ph.l).

7. The Deseent of Mun. Riclation of man to the brute reation; his ancestral line; inration of human life on the planet ; growtla of mincl, reason,

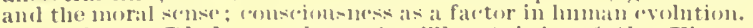

By E. D. Cork, Ih.1)., anthor of ".The Origrin of the Fittest."

S. Evolution of Mind. Whr mind and the nervous system: the nature of mind; correspendenes of lifo and mind; the growtl of comscionsmess; nature and evolution of intelligences: instinct, memory, reason, feelingrs, will.

By RomE:T (i. ECCLEs, M.1), anthor of "The lielativity of Knowl"iclere," etc.

Catalogue CONTINUED ON NEXT PAGE. A] 


\section{Modern Science Essayist---Catalogue Continued.}

The lecturers in this collection present the theory of evolution instructively and attractively.-Boston Globe.

There is nothing weak or commonplace in these discussions.-Charleston (S. C.) News.

All these papers are full of thought, presented in clear language, and in an admirable spirit.-Religio-Philosophical Journal.

9. Evolution of Society. Primitive man; growtl of the family, eity and State; development of the domestic relations; marriage; ceremonial and political institutions; is society an organism ?

By JAsies A. Skiltos, author of "Evolution of the Mechanic Arts."

10. Evolution of Theology. Origin of religious beliefs; ideas of primitive unan ; animisu, and ancestor-worship; growth of nature-worslip and idolatry; polytheism monotheism and pantleism; the doctrine of the Absolute.

By \%. SiDNEY SAyPson, author of "Primitive Man."

11. Evolution of Morals. How altruism grows out of egoism; the proper balance; characteristics and relative value of ethical systcms; utilitarianism, rational and empirical ; intluence of the evolutionary theory of morals on ethical sanetions.

By Dr. LEwis G. JAxEs, author of "Evolution of the Earth," "The Scope and Principles of the Evolution Philosophy," "A Study of Primitive Christianity," etc.

12. Pronfs of Evolution. a, from geology; b, from morplology; c, from embryology; $d$, from metamorphosis; e, from rudimentary organs; f, from geograplical distribution; $\mathrm{g}$, from discovered links; $\mathrm{h}$, from artificial loreeding; i, from reversion; $\mathrm{k}$, from mimicry.

By Nelion C. Paishali.

13. Evolution as Related to Religious Thought. The doctrine of the unknowable; special creation as related to Darwinism; Spencer's reconciliation of religion and science; the doctrine of design; law and miracle.

By Rev. JoHx IV. CHAIWICK, author of "Charles Robert Darwin," "The Faitl of Reason," "The Bible of 'To-day," etc.

14. The Philosophy of Evolution. Relation of the doctrine to prevailing philosophical systems; metaphysies and the scientific method; nlaterialism and the evolution pliilosophy : realism and idealism; beneficent results of the prevalence of materialisin on liuman progress.

By STARR Hoxt NichoLs, author of "Monte Rosa, or the Epic of an Alp," etc.

15. The Effects of Evolution on the Coming Civilization. Plans for social regeneration as tested by evolution; Communism, Nationalism, and Socialism: probable influence of the evolntion philosophy in the settlement of social and economic prohlems.

By ReV. Jixut J. SAFAGE, author of "The Religion of Evolution," "The Morals of Evolution," etc.

16. The Scope and Principles of the Evolution Philosophy. Wallace on I arwinisu ; evolution a universal nethod ; agnosticism - what is it: the nature and limitations of knowledge; the relations of the evolntion plifosophy to materialism and idealism; to the doctrines and methods of the Christian church; its relations to sociology; its attitude toward the practical problems of social life.

By Dr. Lewis G. JANes, author of "A Study of Primitive Christianity," "Evolution of the Earth," etc.

17. The Moral and Religions Aspects of Herbert Spencer's Philos. ophy. Spencer's Theory of Religion; Spencer's Theory of Morality; the Rclation of Religion to Morality from the spencerian point of view.

By SYLYAN DreY. 


\section{Modern Science Essayist-.-Catalogue Continued.}

A gliuce will sufficiently indicate the admirable skill and thought that have becn brouglit to bear upon these suljects. - Boston Saturday Evening Gazette.

The leeturers are men of wide researel, thoroughly accuainted with the topics of which they treat.-Charleston (S. C.) News.

jo. The Relativity of Knowledye. The nature of sense-pereeption; sight, inmull, tiste, sull, feeling; the doctrine of the Unknowable; the relative nature of matter, motion, form, weight, extensiom; the relativity of ethical and sex:ial theories; the truth of detinite relations; the doctrine of relativity assures cliarity and mental freedom.

IBy lionent G. ECCLEs, M.D., author of "Evolution of Mind."

19. A Study of Matter and Motion. An excellent digest of a muel vexed question, with quotations from many authorities, - P'rof. Youmans, Herbert siveneer, Geo. Henry Lewes, l'rof. Helnilioltz, l'rof. Coues, etc., ete.

liy IION. A. N. Alinas.

We must not allow any prejudicc of thought on account of the cry of "materialism." - T"ext. 1.6.

20. Irimitive Man. Man as revealed by arehæological studies; evidenees of man's antiquity; geological periods; man's appcaranee in the plioeenc; palasolithic and neolithie races; the ares of bronze and iron; caveinen and lake-dwellers; dolmen- and mound-builders; primitive implements and tools; proofs of man's natural cvolntion.

By Z. SiDNky SAMP'son, authol of "Evolution of Theology."

21. Growth of the Marriage Relation. Marriage a primitive institution; its earlier forns; no cvidence of original promiseuity; exogamy and endorany; group-marriage; polygyny, polyanflry and monogamy; marriage by capture; monogany the highest form of the relation; divoree and divorce-laws; marriage a contraet; its regulation ly the State.

Dy C. STANIIAND WAKk, anthor of "The development of Marriage and Kinship," "The Evolution of Morality," cte.

2:. Holution of the State. The growth of political institutions; the patriarehal fanily; the trihe and clan; the ancient eity; monarehieal and repesentative governments; constitutions - written and unititen; the Amerit:an liepululic -its sulecess and its dangers; cvils of munieipal government; what final form will the State assume?

liy JOIIN A. TAYHAR.

¿::. Lvolution of $L$ Inu. How law begins; statute law and judge-made law; the conversion of enstoms into law; religions sanetions; lexal fietions; the development of equity juri-prudenee; the "ommon law; legislation; the codlifiation of laws; laws for the collection of debts; personal rights under the law.

liy l'lioḱ. liugus Singluon.

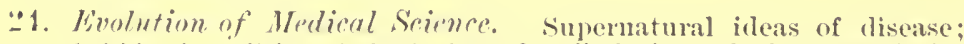
fetislism in mediene; the beginnings of medieal seience; l'ythagoras and llipeperates, Celsus and falen; Cluristianity and mediual seience; the Wollammedan influence; lowneopathy and allopatlyy ; fools and poisons; the development of stlpery, allabmy, pliysiology, (lomistry and plarmacy; bacteriology; the Emowili of millitiry sejence.

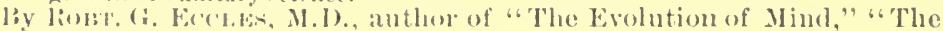
lichatuvity of knowleclire," ete".

2.7. Exolution of Arms and fromor. The necessity for arms and

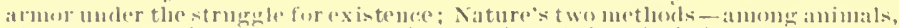
flants, men, nations; low arms and armer lave letl to the industrial arts ; to a higluer manleowl; to en-operative eflort; to indivilnalism; the weapens of thought; onr National poliey as regards thefenses; the two mothods in religion, burials, law, social saforty; wi this rudestalk the flower at last of universal peace.

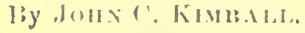




\section{Modern Science Essayist---Catalogue Continued.}

The lectures are entertaining and instructive.- Albany Aryus.

26. Evolution of the Mechanic Arts. Development of the humin hand; the earliest use of implements and tools; man's mechanical structure and adaptation for work; the psychology of the mechanic arts; the rolation of mechanics to mental evolution; the genesis of invention; patents alid patcntlaws; inventions in agriculture and mannfactures; have tley benefitol the laboring elasses?

By JAMES A. SKILToN, author of "The Evolution of Society."

27. Evolution of the Wages System. The definition of wases: economic characteristics of the wages system; wages the outgrowth of slavery; origin and (lavelopment of the wages system; its relation to inaterial improvoment, social freclom, and a progressive civilization; to the welfare and pruyriss of the laboring classes; the factory system; importance of stipulated iurours; the wages system compared witl Nationalism and Socialism; its relation to social reform.

By Prof. George Gunton, author of "Wealth and Progress," "Priuciples of Social Economies," "Economic Heresies of Henry George," ete.

28. Education as a Factor in Civilization. The beginnings of erltcation; early methods in Egypt, Persia, China, Greece and Rone; earıy (thrivtian ideas of education; Catlolic and Protestant views; the common-A-luonl system; influcnce of Comenins, Pestalozzi and Frocbel; the kinder,arten; manual training; education and erime; the university; classical and seirntifie studies; the higher education of women; co-cducation; the futurc of our educational system.

By Miss Catroline B. Le Row.

29. Evolution and Social Reform: I. The Theological Methorl. Religion the formative principle of social growtl; its relation to Socialisin; theological norality; influence of Christianity on social development; New 'Testament ideas of marriage and wealth; early Christian Socialism; monasticisu ; influence of the Jews and Mohammedans; the church and inclustrialism; "ury or interest; tle church and slavery; alms-giving and pauperism; the errect of preaching on cliaracter; repentance, conversion and atonement; the rcligious method the method of personal character.

By Rev. John W. CIADWICK. anthor of "Evolution as Related to Religious Tiought," "Charles Robert Darwin," etc.

30. Evolution and Social Reform: II. The Socialistic Methorl. Communism, Socialism and Nationalism; the methods defined; origin of tlesir mocern phases; tendencies of Socialism to militantism; State-Socialism; the doctrine of equality of carnings; equality $2 s$. liberty; Mr. Bellany's theory eriticized; Henry George and the "single-tax"; the injustice of land-confisution : relation of land-values to the value of improvements ; socialistic scliemes artificial, not organic; profit-sharing and voluntary eo-operation; opportunisu.

By Wilizan PotTs, author of "Evolution of Vegetal Life."

31. Evolution and Social Reform: III. The Anarchistic Methom: Anarchy regarded as a science; its opposition to government ly physical for..; its methods not revolutionary lut evolutionary; anarchism in social customs; its economic principles; involuntary poverty, its causes and cure; injustifes of rent, interest and profits; social parasites; anarchism and the loallot; its motheil that of cdncation and peaceful propagandism; its ideal that of nutualisu between free individuals.

By II ugi O. Pextecost, editor of The Twentieth Century.

32. Evolution and Social Reform: IV. The Scientific Methu].

The seientific method based on the uniformity of Nature; the polarity of hulivit: ualism and Socialism; the psychological argument; necessity for governurutil limitation ; the scientific method as distinguished from the theological, the suralistic and the anarchistic; it advocates the golden mean; it cultivates individual independence; its relation to erlucation and ethical culture.

By Danifi, GRenicaf Thompson, anthor" of "A System of Psyelology," "The Prollem of Evil," "Herlert Spencer," etc. 


\section{Modern Science Essayist-.-Catalogue Continued.}

"No one who wishes to comsider the philosopley of evolution ean well afrora to be witlout this series of papers."- C'hristian liegister.

:3:;. Asa. Gray: His Life and Work. Il is birth and youth: lois indelotedness to Amos Laton; his relations witl Dr. Joln 'Torrey; his works on liotany; the "North American Flora"; his contributions to the doctrine of Fvolution; his correspondence with J)arwin; his personal eharacteristies; his genius recognized by other lotanists; his great industry; his unolt rusive inodesty; causes of his unfinished work.

Liy Mis, Mary 'Tre.tT, autlor of "Ilome Studies in Nature," "My Garden l'ets," "Through a Microseope," ete.

i: Lidward Livingston Joumans: The Wan and His Work.

Ilis birth and ancestry; his education; his early interest in natural science; his lolindness; his interest in reforms; his eontributions to chemistry: his ("areer as ascientific lecturer; his acceptance of the doetrine of Evolution; his introluction of llerlert sipencer to America; his establislunent of the "International Geientific Series" and the l'opmlar seipnee Momthly, lis visits to England; lis loroad, d'mocratic spirit and nnselfish personal elaracter.

By I'lok. Jolin Fiske, anthor of "Cosmic P'lilosopliy," ete.

\section{T. EACH NUMBER, TEN CENTS.}

W Also, the First Fifteen Essays above outlined, in One Volume, "Lvolution," fine cloth, 408 pages, Illustrated, with Complete Index, $\$ 2.00$, postpaid.

Ros Also, the Essays from 16 to 34 inclusive (except 17 and 19, which were special issues) reprinted in One Volume, "Sornologr," miform with "Evolutiox," fine cloth, 40 s pages, with Complete Index, \$2.00, postpaid.

* Sint postpail, on receipt of priee, by JAnks II. WEst, Publisher, Bostom.

\section{The. I'ay out of Agnosticism:}

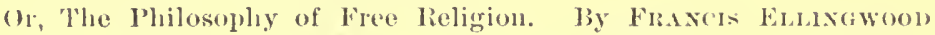
A 1:isot, Pli.l). Cloth, \$1.00.

This little book, giving the substance of a course of lectures in Harvarl l'nisersity

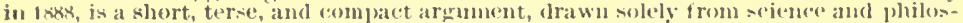

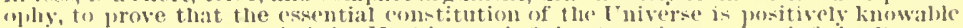
and knuwn as at onee an infinite Machine, an infinite () reanism, and an infinite ['('rson :

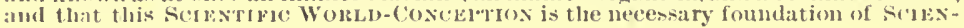
Titric lirines.

\section{Ethical Religion.}

A volume of leetures griven, for the most part, loefore the society for Whical Culture, Chicago. By Wa. M. Nillwk. \$1.50.

There is here, in glowing, suggestive cpitome, the extence of true human leang and doing. - The New Ielecl. Another prouf that ideas as well as clollars are eurrent in Ancriea. - Germon levien. Tho (biapte on l)arwinism in lethics is a particularly atsle cliscorasion of that topic, and it is fillod with high and nolole sonceptions of nan's respousibility to the law which siys, Thou shalt do right or gerish.- Jhe Beucon.

** Any of the ahove sent postpaid on receipt of price. Address,

\section{JAMES H. WEST, Publisher,}

196; Simmer Stret, Bostox. 
"Our part is to conspire with the new works of new days."-Emerson.

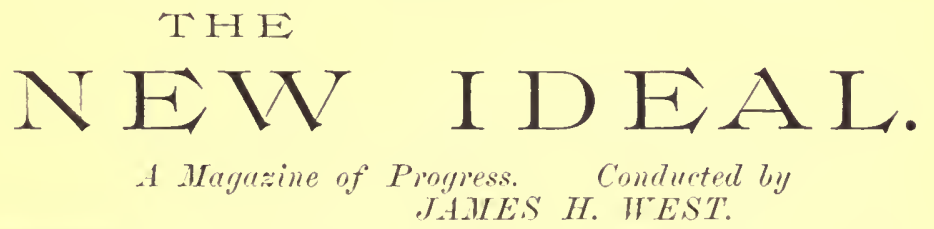

SOME OF THE NOTABLE WRITERS

From "Whom Articles hare Alrealy Appeared in "The New Iteal."

O. B, Frothingham, Edwin D. Mead,

William Lloyd Garrison,

William il. Salter,

Hon. George F. Talbut.

Damiel Greenleaf Thompson,

Joseph Dana Miller,

Prof. A. E. Dolbear, Ph.D..

Rev. W. G. Todd.

Hon. A. T. Adams,

Rev. X. P. Gilman,

Dr. Rolt. G. Eceles,

Prof. John Fiske,

Rev. John C. Kimball.

Mrs. Ellen B. Dietrick.

Mrs. Laura Ormiston Cliant.

Mrs. Inna Garlin Spencer,

Pereival Clubb.

Jenkin Lloyd Jones,

George II. Hadley.

Capt. Robt. C. Adams,

Mon(-ure I). Conway,

Dr. C. T. storkwell,

Prof. W. D. Gumning,

Walter F. Wells,

Mrs. sara 1. Lnderwood,

Frelleric A. Hinckley,

B. IV. Ball.

Charles D. B. Mills,

Elizabeth J3. Cliace.
Francis E, Abbot, Pli.D.,

Thomas Wentworth Higginson, William J. Potter,

Fred. May Holland, E. 1'. Powell,

IIugh O. Pentecost,

Res. Dr. MeGlym,

Edward Bellamy.

Rev. W. D. P. Bliss,

Laurence Gromlund,

Dr. Erlmund Montgomery,

Minot J. Savage,

Dr. Lewis $G$. Janes,

B. F. Lnderwood, William G. Babcock,

Abby M. Gamett,

Mirs. Ednah D. Cheney,

Velly Booth simmons,

Horace L. Traubel, s. Burms Weston,

Clrarles K. Whipple,

George W. Buckley,

Rev. Perry Marshall,

Elissa X. Moore,

Lillie B. Chace Wyman,

Rer. II. H. Brown.

John 'T. Mawkins,

C. A. Lane,

simeon Carter,

Mrs. Mary Guming.

THE XEW IDEAL fills a strong, distinct need of the present lay in the periodical line. Its aim is toward practicalizing the truths of science and religion; to fill human needs thromel practical, scientific, broad thonglit. And it camnot but accomplish muel towari the realization of its jdeal. The natter contained in all the numlers thus far is of a nature to attract the thought of all intelligent readers, and will he the means of the magazine winning its way into a strong circle of supporters." - Bostom Times.

"The publication is not of an ephemeral nature. It is an outgrowtl of the new turn given to the world's scientific and religrous thought by the great prophets of the gospel of Evolution, and it has enlisted as writers some of the most prominent disciples of this new gospel."-Ohio state Jourral. 


\title{
"The Neru Ideal" Monthly.
}

"THE XFW IDEAL has contributions of marked ability from many of the most advanced thinkers of the day. You may not agree with sonc of then, lint you will be profited and instructed by knowing what tluey luave to say, and you will of ten come across an artiele whicli clears the atmospliere from error and humburgery like a beneficent thunder-storm. In fact, TuE XEw IbEAL is indispensalie to those who seek to keep abreast of the seething current of contenporary thought." - Springfield (1). Repulilie-Times.

"We like its outspokcn character, and always learn from it what is going on anong people who use the free lance." "In nearly every paper good points are inade, and the nlagazine is leserving of attention from thoughtful persons. "- Boston JJerth.

"Interesting from leginning to end, being filled with articles tlat are scluolarly and sugrestive, thomirl out of the beaten tracks of orthodox opinion." - Rochester bemocrat and Chronicle.

"Its typograply is leautiful, and its contents of a character to interest and instruet. To class of contributors for any jublication are more erudite, liberal, profoumel or logieal." - Ottrura Tribune.

"THF XEw I EA L dis(usses religions and social topics from a lileral standpoint. It is raliual without being offensive, and tends towards rationalism without departing from thouglitful and lionest methods." - Tolcdo Blade.

"A very sugreetive and helpful magazine for all classes of thouglitul people." - Lonelliox Pojndi.

"The Magazine will find many interested readers, botll beeanse of the rejutation of its writers and tle subjects treated of."-Tacoma sumay.Times.

"On every page is the inpress of liberal thouglit and progressive tendencies." - Norristou'n Heralil.

"The general contributions are in the fore rank of advaneed thouglt. The elitorials seintillate witl trutlis clearly and eoncisely expresied. TII $\mathrm{X}_{\mathrm{W}}$ InlidL is likely to receive, as it slowlal, an extended jatlonage." - Sumuer of Lisht.

"THE JEW IDFAL is doing a most valuable service to civilization." - Jrooklyn Times.

"It is liberal, radical, lut not aggressive, and opens new trains of thouglt on religjous and soeial topies. Logieal and well-written articles." - Burliuglon /loukeye.

"As a Magazine THF NEW Ink:AL ranks among the best, able writers giving their views upon living questions." - Jeriston Jourum.

"It will find a host of realers, botl in the evangelistic and rationalistic world." - lew Bidjord standard.

"Entertaining not only for the wiele range of topics discussed, but for tle original

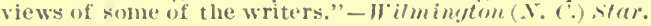

"Contains very interesting and instructive articles, that cannot fail to awaken new trains of tlouglit." - $\$$. . John filolie.

"leople laving a tendency towarel liberalism in religion - from cautious revisers

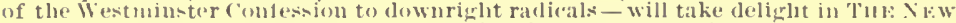

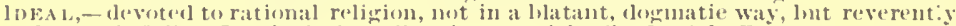
and thoumlatfully. I'artienlarly woll-written articles." - Bubfolo Express.

"Its whole make-up is in good taste, and its thouglit is exeellent in its ref resling vitality." - (pinion-1)ullowl:.

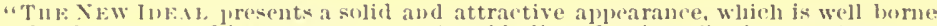
out liy the nature of its contents. . . In able list of writers." - Boston Commonurertiti.

"Tuv NEw Ins. is bold, out-poken and earnest. It lobles a religrions point of view very differont from onr own, hut wo commend the alparent homesty of its seareh after truth." - romerregliemalist.

"This earnest and hirrli-uincled publieation. . . offers substantial food for its readirs."-Litcrory H"urld.

"Full of interest. . . 'I $11 \mathrm{~F}$. $\mathrm{F}$ Ibkil, is an able, lold, honest, progressive Magazine."-Brocklym situmalart-l'nioul.

"Fvery page empluasizes the liroad and seloblarly unethod that gudes the conduct of tle Magazine." - Boston Times.

\section{JAMES H. WEST, Publisher,}

\author{
196 Simmer Sitrest, liostox.
}




\section{THE NEW IDEAL 1890}

\section{MARCH (Principal Contents).}

\section{GENERAL CONTRIBUTIONS-}

The Nobility of Man,.......................... P. POWELL 103 Socialism, Love, and Sympathy,...........LAUREXCE GRONLUND 106 Idealward (Poem),$\ldots \ldots \ldots \ldots \ldots \ldots \ldots \ldots \ldots \ldots$.................. TRAUBEL 111 Optimism and Ethics,......................... M. HOLLAND 111 The Workingman's "Wasted Leisure,"........MRS. MARY GUNNING 114 Quid Ergo (Poem), ................................. LANE 116

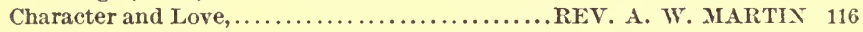
Bellamy's Critic Criticized, II., .................REV. W. G. TODD 120 Cypress-Crowned (Poem),$\ldots \ldots \ldots \ldots \ldots \ldots \ldots \ldots \ldots$................... WES 123 Our Present Mode of City Government,...........JOHN A. TAYLOR 123 Fatalistic Science and Human Self-Determination, IY.,

DR. EDMUND MONTGOMERY 127 The Racer (Poem),$\ldots \ldots \ldots \ldots \ldots \ldots \ldots \ldots$. . . . ELS. ELSSA M. MOORE 135 Progress in Catholic Thought, ...............THOMAS B. PRESTON 136

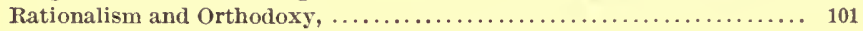

\section{APRIL (Principal Contents).}

\section{GENERAL CONTRIBUTIONS-}

There are Two Sides that are One,............REV. H. H. BROTX 141

Truth Full Rounded,.........................W.. J. POTTER 145

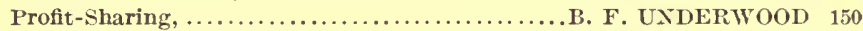

Appreciation (Poem),........................ TODV. W. G. 152

Our Hope of Immortality, ..............MRS. HELEN N. PACKARD 152

Primitive Man,$\ldots \ldots \ldots \ldots \ldots \ldots \ldots \ldots \ldots \ldots \ldots \ldots \ldots$. SIDNEY SAMPSON 156

Leaving the Old Farm (Poem),............NELLY BOOTH SIMIONS 160

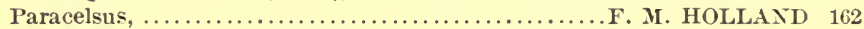

The Modern Way of "Getting There,".............EEO. H. HADLEY 164

The Dogma of Infallibility, .............REV. GEO. W. BLCKLEY 168

Evolution (Poem) $\ldots \ldots \ldots \ldots \ldots \ldots \ldots \ldots \ldots \ldots$. HORACE L. TRALBEL 175

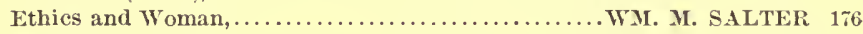

Matter and Motion,............................... N. ADAMS 177

Competition and Co-operation,.................. F. UXDER WOOD 180

The Labor Question: Is it Moral or Economic ?..........F. HARMER 181

\section{MAY (Principal Contents).}

GENERAL CONTRIBUTIONS-

The Man Jesus [A Posthumous Discourse],...PROF. W. D. GUXXIX 189 Darwin, the Jolnn the Baptist of a New Gospel,

HOX. GEO. F. TALBOT 199

Agitation no Cause for Alarm, .........MRS. SARA A. UNDERWOOD 203

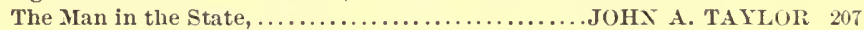
Herbert Spencer and the Land Question,.......WALTER F. WELLS 210 Gladstone and our Statesmen, ................... MI. HOLLAND 212

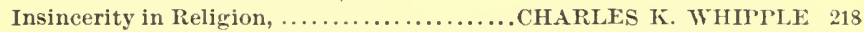
The Basic Reason for Soeial Reform, ..LAURENCE GRONLUXD, M.A. 221 Fatalistic Science and Human Self-Determination, $Y$.,

DR. EDMUND MONTGOMERY

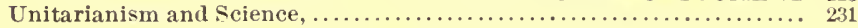
A Wood-Chopper on the Social Cuestion, ....................... 231 


\section{THE NEW IDEAL 1890.}

\section{JULY-- AUGUST (Principal Contents).}

GENERAL, CONTRIBUTIONS-

Moral Edueation and Personal Effort as Faetors of Soeial Reform,

FRAXCIS E. AlBBO'T, I'h.D. 288

Arnold Toynbe ; or I'ersonal Influence in Social Reform,

PERCIVAL CHULB 299

Nethods of P'ersonal Alleviation,...MRS. LALRA OlinISTON CIIANT 303

Soeial Progress thronglx Organized Effort,...JWXKIX LLOYD JONEA 311

The Necessity for the Inerease of Opportunity,....F. A. IINCKLAY 317

The I'resent Aspect of Affairs in Japan, . REV. WII. E. GRIFFIS, 1).1). 322

The Need of Industrial Elneation in India, KESHAV MALHAR BHAT 332

The Elueation of Women in Ceylon,.......MRS. SLSAN A. EXGLISI, 337

Liberal Religions Thought in the East,............ II. PAI'AZIAN $3+3$

The Opening up of Afriea,.............ARCHIBALI) II. GRIMKE 349

I'rogressive Thonght in Constantinople,..........EDWIN 1). MEAD 378

Ethies and Industrial Reform,...............WM. M. SALTER 367

Law, I'hysieal and lloral,................ LR. LEWIS G. JANES 370 Addresses,$\ldots \ldots \ldots \ldots \ldots \ldots \ldots \ldots$. I'RESIDENT WM. J. IOTTER 283, 320

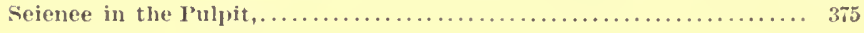

\section{SEPTEMBER (Principal Contents).}

GENERAL CONTRIBLTIONS-

First I'rineiples in Social Reform, ..... l'lRof. A. E. IOOLlBE.AR, I'h.D. 379

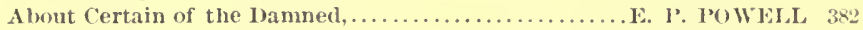

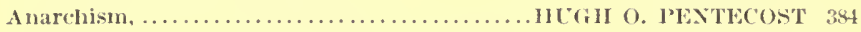

The Test : or, Natural and Divine Love (loem),.......... C.AlTTER 391

A Critieism of I)r. Jowden's Estimate of "I'rometheus Inlmmel,"

The Seientifie Nethod in Soeial Reform,

A. M. (IANNETT 392

DANIEL, GREENLEAF THOMISON 394

Zetetia (I'oem) ...................................... 401

The Brahmin Caste of New England,........ CHARLES K. WHIl'lle 401

“Voluntary co-operation," ...................WALTER F. WELIA 40

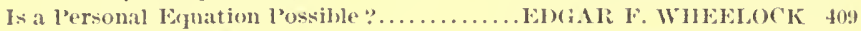

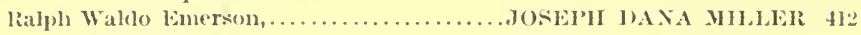

\section{OCTOBER (Principal Contents).}

GENLRAI, (ONTHHITIONS-

Tariff Lesoms frem Australia, ................... N. HOLLAND 427

Edward l,ivingston Vommans: His Early Career,..PlRoF. JOIN FISK F 431

Facts and l'robalilities in Regard to Jesus,.. CHARLES K. WHIl'lle 436

I'olities, Edueation, and Soeial Reforn.

I)ANHEL (IEEENLEAF THOMISON 41

On Reading Datthew Arnold's Lssay on lleine (Poem),

II. A. WARREN 46

Wages and Tarifs: A Reply to Mr. F. .H. Holland,.... T. T. WKINS 4t

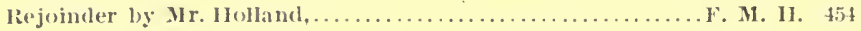

Was Jesus an kthical loligionist?........REV. PLIRY MARSHAL. 42k

The Evolution of Liberty, ..................RFV. H. II. BROWX Hiz

Obligation and the Sense of Ohligation, .....WHLLAM M. SALTER 472

The kreutzer Sonata and the (others, . . . . . . . . . . . . . . . . . 


\section{BOOK FOR TRUTH-LOVERS.}

\section{A Study of Primitive Christianity}

BY LEWIS G. JANES.

Reriscd Edition. $319 \mathrm{pp}$. Seo. Cloth, H'rice, $\$ 1.50$.

Treats of the natural evolution of the Cluristian Religion, accorrling to the historical method; applying the assured results of modern criticism to the question of the historieal verity of Jesus, the investigation of his life and teacling, and the development of organized Chnistianity.

"Free and seholarly eritieism of the origin of Christianity."Boston Commonrealth.

"The result of diligent rescarch in listorieal authorities, and careful, logical thought in an endeavor to arrive at fundamental trutlis." - Brentano's Book Chat.

"A cool, quiet, painstaking and fearless examination of the religious belicf of Clnristians." - Sidney s. Rider"s Book Notes.

\section{CONTEMTS:}

Preface, ly Rev. J. W. C'ladwick. Author's Preface to Second Edition.

Introduction. I.-Palestine in the Roman Period. 11,-Society and Rcligion in the Roman Empire. III.-Sonrces of Information. IV.-Theological Aspects of the Religion of Jesus. Y.-Social Aspects of the Religion of Jesus. VI. - Myth and Miracle in the fospel Stories. VII.-The Christianity of Paul. VIII.-The Apostolic Ige. IX.-The Martyr Periol. X--Christianity the State Religion.

DF Complete Rejerences, Bibliogruphy and Index.

** Sicut postpaid on receipt of price by

THe New Ineal Compaxt,

Bostom, Mass.

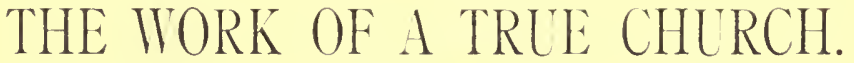

AN ESSAY

Devoted to a consideration of the Feeds of Mankind in the modern world.

\section{By .JAIES H. WES'T,}

Editor of The Ner Idfal. Author of "The complete Life," "Tplifts of Heart and Will," "Yoices of Youth," etc., etc.

Pamphlet. Single copy, 6 cents. Five copies, 15 cents.

*** Mailed postpaid, on reccipt of price, by

The NeW Ineal Compary. 


\section{Uplifts of Heart and Will.}

By JAMES H. WEST.

A Series of Thirty-Seven Religious Meditations, or Aspirations, Fitted for Private or P'ublic Religious Uplooking. Addressed to Earnest Men and Women.

"It takes a soul to move a body.

* Life develops from within."

\section{PRESS CRITICISMS.}

"On purely rational grounds it is not easy to meet the position [of this little book], exeept by saying that the words and forms of our [usual] devotion must be accepted as frankly symbolic, and not amenable to the understanding.*** It is good to welcome a religious seienee better than the old hard bigotry. Still, while we by no means aeeept these 'Uplifts' as a neeessary or an adequate substitute for the eustomary exereises of devotion, they are at least better fitter than the ordinary praetice to a state of mind far from uncommon, and greatly deserving of respeet."-From a seven-page notice in the Unitarian Review.

"A man of gifts and graees making an effort to get out of the old and worn-out way of petitioning for special things to a deity supposed to deal in special providenees. Heartfelt and choicely worded, the book is the reaeling ont for more life and light of an earnest man."-ReligioPhilosophical Journal.

"Tle outpourings of a soul deeply religious in the best sense, but suspieious of forms. Truly beautiful inrocations. The volume contains the strongest possible testimony to the indestructibility of the religious sentiment. The poems at the end are also full to overflowing with noble feeling. 'This volume is one of the many assurances that the liberal ehureh will fast enough gather poetry, music and art, to invest its nobler thought."-New Theology Herald.

\section{PERSONAL EXPRESSIONS.}

An aged man, a plrysician,- of whom we know nothing exeept that he ordered a copy of the book,-writes: "I have read with delight tlie little book, 'Uplifts of Ileart and Will.' I am now nearly 62 years of age, and have lived a lonely life as regards the satisfying of my liberal religious aspirations. Your little book fills a void in my soul's loneliness which I have suffered for more than forty years."

A Boston lady writes: "They are very encouraging - just what I need. Many hours of earnest thouglit and conscientious work must hive gone to their writing. It is good to have peace and truth in the heart! We must hold to that! I look into the book often, and I hope it will do good to many."

From a Unitarian minister: "I hail the 'Uplifts' as a good sign,another step out into the free, where we must be content to let all consecrated thinking go."

From a liberal thinker: "I am well pleased with the 'Uplifts,' and especially because they come near to my own spirit's workings, when I have felt as if I stood alone."

Price of the above Book, neatly bound in Cloth, 5o Cents.

* For sale by all Booksellers, or may be ordered of 'THE NEw IDEAL. 


\title{
THE COMPLETE LIFE.
}

\section{Six Diseourses,}

\section{FROM THE STANDPOINT OF MODERN THOUGHT.}

\author{
BY JAMES H. WEST, \\ AOTHOR OF "UPLIFTS OF HEART AND WILL," "YOICES OF YOUTH," ETC., ETC.
}

"This world-it means intensely, and means good;

To find its meaning is my meat and drink."

[From The Chicago Evening Journal.]

"Would that all pulpits rang with words as brave and true as we find in the published sermon-lectures of James H. West, brought out in book form with the title 'The Complete Life.' Every word the author indites is golden, and should be read by young and old. Such books are genuine uplifts of heart and mind, and when we get to heaven, if we ever do, through earth's sordid dust and mire, we shall have men like James H. West to thank for finding our way there."

[From The Christian Register.]

"In all these discourses Mr. West shows a sympathy with Nature, a poetic and a spiritual sense of the divine forces that are working in Nature and in man. The moral tone is always earnest, and the moral ideal is high. They are sermons which bear on right thought and right living. The author finds in the natural the synonym of the divine. He finds a moral purpose budding and blooming in the nature of man."

Fine Cloth, Gilt Stamp, - 60 Cents.

\section{VARIOUS MATTERS BY MR. WEST.}

VOICES OF YOUTH : "Holiday Idlesse, and other Poems." New

Red-Line Edition. Illustrated. Printed on heavy paper, with extra wide margins. Handsomely bound in appropriately pictured covers illustrating the title-poem. Large square 12 mo, 252 pages. Price, postpaid, $\$ 1.00$.

"Mr. West has undoubted poetic conceptions and sympathies. In much of his verse he shows himself to be a genuinc interpreter. His expression is oftcn a fine instrument; melodious, imaginative, and vital. Even where one notes an imperfection of form, a fine thought or a beautiful fancy redeems the fault."-Christian Union.

"His poems rank easily in the higher grade of those published in these days." - Congregationalist.

HYMNS LOOKING ONWARD, INWARD, UPWARD. "Valuable as

a collection of untheological religious verse, even when not intended

to be sung." Single copies, postpaid, 10 cents. More than ten copies,

5 cents each.

"A pamphlet of Forty-Two Hymns, collected and arranged by James H. Wcst. Older collections of church hymns furnishing little that he could usc consistently with modern rational religious thought, this thin pamphlet was printed for temporary use, to serve until something larger and better should bc demanded by a growing consistency on the part of liberals as a whole. These hymns are of limman hoje and human endea vor, anıl are valuable as a collection of untheological religious versc, cvell when not intended to be sung."-Index.

KALLIGO: A POEM. A forty-page Brochure, bound in illuminated cards, witl two Illustrations and Proem. A Tale of the Florida Everglades. Red-Lined. Price, postpaid, 25 cents.

"Exccllent verse, of a very gcnuine sort,-full of suggestivencss, aspiration, and the glow of true fceling. * * Enusually clear in outline and strong in expression." - Christian Union.

"The poems of Mr. West are more than cntertaining, they are helpful. His grasp upon familiar objects, and a faculty of voicing poetic thought concerning them, give a real pleasure."-Acliocate. 


\section{JAMES H. WEST, Publisher, Boston.}

The Moral and Religious Aspects of Herbert Spencer's Philosophy. By SYLYNA IREY. I'ampllet, 10 cents.

"An able popular interpreter of the evolution philosophy."

Scientific Theism. By Fraxcis F. Anвort, Plı.D. Clotll, 242 pages, $\$ 2.00$.

"Dr. F. 1'A Ablot's new book, 'Scientifie Theism,' contirms the opinion of the few lest ahle to junlge, that he is the allest philosophical thinker in Ameriea, and that his work seems to be the foumdation of that deeper religion of the future, sure to eome, whieh will satisfy lotll the head and the heart of man."- Vr. E. B. Heskell, in Boston siundeiy Herctel.

The Philosophy of Free Religion. By Frax('ts E. Arisor, Plı. I).

A series of Nine Papers printed in THE NEW IDEAL. The series mailed, postpaid, for $\$ 1.00$.

The Evolution of Immortality. Suggestions of an Individnal Immortality, based upon our Organic and Life History. By C. ' $\mathrm{T}$.

STockwri. Cloth, 12mo, gilt top, uncut edges, 69 parres, \$\$1.00.

"One of the most suggestive and lest developed essays on personal immortality which liter years have prodnced."-Jitertry Workl.

Science and Immortality. Cloth, 75 cenits; paper, 50 cents.

A "Symposium," giving the opinion of many of the most prominent seientific men in this country, concerning the relation of science to the question of immortality. Concise, candid, the earnest thomght of the foremost thinkers of the day, whetler of expectation or of doubt.

The Morals of Evolution. By M. J. SAYAdE, 191 pages, \$1.00.

Treats such topies is The origin of foothess, Tle Nature of fioodness. Tlue Sense of obligation, The Relativity of Dnty, Morality and Religion in the Futnre, etc. cte. "We all ow . Mr. Savage thanks for the earnestness. frankness, and ability with which he lias here illnstrited the modern seientific methuty of dealing with history philosophy, and morility." "The hook is a fund of intellectuil and moral eheer."

Evolution: A Summary of Evidence. By Capt. RoBr. C. AndMs, Autlor of "Travels in Faitle from Tradition to lieason." Pamplilet, $4+$ pacess. 25 cents.

"An athuirable fresentation and summing up of the Evolution Argument."

A Study of Primitive Christianity. 13y L.WW ( $\mathrm{Y}$. J.1.E. :319 piteres, \$1.j).

Treit to of the natural evolution of the Cluristian lieliorion, aecoreliner to the historical methesl, applying the ascures results of medern criticion to the guestion of the historifil verity of Jesus, the inventigation of his life and teacling, and the development of organized Cloristianity.

Uplifts of Heart and Will. I Series of Religrious Meclitations, or

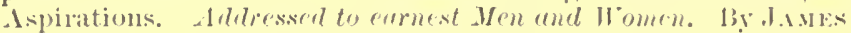
11. Wrise, ('loth, square 1smo., hereled edges. Price, postpaid, incents. (In paper (oovers, :30 (cts.)

"(In purely rational grounds it is not easy to meet the position [of this lat le hook], exrepit ly saving that the worls and forms of our [11 sinal] devotom

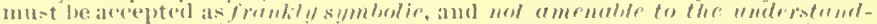

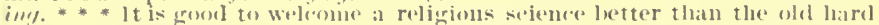

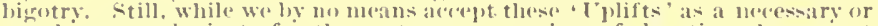
an adeduate sulestitute for the enstomatry exereises of devotion, they are at least leetter fitted thin the ordinary priaction to at state of mind far from uncommon, and greatly denerving of resiect." - Frmm at seecn-puge notice in the lniturinh Revieir.

The Duties of Women. By Fraxces Powen (")1BE. Cloth, \$1.00.

"The profoundest, wisest. pur"st, nolilest book in prineiple, aim and tono get written upous tle true position of eromem in soreinty." 



DATE DUE

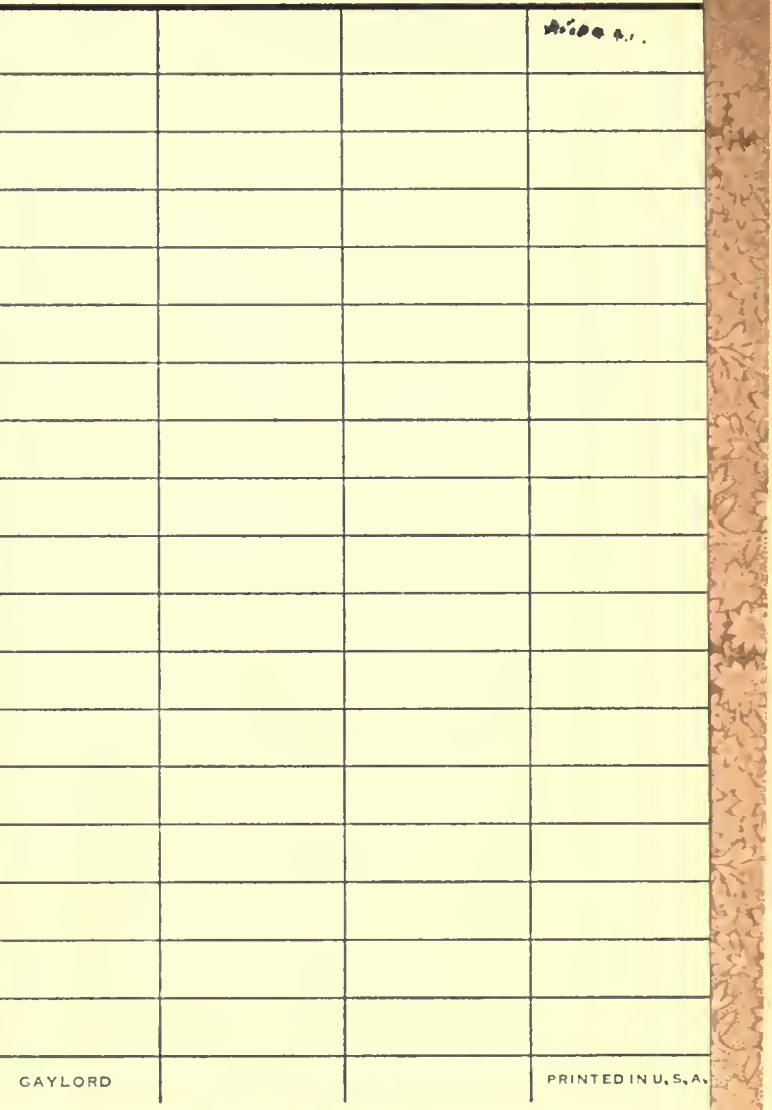

कy $x^{2} x+3$ ?

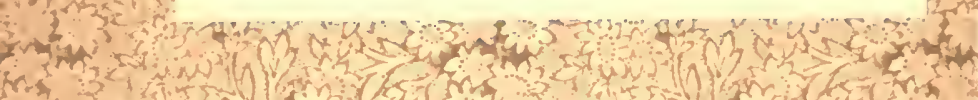

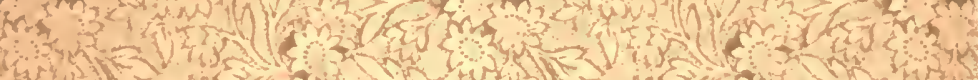

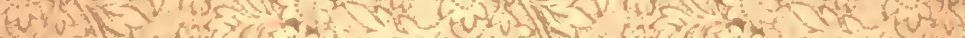

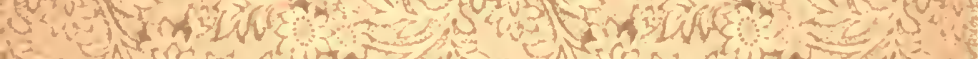

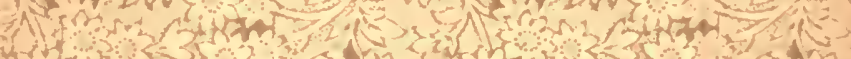

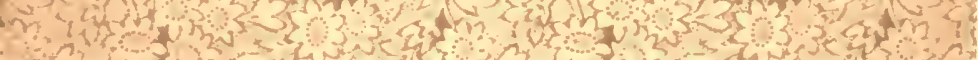

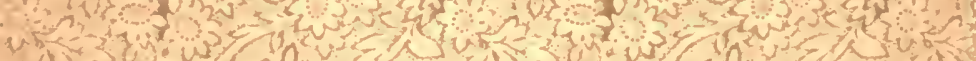

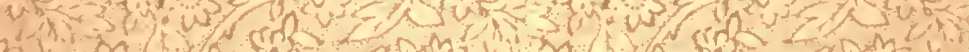

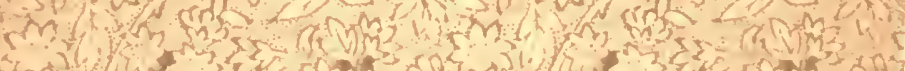
menta

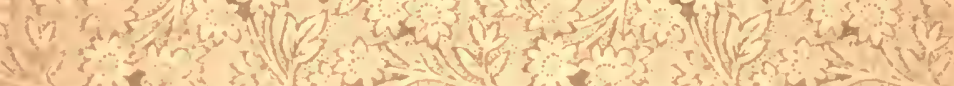

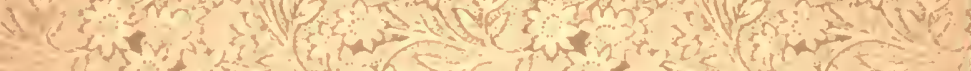
rive 
UC SOUTHERN REGIONAL LIBRARY FACILITY

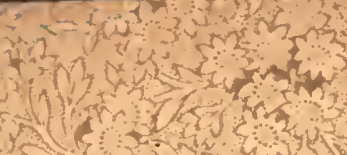

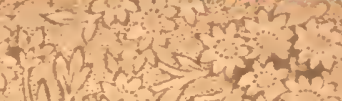

inition

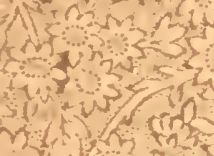

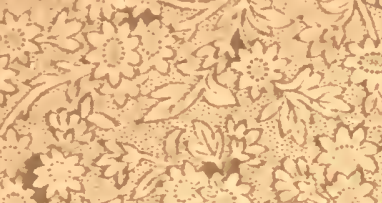

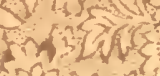

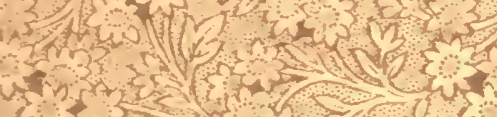

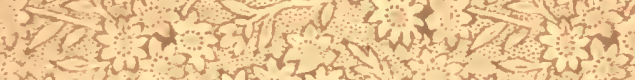

Mningent?

Nintexter

wins

C,

ind

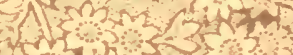

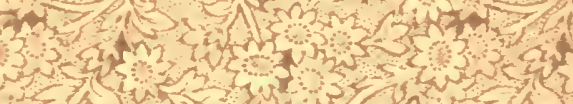

r.

(1) हn

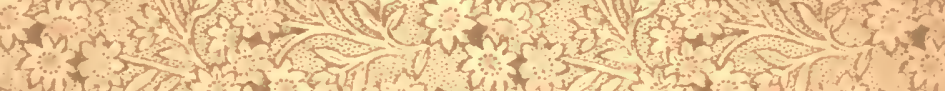

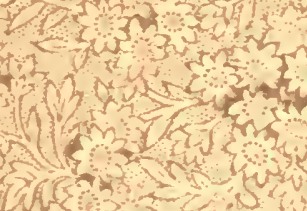

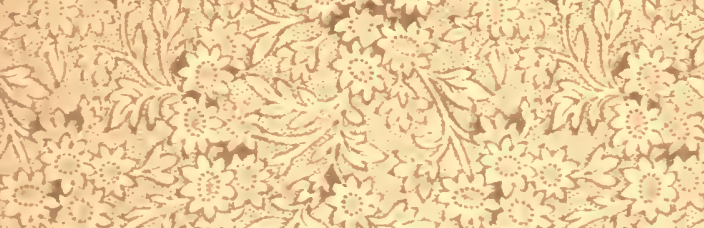

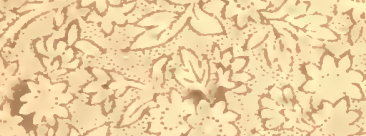


